DOC.20050223.0002

QA: QA

ANL-MGR-GS-000004 REV 00

February 2005

\title{
Peak Ground Velocities for Seismic Events at Yucca Mountain, Nevada
}

Prepared for:

U.S. Department of Energy

Office of Civilian Radioactive Waste Management

Office of Repository Development

1551 Hillshire Drive

Las Vegas, Nevada 89134-6321

Prepared by:

Bechtel SAIC Company, LLC

1180 Town Center Drive

Las Vegas, Nevada 89144

Under Contract Number

DE-AC28-01RW12101 


\section{DISCLAIMER}

This report was prepared as an account of work sponsored by an agency of the United States Government. Neither the United States Government nor any agency thereof, nor any of their employees, nor any of their contractors, subcontractors or their employees, makes any warranty, express or implied, or assumes any legal liability or responsibility for the accuracy, completeness, or any third party's use or the results of such use of any information, apparatus, product, or process disclosed, or represents that its use would not infringe privately owned rights. Reference herein to any specific commercial product, process, or service by trade name, trademark, manufacturer, or otherwise, does not necessarily constitute or imply its endorsement, recommendation, or favoring by the United States Government or any agency thereof or its contractors or subcontractors. The views and opinions of authors expressed herein do not necessarily state or reflect those of the United States Government or any agency thereof. 
QA: QA

Peak Ground Velocities for Seismic Events at

Yucca Mountain, Nevada

ANL-MGR-GS-000004 REV 00

February 2005 


\section{Scientific Analysis Title}

Peak Ground Velocities for Seismic Events at Yucca Mountain, Nevada

3. DI (including Revision Number)

ANL-MGR-GS-000004 Rev 00

4. Total Appendices

A, B, C, D

5. Number of Pages in Each Appendix

\begin{tabular}{|l|l|}
\hline \multicolumn{1}{|c|}{ Printed Name } \\
\hline 6. Originator & $\begin{array}{l}\text { Kevin Coppersmith and Richard } \\
\text { Quittmeyer } \\
\text { 7. Checker }\end{array}$ \\
\hline 8. QER & Kenneth Gilkerson \\
\hline 9. Responsible Manager/Lead & Jerry King \\
\hline 10. Responsible Manager & Jerry King
\end{tabular}

\section{Remarks}

The main body of the report was prepared by Kevin Coppersmith and Richard Quittmeyer. Robert Youngs was assisted in technical checking by Kathryn Hanson. Appendix A was prepared by David Buesch. Appendix B was prepared by Branko Damjanac. Appendix C was prepared by Walter Silva, Ivan Wong, and Richard Quittmeyer. Jerry King was the technical facilitator and integrator for the study.

The report addresses OCRWM Condition Report 3898.

\begin{tabular}{|l|l|}
\hline \multicolumn{2}{|c|}{ Change History } \\
\hline 12. Revision No. & 13. Description of Change \\
\hline Rev 000 & \\
\hline & \\
\hline & \\
\hline & \\
\hline & \\
\hline
\end{tabular}


INTENTIONALLY LEFT BLANK 


\section{CONTENTS}

Page

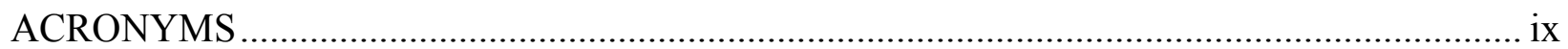

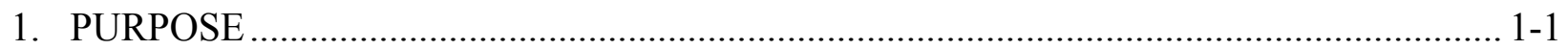

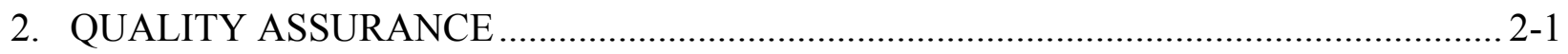

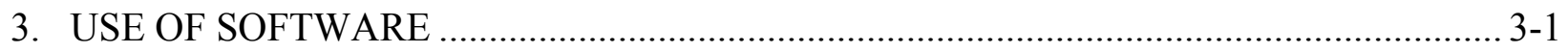

4. INPUTS

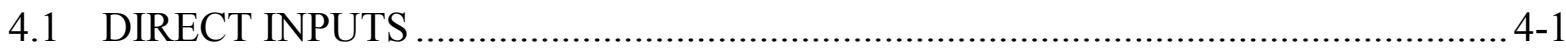

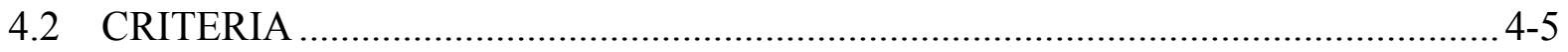

4.3 CODES, STANDARDS, AND REGULATIONS ................................................. 4-8

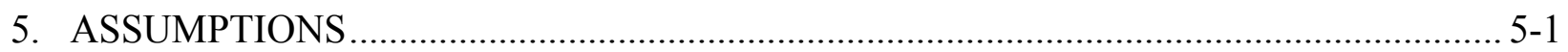

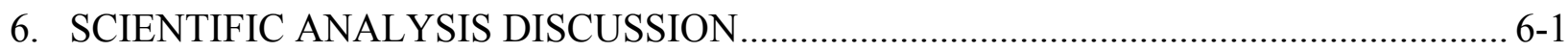

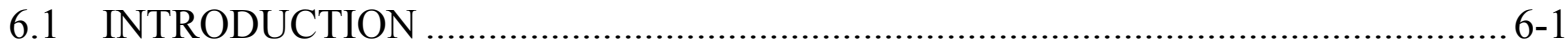

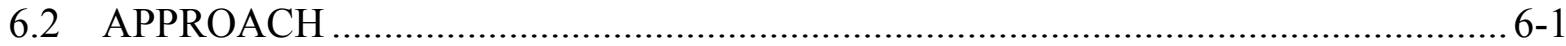

6.3 GEOLOGIC OBSERVATIONS REGARDING SEISMICALLY-INDUCED

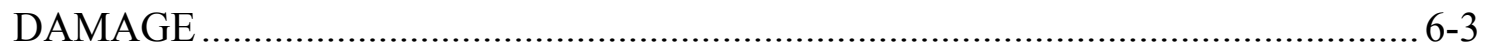

6.3.1 Petrogenesis of Fractures ........................................................................ 6-4

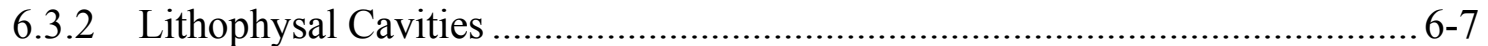

6.3.3 Inter-lithophysal Fractures..................................................................... 6-8

6.3.4 Conclusions from Geologic Observations ……………............................... 6-10

6.4 THRESHOLD SHEAR STRAIN DISTRIBUTION FOR TOPOPAH SPRING

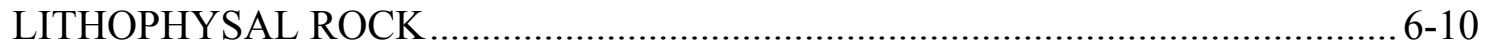

6.4.1 Laboratory Test Results ......................................................................... 6-13

6.4.2 Numerical Simulation Results ............................................................... 6-14

6.4.3 Assessment of Threshold Shear Strain Probability Distribution .................... 6-17

6.5 GROUND MOTION CALCULATION ……….............................................. 6-18

6.6 BOUND TO HORIZONTAL PEAK GROUND VELOCITY EXPERIENCED AT

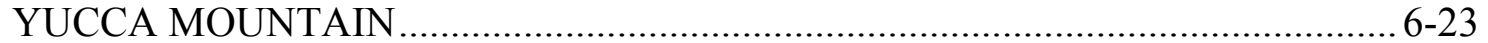

6.7 BOUND TO EXTREME GROUND MOTION AT YUCCA MOUNTAIN .............. 6-24

6.8 HAZARD CURVE FOR HORIZONTAL PEAK GROUND VELOCITY AT THE WASTE EMPLACEMENT LEVEL …………………...................................... 6-25

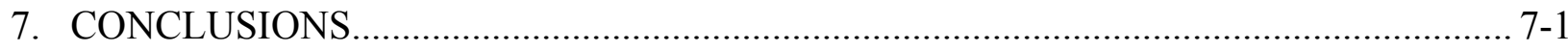

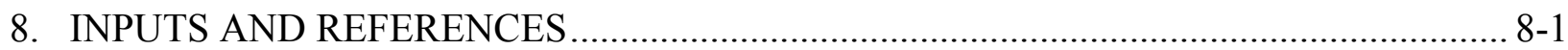

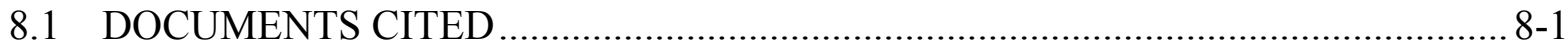

8.2 CODES, STANDARDS, REGULATIONS, AND PROCEDURES ............................ 8-9

8.3 SOURCE DATA, LISTED BY DATA TRACKING NUMBER …………............... 8-9

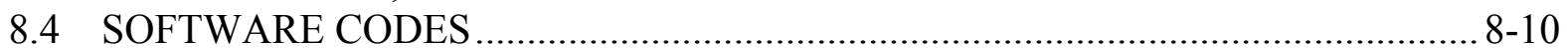




\section{CONTENTS (CONTINUED)}

Page

8.5 OUTPUT DATA, LISTED BY DATA TRACKING NUMBER

APPENDIX A - GEOLOGIC LIMITS ON THE FORMATION OF FRACTURES IN THE LITHOPHYSAL AND NONLITHOPHYSAL ROCKS OF THE CRYSTAL-POOR MEMBER OF THE TOPOPAH SPRING TUFF

APPENDIX B - STRAIN LEVELS RELATED TO DAMAGE IN TOPOPAH SPRING TUFF

APPENDIX C - CALCULATION OF PEAK GROUND VELOCITIES FOR EXTREME GROUND MOTIONS

APPENDIX D - DOCUMENTATION OF THE USE OF COMMERCIAL-OFF-THESHELF SOFTWARE (1 CD) 


\section{FIGURES}

Page

1-1. Relations Among Seismic Analysis and Modeling Activities

6-1. "Cooling to Indeterminate Ratio" (C/I ratio) of Fractures by Lithostratigraphic Zone or Subzone in the Densely Welded and Crystallized Topopah Spring Tuff.

6-2. Example Panel Map of Lithophysal Cavities, Lithophysal Rims, Spots, and Lithic Clasts.....

6-3. Comparison of Modeled Fracture Development in Lithophysal Rock Samples that are Deformed to Failure to Observed Fractures in the Enhanced Characterization of the Repository Block Cross-Drift

6-4. Fractures Developed during Modeled Deformation of a 1-Meter by 1-Meter Synthetic Lithophysal Sample

6-5. Calculated Shear Strain Increment For 288-mm Diameter Samples

6-6. Shear Strain Increment Determined Using the Peak-Stress Criterion, Overburden $=250 \mathrm{~m}$

6-7. Assessed Probability Distribution of Threshold Shear Strain for Topopah Spring Lithophysal Rock $6-18$

6-8. Probability Distribution of Bounding Horizontal PGV

6-9. Individual and Average Bounded PGV Hazard Curves for the Waste Emplacement Level

6-10. Comparison of Horizontal PGV Hazard Curves for Bounded and Unbounded Ground Motion at the Waste Emplacement Level. 


\section{TABLES}

Page

3-1. Qualified Software Used in the Analysis ........................................................... 3-1

4-1. Direct Inputs Used in the Analysis ..................................................................... 4-1

4-2. Panel Map Images Examined in this Analysis............................................................ 4-2

4-3. Project Requirements Pertaining to the Bounding Peak Ground Velocity Analysis ....... 4-5

6-1. Summary of Statistics of Calculated Shear Strain Limits Based on 250 Meters of Overburden

6-2. Mean Shear-strain Increments Determined from Numerical Simulation of the Mechanical Behavior of Lithophysal Rock

6-3. Modeled and Interpolated/Extrapolated Horizontal Peak Ground Velocity for Shear Strain Values....

7-1. Summary of Applicable Yucca Mountain Review Plan, Final Report Acceptance Criteria and How They are Addressed in this Report. 


\section{ACRONYMS}

BSC Bechtel SAIC Company, LLC

CFR Code of Federal Regulations

CJ cooling joint

CRWMS M\&O Civilian Radioactive Waste Management System, Management and Operating Contractor

DLS Detailed Line Survey

DOE U.S. Department of Energy

DTN Data tracking number

EBS Engineered barrier system

ECRB Enhanced characterization of the repository block

ESF Exploratory Studies Facility

FLT fault

FZ fault zone

LMT lower mean tuff (set of dynamic material property curves)

NRC U.S. Nuclear Regulatory Commission

OCRWM Office of Civilian Radioactive Waste Management

OSF onset of systematic fracturing

PGV Peak ground velocity

PSHA probabilistic seismic hazard analysis

RHH repository host horizon

SC safety category

SH shear

SHZ shear zone

SSF small-scale fracture

STN Software tracking number

TBM tunnel boring machine

TSPA Total system performance assessment

UMT upper mean tuff (set of dynamic material property curves)

VPP vapor phase parting

VPL vapor phase lining

YMP Yucca Mountain Site Characterization Project 


\section{INTENTIONALLY LEFT BLANK}




\section{PURPOSE}

This report describes a scientific analysis to bound credible horizontal peak ground velocities (PGV) for the repository waste emplacement level at Yucca Mountain. Results are presented as a probability distribution for horizontal PGV to represent uncertainties in the analysis. The analysis also combines the bound to horizontal PGV with results of ground motion site-response modeling (BSC 2004 [DIRS 170027]) to develop a composite hazard curve for horizontal PGV at the waste emplacement level. This result provides input to an abstraction of seismic consequences (BSC 2004 [DIRS 169183]). The seismic consequence abstraction, in turn, defines the input data and computational algorithms for the seismic scenario class of the total system performance assessment (TSPA). Planning for the analysis is documented in Technical Work Plan TWP-MGR-GS-000001 (BSC 2004 [DIRS 171850]).

The bound on horizontal PGV at the repository waste emplacement level developed in this analysis complements ground motions developed on the basis of PSHA results. In the PSHA, ground motion experts characterized the epistemic uncertainty and aleatory variability in their ground motion interpretations. To characterize the aleatory variability they used unbounded lognormal distributions. As a consequence of these characterizations, as seismic hazard calculations are extended to lower and lower annual frequencies of being exceeded, the ground motion level increases without bound, eventually reaching levels that are not credible (Corradini 2003 [DIRS 171191]). To provide credible seismic inputs for TSPA, in accordance with 10 Code of Federal Regulations (CFR) 63.102(j) [DIRS 156605], this complementary analysis is carried out to determine reasonable bounding values of horizontal PGV at the waste emplacement level for annual frequencies of exceedance as low as $10^{-8}$. For each realization of the TSPA seismic scenario, the results of this analysis provide a constraint on the values sampled from the horizontal PGV hazard curve for the waste emplacement level.

The relation of this analysis to other work feeding the seismic consequence abstraction and the TSPA is shown on Figure 1-1. The ground motion hazard results from the PSHA provide the basis for inputs to a site-response model that determines the effect of site materials on the ground motion at a location of interest (e.g., the waste emplacement level). Peak ground velocity values determined from the site-response model for the waste emplacement level are then used to develop time histories (seismograms) that form input to a model of drift degradation under seismic loads potentially producing rockfall. The time histories are also used to carry out dynamic seismic structural response calculations of the drip shield and waste package system. For the drip shield, damage from seismically induced rockfall also is considered. In the seismic consequence abstraction, residual stress results from the structural response calculations are interpreted in terms of the percentage of the component (drip shield, waste package) damaged as a function of horizontal PGV. The composite hazard curve developed in this analysis, which reflects the results of site-response modeling and the bound to credible horizontal PGV at the waste emplacement level, also feeds the seismic consequence abstraction. The composite hazard curve is incorporated into the TSPA sampling process to bound horizontal PGV and related seismic consequences to values that are credible. 


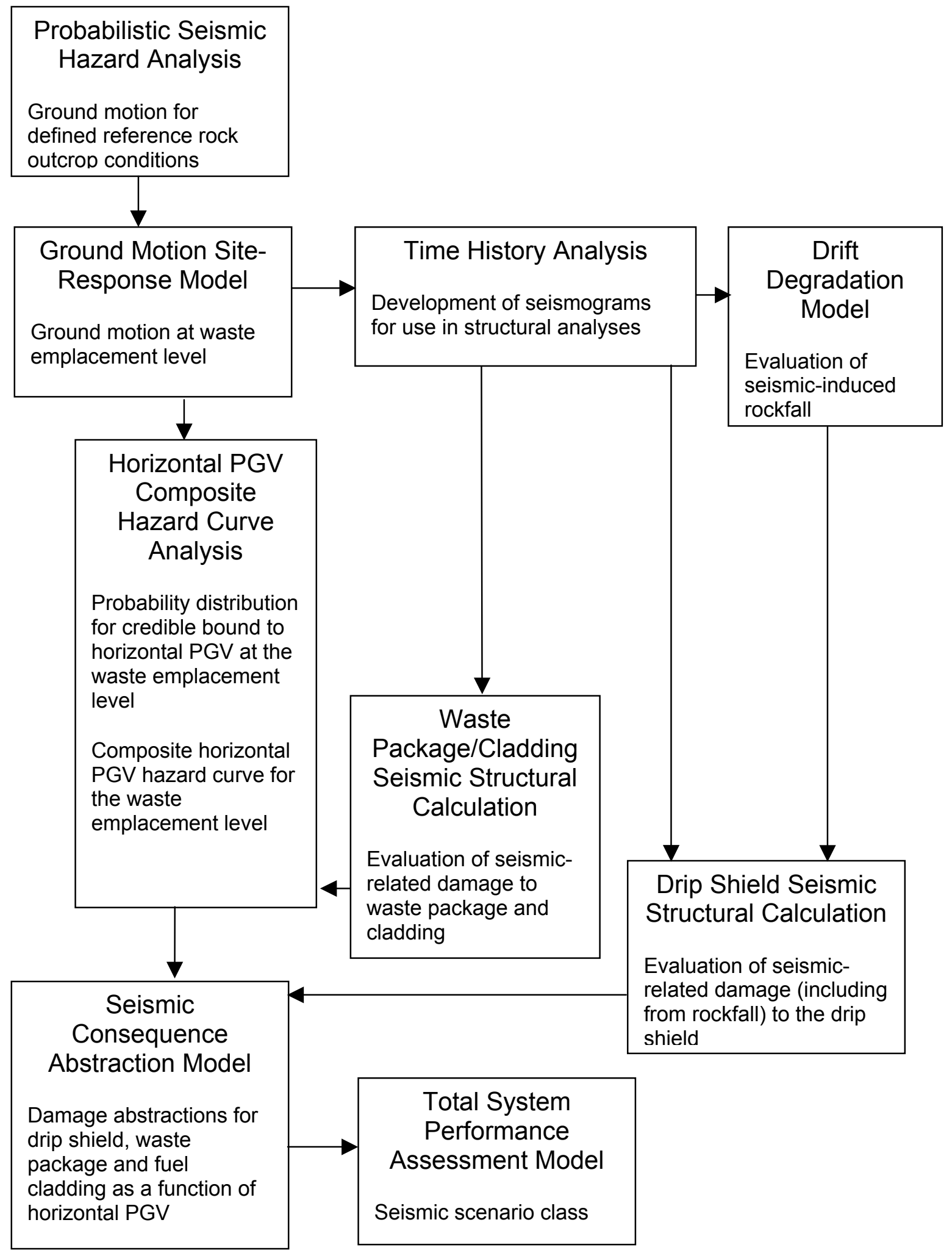

Figure 1-1. Relations Among Seismic Analysis and Modeling Activities

In developing time histories to support calculations of the dynamic response of engineered barrier system (EBS) components (e.g., drift, drip shield, waste package, pallet), the levels of 
ground motion determined in the PSHA were used without consideration of their ability to be realized at Yucca Mountain. Thus, some of the time histories representing ground motion with annual frequencies of exceedance of $10^{-5}, 10^{-6}$, and $10^{-7}$ (BSC 2004 [DIRS 170027], Section 6.3) are unrealistic in that the levels of ground motion calculated likely can not be sustained at Yucca Mountain. Nevertheless, they were used to evaluate the performance of EBS components as if those levels of ground motion could be achieved to determine the sensitivity of structural response calculations to extreme ground motions. The EBS component damage functions based on those results, therefore, to some degree represent damage from ground motions that are higher than are credible for Yucca Mountain. By incorporating a reasonable bound on horizontal PGV at the waste emplacement level into the sampling process for TSPA through the composite hazard curve, the sampled horizontal PGV hazard is limited to credible values.

This analysis depends on predictions of rock deformation that would be caused by extreme ground motions at the waste emplacement level at Yucca Mountain and the fact that such deformation is not observed. The lack of such deformation is used to conclude that lithophysal rocks of the Topopah Spring Tuff have not experienced ground motions large enough to cause the predicted deformation during the approximately 12.8 million years (Sawyer et al. 1994 [DIRS 100075], Table 1) since their deposition. Analysis limitations include the following:

- The 12.8 million years age of the Topopah Spring Tuff does not preclude the possibility that ground motions large enough to cause rock deformation occurred at the Yucca Mountain site prior to its deposition or will occur in the future.

- The lack of observations of the type of rock deformation that would be expected if Yucca Mountain had experienced extreme ground motion levels is limited to those portions of the mountain that are exposed in the Exploratory Studies Facility (ESF) and the Enhanced Characterization of the Repository Block (ECRB) Cross-Drift. Although samples and study locations are spatially and stratigraphically distributed throughout the rock mass, a small percentage of the total repository rock mass is sampled.

- Geologic studies of fracture distribution, genesis, and characteristics in the ESF and ECRB Cross-Drift were not carried out specifically to look for deformation predicted to be associated with extreme ground motion levels.

- Testing of lithophysal rock samples to provide information on the shear strains associated with fracture generation is carried out on laboratory-scale samples. The testing of large samples represents an approximation to in situ mechanical behavior.

- Shear strains at which lithophysal rock of the Topopah Spring Tuff exhibits systematic macro-scale fracturing is modeled using a two-dimensional discontinuum numerical approach.

- Modeling to determine the shear strains that would be induced by ground motions in the rock at the waste emplacement level employs a one-dimensional equivalent-linear approach. 
- Translation of a probability distribution for the shear strain threshold at which geologically observable rock failure would occur due to severe ground motion to an equivalent distribution for horizontal peak ground velocity is based on the mean values of dynamic shear strain and peak ground velocity from site-response calculations. Mean values are used to approximate the translation rather than including the range of results due to aleatory variability in site material properties.

Because of uncertainties in the data, analyses, and modeling, and the limitations listed above, the value for a bound on credible horizontal PGV is provided as a probability distribution. 


\section{QUALITY ASSURANCE}

Development of this analysis report and supporting analyses are subject to the Yucca Mountain Project's quality assurance program (BSC 2004 [DIRS 171850], Section 8.1). Approved quality assurance procedures identified in the technical work plan (BSC 2004 [DIRS 171850], Section 4.1), including AP-SIII.9Q (Scientific Analyses), were used to conduct and document the activities described in this report. The work was carried out as planned.

The technical work plan also identifies the methods used to control the electronic management of information during the activities (BSC 2004 [DIRS 171850], Section 8.1). Checksums and parity checks performed during information transfer and storage, plus existing computer system security measures, provide adequate assurance of the integrity of transferred and stored information. There were no variances from the planned methods.

This analysis activity addresses in part characteristics of the bedrock at Yucca Mountain, a natural barrier identified on the Q-List as a Safety Category (SC) item per AP-2.22Q (Classification Analysis and Maintenance of the Q-List). 


\section{INTENTIONALLY LEFT BLANK}




\section{USE OF SOFTWARE}

The section describes software directly used in the analysis. Both qualified software (Table 3-1) and commercial-off-the-shelf programs are employed.

Table 3-1. Qualified Software Used in the Analysis

\begin{tabular}{|l|l|c|l|}
\hline \multicolumn{1}{|c|}{ Name [DIRS] } & \multicolumn{1}{c|}{ Tracking Number } & Version & \multicolumn{1}{c|}{ Operating Environment } \\
\hline LOGNORM [DIRS 170313] & $10384-1.01-00$ & 1.01 & PC/DOS 6.22-QEMM 9.0 \\
\hline NORM [DIRS 163313] & $10386-1.01-00$ & 1.01 & PC/DOS 6.22-QEMM 9.0 \\
\hline EARTHVISION [DIRS 167994] & $10174-5.1-00$ & 5.1 & SGI/IRIX 6.5 \\
\hline
\end{tabular}

The software program LOGNORM V1.01 (Pacific Engineering and Analysis 2004 [DIRS 170313]) is used to determine the median values of horizontal peak ground velocity and shear strain as a function of depth using the results of a suite of previous ground-motion site-response model calculations as input. The program was selected for this purpose because it has the required capabilities and is part of a suite of programs that were designed and are intended to work with and support the ground-motion site-response model calculations. There are no limitations on outputs due to the selection of this software. The software was used within its range of validation; its ability to determine the average and statistics as a function of depth of a parameter with an assumed lognormal distribution has been validated (DOE 2004 [DIRS 170315], Section 2.3.10).

The software program NORM V1.01 (Pacific Engineering and Analysis 2002 [DIRS 163313]) is used to compute the average horizontal peak ground velocity and shear strain over the average depth range for the lower lithophysal zone. The inputs for this computation are median curves as a function of depth determined by LOGNORM. The program was selected for this purpose because it has the required capabilities and is part of a suite of programs that were designed and are intended to work with and support the ground-motion site-response model calculations. There are no limitations on outputs due to the selection of this software. The software was used within its range of validation; its ability to determine the average and statistics of a parameter has been validated (DOE 2002 [DIRS 170314], Section 3.2).

The software program EARTHVISION V5.1 (Dynamic Graphics 2000 [DIRS 167994]) is used to determine the average depth range for the lower lithophysal unit of the Topopah Spring Tuff. Input to the program consists of the Geologic Framework Model (Data Tracking Number (DTN) MO0012MWDGFM02.002 [DIRS 153777]). The program was selected for this purpose because it is the program used to develop the geologic model of the Yucca Mountain site. There are no limitations on outputs due to the selection of this software. The software was used within its range of validation.

Commercial-off-the-shelf software programs Microsoft ${ }^{\circledR}$ Excel 97 SR-2 and Microsoft ${ }^{\circledR}$ Excel 2000 were used in carrying out several components of the analysis. Standard functions of the programs were used and results are not dependent on use of these particular spreadsheet programs. Formulae used, input data, and output values are documented in Appendix D to this report. 
Microsoft ${ }^{\circledR}$ Excel was used in evaluation of geologic data to sort fracture data and to determine the percentages of fractures with certain characteristics. The program also was used to display the results of the evaluations. Appendix D contains the workbooks ( $P G V$ ECRB DLS Frac-Fill.xls, PGV SSF DLS Frac-Fill.xls) developed for analysis of fracture data showing the input data and results. Formulae used also are included.

Microsoft ${ }^{\circledR}$ Excel was also used to identify the intact shapes of lithophysae versus structural damage that might result from post-cooling stresses induced by seismic shaking. Appendix D contains the workbook (PGV Lithop Shapes ECRB.xls) used to compile and analyze descriptions and photographic interpretations of lithophysal cavity data in the ECRB Cross-Drift. Information on inputs, outputs, and formulae are contained in the workbook.

Microsoft ${ }^{\circledR}$ Excel also was used in determining the shear strain increment that lithophysal rock underwent in being deformed from in situ conditions to failure. Similar spreadsheets were developed for analysis of both laboratory test results and results of numerical simulations. Inputs, outputs, and formulae used are documented in Appendix D (Limiting strains -Lab Tests.xls, Limiting strains -Numerical Sims.xls).

Microsoft ${ }^{\circledR}$ Excel also was used to average the horizontal peak ground velocity and shear strain values determined for two wave propagator types (vertical and inclined propagation). For each annual frequency of exceedance considered, the average values are computed for the 8 combinations of base-case velocity profile, base-case dynamic property curves, and oscillator frequency range. These combinations reflect uncertainties in the input parameters and also the range of earthquakes that contribute to the annual frequency that a given level of ground motion will be exceeded. Inputs, outputs, and formulae used are documented in Appendix D (PGV\&Strain-Average of Vertical \& Inclined Results.xls).

Microsoft ${ }^{\circledR}$ Excel also was used to determine values of horizontal peak ground velocity at specified values of dynamic shear strain. For each of the 8 cases representing uncertainty in site properties, linear interpolation or extrapolation was used based on the results in the workbook PGV\&Strain-Average of Vertical \& Inclined Results.xls. Inputs, outputs, and formulae used are documented in Appendix D (PGV v Shear Strain.xls).

Microsoft ${ }^{\circledR}$ Excel also was used to compute probability densities and seismic hazard curves for the waste emplacement level. Probability densities were computed for shear strain threshold using a triangular distribution. Probability densities for horizontal PGV were determined from the triangular distribution for shear strain threshold. An unbounded horizontal PGV hazard curve for the emplacement level was determined from results of site-response modeling. Modified hazard curves for horizontal PGV at the emplacement level are determined from the hazard curve for unbounded motions and the probability distributions for the bound on horizontal peak ground velocity. Inputs, outputs, and formulae used are documented in Appendix D (Probability Distributions.xls).

Commercial-off-the-shelf software programs CorelDraw ${ }^{\circledR} 9$ and CorelDraw 10 were also used in the analysis. These programs were used to display data as part of the evaluation of geologic data from mapped panels in the ECRB Cross-Drift. 
Two other software programs also are mentioned in this report, but are not used in the analysis. PFC2D (Software Tracking Number [STN] 10828-2.0-01) (BSC 2004 [DIRS 169930]) and UDEC (STN 10173-3.1-00) (BSC 2002 [DIRS 161949]) were used in previous modeling and analysis activities to simulate compressive tests of Topopah Spring Tuff (BSC 2003 [DIRS 166660], Attachments V, VI, VIII). In this analysis, the results of the previous work are used and the software programs cited to indicate which program was used to generate which result. Because the software programs are not used in this analysis, they are not included in Table 3-1. 


\section{INTENTIONALLY LEFT BLANK}




\section{INPUTS}

This section describes the direct inputs, criteria, and codes for the analysis.

\subsection{DIRECT INPUTS}

Direct inputs are used in carrying out five components of the analysis:

1. Evaluation of geologic data from the ESF and the ECRB Cross-Drift for evidence of ground motion-induced damage to the rock.

2. Interpretation of laboratory rock testing data to determine the shear-strain threshold at which failure occurs for lithophysal rock.

3. Evaluation of previous numerical simulations of lithophysal rock deformation to determine the shear-strain threshold at which failure occurs.

4. Evaluation of previous ground-motion site-response model results to determine the level of shear strain that is associated with various levels of horizontal PGV at the waste emplacement level.

5. Development of a hazard curve for horizontal PGV at the waste emplacement level.

This section lists the direct inputs used (Table 4-1) and discusses their appropriateness.

Table 4-1. Direct Inputs Used in the Analysis

\begin{tabular}{|l|l|}
\hline \multicolumn{1}{|c|}{ Description } & \multicolumn{1}{|c|}{ Data Tracking Number } \\
\hline $\begin{array}{l}\text { Detailed Line Survey Data For Stations 00+00.89 to 14+95.18, } \\
\text { ECRB Cross-Drift }\end{array}$ & GS990408314224.001 [DIRS 108396] \\
\hline $\begin{array}{l}\text { Detailed Line Survey Data For Stations 15+00.85 to 26+63.85, } \\
\text { ECRB Cross-Drift }\end{array}$ & GS990408314224.002 [DIRS 105625] \\
\hline $\begin{array}{l}\text { Detailed Line Survey Data for Horizontal and Vertical Traverses, } \\
\text { ECRB }\end{array}$ & GS040108314224.001 [DIRS 169591] \\
\hline $\begin{array}{l}\text { Lithophysal Study Data from the Tptpll in the ECRB from stations } \\
\text { 14+44 to 23+26 [especially see the part on Panel Maps] }\end{array}$ & GS021008314224.002 [DIRS 161910] \\
\hline $\begin{array}{l}\text { ESF, ECRB Cross-Drift Small Scale Fracture Study: Detailed Line } \\
\text { Survey Data for Horizontal and Vertical Traverses 2003 }\end{array}$ & GS040408314224.003 [DIRS 170312] \\
\hline Fractures in slabs of core in crystallized Topopah Spring Tuff & GS040808314224.005 [DIRS 171964] \\
\hline $\begin{array}{l}\text { Mechanical Properties Of Lithophysal Tuff, Batch \#1 (Test Dates: } \\
\text { July 31, 2002 Through August 16, 2002) }\end{array}$ & SN0208L0207502.001 [DIRS 161871] \\
\hline $\begin{array}{l}\text { Mechanical Properties Of Lithophysal Tuff, Batch \#2 (Test Dates: } \\
\text { October 22, 2002 Through October 25, 2002) }\end{array}$ & SN0211L0207502.002 [DIRS 161872] \\
\hline
\end{tabular}


Table 4-1. Direct Inputs Used in the Analysis (Continued)

\begin{tabular}{|l|l|}
\hline \multicolumn{1}{|c|}{ Description } & \multicolumn{1}{|c|}{ Data Tracking Number } \\
\hline $\begin{array}{l}\text { BSC (Bechtel SAIC Company) 2003. Subsurface Geotechnical } \\
\text { Parameters Report. 800-K0C-WIS0-00400-000-00A. Las Vegas, } \\
\text { Nevada: Bechtel SAIC Company. ACC: ENG.20040108.0001. } \\
\text { [DIRS 166660] }\end{array}$ & Not applicable \\
\hline $\begin{array}{l}\text { BSC (Bechtel SAIC Company) 2004. Development of Earthquake } \\
\text { Ground Motion Input for Preclosure Seismic Design and } \\
\text { Postclosure Performance Assessment of a Geologic Repository at } \\
\text { Yucca Mountain, NV. MDL-MGR-GS-000003 REV 01. } \\
\text { Las Vegas, Nevada: Bechtel SAIC Company. [DIRS 170027] }\end{array}$ & MO0409MWDGMMIO.000 [DIRS 172216] \\
\hline Geologic Framework Model (GFM2000) & MO0012MWDGFM02.002 [DIRS 153777] \\
\hline $\begin{array}{l}\text { Peak Ground Velocity for the Repository Level (Point B) at 10 } \\
\text { Annual Exceedance Frequency }\end{array}$ & MO0404PGVRL104.000 [DIRS 170437] \\
\hline $\begin{array}{l}\text { Peak Ground Velocity for the Repository Level (Point B) at 10 } \\
\text { Annual Exceedance Frequency }\end{array}$ & MO0401SEPPGVRL.022 [DIRS 169099] \\
\hline $\begin{array}{l}\text { Peak Ground Velocity for the Repository Level (Point B) at 10 } \\
\text { Annual Exceedance Frequency }\end{array}$ & MO0303DPGVB106.002 [DIRS 162712] \\
\hline $\begin{array}{l}\text { Peak Ground Velocity for the Repository Level (Point B) at 10 } \\
\text { Annual Exceedance Frequency }\end{array}$ & MO0210PGVPB107.000 [DIRS 162713] \\
\hline
\end{tabular}

Geologic mapping data on the occurrence and genesis of fractures within lithophysal units of the Topopah Spring Tuff (DTNs: GS990408314224.001 [DIRS 108396], GS990408314224.002 [DIRS 105625], GS040108314224.001 [DIRS 169591], GS040408314224.003 [DIRS 170312], and GS040808314224.005 [DIRS 171964]) are used in Section 6.3 to evaluate whether observed joints and faults exhibit characteristics expected for features created by extreme levels of ground motion. Fracture data associated with these DTNs are considered in making this evaluation. Representative panel maps (Table 4-2, DTN GS021008314224.002 [DIRS 161910]) were also examined to compare observed features with those predicted by numerical modeling of rock failure.

Table 4-2. Panel Map Images Examined in this Analysis

\begin{tabular}{|c|c|c|c|}
\hline Image Identification & Image Identification & Image Identification & Image Identification \\
\hline PP0660L & PP0816R & PP1035L & SSF1886L \\
\hline PP0660R & PP0910L & PP1035R & SSF1920L \\
\hline PP0740L & PP0910R & PP1220L & SSF2019L \\
\hline PP0740R & PP0935L & PP1218R & SSF2071L \\
\hline PP0815L & PP0935R & SSF1805L & SSF2125L \\
\hline
\end{tabular}

Source: Appendix A, Table A4-1

These geologic data are appropriate for use in this analysis because they represent the available geologic information on the characteristics of fractures in the lithophysal units of the Topopah Spring Tuff and the spatial relation of those fractures to lithophysae. While the data were not specifically gathered for the purpose of comparison to numerical modeling results of rock damage, the data are adequate to determine whether the observed features are indicative of the type of pervasive deformation that is predicted if extreme levels of ground motion were to have occurred. 
Results of laboratory testing to determine the mechanical properties of lithophysal rock (DTNs: SN0208L0207502.001 [DIRS 161871] and SN0211L0207502.002 [DIRS 161872]) are used in Section 6.4.1 to determine the shear strain increment in deforming the rock from in situ conditions to failure. Specific data used are values for Young's modulus, Poisson's ratio, and ultimate strength. Data from all samples were used. Data on the length-to-diameter ratio of tested samples are used to identify a subset of samples with a ratio greater than 1.5. In addition to determining statistics for the shear strain increment based on all samples, statistics for this subset also are computed.

These particular mechanical property data are appropriate for use because they were determined from tests of 288-mm-diameter samples of lithophysal rock from the Topopah Spring Tuff. Mechanical properties determined from such large-diameter samples better reflect the behavior of the in situ rock in that they can include larger lithophysae than smaller samples. Data for lithophysal rock are analyzed because the lithophysal rock units are weaker than the nonlithophysal units. They would, therefore, show evidence of ground motion-related damage at lower levels of ground motion than would nonlithophysal rock.

Data on the lithophysal content of rock samples tested is used in displaying the shear strain threshold results, but is not used directly in the analysis. The lithophysal content data are included in the data set with DTN: SN0305L0207502.005 [DIRS 163373].

To complement the results of laboratory testing, numerical simulations of the mechanical behavior of lithophysal rock from the Topopah Spring Tuff (BSC 2003 [DIRS 166660], Attachments V, VI, VIII) also are used in Section 6.4.2 to determine the shear strain increment in deforming the rock from in situ conditions to failure. In these numerical simulations, which were carried out previously, lithophysae were represented in alternative ways. For simulations using the software code PFC2D (STN 10828-2.0-01) (BSC 2004 [169930]), lithophysae were represented both as $90 \mathrm{~mm}$ circles and using shape stencils based on observations in the ECRB. For simulations using the software code UDEC (STN 10173-3.1-00) (BSC 2002 [DIRS 161949]), lithophysae were represented as $90 \mathrm{~mm}$ circles. Results of all three sets of simulations are used in this analysis.

Specific data used from each simulation are Young's modulus, Poisson's ratio, yield stress, and peak stress. For the simulations that used the software code PFC2D, Young's modulus, Poisson's ratio, and peak stress are taken from the file ShapeStudy.xls (BSC 2003 [DIRS 166660], Attachment VIII, Compact Disc 1: $\backslash$ AppD_CD01\PFC_runs $\backslash$ ShapeStudy $\backslash$ ). For the simulations that used the software code UDEC, Young's modulus, Poisson's ratio, friction angle, and peak stress are taken from the file summary2_newest.xls (BSC 2003 [DIRS 166660], Attachment VIII, Compact Disc 20: $U$ UDEC_CD1\). Values of yield stress are determined for both PFC2D and UDEC simulations by plotting volumetric strain and axial stress as a function of axial strain from restored *.SAV files (BSC 2003 [DIRS 166660], Attachment VIII, Compact Discs 2 through 24). As for the laboratory testing results, data on the lithophysal porosity (BSC 2003 [DIRS 166660], Attachment VIII, ShapeStudy.xls, summary2_newest.xls files) of each simulated sample tested is used in displaying the shear strain threshold results, but is not used directly in the analysis. 
The numerical simulations of the mechanical behavior of Topopah Spring Tuff lithophysal rock are the result of previous modeling activity (BSC 2003 [DIRS 166660], Sections 9.1, 9.2 and Attachments V, VI, and VIII]; BSC 2004 [DIRS 166107], Sections 7.5 and 7.6; BSC 2004 [DIRS 172334], Section 6.5). They are appropriate inputs because they model the strains developed in such rock as the rock is stressed to failure. Numerical simulations, conducted with a suitably-calibrated model, complement the results from laboratory testing by allowing representation of synthetic rock samples that contain more variable lithophysae shapes, distributions, and levels of porosity than can be physically tested. The simulations also allow a large number of numerical testing simulations to be run in which full control of applied pressures and monitoring of deformation response is possible. It is therefore possible to fully explore the variability of lithophysal rock mass strain at failure for the range of expected in situ conditions.

Ground-motion site-response modeling data (DTN: MO0409MWDGMMIO.000 [DIRS 172216]) are used in Section 6.5 to determine the level of horizontal PGV associated with various levels of ground-motion-induced shear strain. Lack of geologic evidence of rock damage predicted to result from extreme levels of ground motion is used to conclude that shear strain levels that would cause such damage have not occurred and, hence, the associated levels of horizontal PGV also have not occurred at Yucca Mountain. Specific data used from the ground-motion site-response modeling results are the variation of horizontal PGV and shear strain with depth from the surface to the bottom of the modeled site materials. Results for ground motion with annual frequencies of exceedance of $10^{-4}, 10^{-5}, 10^{-6}$, and $10^{-7}$ are used to cover the range of uncertainty in the level of shear strain at which damage would occur. For each annual frequency of exceedance, the input to the analysis consists of results from a suite of 2880 model runs to accommodate variability and uncertainty in site dynamic material properties and the range of earthquake magnitudes and distances contributing to the seismic hazard.

These ground-motion site-response data are the result of previous modeling (BSC 2004 [DIRS 170027], Section 6.3.4). They are appropriate for use in this analysis because they provide the link between ground-motion-induced strain and horizontal PGV at the waste emplacement level. Because the ground motion input to the site-response modeling is based on the results of the PSHA for Yucca Mountain, the results incorporate the uncertainties and randomness that were determined as part of the PSHA process. Because uncertainties and randomness in site dynamic material properties are also accommodated in the site-response modeling, the resulting horizontal PGV and shear strain data are consistent with the hazard level of the input ground motions.

Ground motion site-response modeling data for horizontal PGV at the waste emplacement level (DTNs: MO0404PGVRL104.000 [DIRS 170437], MO0401SEPPGVRL.022 [DIRS 169099], MO0303DPGVB106.002 [DIRS 162712], and MO0210PGVPB107.000 [DIRS 162713]) are used to develop a hazard curve. They are appropriate for this use because they represent the site-specific horizontal $\mathrm{PGVs}$ for the waste emplacement level with annual frequencies of exceedance of $10^{-4}, 10^{-5}, 10^{-6}$, and $10^{-7}$, respectively. The horizontal PGV hazard curve developed from these data represents unbounded ground motions. A composite hazard curve that incorporates the effect of a bound to horizontal PGV at the waste emplacement level also is developed. 


\subsection{CRITERIA}

Project requirements are identified in Project Requirements Document (TER-MGR-MD-000001) (Canori and Leitner 2003 [DIRS 166275]). The requirements that pertain to this analysis report and their links to 10 CFR 63 [DIRS 156605] are summarized in Table 4-3.

Table 4-3. Project Requirements Pertaining to the Bounding Peak Ground Velocity Analysis

\begin{tabular}{|l|l|l|}
\hline \multicolumn{1}{|c|}{ Requirement Number } & \multicolumn{1}{|c|}{ Title } & \multicolumn{1}{c|}{ 10 CFR 63 Link } \\
\hline PRD-002/T-004 & Content of Application & 10 CFR 63.21 \\
\hline PRD-002/T-011 & Purpose and Nature of Findings & 10 CFR 63.101 \\
\hline PRD-002/T-015 & Requirements for Performance Assessment & 10 CFR 63.114 \\
\hline
\end{tabular}

This report addresses criterion PRD 002/T-004 by describing a reasonable bound to horizontal PGV that potentially affect the performance of the geologic repository at Yucca Mountain. It thus provides information needed for a complete description of the site.

This report addresses criterion PRD 002/T-011 by describing the technical basis and justification for the range of parameter distributions characterizing a reasonable bound to horizontal PGV at Yucca Mountain. This distribution is used in assessing the performance of a repository.

This report addresses criterion PRD 002/T-015 by describing horizontal PGV that form part of the information on disruptive events that is used to evaluate the performance of a repository at Yucca Mountain. The report also describes the uncertainties and variability in parameter values that provide input to the analysis of a credible bound to horizontal PGV and the alternative models considered.

Criteria are also provided by the Yucca Mountain Review Plan, Final Report (NRC 2003 [DIRS 163274]). Relevant acceptance criteria from this document are:

- Acceptance criteria listed in Section 1.5.3 of NRC (2003 [DIRS 163274]) are based on meeting requirements of 10 CFR 63.21(b)(5) [DIRS 156605], which relate to description of site characterization work:

1. The "General Information" section of the license application contains an adequate description of site characterization activities.

2. The "General Information" section of the license application contains an adequate description of site characterization results.

This report addresses Part 1 of criterion 1 and Parts 1 and 2 of criterion 2 by providing a reasonable bound to horizontal PGV that forms part of the description of site characterization activities and results. 
- Acceptance criteria listed in Section 2.2.1.2.2.3 of NRC (2003 [DIRS 163274]) are based on meeting requirements of 10 CFR 63.114(d) [DIRS 156605], which relate to identification of events with probabilities greater than $10^{-8}$ per year:

1. Events are adequately defined.

2. Probability estimates for future events are supported by appropriate technical bases.

3. Probability model support is adequate.

4. Probability model parameters have been adequately established

5. Uncertainty in event probability is adequately evaluated.

This report addresses Parts 1 and 2 of criterion 1, Part 1 of criterion 2, Part 1 of criterion 3, Part 1 of criterion 4, and Part 1 of criterion 5 by describing the technical justification for a reasonable bound to horizontal PGV that is used to analyze performance of the repository. The bound is based on models of rock deformation and ground motion and on empirical observations from laboratory testing and geologic investigations. In addition, the report discusses how inputs to the analysis were determined and how uncertainties are accommodated by the analysis.

- Acceptance criteria in Section 2.2.1.3.2.3 of NRC (2003 [DIRS 163274]) are based on meeting the requirements of 10 CFR 63.114(a) (c) (e) and (g) [DIRS 156605], which relate to mechanical disruption of engineered barriers:

2. Data are sufficient for model justification.

3. Data uncertainty is characterized and propagated through the model abstraction.

This report addresses Parts 1 and 3 of criterion 2 and Parts 1, 2, and 3 of criterion 3 by describing the use of data to develop inputs to the seismic consequence abstraction model and how data uncertainty is incorporated into the analysis.

The Yucca Mountain Review Plan, Final Report (NRC 2003 [DIRS 163274]) also provides information on the review methods that will be used to assess whether the acceptance criteria have been met. Review methods specifically relevant to the analysis described in this report are:

Section 2.2.1.2.2.2

\section{Review Method 1 Event Definition}

Evaluate whether the definitions for events (potentially beneficial or disruptive), applicable to the Yucca Mountain repository, are unambiguous; probabilities are estimated for the specific event; and event definitions are used consistently and appropriately in probability models. 
Confirm that probabilities of intrusive and extrusive igneous events are calculated separately. Verify that definitions of faulting and earthquakes are derived from the historical record, paleoseismic studies, or geological analyses. Confirm that criticality events, for the purpose of initial screening of the features, events, and processes list, are calculated separately, only by location of the criticality event (e.g., in package, near field, and far field).

\section{Review Method 2 Probability Estimates}

... Verify that probability estimates for future faulting and seismic events have considered past patterns of these events in the Yucca Mountain region. Examine the adequacy and sufficiency of characterization and documentation of past faulting and seismicity in the Yucca Mountain region, since 2 million years ago. This should include characterization of uncertainties in the age, timing, magnitude (i.e., displacements), distribution, size, location, and style of faulting and seismicity. Evaluate whether interpretations of faulting and seismicity from surficial and underground mapping, interpretations of geophysical data, or analog investigations are internally consistent and geologically feasible, so reasonable projections can be made about the probability of future faulting and earthquake induced ground vibrations at the site.

\section{Review Method $4 \quad$ Probability Model Parameters}

Verify whether the parameters used to calculate the probability of events, applicable to the Yucca Mountain repository, are reasonable, based on data from the Yucca Mountain region or analogous natural systems, and/or design and engineering characteristics of the proposed Yucca Mountain repository system.

... Verify whether parameter values used in probabilistic seismic and fault displacement hazard assessments are adequately supported by Yucca Mountain region faulting and earthquake data or appropriate analogs, so the effects of faulting and seismicity are appropriately factored into repository performance. Verify that parameters are consistent with the range of faulting characteristics and seismicity observed in the Yucca Mountain region, or with parameters derived from representative analogs, and ascertain that the parameters account for variability in data precision and accuracy. For example, confirm that the U.S. Department of Energy adequately evaluated uncertainties in faulting or earthquake activity (i.e., recurrence). Confirm that the U.S. Department of Energy has established reasonable and consistent correlations between parameters, where appropriate. Where sufficient data do not exist, confirm that parameter values and conceptual models are based on appropriate use of other sources, such as expert elicitation, using NUREG-1563 (Kotra et al., 1996).

Review Method 5 Uncertainty in Event Probability

... Verify that probabilities used in the evaluation of faulting and seismicity effects on repository performance include both infrequent seismic and faulting 
events with relatively large magnitude ground motions and fault displacements, and the cumulative effects of repeated ground motions or fault displacements from more frequent and lower magnitude seismic or faulting events.

\subsection{CODES, STANDARDS, AND REGULATIONS}

There are no codes or standards other than those discussed in Section 4.2 that pertain to the analysis of a reasonable bound to horizontal PGV. 


\section{ASSUMPTIONS}

Assumptions are used, in the absence of direct confirming data or evidence, in the analysis of results of lithophysal rock deformation, both from laboratory testing and from numerical simulation. These assumptions are described below.

1. For laboratory testing of lithophysal rock samples, if Poisson's ratio is not determined, a value of 0.3 is assumed in calculating the shear-strain increment from in situ conditions to failure. About 80 percent of Poisson ratio determinations for lithophysal rock at Yucca Mountain fall in the range of 0.1 to 0.3 (BSC 2003 [DIRS 166660], Figure 8-58). The mean value is 0.21 . A value of 0.3 is assumed in the shear-strain increment calculations (if a value from testing is unavailable) because larger values of Poisson's ratio result in larger calculated shear-strain increments. Larger shear-strain increments lead to a larger shear-strain threshold, which implies a higher bound to horizontal PGV. The assumption is used in Section 6.4.

2. For both laboratory testing and numerical simulation of the deformation of lithophysal rock samples, if the friction angle is not determined, a value of 30 degrees is assumed in calculating the shear-strain increment in going from in situ conditions to failure. Values of internal friction angle for intact lithophysal rock at Yucca Mountain, determined from compressive test results, vary from about 45 to 60 degrees (BSC 2003 [DIRS 166660], Table 8-40). Numerical simulation results for the lithophysal rock mass indicate internal friction angles ranging from about 30 to 40 degrees (Appendix D, Limiting Strain-Numerical Sims.xls, Worksheet "UDEC 250m"). A value of 30 degrees is assumed for internal friction angle (if test results or numerical simulation results do not include a value) because smaller values of internal friction angle result in larger calculated shear-strain increments. Larger shear-strain increments lead to a larger shear-strain threshold, which implies a higher bound to horizontal PGV. The assumption is used in Section 6.4 .

3. In determining the in situ stress state for the lithophysal rocks of the Topopah Spring Tuff, a lithostatic stress gradient of $0.01925 \mathrm{MPa} / \mathrm{m}$ depth is assumed. This value is used in calculating the magnitude of the vertical stress $\left(\sigma_{1}\right)$ for two representative depths (250 and $400 \mathrm{~m}$ ) for the repository emplacement level. This value is consistent with the unit weight calculated from information provided in the Drift Degradation Analysis (BSC 2004 [DIRS 166107], Table E-1) for units of the Paintbrush Group. Determination of the shear-strain increment in going from in situ conditions to failure is insensitive to reasonable values of unit weight. The assumption is used in Section 6.4.

4. In determining the in situ stress state for the lithophysal rocks of the Topopah Spring Tuff, it is assumed that the magnitude of the horizontal stress is 0.5 times that of the vertical stress. This is consistent with results from a hydraulic fracturing investigation in the ESF (CRWMS M\&O 1997 [DIRS 147458], pp. 1, 15, 16) that determined a horizontal to vertical stress ratio of 0.3 to 0.7 , taking into account the range of horizontal stress and uncertainties in the results. If the upper value from the range were assumed, calculated shear strain increments (percent strain) would be higher by a few to about 10 percent. The assumption is used in Section 6.4. 


\section{INTENTIONALLY LEFT BLANK}




\section{SCIENTIFIC ANALYSIS DISCUSSION}

\subsection{INTRODUCTION}

The purpose of this analysis report is to establish a reasonable bounding peak ground velocity (PGV) for the emplacement level of the Yucca Mountain site (Point B of BSC (2004 [170027], Figure 1-1)). This site-specific PGV is assessed to be appropriate considering annual frequencies of exceedance as low as $10^{-8} / \mathrm{yr}$. PGV is the ground motion measure that is correlated with potential seismic damage to the engineered barrier system (EBS) components in the seismic consequence abstraction (BSC 2004 [DIRS 169183], Section 6.1.3). The results of the PSHA are expressed as seismic hazard curves at a hypothetical rock outcrop (Point A of (BSC 2004 [DIRS 170027], Section 6.2.2)). Site response analyses are used to modify the Point A ground motions to account for site-specific material properties (BSC 2004 [DIRS 170027]) and to develop seismic hazard curves that are appropriate for conditions at the emplacement level of the repository (Point B). The annual frequency of exceedance of ground motions and the amplitudes of the ground motions, expressed as PGV, are used as input to the seismic consequence abstraction (BSC 2004 [DIRS 169183]). In turn, the results of the consequence abstraction are input to the seismic scenario that is used in the TSPA (Figure 1-1).

Analysis of the response of EBS components to various levels of ground motion has shown that damage occurs at PGV amplitudes that are associated with annual frequencies less than or equal to $10^{-6} / \mathrm{yr}$ (BSC 2004 [DIRS 169183], Sections 6.1.3 and 6.3). At these annual frequencies down to $10^{-8} / \mathrm{yr}$, the mean hazard estimate is quite sensitive to the tails of the ground motion attenuation distribution, which is represented by unbounded lognormal distributions on the aleatory variability. As a result, the mean hazard curve lies well above the median hazard curve and above the $85^{\text {th }}$ percentile curve (BSC 2004 [DIRS 170027] Figures 6.2-1 through 6.2-3). In addition, the assessed epistemic (scientific) uncertainty in ground motion attenuation is large for the large-magnitude, short-distance earthquakes that control the seismic hazard at annual frequencies of exceedance in the range $10^{-6}$ to $10^{-8}$. It is judged that the resulting mean PGV values at these annual frequencies of exceedance may be physically unrealistic (Reiter 2004 [DIRS 170694]). The present analysis is aimed at estimating a bounding horizontal PGV that has a physical basis. This bound, which is represented as a probability distribution to account for uncertainties, is then used to limit the level of mean PGV values at annual frequency levels down to $10^{-8} / \mathrm{yr}$.

\subsection{APPROACH}

The approach taken to assess bounding PGV for the emplacement level of the Yucca Mountain site is to consider physical limits on the amplitude of ground motions. Amplitudes of ground motions are limited by the strength of the materials through which they propagate. At high enough levels of seismic shaking the rocks at the emplacement level, particularly the lithophysal tuffs, would undergo mechanical damage, would fracture, and fail. A key geologic finding in the ESF and ECRB is the absence of mechanical damage of the type expected from extreme seismic shaking in the 12.8-million-year old volcanic rocks at the emplacement level. There are fractures and minor faults observed in the excavations, but these appear to be related primarily to the early cooling history of the rocks or, in the case of known faults, localized zones of displacement. Extreme seismic shaking over dimensions of the repository would result in widespread damage. 
The absence of such damage means that the rocks have not experienced ground motions of sufficient amplitude to cause failure since the time that they were deposited. Laboratory tests and modeling provide the means of assessing the shear strain increments required to cause failure of the lithophysal rock. In turn, ground motion modeling provides a means of assessing the site-specific ground motions that would cause these shear strains. Through this approach, the amplitudes of ground motions are assessed that have not been achieved or exceeded during the past 12.8 million years at the emplacement level of Yucca Mountain. This conclusion provides the basis for the analysis of reasonable bounds on PGV.

Rock testing data, geologic data, and ground-motion site response data are combined to determine a bound to horizontal PGV. The analysis consists of four steps. First, laboratory testing and numerical simulations of lithophysal rock deformation are used to determine the shear-strain threshold for rock failure. Second, the results of the numerical simulations are combined with geologic observations in the ESF and ECRB Cross-Drift to conclude that the Topopah Spring lithophysal zones have not experienced shear-strains exceeding the threshold for failure. Third, ground-motion site response data are used to assess the level of horizontal PGV that would be required to generate shear strains exceeding the shear-strain threshold for failure. Fourth, it is concluded that such a level of horizontal PGV has not been reached at Yucca Mountain since the rocks were deposited 12.8 million years ago. This is taken as a reasonable bound for the level of ground motion to be considered in TSPA.

Key issues associated with the approach are the following: the resolution of the geologic observations, including identifying the origins of fractures and features and their association with depositional (e.g., cooling of the tuffs) or post-depositional processes (e.g., seismic shaking); threshold shear strain levels associated with failure of the lithophysal tuffs, given in situ stress conditions; definition of failure criteria that are consistent with the resolution of the geologic observations; and PGV ground motions associated with particular levels of threshold shear strain. Each of these key issues is associated with uncertainty and the approaches to addressing these uncertainties are given in Sections 6.3, 6.4, and 6.5.

The analysis of maximum ground motions conducted for the PEGASOS project in Switzerland (Abrahamson et al. 2004 [DIRS 170686]) consisted of evaluating limits based on considerations of seismic source properties, as well as limitations in the strength capacities of the soils underlying the sites. The approach being followed for the present analysis is analogous to the latter approach used in Switzerland inasmuch as limits on the shear strength of the local transmission medium provide a fundamental constraint on the amplitude of the ground motions.

The analysis presented in this report uses the results of testing and modeling of the shear strains required to fail the lithophysal rocks at the emplacement level, and the results of the geologic evidence for the lack of seismically-induced damage, to arrive at a probability distribution on failure or threshold shear strain. Threshold shear strain values are then translated into ground motions (PGV) using the site response model for Yucca Mountain at the emplacement level. The resulting PGV values are then combined with the failure shear strain probability distribution to arrive at a probability distribution on bounding PGV.

The concept used to develop a bounding ground motion distribution is analogous to defining a maximum earthquake magnitude that defines the upper bound to an earthquake recurrence 
relationship for probabilistic seismic hazard analyses (Budnitz et al. 1997 [DIRS 103635], Section 4.2.2). Maximum magnitudes are specific to individual seismic sources. Because the historical record is usually short relative to the recurrence interval for the largest earthquake that a seismic source can generate, the assessment of maximum magnitude is uncertain and commonly expressed as a probability distribution (Budnitz et al. 1997 [DIRS 103635], Section 4.3.2). There is no single unique method of estimating maximum magnitude. Typically, the assessment is made considering a combination of observed seismicity data and physical constraints. The observed record includes earthquakes that have occurred in association with the particular seismic source historically, as well as earthquakes that have occurred in association with analogous seismic sources. Physical constraints include estimates of the maximum dimensions of rupture that a seismic source might entail (e.g., fault rupture length, displacement per event). These various data and estimates, none of which individually provides a unique maximum magnitude estimate, are used to develop a judgment expressed as a probability distribution on maximum magnitude for a seismic source of interest (Budnitz et al. 1997 [DIRS 103635], Section 4.3.2), reflecting the epistemic uncertainty.

In a comparable way, the bounding ground motion is rare and uncertain, it is specific to the site of interest, and there is no single dataset that uniquely defines it. Approaches to estimating bounding ground motions include consideration of the observational record, including both site-specific and analogue ground motion recordings, as well as physical constraints on seismic source properties, transmission path, and local strength characteristics. The approach taken in this analysis focuses on ground motion limits based on strength properties of the rock. The result of the analysis is a probability distribution on bounding PGV that, much like a maximum magnitude distribution, reflects the epistemic uncertainty.

Subsequent sections of this report provide the documentation for the steps outlined in this approach. Section 6.3 summarizes the geologic observations regarding the presence or absence of seismic shaking-related damage in the lithophysal tuffs comprising the emplacement level of the repository. Section 6.4 summarizes the testing and modeling information related to the tuffs and the threshold shear strain distribution that is developed in light of that information. Section 6.5 provides a summary of the site-specific ground motion calculations that translate the threshold shear strain values into PGV values at the emplacement level. Section 6.6 presents the bounding PGV distribution, which is assessed through a consideration of the geologic data, testing and modeling, and ground motion calculations.

\subsection{GEOLOGIC OBSERVATIONS REGARDING SEISMICALLY-INDUCED DAMAGE}

A key element of the approach to bound horizontal PGV at the waste emplacement level is using the geologic data collected in the ESF and ECRB Cross-Drift to determine whether pervasive seismically-induced fracturing and other rock damage has occurred at Yucca Mountain. The features in a rock represent the major processes that have occurred throughout its geologic history; therefore, the features are used to reconstruct the sequential development of the rock-forming processes. This sequential development of features is placed in a temporal (or petrogenetic) framework that constrains how and when subsequent processes occurred. Furthermore, this petrogenetic framework is used to evaluate whether the rocks have ever experienced shear strains great enough to result in mechanical failure. One of the prime sources 
of shear strain to be considered is that associated with paleoseismic events. Three types of geologic observations were made to evaluate whether pervasive seismically-induced fracturing has occurred at Yucca Mountain in the rocks of the repository horizon since their deposition: (1) evaluation of the petrogenesis of fractures relative to their association with deposition/cooling versus mechanical damage subsequent to cooling; (2) evaluation of damage or collapse of lithophysal cavities in response to shear strains; and (3) comparison of rock mechanics modeling of inter-lithophysal fractures with panel photographs in the ECRB. A summary discussion of these geologic observations is given in Sections 6.3.1 through 6.3.4 and a detailed discussion is provided in Appendix A.

\subsubsection{Petrogenesis of Fractures}

The lithostratigraphic units in the Topopah Spring Tuff comprising the repository host horizon consist of densely welded, crystallized, and lithophysal or nonlithophysal rocks. Fractures in the densely welded and crystallized ignimbrites of the Topopah Spring and Tiva Canyon Tuff are identified on the basis of crystallization and mineralization features as "cooling" fractures, which includes Type 1 and Type 2 fractures (Buesch et al. 1999 [DIRS 165483]) and "post-cooling" fractures, herein referred to as Type 3 fractures. During the welding process, the redistribution of the vapor phase resulted in development of lithophysae and transfer of the vapor phase along fractures. During and shortly after the development of lithophysal cavities and early-formed (Type 1) fractures, the glass crystallized in the presence of the vapor along the margins of lithophysal cavities and fractures to form light gray to pinkish gray rims. Even some of the matrix-groundmass surrounding the lithophysae and some fractures crystallized to form grayish red purple borders and reddish gray matrix-groundmass, and these features are consistent with crystallization of the matrix-groundmass in the presence of vapor. Fractures that formed late in the cooling history of the deposit do not have rims, formed when the rock was mostly (if not entirely) crystallized, and these fractures are indicative of Type 2 fractures. Vapor-phase mineral coatings typically are on cooling fractures, but they are not necessarily on all cooling fractures because the fracture could have formed after most of the vapor phase had been removed from the area, or the three-dimensional network of fractures simply did not penetrate a region of abundant vapor phase material. Lack of distinctive features such as rims or vapor-phase mineral coatings means that some Type 2 fractures might not be identified as being cooling fractures and might be identified as Type 3 fractures (those that formed after the rock had cooled to the ambient temperatures of a rock at the paleogeomorphic surface). Therefore, some of the "indeterminate" fractures (those that do not have distinctive "cooling" related features such as rims or vapor-phase mineral coatings) can be consistent with being Type 2 cooling fractures.

Samples for mapping of fractures on slabs of core were collected from two surface-based boreholes and 32 tunnel-based boreholes located in the ESF Main-Drift and the ECRB Cross-Drift. These boreholes were used to collect samples that represent different lithostratigraphic zones, spatial variations within the zones, samples from different sizes of core, and samples to be compared to those collected near the tunnel walls to evaluate induced fractures from the tunnel boring machine. Detailed Line Survey (DLS) data on fractures in the ECRB were also evaluated as part of this assessment. Although the DLS data focused on geometric relations of the fractures, other features such as rims developed on fracture walls and material coating or filling the fractures also were documented. 
Of the 2,022 fractures mapped in the densely welded and crystallized rocks of the Topopah Spring Tuff, 69.7 percent (1,410 fractures) are cooling related fractures and 30.3 percent (612 fractures) are indeterminate, although these indeterminate fractures might also have formed during the late stage of cooling (see discussion in Section A1.1). These relations are also represented by the "cooling to indeterminate ratio" (C/I ratio) for each sample where the total number of cooling fractures are divided by the total number of indeterminate fractures (Figure 6-1). A C/I ratio of 1 indicates there are equal numbers of cooling and indeterminate fractures in a sample; a ratio larger than 1 indicates there are proportionately more cooling fractures than indeterminate fractures; and a ratio smaller than 1 indicates there are proportionately less cooling fractures than indeterminate fractures. The $\mathrm{C} / \mathrm{I}$ ratio is plotted by sample (Figure 6-1a) or as a distribution function for each lithostratigraphic unit (Figure 6-1b). For lithostratigraphic units with greater than 5 samples, there is an asymmetric distribution of the $\mathrm{C} / \mathrm{I}$ ratios with cooling fractures being more abundant than indeterminate fractures. This indicates the strong influence of stresses induced during cooling on the formation of fractures. To calculate the C/I ratio and avoid division into or by " 0 ," if there are no cooling or indeterminate fractures in a sample, then a value of 0.1 is assigned to that type of fracture in that sample. 

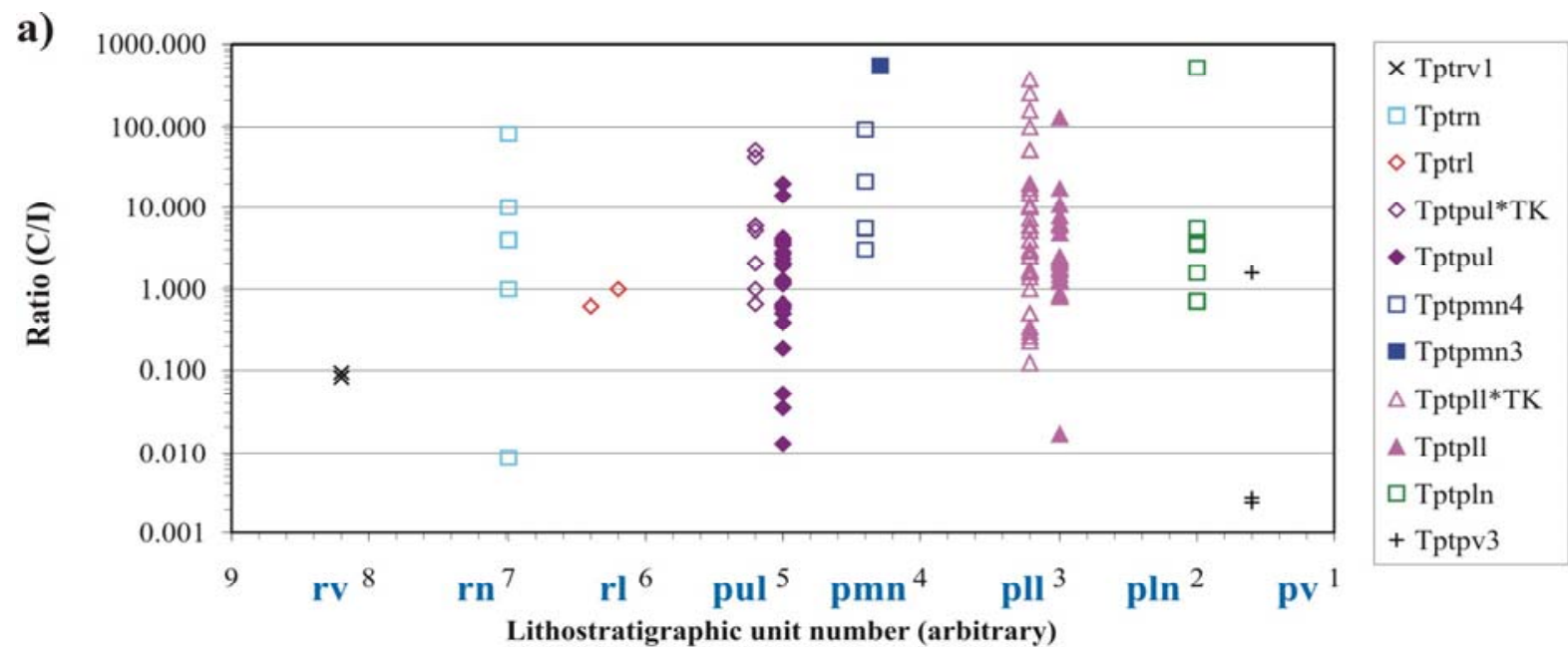

b)
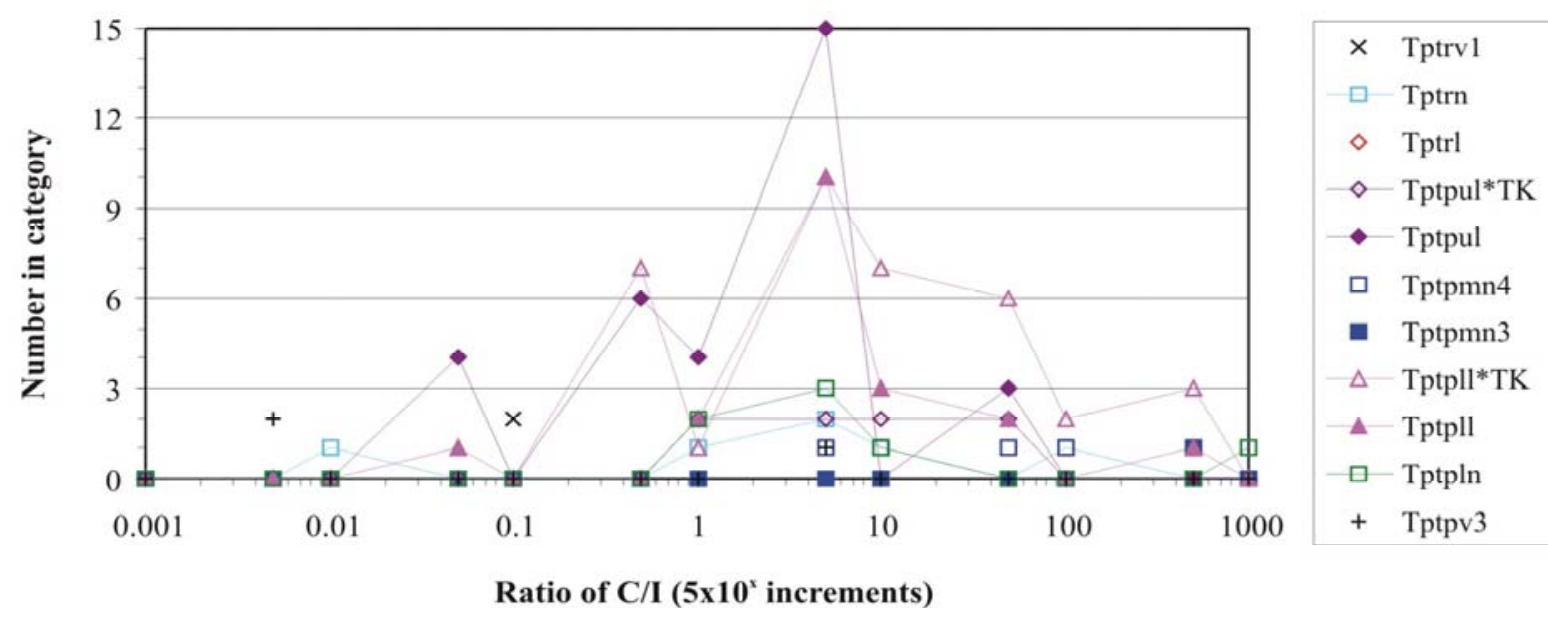

Source: DTN GS040808314224.005 [DIRS 171964].

NOTES: Table A1-2 in Appendix A provides an explanation of the symbols for the various lithostratigraphic units. For the shortened versions used on the x-axis in part a), the leading "Tpt" is dropped.

a) $\mathrm{C} / \mathrm{l}$ ratios of individual samples plotted by lithostratigraphic zone or subzone.

b) The number of $\mathrm{C} / \mathrm{I}$ ratio values in $5 \times 10^{\mathrm{x}}$ increments plotted by lithostratigraphic zone or subzone. Lines are only plotted for units with 5 or more samples.

Figure 6-1. "Cooling to Indeterminate Ratio" (C/I ratio) of Fractures by Lithostratigraphic Zone or Subzone in the Densely Welded and Crystallized Topopah Spring Tuff

Data from the fractures in slabs of core and DLS in the ECRB Cross-Drift were collected for different reasons and represent different scales of sample size and resolution; however, they lead to a consistent set of conclusions regarding the petrogenesis of fractures: (1) approximately 70 percent of fractures are positively related to cooling and 30 percent are indeterminate (but might be late-stage cooling related), and (2) the vast majority of fractures have no evidence of shear or mechanical degradation. 


\subsubsection{Lithophysal Cavities}

Lithophysal cavities developed very early in the formation of the rock and may be indicators of applied strains. Of the 1410 lithophysae described in the panel maps and inventoried in the panel photographs, all the lithophysae have shapes that are consistent with the initial formation of the lithophysae during welding of the ignimbrite. An example of the panel maps is given in Figure 6-2.
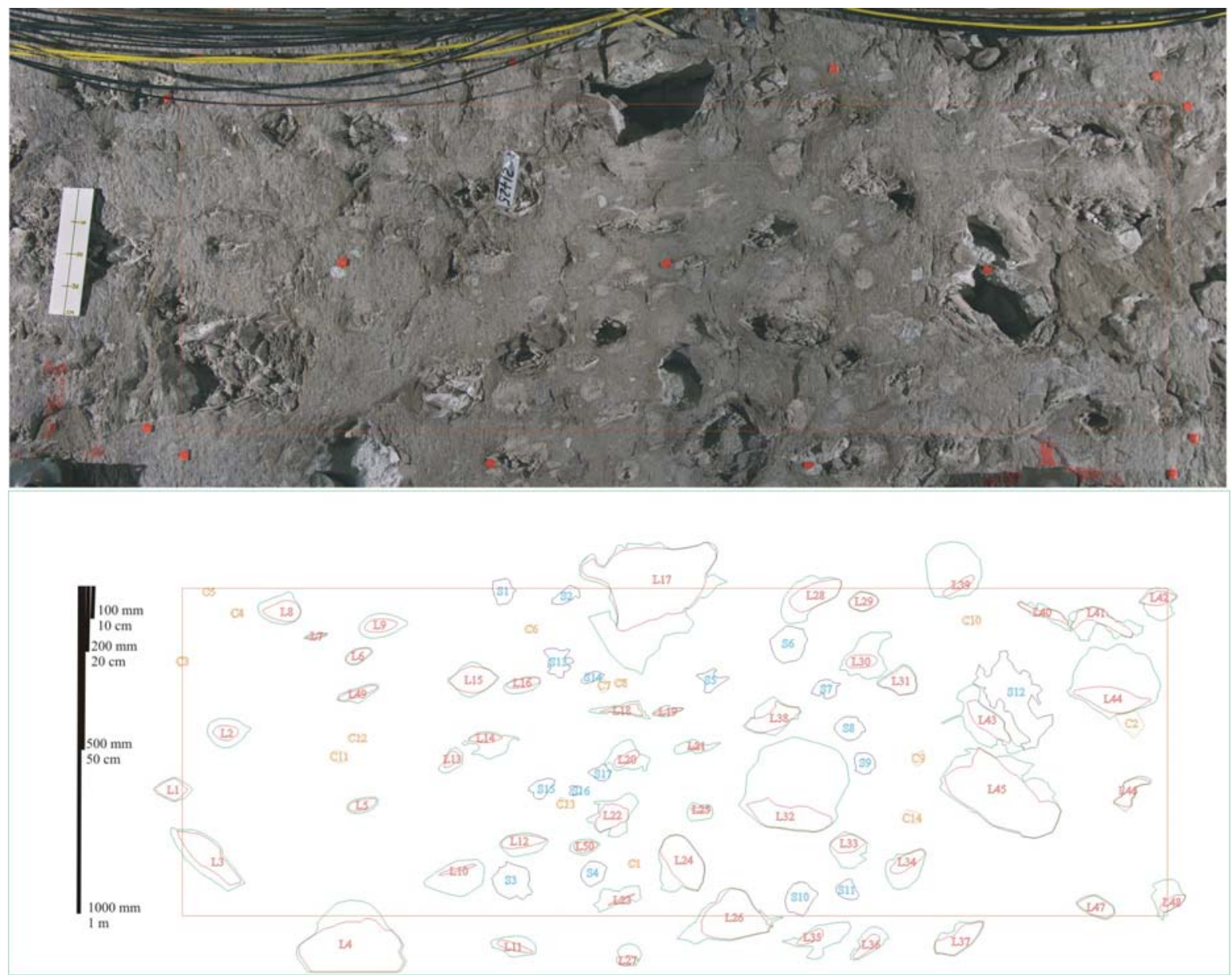

Source: Panel maps in DTN GS021008314224.002 [DIRS 161910].

NOTE: Panel map at station location $21+25$ on the left rib with photograph and mapped features displayed separately. Lithophysal cavities are labeled in red with red lines outlining the cavity and green lines outlining the rim. Spots are labeled in cyan with outlines in cyan. Lithic clasts are labeled in orange and outlined in orange.

Figure 6-2. Example Panel Map of Lithophysal Cavities, Lithophysal Rims, Spots, and Lithic Clasts

None of the lithophysae show "damage" or collapse that could be the result of extreme earthquake ground motions. Of the 1,444 lithophysae inspected, only 7 are transected (or intersected) by fractures greater than $1 \mathrm{~m}$ in trace length (the fractures were mapped during collection of DLS data), and only 5 are transected by shears. Although a few lithophysae are transected by fractures, are the terminal end of fractures, or occur along shears, none have appreciable effects of damage to the walls of the lithophysae. 


\subsubsection{Inter-lithophysal Fractures}

On the basis of numerical simulations of rock mechanic properties using the software code PFC2D (BSC 2003 [DIRS 166660], Attachments V, VIII), one of the most diagnostic relations of lithophysal rocks that have been subjected to shear strains greater than about 0.1 to $0.2 \%$ is the development of a pervasive network of inter-lithophysal fractures (Section 6.4 and Appendix B). Twenty photographs of tunnel walls in rocks that contain lithophysae from the upper lithophysal and lower lithophysal zones (including two photographs from the lithophysae-bearing subzone of the middle nonlithophysal zone), were examined to evaluate the geometry of fractures and their relation to lithophysae. Most of the relations of lithophysae and fractures in the photographs are consistent with (1) localized in situ fracturing of the matrix-groundmass during cooling of the rock mass, or (2) minor amounts of extension of the rock mass, probably during structural tilting of the mountain. A pervasive network of inter-lithophysal fractures is not observed. An example of the interpretations made of the panel maps is given in Figure 6-3. 

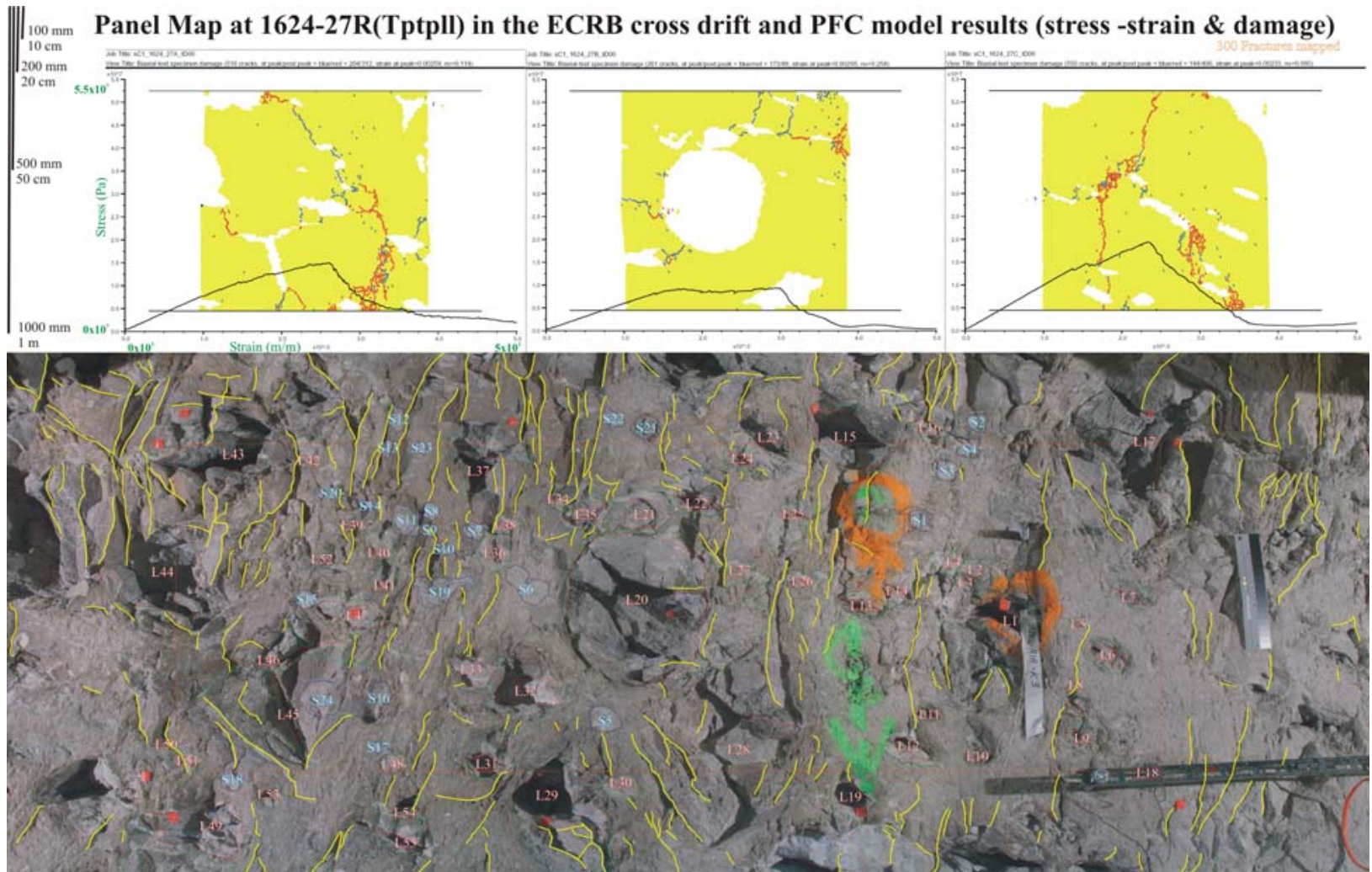

Source: GS021008314224.002 [DIRS 161910] and BSC (2003 [DIRS 166660], Attachment V-Appendix B, Figure B-4).

NOTE: Upper part of figure shows stress-strain model results (BSC 2004 [DIRS 172334]) using the software code PFC2D. Blue lines are micro-fractures formed prior to failure at peak strength and red lines are micro-fractures formed post-failure at peak strength. Embedded lithophysae are derived from stencils taken from the panel map below. The lower part of the figure is the panel map at $16+24$ on the right wall with 300 photographically interpreted fractures (yellow lines).

Figure 6-3. Comparison of Modeled Fracture Development in Lithophysal Rock Samples that are Deformed to Failure to Observed Fractures in the Enhanced Characterization of the Repository Block Cross-Drift 


\subsubsection{Conclusions from Geologic Observations}

Data from the systematic characterization of fractures in boreholes and detailed examination of panel maps and photographs in the ECRB Cross-Drift supports a cooling-related origin for most fractures observed in underground exposures of lithophysal rock of the Topopah Spring Tuff. Collapsed lithophysae and widespread fractures with characteristics (shear offset, inter-lithophysal connections) that would be expected if the shear strain threshold for lithophysal rock had been exceeded at Yucca Mountain are not seen. Although the samples used in the studies are limited in size and scale relative to the entire rock mass, one of the underlying strengths of these studies is that samples and study locations are spatially and stratigraphically distributed throughout the rock mass. Thus it is concluded that the shear-strain threshold for failure of lithophysal rock at Yucca Mountain has not been exceeded since the rocks were deposited about 12.8 million year ago.

\subsection{THRESHOLD SHEAR STRAIN DISTRIBUTION FOR TOPOPAH SPRING LITHOPHYSAL ROCK}

This section summarizes previously performed laboratory testing and modeling results that are used to relate shear strain increments to rock damage, and uses that information to develop a probability distribution on a threshold shear strain that would lead to geologically observable damage in Topopah Spring Tuff lithophysal rock. The geologic evidence for the absence of such damage has been summarized in Section 6.3 and described in Appendix A. A more detailed description of the numerical determination of the relationship of strain to damage for lithophysal rock is given in Appendix B.

Both laboratory testing and numerical modeling have been used to study the mechanical behavior of lithophysal rock at Yucca Mountain. Laboratory testing provides mechanical properties data, including strength and strain at initial yield and at peak stress, from the upper and lower lithophysal units of the Topopah Spring Tuff at Yucca Mountain (DTNs: SN0208L0207502.001 [DIRS 161871] and SN0211L0207502.002 [DIRS 161872]). For the analysis summarized here (and discussed in more detail in Appendix B), large samples (288-mm diameter) are used. The larger sample size contains numerous lithophysae and thus the mechanical properties derived from this testing are more representative of in situ conditions in the repository host horizon.

Numerical models using the software codes PFC2D and UDEC (BSC 2003 [DIRS 166660], Attachments V, VI, VIII) complement the laboratory testing results. These models have been calibrated to reproduce the observed mechanical response and failure mechanisms of lithophysal rock. These calibrated numerical models therefore provide a mechanical simulation tool that is used: 1) to understand the basic mechanics of deformation and failure mechanisms of lithophysal rocks, and 2) as a means to extend the laboratory testing results to understand the impact of in situ variability of the sizes, shapes and distribution of lithophysal cavities on the range of mechanical response (e.g., stress-strain behavior) and failure mechanisms. Using the calibrated models, it is also possible to examine the expected observable physical condition of the rock mass as a function of the applied stress and shear strain history. The observable physical conditions may include the mode and extent of lithophysae deformation and intact rock matrix fracturing that would be expected if the rock mass were subjected to specific seismically-induced stress and shear strain histories. 
Figure 6-4 illustrates typical fracturing predicted by the calibrated PFC2D model occurring in a simulated ("synthetic") lithophysal rock sample that has been stressed to failure under uniaxial compression. In this simplest of modeling approaches, the lithophysal voids are represented as circular holes distributed throughout the sample. The rock matrix in this model is composed of several thousand circular particles (too small to be seen at this scale) which are bonded with tensile and shear bonds at their contacts. Fractures, which occur due to breakage of these contact bonds when the sample is stressed, can be seen as red and blue lines within the sample. Analyses of compression of synthetic rock samples show that stress-induced fractures would be expected to interconnect the lithophysae, which act as locations of stress concentration within the mass. This form of predicted fracture development-ubiquitous, long inter-lithophysal fracturing - would allow such fractures to be distinguished in underground observations from the typical cooling fractures as described in Appendix A.

The modeling has been used to simulate shear strain states in the synthetic lithophysal rock samples that would be expected in situ if the rock mass were subjected to seismic events. The threshold shear strain is the shear strain at which the lithophysal rock would undergo damage ${ }^{1}$ that would be recognizable to geologists in the field. Correlation of this damage state directly to shear strain is uncertain because development of damage is a progressive process that evolves with increased levels of strain. Clearly, the state at which the first microfractures appear in the intact rock matrix would be an underestimate of the threshold shear strain, because a few unconnected fractures would be unnoticed in the field. A more appropriate threshold shear strain level can be derived by taking into account the stress-strain response for typical brittle rocks. When a brittle rock is loaded in compression, it is typical to monitor the applied stress difference (the axial stress minus the confining stress) as well as the axial and lateral (or circumferential) strains. The stress-strain response of the sample is typically plotted as the axial stress versus axial strain (see Appendix B, Figures B-3 and B-6) as well as the volumetric (axial plus circumferential) strain versus the axial strain (see Appendix B, Figure B-3). The typical stress-strain plot shows an initial nonlinear portion related to seating of the loading platens and closure of open microfractures related to drilling and removal of the sample from its in situ stress condition. This is followed by a linear portion of the plot related to loading of the sample and defines the elastic modulus of the material. The stress-strain curve then departs from linearity, indicating the beginning of microfracture development. Coalescence of the microfractures into through-going macrofractures results in macroscopic failure of the sample and defines its peak strength.

It is straightforward in the calibrated numerical model to define the shear strain levels at which micro fracturing and peak strength are reached, and to display the physical deformation and fracturing state that would be observed at each of these strain levels. In particular, the strain at which yield is reached is most easily defined as the point at which the volumetric strain begins to reverse, indicating dilation of the lateral strains (see Appendix B, Figure B-3). The reversal of the volumetric strain (dilation) occurs as a result of rapid coalescence of microfractures into macrofractures, and represents a lower bound to the peak strength. The strain state at the peak

\footnotetext{
1 "Damage" here refers to the physical effects of permanent deformation of the rock mass that develop in response to applied strain. The damage may take the form of new fractures, deformed or collapsed lithophysae, new shear deformation and/or dilation of existing cooling fractures, etc.
} 
stress is an upper bound to the threshold strain representing the state for which the fractures connecting lithophysae are pervasive and would be distinguishable in the geologic panel maps of the ESF and the ECRB Cross-Drift. Appendix B also discusses an intermediate state at which the onset of systematic fracturing (OSF) is attained. While the physical damage state associated with these various strain states are documented based on the results of the numerical simulations, data from the laboratory tests provide information only on the peak stress (strength) of the samples. Thus, for this analysis the assessment of shear-strain threshold is carried out on the basis of peak stress. This approach results in higher shear-strain increments and a higher bound to horizontal PGV than if one of the other damage states, based on lower shear-strain increments, were used.

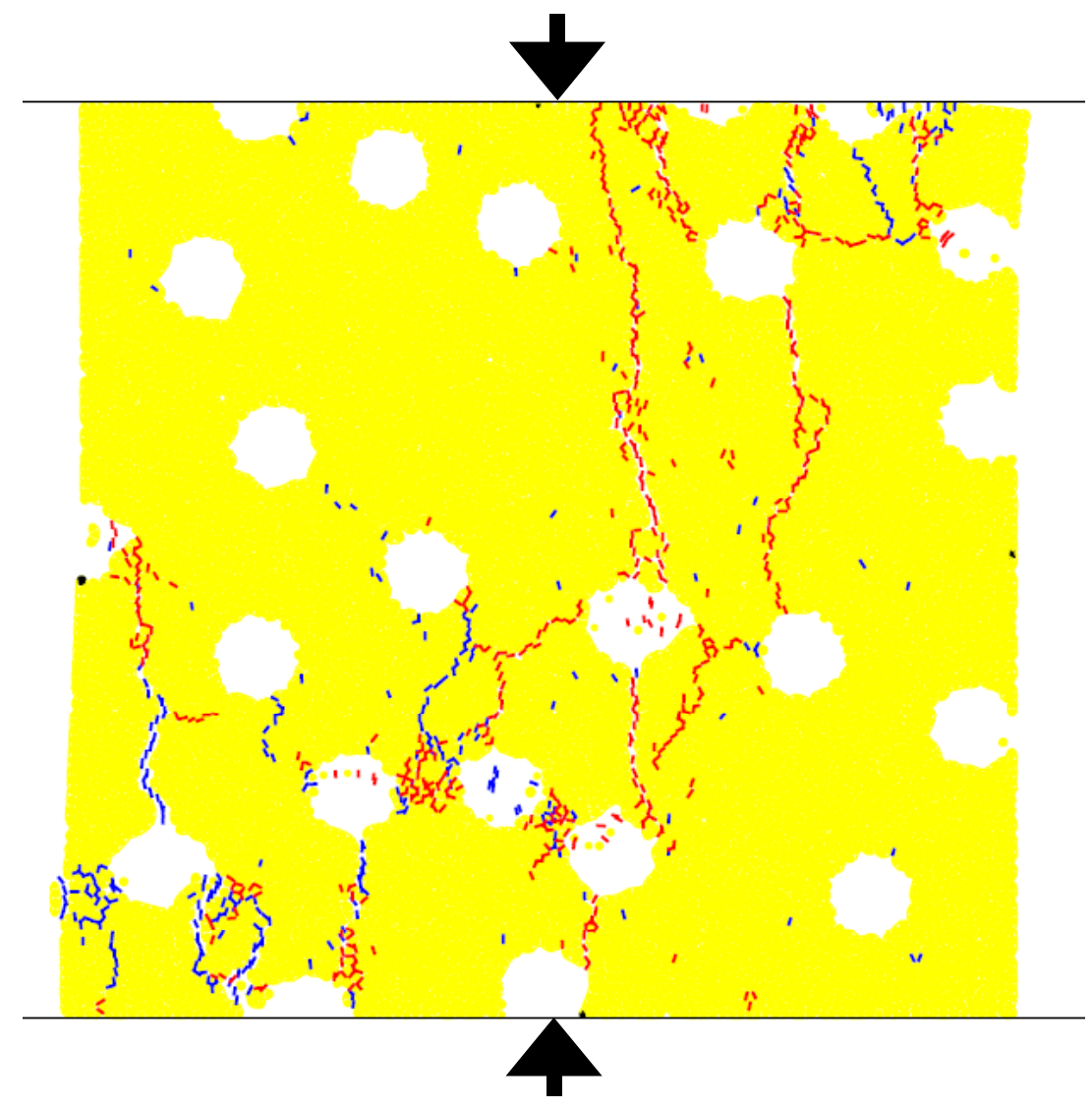

Source: Damjanac et al. (2004 [DIRS 172060], Figure 1).

NOTE: Blue and red lines indicate stress-induced fractures developed during a simulated uniaxial compression test. The arrows indicate the direction of applied uniaxial compression. Blue lines indicate fractures that developed prior to reaching the peak stress; red lines indicate fractures that developed after the peak stress was reached. "Fractures" located in the middle of a circular void represent particles that have broken off from the edge of the void. The modeling was carried out using the software code PFC2D (BSC 2004 [DIRS 169930]).

Figure 6-4. Fractures Developed during Modeled Deformation of a 1-Meter by 1-Meter Synthetic Lithophysal Sample

The laboratory tests and numerical simulations on which the assessment of threshold shear strain, and the associated uncertainty, are based are discussed below in Sections 6.4.1 and 6.4.2. 


\subsubsection{Laboratory Test Results}

Uniaxial compression tests were conducted on samples from lithophysal and nonlithophysal Topopah Spring Tuff (Price 2004 [DIRS 170894]). Testing of lithophysal tuff is particularly challenging due to the lithophysae. Large diameter samples are required for determination of representative rock mass mechanical properties. As expected, the mechanical properties of the lithophysal tuff exhibit a strong dependence on porosity, which, in turn, can be viewed as a form of sample size dependency. Therefore, the results obtained from the tests on the largest samples, the 288-mm diameter cores (diameter several times larger than the included lithophysae) taken from the ESF and ECRB Cross-Drift, are considered to be the best representation of the mechanical behavior of the lithophysal tuff. The uniaxial compression tests provide stress-strain behavior of the lithophysal tuff, which includes the axial stress and strain levels associated with peak strength.

The axial strain to failure measured in uniaxial compression tests cannot be used directly as the strain increment required to cause fracturing of lithophysal rock because this strain corresponds to a particular uniaxial stress (and corresponding strain) path from the initial, unstressed state to the failure state. The rock mass exposed in the Yucca Mountain ESF and ECRB Cross-Drift is already under an in situ state of stress (and strain) with a significant deviatoric component. The horizontal principal stress components are between $30 \%$ and $70 \%$ of the vertical principal stress (CRWMS M\&O 1997 [DIRS 147458], pp. 1, 15, 16) (see Assumption 4 in Section 5). In Appendix B, a methodology is discussed for calculating the shear-strain increment that corresponds to the stress change from the in situ stress state to the limiting stress state defined by the yield condition for the rock (see Appendix B, Figure B-4). It is assumed that the lithophysal rock mass behaves as a linear elastic material until the limiting state is reached. The stress path from the initial stress state to the limiting state during a strong seismic ground motion can be arbitrary. In this analysis, the shear strain increment is calculated for the stress path in which the mean stress does not change. Cyclic shear strain under constant vertical stress, which is typically a dominant mode of deformation during a seismic ground motion, results in the stress path along which the mean stress is invariant.

The shear strain increments at peak strength were calculated for laboratory results obtained on 19 288-mm diameter samples taken from the ESF and ECRB Cross-Drift. The experimental results were obtained for unconfined compression conditions only. An internal angle of friction of $30^{\circ}$ was assumed in the calculation (Section 5, Assumption 2). This assumption results in conservative (larger) estimates of the shear strain associated with peak strength and thus larger potential peak ground velocities to produce observable yield in situ. The results for the 288-mm diameter samples, using an overburden depth of $250 \mathrm{~m}$ and divided into two categories based on height-to-diameter ratio ( $H / D>1.5$ and $H / D \leq 1.5$ ), are shown in Figure 6-5 as a function of lithophysal porosity. It is preferred to have the height-to-width, or height-to-diameter, ratio for the laboratory test sample equal to or larger than 2 to minimize the effect of friction between the loading plates and the sample. The sample to platen friction exerts a small radial confining stress to short-length samples, thus resulting in artificially higher compressive strengths. Note that the results show no relationship between shear strain at failure and lithophysal porosity (Figure 6-5). Statistics of the results are presented in Table 6-1. 
Table 6-1. Summary of Statistics of Calculated Shear Strain Limits Based on $250 \mathrm{~m}$ of Overburden

\begin{tabular}{|l|c|c|c|}
\hline & $\begin{array}{c}\text { Number of } \\
\text { Samples }\end{array}$ & Mean & $\begin{array}{c}\text { Standard } \\
\text { Deviation }\end{array}$ \\
\hline 288-mm diameter, H/D > 1.5 & & $\%$ & $\%$ \\
\hline 288-mm diameter, all & 13 & 0.16 & 0.04 \\
\hline
\end{tabular}

Source: Appendix B, Table B-2

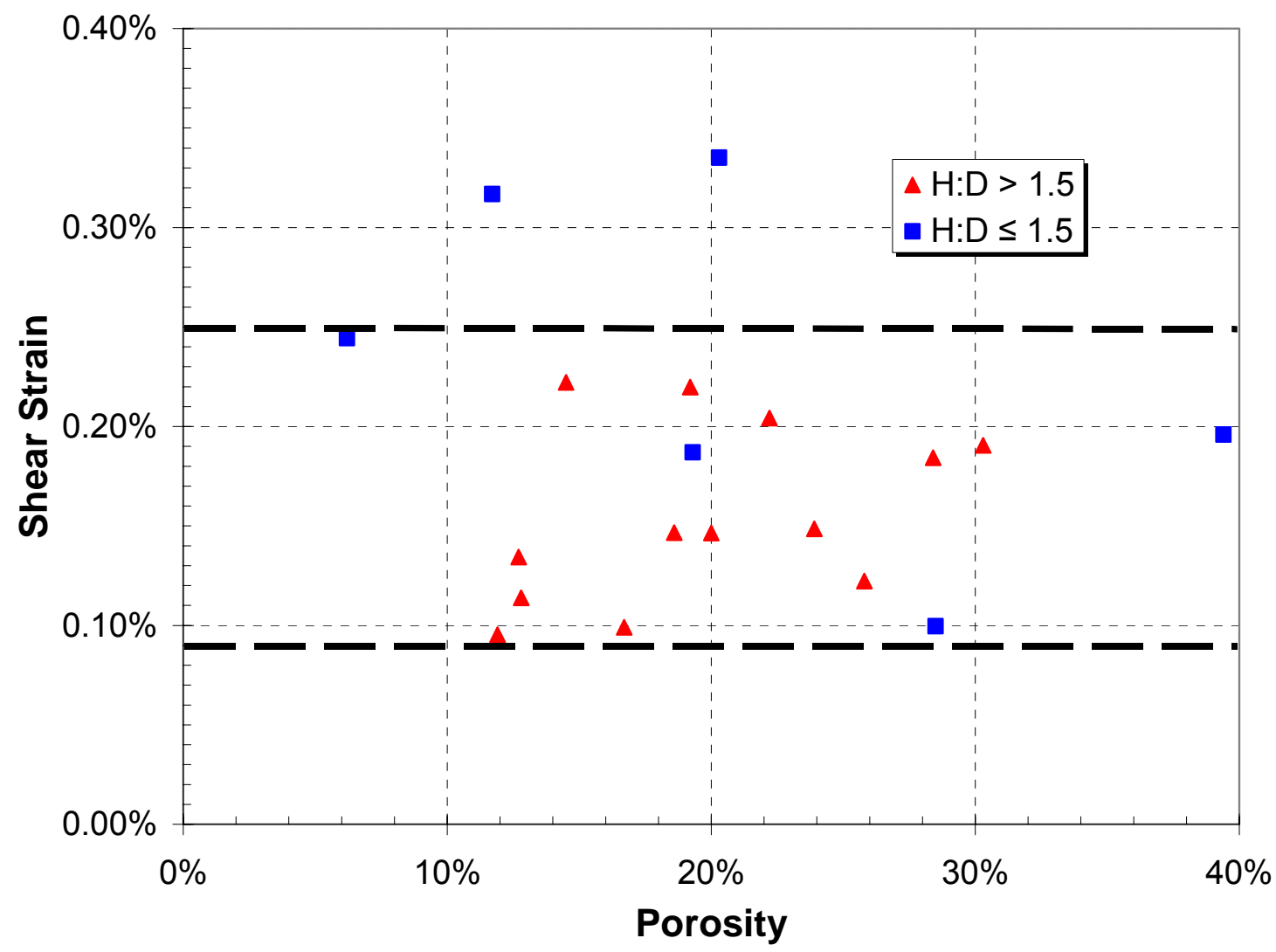

Source: Appendix B, Figure B-7.

NOTE: Shear-strain increments are calculated for an overburden depth of $250 \mathrm{~m}$. For this case, the mean shear-strain increment for all $288-\mathrm{mm}$ diameter samples is $0.18 \%$ strain. For the samples having a ratio $H / D>1.5$, which are considered the best representation of the mechanical behavior of lithophysal rock, the mean shear-strain increment is $0.16 \%$ (Table 6-1). The bold horizontal dashed lines indicate the lower and upper bound of the shear strain threshold probability distribution developed in Section 6.4.3.

Figure 6-5. Calculated Shear Strain Increment for 288-mm Diameter Samples

\subsubsection{Numerical Simulation Results}

To supply additional evidence regarding threshold shear strain levels, the results of the existing numerical tests, which were conducted to examine the effect of lithophysal porosity on the mechanical properties of tuff, are re-analyzed to determine the strain at particular damage states (see Appendix B for detailed discussion). The simulations were carried out using PFC2D (BSC 2004 [DIRS 169930]) and UDEC (BSC 2002 [DIRS 161949]). PFC2D represents the rock 
as a bonded assembly of disks whereas UDEC represents the rock as a bonded assembly of polygons. The results of the numerical simulations are reported by BSC (2004 [DIRS 172334], Section 6.5) and incorporated into BSC (2003 [DIRS 166660], Sections 9.1, 9.2, Attachments V, VI, and VIII). The original reports provide details of the various numerical models and testing procedures.

The numerical models of the rock mass first were calibrated to reproduce the mechanical behavior observed in the laboratory compression tests (BSC 2004 [DIRS 172334], Section 6.5). Subsequently, the effects of changing lithophysal porosity and shape of lithophysae were investigated. Thus, it is assumed in the numerical analysis that lithophysal porosity and lithophysae shape are the only parameters affecting mechanical behavior of the lithophysal rock mass. The distribution of the lithophysae within a laboratory sample can also impact the strength, resulting in additional variability in test results. This is probably the main reason the numerical results show less scatter than what is observed in the laboratory tests. The numerical models, however, clearly show the controlling impact of lithophysal voids on strength and elastic modulus, and demonstrate the same trends in strength and modulus with porosity as observed in the laboratory.

Results of the numerical compressive tests show that the lithophysal rock will fail through the development of fractures that extend generally from one lithophysal void to another (Figure 6-4) (BSC 2004 [DIRS 172334], Section 6.5). The failure mechanism is a function of tensile splitting between adjacent lithophysal voids that is caused by the induced tensile stresses in the material between the voids. Strains induced by extreme ground motion would be expected to cause this style of deformation (i.e., fractures that connect lithophysae). Thus, seismic-induced fracturing would be distinguishable from fractures related to cooling of the deposits, which do not typically show intersections with lithophysae (Appendix A).

Shear-strain increments required to deform the numerical synthetic samples from in situ conditions to failure were determined. Shear strain increments were calculated for two failure criteria: peak stress (strain state at ultimate strength) and yield stress (state at volumetric strain reversal). Values of Young's modulus, Poisson's ratio, friction angle, peak stress, and yield stress were taken from the results of the numerical simulations. If a friction angle was not determined as part of the numerical simulation, a value of 30 degrees was used (Section 5, Assumption 2). Shear-strain increments were calculated for in situ conditions at two representative waste emplacement level depths: 250 and $400 \mathrm{~m}$.

The shear strain increments are calculated and, as an example, Figure 6-6 shows the results for the state at peak stress at $250 \mathrm{~m}$ overburden. The results for three types of $2 \mathrm{D}$ simulation are superimposed on the graph shown in Figure 6-6: (a) circular voids, modeled by PFC2D; (b) actual complex shapes traced from geologic field maps (stenciled voids), modeled by PFC2D; and (c) circular voids, modeled by UDEC. In Figure 6-6, the engineering shear strain (axial strain minus lateral strain) increment for a peak stress state is plotted against lithophysal porosity. Mean shear strain increments and standard deviations are listed in Table 6-2. 


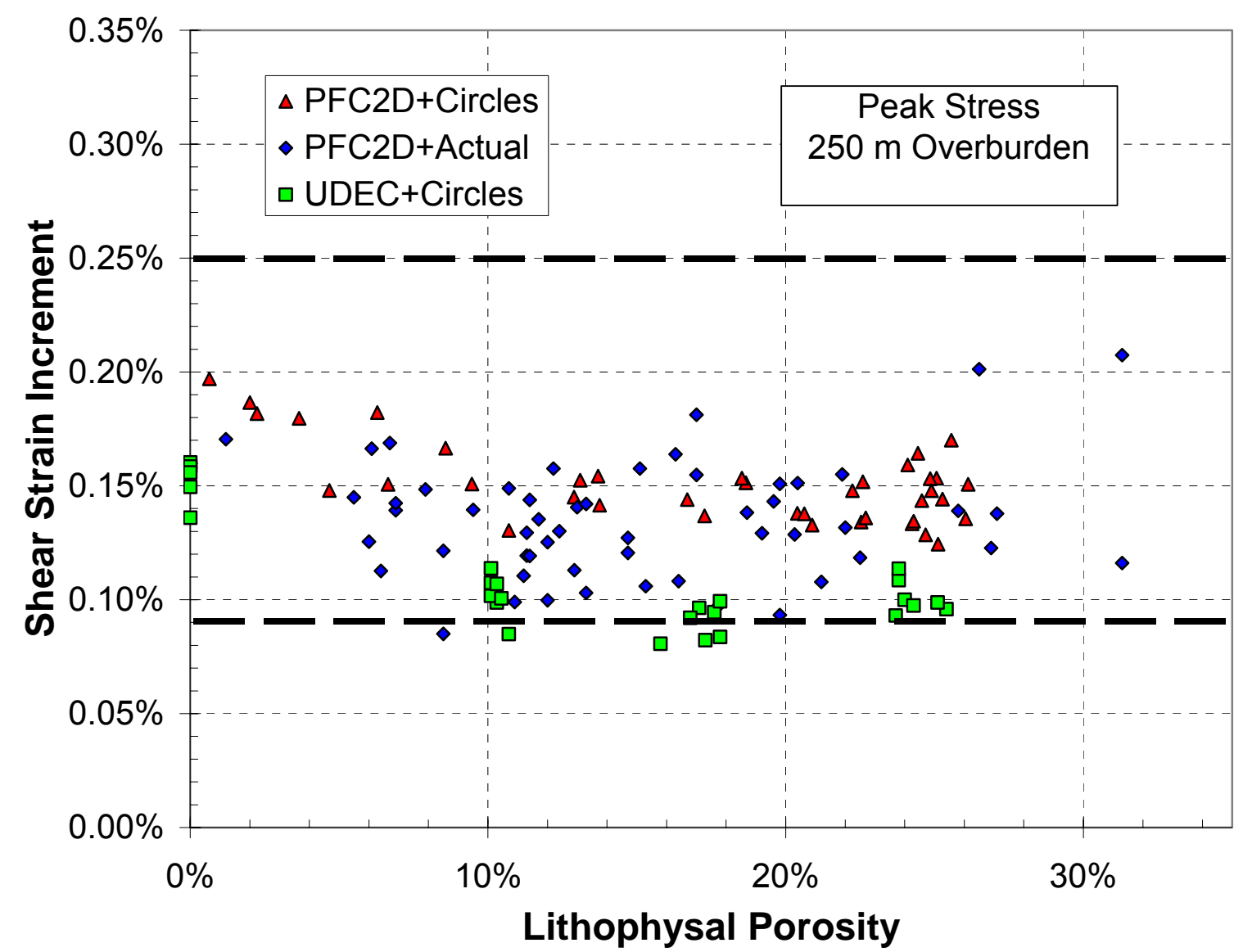

Source: Appendix B, Figure B-9.

NOTE: Shear strain increment determined for an overburden depth of $250 \mathrm{~m}$. Numerical simulations carried out using software codes PFC2D and UDEC. The bold horizontal dashed lines indicate the lower and upper bound of the shear strain threshold probability distribution developed in Section 6.4.3.

Figure 6-6. Shear Strain Increment Determined Using the Peak-Stress Criterion, Overburden $=250 \mathrm{~m}$ 
Table 6-2. Mean Shear-strain Increments Determined from Numerical Simulation of the Mechanical Behavior of Lithophysal Rock

\begin{tabular}{|c|c|c|c|}
\hline \multirow{2}{*}{$\begin{array}{c}\text { Depth for In Situ } \\
\text { Conditions } \\
(\mathrm{m})\end{array}$} & \multirow[b]{2}{*}{$\begin{array}{l}\text { Simulation } \\
\text { Approach }\end{array}$} & Failure Criterion $=$ Peak Stress & Failure Criterion $=$ Yield Stress \\
\hline & & $\begin{array}{l}\text { Shear Strain Increment }{ }^{\mathrm{c}}(\%) \\
\text { (mean } \pm \text { standard deviation) }\end{array}$ & $\begin{array}{l}\text { Shear Strain Increment (\%) } \\
\text { (mean } \pm \text { standard deviation) }\end{array}$ \\
\hline \multirow[t]{3}{*}{250} & PFC2D+Circles ${ }^{a}$ & $0.15 \pm 0.02$ & $0.14 \pm 0.02$ \\
\hline & $\mathrm{PFC} \mathrm{D}+$ Actual $^{\mathrm{b}}$ & $0.13 \pm 0.03$ & $0.11 \pm 0.04$ \\
\hline & UDEC+Circles & $0.11 \pm 0.02$ & $0.09 \pm 0.03$ \\
\hline \multirow[t]{3}{*}{400} & PFC2D+Circles & $0.16 \pm 0.02$ & $0.15 \pm 0.02$ \\
\hline & PFC2D+Actual & $0.15 \pm 0.03$ & $0.12 \pm 0.05$ \\
\hline & UDEC+Circles & $0.12 \pm 0.02$ & $0.10 \pm 0.03$ \\
\hline
\end{tabular}

a Lithophysae are represented in model as circular holes.

b Lithophysae are represented in model as actual complex shapes traced from geologic field maps.

${ }^{c}$ Shear strain increment is the increment in shear strain from the in situ stress state to the failure criterion. Failure criterion based on either a peak failure stress or yield stress condition.

Source: Appendix D, Limiting Strains-Numerical Sims.xls

Although the UDEC and PFC2D models were calibrated to the same laboratory results, the shear strain increment calculated from the UDEC results is systematically smaller than the shear strain increment calculated from the PFC2D results. One reason for this is that the UDEC synthetic sample is calibrated in such a way that its strength is slightly less than the strength of the PFC2D sample; at the same time, stiffness of the UDEC sample is larger than the stiffness of the PFC2D sample, resulting in the smaller strain increment calculated based on UDEC results. The other reason is that shear strain increment based on the PFC2D results is calculated assuming a friction angle of $30^{\circ}$ (Section 5, Assumption 2). The shear strain increment based on the UDEC results is calculated using friction angles determined from the UDEC results, which generally are larger than $30^{\circ}$. In this case, smaller friction angles result in larger shear strain increments.

\subsubsection{Assessment of Threshold Shear Strain Probability Distribution}

Given the laboratory test data and the numerical simulations discussed in Sections 6.4.1 and 6.4.2, an assessment is made of the shear strain level at which geologically-observable damage would occur. This level is termed the "threshold shear strain" level for this analysis. As discussed previously in Section 6.4, the damage state associated with the peak stress is selected as the damage state for this analysis. Modeling studies described in Appendix B examined the evolution of axial stress, volumetric strain and the onset of systematic fracturing as functions of axial strain. The differences between strains at peak stress, at the point of volumetric strain reversal, and at the onset of systematic fracturing are relatively small (See Appendix B, Section B2.1, Figure B-3). These results justify use of shear strain increments determined for the state at peak stress as a reasonable threshold shear strain. 


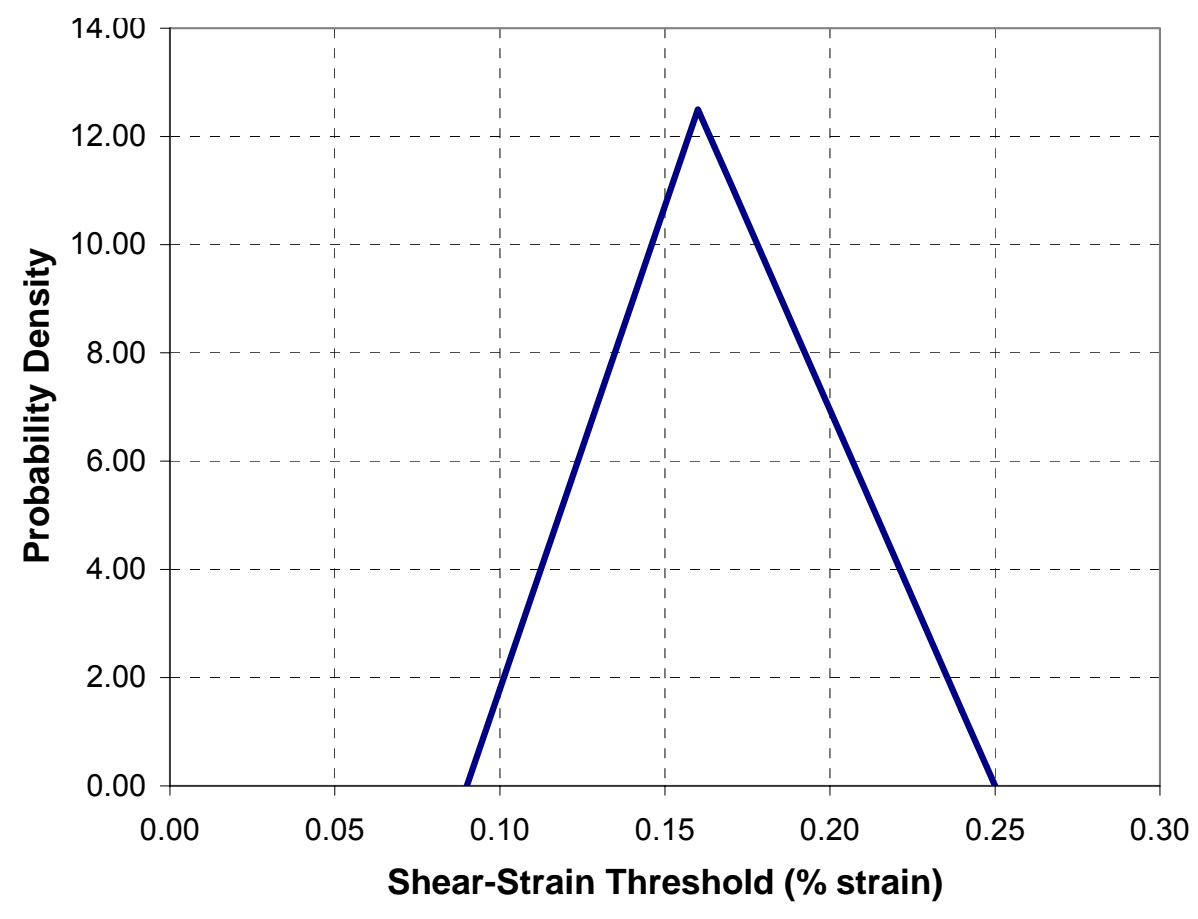

Source: Appendix D, Probability Distributions.xls.

Figure 6-7. Assessed Probability Distribution of Threshold Shear Strain for Topopah Spring Lithophysal Rock

Epistemic uncertainty in the assessment of the threshold shear strain is represented by the triangular probability distribution in Figure 6-7. The mode of the distribution is $0.16 \%$ strain, which is the mean of the testing data for the 288-mm-diameter samples with ratio $H / D>1.5$ (Table 6-1). This value also is consistent with the mean estimates based on the PFC2D numerical simulations, which range from about $0.13 \%$ to $0.18 \%$ (Table $6-2$ ). The lower limit of the triangular distribution lies at $0.09 \%$ strain, which bounds the shear strain increments for the 288-mm diameter laboratory test data (Figure 6-5). The upper limit of the distribution lies at $0.25 \%$, which bounds most of the shear strain limits from the laboratory tests (Figure 6-5). As shown in Figure 6-5, two of the laboratory determinations of shear strain increment (for samples with H/D less than or equal to 1.5) fall outside the assessed distribution. This is justified because the focus of the assessment is on the shear-strain threshold for the weaker rock at Yucca Mountain, which would show pervasive inter-lithophysal fracturing at lower ground motions. The laboratory results for samples with H/D less than or equal to 1.5 would likely overestimate the shear strain threshold. The numerical simulations suggest the upper value of shear-strain threshold is closer to $0.20 \%$. Calculation of the probability density for the triangular distribution is documented in Microsoft ${ }^{\circledR}$ Excel workbook Probability Distributions.xls on worksheet Shear-Strain Threshold (Appendix D).

\subsection{GROUND MOTION CALCULATION}

This section summarizes the analysis of ground motions for the threshold shear strain distribution assessed in Section 6.4.3. The analysis is given in Appendix $\mathrm{C}$ and results in the horizontal peak ground velocity $(\mathrm{PGV})$ associated with threshold shear strains for the repository 
horizon. Ground motion site-response modeling has been carried out for the Yucca Mountain site (BSC 2004 [DIRS 170027], Section 6.3). As part of the site response output, information is provided on the variation with depth (from the surface to the waste emplacement level) of the peak ground velocity and dynamic strain. By comparing the calculated horizontal PGV and dynamic shear strain at the depth of the Topopah Spring Tuff lower lithophysal unit for a suite of ground motion levels, the shear-strain threshold determined from laboratory testing and numerical simulations is associated with a value of horizontal PGV. That is, the results of the site response modeling are used to determine the level of horizontal PGV that would be required to generate dynamic shear strains in the lithophysal rock that exceed the threshold at which the rock would fail producing geologically observable damage.

As part of the process to develop seismic inputs for postclosure analyses, the ground-motion site-response model is run for various combinations of input parameters. These combinations reflect uncertainties in the input parameters and also the range of earthquakes that contribute to the annual frequency that a given level of ground motion will be exceeded. Ground motions forming input to the site-response model (i.e., control motions) are developed for two frequency ranges (5 to $10 \mathrm{~Hz}$ and 1 to $2 \mathrm{~Hz}$ ) to account for the fact that, at a given hazard level, different earthquakes dominate the ground motion at different frequency ranges of the response spectrum. Relatively close earthquakes usually dominate at higher frequencies, while larger, but more distant earthquakes can dominate at lower frequencies. Also, because the dynamic behavior of the site materials is potentially nonlinear, the range of earthquake magnitudes contributing to the hazard for each frequency range is also important. Three earthquakes represent the range of magnitudes for each of the two frequency ranges, resulting in six earthquakes for each component of ground motion (the deaggregation earthquakes) that form the control motion for the site-response model. Finally, both vertically propagating seismic waves and inclined seismic waves are considered in the modeling process.

Uncertainty and variability in the dynamic properties of the site materials also is accommodated in the site-response model. Uncertainty is incorporated through use of alternate base-case velocity profiles and alternate base-case sets of dynamic material property curves. Variability is incorporated by stochastically varying the velocity profiles and dynamic material property curves about their base case.

The uncertainty and variability in the base-case properties translates into uncertainty in the level of horizontal PGV that is associated with a particular shear-strain threshold. For each combination of base-case velocity profile (P1 or P2), base-case dynamic property curves ("Upper Mean Tuff" [UMT] or "Lower Mean Tuff" [LMT]), and wave propagator type (inclined or vertically incident), site response is determined using the deaggregation earthquakes as the input control motion. For a given combination, each deaggregation earthquake control motion is propagated through 60 randomized velocity profiles with associated randomized dynamic property curves producing 60 curves of horizontal PGV and shear strain versus depth. Results for the three deaggregation earthquakes associated with each frequency range (5 to $10 \mathrm{~Hz}$ and 1 to $2 \mathrm{~Hz}$ ) are combined and then median PGV and median dynamic shear strain values versus depth are determined. To characterize the median PGV and dynamic shear strain for the lithophysal units, PGV and strain are averaged for the depth range from 290 to $392 \mathrm{~m}$ (951 to $1,286 \mathrm{ft}$ ), the average depth range of the lower lithophysal unit of the Topopah Spring Tuff (Appendix C, Section C2.2). For each combination, the values obtained for the two types of 
wave propagators (vertical and inclined) are then averaged resulting in eight pairs of PGV and shear strain corresponding to the combinations examined (1 to $2 \mathrm{~Hz} / \mathrm{P} 1 / \mathrm{UMT}$, 1 to $2 \mathrm{~Hz} / \mathrm{P} 1 / \mathrm{LMT}, \quad 1$ to $2 \mathrm{~Hz} / \mathrm{P} 2 / \mathrm{UMT}, \quad 1$ to $2 \mathrm{~Hz} / \mathrm{P} 2 / \mathrm{LMT}, \quad 5$ to $10 \mathrm{~Hz} / \mathrm{P} 1 / \mathrm{UMT}$, 5 to $10 \mathrm{~Hz} / \mathrm{P} 1 / \mathrm{LMT}, 5$ to $10 \mathrm{~Hz} / \mathrm{P} 2 / \mathrm{UMT}, 5$ to $10 \mathrm{~Hz} / \mathrm{P} 2 / \mathrm{LMT}$ ). This process is carried out for 4 hazard levels $\left(10^{-4} / \mathrm{yr}, 10^{-5} / \mathrm{yr}, 10^{-6} / \mathrm{yr}, 10^{-7} / \mathrm{yr}\right)$ resulting in a suite of values associating horizontal PGV and dynamic shear strain (Table 6-3). In addition to the 8 pairs of shear strain and corresponding horizontal PGV values determined for the 4 hazard levels, those results were also used to linearly interpolate or extrapolate horizontal PGV values for target values of shear strain $(0.05,0.10,0.20,0.30,0.40,0.50 \%)$ (Table 6-3). These results are used in Section 6.6 to determine a reasonable bound for horizontal PGV at the waste emplacement level for Yucca Mountain. 
Table 6-3. Modeled and Interpolated/Extrapolated Horizontal Peak Ground Velocity for Shear Strain Values

\begin{tabular}{|c|c|c|c|c|c|c|c|c|}
\hline \multirow[t]{2}{*}{$\begin{array}{l}\text { Annual } \\
\text { Frequency of } \\
\text { Exceedance } \\
(1 / y r) \\
\end{array}$} & \multicolumn{2}{|c|}{$\begin{array}{l}\text { Velocity Profile P1 + Upper } \\
\text { Mean Tuff Dynamic Material } \\
\text { Property Curves + } 1 \text { to } 2 \mathrm{~Hz}\end{array}$} & \multicolumn{2}{|c|}{$\begin{array}{l}\text { Velocity Profile P1 + Lower } \\
\text { Mean Tuff Dynamic Material } \\
\text { Property Curves }+1 \text { to } 2 \mathrm{~Hz}\end{array}$} & \multicolumn{2}{|c|}{$\begin{array}{l}\text { Velocity Profile P2 + Upper } \\
\text { Mean Tuff Dynamic Material } \\
\text { Property Curves }+1 \text { to } 2 \mathrm{~Hz}\end{array}$} & \multicolumn{2}{|c|}{$\begin{array}{l}\text { Velocity Profile P2 + Lower } \\
\text { Mean Tuff Dynamic Material } \\
\text { Property Curves }+1 \text { to } 2 \mathrm{~Hz}\end{array}$} \\
\hline & $\begin{array}{l}\text { Modeled } \\
\text { Horizontal } \\
\text { Peak Ground } \\
\text { Velocity } \\
\text { (cm/sec) }\end{array}$ & $\begin{array}{c}\text { Modeled Shear } \\
\text { Strain }\left(\gamma_{y z}, \%\right)\end{array}$ & $\begin{array}{l}\text { Modeled } \\
\text { Horizontal } \\
\text { Peak Ground } \\
\text { Velocity } \\
\text { (cm/sec) }\end{array}$ & $\begin{array}{c}\text { Modeled } \\
\text { Shear Strain } \\
\left(\gamma_{\mathrm{yz}}, \%\right)\end{array}$ & $\begin{array}{c}\text { Modeled } \\
\text { Horizontal } \\
\text { Peak Ground } \\
\text { Velocity } \\
(\mathrm{cm} / \mathrm{sec})\end{array}$ & $\begin{array}{c}\text { Modeled } \\
\text { Shear Strain } \\
\left(\gamma_{\mathrm{yz}}, \%\right)\end{array}$ & $\begin{array}{c}\text { Modeled } \\
\text { Horizontal } \\
\text { Peak Ground } \\
\text { Velocity } \\
(\mathrm{cm} / \mathrm{sec})\end{array}$ & $\begin{array}{c}\text { Modeled } \\
\text { Shear Strain } \\
\left(\gamma_{y z}, \%\right)\end{array}$ \\
\hline $1 \times 10^{-4}$ & 45.26 & 0.020 & 47.27 & 0.023 & 45.17 & 0.018 & 43.67 & 0.024 \\
\hline $1 \times 10^{-5}$ & 110.67 & 0.050 & 104.48 & 0.076 & 111.40 & 0.048 & 105.82 & 0.089 \\
\hline $1 \times 10^{-5}$ & 242.65 & 0.118 & 231.98 & 0.263 & 244.31 & 0.116 & 231.41 & 0.331 \\
\hline $1 \times 10^{-7}$ & 512.01 & 0.270 & 499.27 & 0.869 & 519.61 & 0.272 & 494.90 & 1.041 \\
\hline
\end{tabular}

\begin{tabular}{|c|c|c|c|c|c|c|c|c|}
\hline & \multicolumn{2}{|c|}{$\begin{array}{l}\text { Velocity Profile P1 + Upper } \\
\text { Mean Tuff Dynamic Material } \\
\text { Property Curves + } 5 \text { to } 10 \mathrm{~Hz}\end{array}$} & \multicolumn{2}{|c|}{$\begin{array}{l}\text { Velocity Profile P1 + Lower } \\
\text { Mean Tuff Dynamic Material } \\
\text { Property Curves + } 5 \text { to } 10 \mathrm{~Hz}\end{array}$} & \multicolumn{2}{|c|}{$\begin{array}{l}\text { Velocity Profile P2 + Upper } \\
\text { Mean Tuff Dynamic Material } \\
\text { Property Curves + } 5 \text { to } 10 \mathrm{~Hz}\end{array}$} & \multicolumn{2}{|c|}{$\begin{array}{l}\text { Velocity Profile P2 + Lower } \\
\text { Mean Tuff Dynamic Material } \\
\text { Property Curves }+5 \text { to } 10 \mathrm{~Hz}\end{array}$} \\
\hline & $\begin{array}{c}\text { Modeled } \\
\text { Horizontal } \\
\text { Peak Ground } \\
\text { Velocity } \\
(\mathrm{cm} / \mathrm{sec})\end{array}$ & $\begin{array}{l}\text { Modeled Shear } \\
\text { Strain }\left(\gamma_{y z}, \%\right)\end{array}$ & $\begin{array}{c}\text { Modeled } \\
\text { Horizontal } \\
\text { Peak Ground } \\
\text { Velocity } \\
\text { (cm/sec) }\end{array}$ & $\begin{array}{c}\text { Modeled } \\
\text { Shear Strain } \\
\left(\gamma_{\mathrm{yz}}, \%\right)\end{array}$ & $\begin{array}{c}\text { Modeled } \\
\text { Horizontal } \\
\text { Peak Ground } \\
\text { Velocity } \\
(\mathrm{cm} / \mathrm{sec}) \\
\end{array}$ & $\begin{array}{c}\text { Modeled } \\
\text { Shear Strain } \\
\left(\gamma_{\mathrm{yz}}, \%\right)\end{array}$ & $\begin{array}{c}\text { Modeled } \\
\text { Horizontal } \\
\text { Peak Ground } \\
\text { Velocity } \\
(\mathrm{cm} / \mathrm{sec}) \\
\end{array}$ & $\begin{array}{c}\text { Modeled } \\
\text { Shear Strain } \\
\left(\gamma_{\mathrm{yz}}, \%\right)\end{array}$ \\
\hline $1 \times 10^{-4}$ & 31.63 & 0.016 & 29.65 & 0.018 & 31.33 & 0.016 & 30.00 & 0.021 \\
\hline $1 \times 10^{-5}$ & 99.29 & 0.051 & 93.24 & 0.072 & 99.70 & 0.049 & 93.86 & 0.085 \\
\hline $1 \times 10^{-5}$ & 246.20 & 0.124 & 237.70 & 0.276 & 249.51 & 0.127 & 235.68 & 0.351 \\
\hline $1 \times 10^{-7}$ & 520.46 & 0.286 & 522.41 & 0.905 & 540.36 & 0.297 & 518.23 & 1.089 \\
\hline
\end{tabular}

Source: Appendix D, PGV v Shear Strain.xIs 
Table 6-3. Modeled and Scaled Horizontal Peak Ground Velocity for Shear Strain Values (Continued)

\begin{tabular}{|c|c|c|c|c|}
\hline & $\begin{array}{c}\text { Velocity Profile P1 + Upper } \\
\text { Mean Tuff Dynamic Material } \\
\text { Property Curves + 1 to 2 Hz }\end{array}$ & $\begin{array}{c}\text { Velocity Profile P1 + Lower } \\
\text { Mean Tuff Dynamic Material } \\
\text { Property Curves + 1 to 2 Hz }\end{array}$ & $\begin{array}{c}\text { Velocity Profile P2 + Upper } \\
\text { Mean Tuff Dynamic Material } \\
\text { Property Curves + 1 to 2 Hz }\end{array}$ & $\begin{array}{c}\text { Velocity Profile P2 + Lower } \\
\text { Mean Tuff Dynamic Material } \\
\text { Property Curves + 1 to 2 Hz }\end{array}$ \\
\hline $\begin{array}{c}\text { Target Shear } \\
\text { Strain Values } \\
\left(\gamma_{\mathrm{yz}}, \%\right)\end{array}$ & $\begin{array}{c}\text { Interpolated/Extrapolated } \\
\text { Horizontal Peak Ground } \\
\text { Velocity (cm/sec) }\end{array}$ & $\begin{array}{c}\text { Interpolated/Extrapolated } \\
\text { Horizontal Peak Ground } \\
\text { Velocity (cm/sec) }\end{array}$ & $\begin{array}{c}\text { Interpolated/Extrapolated } \\
\text { Horizontal Peak Ground } \\
\text { Velocity (cm/sec) }\end{array}$ & $\begin{array}{c}\text { Interpolated/Extrapolated } \\
\text { Horizontal Peak Ground } \\
\text { Velocity (cm/sec) }\end{array}$ \\
\hline 0.05 & 110.67 & 76.09 & 115.92 \\
\hline 0.10 & 208.44 & 120.67 & 213.93 \\
\hline 0.20 & 388.85 & 188.96 & 392.95 \\
\hline 0.30 & 566.06 & 248.31 & 568.86 \\
\hline 0.40 & 743.27 & 292.46 & 711.34 \\
\hline 0.50 & 920.48 & 336.60 & 215.52 \\
\hline
\end{tabular}

\begin{tabular}{|c|c|c|c|c|}
\hline & $\begin{array}{l}\text { Velocity Profile P1 + Upper } \\
\text { Mean Tuff Dynamic Material } \\
\text { Property Curves + } 5 \text { to } 10 \mathrm{~Hz}\end{array}$ & $\begin{array}{l}\text { Velocity Profile P1 + Lower } \\
\text { Mean Tuff Dynamic Material } \\
\text { Property Curves + } 5 \text { to } 10 \mathrm{~Hz}\end{array}$ & $\begin{array}{l}\text { Velocity Profile P2 + Upper } \\
\text { Mean Tuff Dynamic Material } \\
\text { Property Curves + } 5 \text { to } 10 \mathrm{~Hz}\end{array}$ & $\begin{array}{l}\text { Velocity Profile P2 + Lower } \\
\text { Mean Tuff Dynamic Material } \\
\text { Property Curves + } 5 \text { to } 10 \mathrm{~Hz}\end{array}$ \\
\hline $\begin{array}{c}\text { Target Shear } \\
\text { Strain Values } \\
\left(\gamma_{y z}, \%\right)\end{array}$ & $\begin{array}{c}\text { Interpolated/Extrapolated } \\
\text { Horizontal Peak Ground } \\
\text { Velocity (cm/sec) }\end{array}$ & $\begin{array}{c}\text { Interpolated/Extrapolated } \\
\text { Horizontal Peak Ground } \\
\text { Velocity (cm/sec) }\end{array}$ & $\begin{array}{c}\text { Interpolated/Extrapolated } \\
\text { Horizontal Peak Ground } \\
\text { Velocity (cm/sec) }\end{array}$ & $\begin{array}{c}\text { Interpolated/Extrapolated } \\
\text { Horizontal Peak Ground } \\
\text { Velocity }(\mathrm{cm} / \mathrm{sec})\end{array}$ \\
\hline 0.05 & 97.74 & 67.48 & 100.73 & 58.98 \\
\hline 0.10 & 198.04 & 113.13 & 197.97 & 101.63 \\
\hline 0.20 & 375.26 & 183.91 & 374.89 & 155.04 \\
\hline 0.30 & 545.08 & 248.56 & 545.47 & 208.44 \\
\hline 0.40 & 714.90 & 293.83 & 716.06 & 254.44 \\
\hline 0.50 & 884.72 & 339.09 & 886.64 & 292.73 \\
\hline
\end{tabular}

Source: Appendix D, PGV $\vee$ Shear Strain.xls 


\subsection{BOUND TO HORIZONTAL PEAK GROUND VELOCITY EXPERIENCED AT YUCCA MOUNTAIN}

Results in Sections 6.3, 6.4, and 6.5 are combined in this section to determine a bound to the level of horizontal peak ground velocity experienced at the waste emplacement level. Laboratory tests and numerical simulations of lithophysal rock deformation demonstrate the shear-strain increments that would be required to fracture such rock at Yucca Mountain. These results are used to establish a shear-strain threshold for fracturing. The numerical simulation results also show the characteristics of fractures that would develop. These fractures would tend to develop such that they connect lithophysae. Geologic observations indicate that the rock exposed in the ESF and ECRB Cross-Drift does not exhibit this type of fracturing; the shear-strain threshold for fracturing has not been exceeded. Thus, it is inferred that ground motions that would generate dynamic shear strains exceeding the threshold have not occurred at the waste emplacement level during the past 12.8 million years (the age of the Topopah Spring Tuff). Site-response modeling determines the level of horizontal PGV that would be associated with dynamic shear strains that exceed the shear-strain threshold and cause fracturing. This allows a bound to be established for the level of horizontal PGV that has been experienced at the waste emplacement level at Yucca Mountain. This bound is then taken to be a reasonable bound for the level of horizontal PGV that is considered in TSPA.

Given the uncertainties in the available data, the bounding horizontal PGV is expressed as a probability distribution. The triangular distribution for shear-strain threshold discussed in Section 6.4.3 is used to develop distributions for bounding horizontal PGV. To translate the shear-strain threshold probability distribution into a distribution for horizontal PGV at the waste emplacement level, the results of the ground-motion site-response modeling are used. For each of the eight site-response modeling cases, which represent epistemic uncertainty in the velocity profile and dynamic material properties at Yucca Mountain (and the two frequency ranges), the values of shear strain and corresponding horizontal PGV are used to transpose the shear-strain threshold distribution (Figure 6-7) to one for horizontal PGV. This results in 8 probability distributions for horizontal PGV (Figure 6-8) (Appendix D, Probability Distributions.xls). The resulting distributions for horizontal PGV depart slightly from a triangular shape because the relation between shear-strain threshold and horizontal PGV is not linear. These distributions fall into two groups depending on whether the UMT or LMT set of dynamic material property curves was used in the site response modeling. For the LMT grouping of distributions, shear strains associated with the shear-strain threshold distribution are generated at relatively lower ground motions (about 100 to $230 \mathrm{~cm} / \mathrm{sec}$ ). For the UMT grouping of distributions, higher ground motions (about 180 to $490 \mathrm{~cm} / \mathrm{sec}$ ) are needed to generate the shear-strain threshold level of shear strains. 


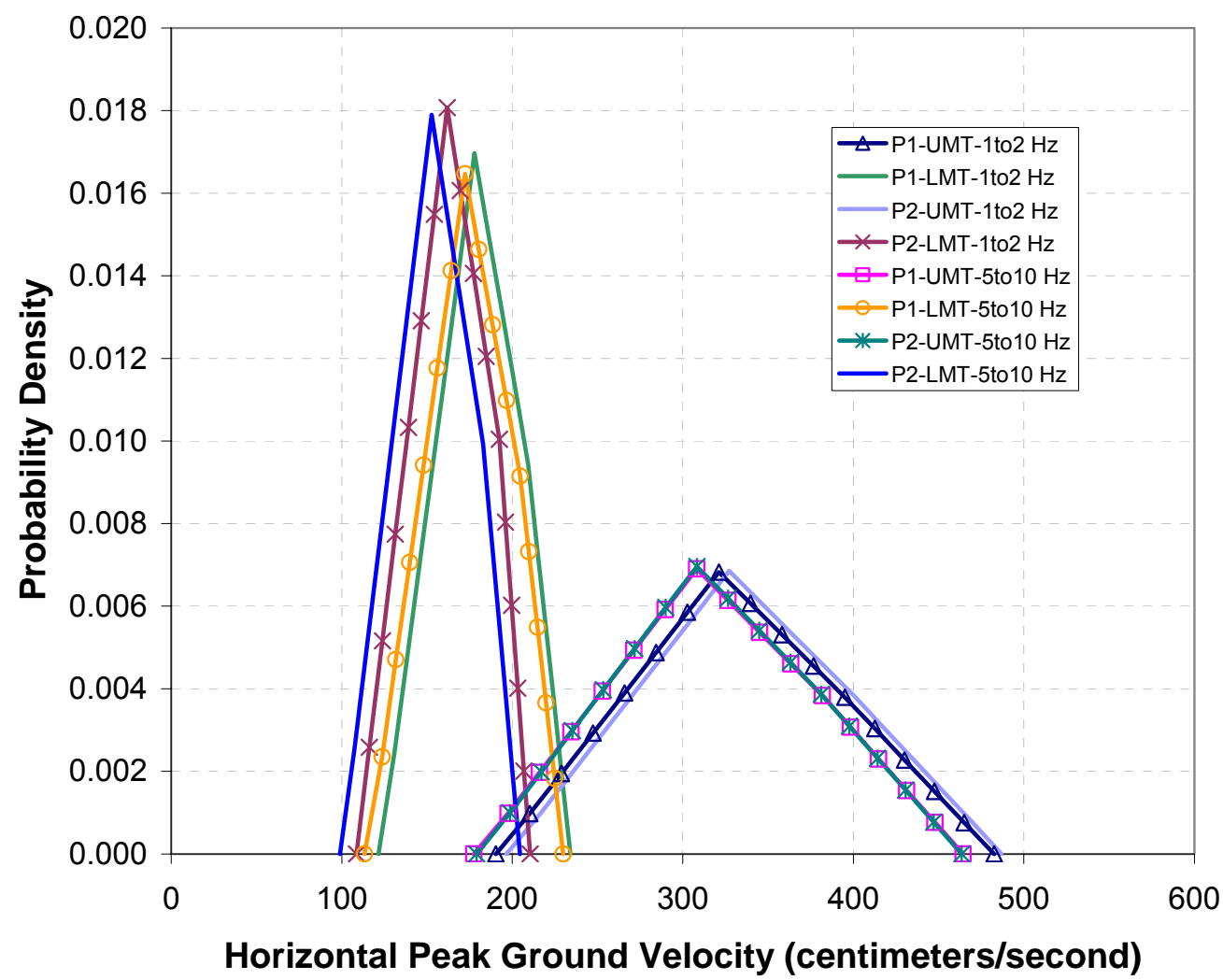

Source: Appendix D, Probability Distributions.xls.

NOTE: In the legend, the notations refer to the various combinations of repository block velocity profile (P1, P2), dynamic material property curves (Upper Mean Tuff (UMT) and Lower Mean Tuff (LMT), and response spectrum frequency range (1to $2 \mathrm{~Hz}$ and 5 to $10 \mathrm{~Hz}$ ).

Figure 6-8. Probability Distribution of Bounding Horizontal PGV

\subsection{BOUND TO EXTREME GROUND MOTION AT YUCCA MOUNTAIN}

As discussed in Section 1, the characterizations of epistemic uncertainty and aleatory variability in the seismic hazard calculations show that, when extended to lower and lower annual frequencies of being exceeded, the ground motion level increases without bound, eventually reaching levels that are not credible and are physically unrealistic. In Section 6.6, an assessment is made of the bound to horizontal PGV experienced at the waste emplacement level at Yucca Mountain. Because the rocks at the emplacement level do not show evidence that this level of horizontal PGV has ever been achieved during the past 12.8 million years, the PGV probability distributions given in Section 6.6 are taken as a reasonable bound for use in TSPA. 10 CFR 63.102(j) [DIRS 156605] provides that “...events (event classes or scenario classes) that are very unlikely (less than one chance in 10,000 over 10,000 years) can be excluded from the analysis." It is recognized that there are not sufficient data to prove that the bounding ground motions given in Section 6.6 have less than one chance in 10,000 of occurrence over 10,000 years, such that they can be excluded from the TSPA per $\S$ 63.102(j) [DIRS 156605]. However, during the 12.8 million years since deposition of the rocks at Yucca Mountain, there have been numerous opportunities for ground motions to exceed levels that would lead to rock 
deformation, if such motion were possible. The nearby Solitario Canyon fault, which is associated with recurrence intervals for large, surface-rupturing earthquakes of 35,000 to 180,000 years (BSC 2004 [169734] Table 4-11), has experienced tens to hundreds of large earthquakes since the time the rocks were deposited. Further, other seismic sources in the region, which are included in the PSHA, also contribute to the potential for exceeding ground motions at the repository horizon, thereby further increasing the probability that extreme ground motions would have been achieved if they were possible.

In defining event classes of input to performance assessment, § 63.102(j) [DIRS 156605] calls for inclusion into the TSPA of credible events: "An event class consists of all possible specific initiating events that are caused by a common natural process (e.g., the event class for seismicity includes the range of credible earthquakes for the Yucca Mountain site)." The 12.8 million year geologic record at the Yucca Mountain site is considered to provide a reasonable basis for identifying what earthquakes are credible at Yucca Mountain. Specifically, it is reasonable to consider that earthquake ground motions that exceed what has been experienced in the last 12.8 million years are not credible and should not be included in the TSPA.

\subsection{HAZARD CURVE FOR HORIZONTAL PEAK GROUND VELOCITY AT THE WASTE EMPLACEMENT LEVEL}

This section describes the development of a mean hazard curve for horizontal PGV at the waste emplacement level. The hazard curve reflects the bound to credible extreme ground motions that was presented in Sections 6.6 and 6.7. First, an unbounded mean hazard curve is developed based on horizontal PGV values determined from ground motion site-response modeling. Next, the probability distributions for the bounding value of PGV (Figure 6-8) are combined with the unbounded hazard curve to develop a composite mean hazard curve for horizontal PGV at the waste emplacement level.

Ground motion site-response modeling determined values of horizontal PGV at the waste emplacement level for annual frequencies of exceedance of $10^{-4}, 10^{-5}, 10^{-6}$, and $10^{-7}$ (BSC 2004

[DIRS 170027], Sections 6.3.1.1.3, 6.3.1.2.3, 6.3.1.4). These data (DTNs: MO0404PGVRL104.000 [DIRS 170437], MO0401SEPPGVRL.022 [DIRS 169099], MO0303DPGVB106.002 [DIRS 162712], and MO0210PGVPB107.000 [DIRS 162713]) provide direct input to the development of a hazard curve reflecting unbounded ground motion. The resulting hazard curve reflects unbounded ground motion because the site-response modeling was based on uniform hazard spectra from the PSHA for Yucca Mountain. The PSHA did not include an assessment of bounds for extreme ground motions. The hazard curve for unbounded horizontal PGV is constructed by using the site-specific values determined by the site-response analysis and interpolating or extrapolating to obtain values for other ground motion levels (Appendix D, Workbook Probability Distributions.xls, Worksheet Hazard Calcs). Interpolation and extrapolation is carried out using the logarithm of horizontal PGV and annual frequency of exceedance.

To obtain a bounded hazard curve, the "triangular" distributions for the bounding value of PGV (Figure 6-8) are combined with the unbounded hazard curve to generate a new composite hazard curve for the repository horizon. The bounded ground motion exceeds a particular value, $x$, only if both the bounding value of PGV is greater than $x$ and the ground motion from the original 
unbounded analysis is greater than $x$. Mathematically, the annual frequency (hazard) that the composite PGV value is greater than a given value, $x$, is defined by the product of the probability that the bounding value for PGV has a value greater than $x$ and the annual frequency that the original unbounded motion has a PGV value greater than $x$. This calculation methodology is implemented on worksheet Hazard Calcs in Microsoft ${ }^{\circledR}$ Excel workbook Probability Distributions.xls (Appendix D). The process involves two steps. First, each of the 8 bounding horizontal PGV distributions is combined individually with the unbounded hazard curve for the waste emplacement level to produce eight modified mean hazard curves. Then for each value of horizontal PGV, the probabilities of the eight modified curves are averaged (arithmetic mean) to determine points on the final modified mean hazard curve (Figure 6-9). Equal weighting of the hazard curves is used to reflect the current assessment that the underlying cases representing epistemic uncertainty in site conditions are equally likely to represent actual conditions at Yucca Mountain. The unbounded hazard curve and the composite mean hazard curve reflecting the bound to horizontal PGV are shown in Figure 6-10.

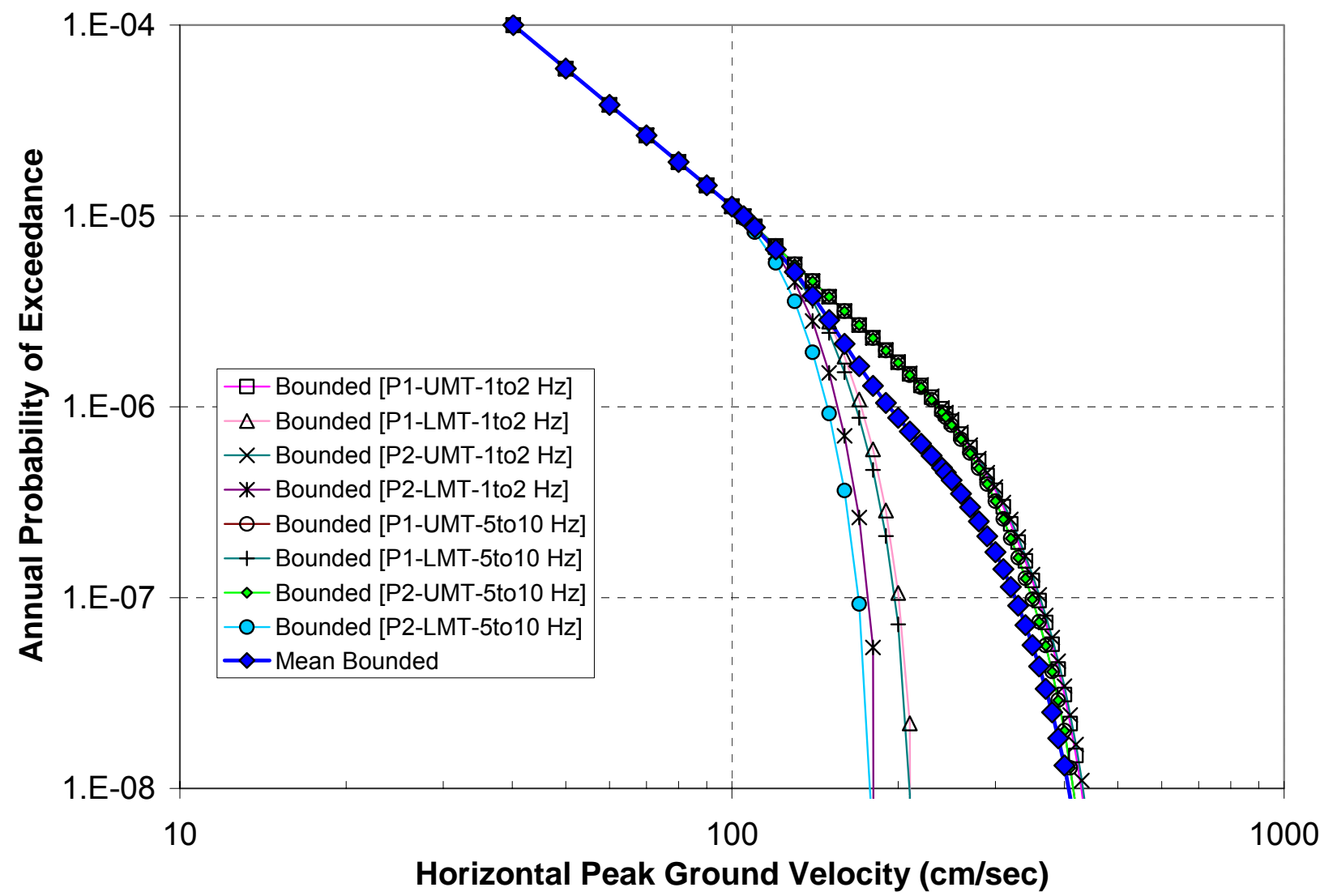

Source: Appendix D, Probability Distributions.xls.

NOTE: The eight hazard curves result from combining the unbounded hazard curve with the eight "triangular" bounds to horizontal PGV. The eight "triangular" bounds represent epistemic uncertainty in the site-response modeling. The Mean Bounded curve represents the average of the other eight curves.

Figure 6-9. Individual and Average Bounded PGV Hazard Curves for the Waste Emplacement Level 


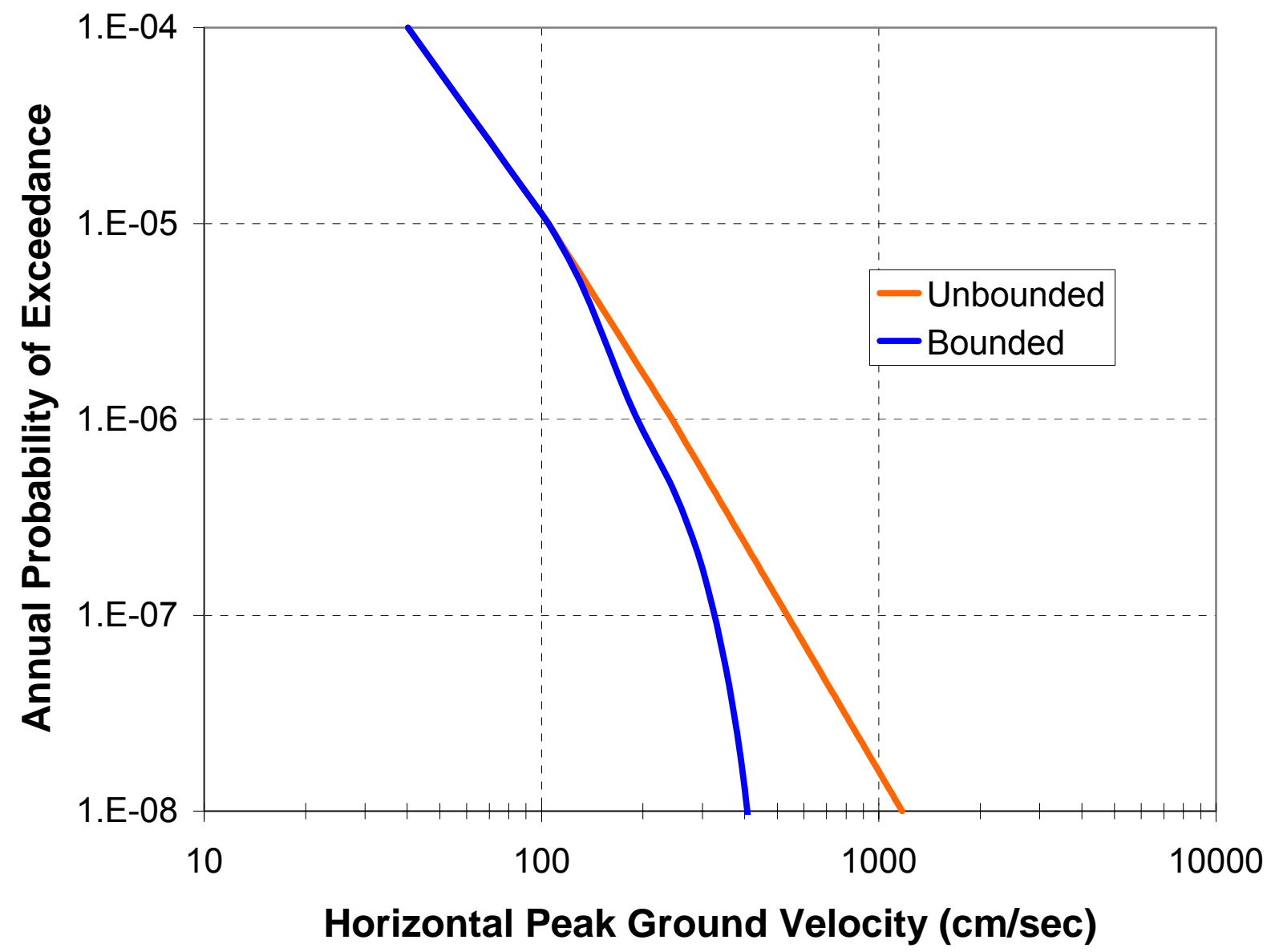

Source: Appendix D, Probability Distributions.xls.

Figure 6-10. Comparison of Horizontal PGV Hazard Curves for Bounded and Unbounded Ground Motion at the Waste Emplacement Level 


\section{INTENTIONALLY LEFT BLANK}




\section{CONCLUSIONS}

Rock testing data, geologic data, and ground-motion site response data are combined to determine a bounding horizontal PGV. The analysis consists of four steps. First, laboratory testing and numerical simulations of lithophysal rock deformation are used to determine the shear-strain threshold for rock failure. Second, the results of the numerical simulations are combined with geologic observations in the ESF and ECRB Cross-Drift to conclude that the Topopah Spring Tuff lithophysal zones have not experienced shear-strains exceeding the threshold for failure. Third, ground-motion site response data are used to assess the level of horizontal PGV that would be required to generate shear strains exceeding the shear-strain threshold for failure. Fourth, it is concluded that such a level of horizontal PGV has not been reached at Yucca Mountain since the rocks were deposited 12.8 million years ago.

Given the uncertainties in the available data, the bounding horizontal PGV is expressed as a probability distribution. A probability distribution is initially assessed for shear-strain threshold using a triangular distribution. It is then transformed into distributions for horizontal PGV on the basis of the ground-motion site-response modeling results.

Laboratory testing results are used to assess a triangular distribution for shear-strain threshold with maximum and minimum values of $0.09 \%$ and $0.25 \%$, respectively, and a modal value of $0.16 \%$ (Figure 6-7). The range is based on the range determined from the laboratory testing results. The mode is assessed on the basis of the mean values determined for the laboratory samples with length-to-diameter ratios greater than 1.5. The range and mode determined from the laboratory testing results are consistent with results from the numerical simulations.

To translate the shear-strain threshold probability distribution into a distribution for horizontal PGV at the waste emplacement level, the results of the ground-motion site-response modeling are used. Eight bounding horizontal PGV distributions are developed to account for the epistemic uncertainty in site-response modeling and the use of two response spectrum frequency ranges. The resulting distributions for horizontal PGV depart slightly from a triangular shape because the relation between shear-strain threshold and horizontal PGV is not linear. These distributions fall into two groups. In one group, the distributions range from about 100 to $250 \mathrm{~cm} / \mathrm{sec}$ and have a mode of about $175 \mathrm{~cm} / \mathrm{sec}$ (Figure 6-8). In the other group, the distributions range from about 200 to $500 \mathrm{~cm} / \mathrm{sec}$ and have a mode of about $335 \mathrm{~cm} / \mathrm{sec}$ (Figure 6-8).

A composite mean hazard curve, relating magnitude of horizontal PGV at the waste emplacement level to its annual frequency of exceedance, is determined by combining results of site-response modeling and the probability distributions for a bound to horizontal PGV at Yucca Mountain. First, a hazard curve for horizontal PGV is developed from site-response calculations for the waste emplacement level. These calculations reflect the unbounded mean uniform hazard spectra from the PSHA. Next, the hazard curve for unbounded motion is combined with the probability distributions for a bound to horizontal PGV. The resulting modified hazard curves are averaged to produce the composite mean hazard curve that reflects the assessed bound to extreme ground motions at Yucca Mountain (Figures 6-9 and 6-10). 
These results have been submitted to the Technical Data Management System as product output and have DTN MO0501BPVELEMP.001. There are no restrictions on subsequent use of these data.

Acceptance Criteria-The work described in this report addresses acceptance criteria from the Yucca Mountain Review Plan, Final Report (NRC 2003 [DIRS 163274]). Relevant acceptance criteria are identified in Section 4.2. Table 7-1 lists the acceptance criteria and indicates how they have been addressed.

Table 7-1. Summary of Applicable Yucca Mountain Review Plan, Final Report Acceptance Criteria and How They are Addressed in this Report

\begin{tabular}{|c|c|}
\hline $\begin{array}{c}\text { Yucca Mountain Review Plan, Final Report } \\
\text { Acceptance Criteria }\end{array}$ & $\begin{array}{l}\text { Summary of How Acceptance Criteria are Addressed } \\
\text { in this Report }\end{array}$ \\
\hline \multicolumn{2}{|l|}{ Section 1.5.3: } \\
\hline $\begin{array}{l}\text { 1. The "General Information" section of the license } \\
\text { application contains an adequate description of } \\
\text { site characterization activities. }\end{array}$ & $\begin{array}{l}\text { In accordance with part } 1 \text { of acceptance criterion } 1 \text {, this } \\
\text { report as a whole provides an description of the site } \\
\text { characterization activity to develop a bound to horizontal } \\
\text { PGV associated with extreme ground motion at Yucca } \\
\text { Mountain. Geologic evidence (Section } 6.3 \text { ) is combined } \\
\text { with rock mechanics results (Section } 6.4 \text { ) and ground } \\
\text { motion results (Section } 6.5 \text { ) to establish the bound } \\
\text { (Sections } 6.6 \text { and 6.7). Implications of the bound for } \\
\text { seismic hazard at Yucca Mountain are presented in } \\
\text { Section 6.8. }\end{array}$ \\
\hline $\begin{array}{l}\text { 2. The "General Information" section of the license } \\
\text { applications contains an adequate description of } \\
\text { site characterization results. }\end{array}$ & $\begin{array}{l}\text { In accordance with part } 1 \text { of acceptance criterion } 2 \text {, } \\
\text { Sections } 6.3,6.4 \text {, and } 6.5 \text { address the features and } \\
\text { processes used to determine a bound for horizontal PGV } \\
\text { associated with extreme ground motion at Yucca } \\
\text { Mountain. }\end{array}$ \\
\hline & $\begin{array}{l}\text { In accordance with part } 2 \text { of acceptance criterion } 2 \text {, } \\
\text { Sections } 6.6,6.7 \text { and } 6.8 \text { address the seismic ground } \\
\text { motions that have the potential to occur in the future at } \\
\text { Yucca Mountain. }\end{array}$ \\
\hline \multicolumn{2}{|l|}{ Section 2.2.1.2.2.3: } \\
\hline 1. Events are adequately defined. & $\begin{array}{l}\text { In accordance with part } 1 \text { of acceptance criterion } 1 \text {, } \\
\text { Section } 6.8 \text { addresses the mean annual frequency of } \\
\text { exceedance for horizontal PGV at the waste emplacement } \\
\text { level at Yucca Mountain. } \\
\text { In accordance with part } 2 \text { of acceptance criterion } 1 \text {, } \\
\text { Sections } 6.6 \text { and } 6.7 \text { address how geologic analyses } \\
\text { (Section } 6.3 \text { ) are combined with rock mechanics results } \\
\text { (Section } 6.4 \text { ) and ground motion calculations (Section } 6.5 \text { ) } \\
\text { to establish a geologically-based credible bound to } \\
\text { horizontal PGV at the waste emplacement level for Yucca } \\
\text { Mountain. }\end{array}$ \\
\hline $\begin{array}{l}\text { 2. Probability estimates for future events are } \\
\text { supported by appropriate technical bases. }\end{array}$ & $\begin{array}{l}\text { In accordance with part } 1 \text { of acceptance criterion } 2 \text {, } \\
\text { Sections } 6.6 \text { and } 6.7 \text { address the development, based on } \\
\text { inferred past patterns of ground motion, of a credible } \\
\text { bound to horizontal PGV at the waste emplacement level } \\
\text { for Yucca Mountain. Section } 6.8 \text { describes development of } \\
\text { a hazard curve for horizontal PGV that reflects the bound. }\end{array}$ \\
\hline
\end{tabular}


Table 7-1. Summary of Applicable Yucca Mountain Review Plan, Final Report Acceptance Criteria and How They are Addressed in this Report (Continued)

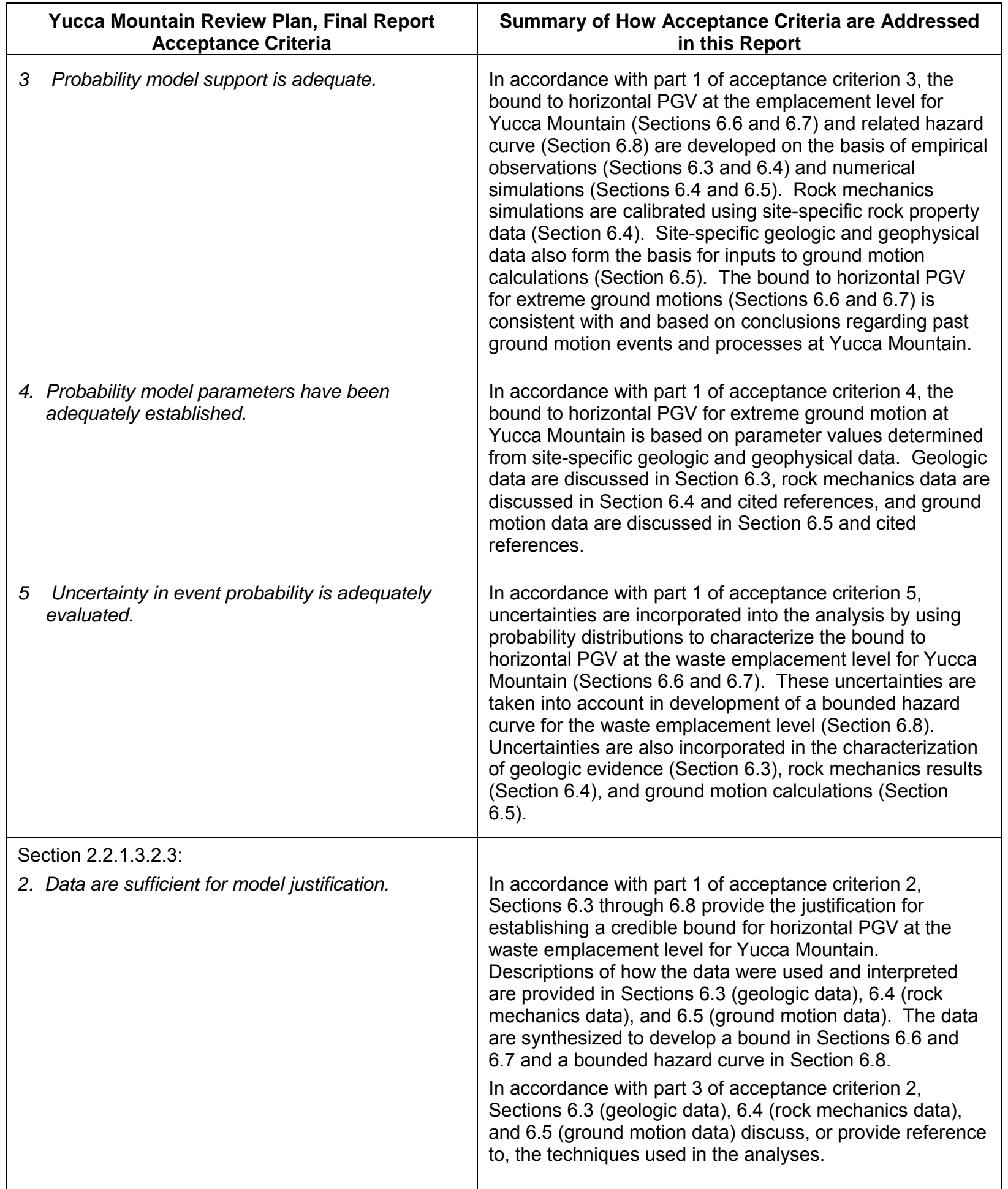


Table 7-1. Summary of Applicable Yucca Mountain Review Plan, Final Report Acceptance Criteria and How They are Addressed in this Report (Continued)

\begin{tabular}{|l|l|}
\hline \multicolumn{1}{|c|}{$\begin{array}{c}\text { Yucca Mountain Review Plan, Final Report } \\
\text { Acceptance Criteria }\end{array}$} & $\begin{array}{l}\text { Summary of How Acceptance Criteria are Addressed } \\
\text { in this Report }\end{array}$ \\
\hline $\begin{array}{l}\text { 3. Data uncertainty is characterized and propagated } \\
\text { through the model abstraction. }\end{array}$ & $\begin{array}{l}\text { In accordance with part } 1 \text { of acceptance criterion } 3, \\
\text { Sections } 6.6 \text { and } 6.7 \text { provide the technical basis for the use } \\
\text { of probability distributions to characterize the uncertainty in } \\
\text { the bound to horizontal PGV for extreme ground motion at } \\
\text { the waste emplacement level. Section } 6.8 \text { describes how } \\
\text { the uncertainties are incorporated into a bounded hazard } \\
\text { curve. Uncertainties in the evaluation of geologic data are } \\
\text { presented in Section } 6.3 \text {. Uncertainties in determination of } \\
\text { a shear-strain threshold are discussed in Section } 6.4 . \\
\text { Uncertainties in ground motion calculations are provided in } \\
\text { Section } 6.5 .\end{array}$ \\
& $\begin{array}{l}\text { In accordance with part } 2 \text { of acceptance criterion } 3, \\
\text { Sections } 6.3 \text { through } 6.8 \text { provide the technical basis for a } \\
\text { bounded hazard curve for horizontal PGV at the waste } \\
\text { emplacement level within Yucca Mountain. This bound to } \\
\text { extreme ground motion is based on site-specific data and } \\
\text { analyses (Sections } 6.3,6.4, \text { and } 6.5) ; \text { it is consistent with } \\
\text { the geological observations at Yucca Mountain. }\end{array}$ \\
& $\begin{array}{l}\text { In accordance with part } 3 \text { of acceptance criterion } 3, \\
\text { Sections } 6.3 \text { (geologic data and analyses), } 6.4 \text { (rock } \\
\text { mechanics data and analyses), and } 6.5 \text { (ground motion } \\
\text { data and analyses) describe how uncertainty and variability } \\
\text { are accommodated. Sections } 6.6 \text { and } 6.7 \text { describe the use } \\
\text { of a probability distribution to incorporate these } \\
\text { uncertainties into the development of a bound to horizontal } \\
\text { PGV for the waste emplacement level at Yucca Mountain. } \\
\text { Section } 6.8 \text { describes incorporation of the bound into a } \\
\text { hazard curve for horizontal PGV. }\end{array}$ \\
\hline
\end{tabular}

The analysis documented in this report is carried out to determine reasonable values of horizontal PGV at the waste emplacement level for annual frequencies of being exceeded considered in postclosure analyses. These are considered to be credible seismic inputs for TSPA, within the intent of $\S 63.102(\mathrm{j})$ [DIRS 156605]. Based on the analyses presented, it is concluded that the bound to the horizontal PGV experienced at Yucca Mountain also provides a reasonable bound to credible ground motions for TSPA. 


\section{INPUTS AND REFERENCES}

\subsection{DOCUMENTS CITED}

170686 Abrahamson, N.A.; Bommer, J.J.; Strasser, F.O.; and Pecker, A. 2004. "The Challenge of Defining Upper Bounds on Ground-Motion Parameters." Seismological Research Letters, 75, (2), 282-283. [El Cerrito, California: Seismological Society of America]. TIC: 256282.

101425 Barton, C.C.; Larsen, E.; Page, W.R.; and Howard, T.M. 1993. Characterizing Fractured Rock for Fluid-Flow, Geomechanical, and Paleostress Modeling: Methods and Preliminary Results from Yucca Mountain, Nevada. Open-File Report 93-269. Denver, Colorado: U.S. Geological Survey. ACC: NNA.19931026.0008.

170690 Brantley, S.R. 1996. "Volcanoes of the United States." VOLCUS 1994. Denver, Colorado: U.S. Geological Survey, Information Services. Accessed July 14, 2004. ACC: MOL.20040902.0235. http://pubs.usgs.gov/gip/volcus/titlepage.html

166660 BSC 2003. Subsurface Geotechnical Parameters Report. 800-K0C-WIS0-00400-000-00A. Las Vegas, Nevada: Bechtel SAIC Company. ACC: ENG.20040108.0001.

170027 BSC (Bechtel SAIC Company) 2004. Development of Earthquake Ground Motion Input for Preclosure Seismic Design and Postclosure Performance Assessment of a Geologic Repository at Yucca Mountain, NV. MDL-MGR-GS-000003 REV 01. Las Vegas, Nevada: Bechtel SAIC Company. ACC: DOC.20041108.0003.

171850 BSC (Bechtel SAIC Company) 2004. Development of Seismic Inputs, Preparation of Seismic Topical Reports, and Evaluation of Disruptive Events Features, Events, and Processes. TWP-MGR-GS-000001 REV 03 ICN 02. Las Vegas, Nevada: Bechtel SAIC Company. ACC: DOC.20040923.0001.

166107 BSC (Bechtel SAIC Company) 2004. Drift Degradation Analysis. ANL-EBS-MD-000027, Rev. 03. Las Vegas, Nevada: Bechtel SAIC Company. ACC: DOC.20040915.0010.

172334 BSC (Bechtel SAIC Company) 2004. Lithophysal Rock Mass Mechanical Properties of the Repository Host Horizon. 800-K0C-SS00-00200-000-00A. Las Vegas, Nevada: Bechtel SAIC Company. ACC: ENG.20041111.0001.

169183 BSC (Bechtel SAIC Company) 2004. Seismic Consequence Abstraction. MDL-WIS-PA-000003 REV 01. Las Vegas, Nevada: Bechtel SAIC Company. ACC: DOC.20041025.0004.

169734 BSC (Bechtel SAIC Company) 2004. Yucca Mountain Site Description. TDR-CRW-GS-000001 REV 02 ICN 01. Two volumes. Las Vegas, Nevada: Bechtel SAIC Company. ACC: DOC.20040504.0008. 
103635 Budnitz, R.J.; Apostolakis, G.; Boore, D.M.; Cluff, L.S.; Coppersmith, K.J.; Cornell, C.A.; and Morris, P.A. 1997. Recommendations for Probabilistic Seismic Hazard Analysis: Guidance on the Uncertainty and Use of Experts. NUREG/CR-6372. Two volumes. Washington, D.C.: U.S. Nuclear Regulatory Commission. TIC: 235076; 235074.

162271 Buesch, D. 2003. "Hydrogeologic Properties of Features in Crystallized Topopah Spring Tuff." E-mail from D. Buesch to D. Kicker and D. Rigby, March 10, 2003, with attachment. ACC: MOL.20030314.0188.

170297 Buesch, D.C. and Lung, R.C. 2003. "Tephrostratigraphic Relations and the Timing and Locations of Faulting Near Exile Hill at Yucca Mountain, Nevada." Proceedings of the 10th International High-Level Radioactive Waste Management Conference (IHLRWM), March 30-April 2, 2003, Las Vegas, Nevada. Pages 388-397.

La Grange Park, Illinois: American Nuclear Society. TIC: 254559.

101433 Buesch, D.C. and Spengler, R.W. 1998. "Character of the Middle Nonlithophysal Zone of the Topopah Spring Tuff at Yucca Mountain." High-Level Radioactive Waste Management, Proceedings of the Eighth International Conference, Las Vegas, Nevada, May 11-14, 1998. Pages 16-23. La Grange Park, Illinois: American Nuclear Society. TIC: 237082.

104612 Buesch, D.C. and Spengler, R.W. 1998. "Detailed Correlation of Lithostratigraphic and Borehole Geophysical Log Data for Identifying Contacts at Yucca Mountain." High-Level Radioactive Waste Management, Proceedings of the Eighth International Conference, Las Vegas, Nevada, May 11-14, 1998. Pages 248-251. La Grange Park, Illinois: American Nuclear Society. TIC: 237082.

165483 Buesch, D.C.; Beason, S.C.; and Spengler, R.W. 1999. "Relations Among Welding, Vapor-Phase Activity, Crystallization, and Fractures in the Tiva Canyon and Topopah Spring Tuffs, at Yucca Mountain, Nevada." Abstracts with Programs - Geological Society of America, 31, (7), A-476 - A-477. Boulder, Colorado: Geological Society of America. TIC: 254857.

100106 Buesch, D.C.; Spengler, R.W.; Moyer, T.C.; and Geslin, J.K. 1996. Proposed Stratigraphic Nomenclature and Macroscopic Identification of Lithostratigraphic Units of the Paintbrush Group Exposed at Yucca Mountain, Nevada. Open-File Report 94-469. Denver, Colorado: U.S. Geological Survey.

ACC: MOL.19970205.0061.

166275 Canori, G.F. and Leitner, M.M. 2003. Project Requirements Document. TER-MGR-MD-000001 REV 02. Las Vegas, Nevada: Bechtel SAIC Company. ACC: DOC.20031222.0006. 
172099 Case, J.B., and Buesch, D.C. 2004. "Simulation of Ventilation Efficiency, and Pre-closure Temperatures in Emplacement Drifts at Yucca Mountain, Nevada, Using Monte Carlo and Composite Thermal-Pulse Methods." 2004 ASME Heat Transfer/Fluid Engineering Summer Conference, July 11-15, 2004, Charlotte, North Carolina, USA. p. 1-7. New York, NY: American Society of Mechanical Engineers (ASME). TIC: 256643.

171191 Corradini, M.L. 2003. Responses and Evaluation from the Nuclear Waste Technical Review Board to the U.S. Department of Energy Presentations given at the February 2003 Joint Meeting held by the Natural System and Engineered System Panel Discussing Seismic Issue. Letter from M.L. Corradini (NWTRB) to M.S.Y. Chu (DOE/OCRWM), June 27, 2003. ACC: HQO.20031017.0002.

147458 CRWMS M\&O 1997. Data Transmittal Package (DTP) for "Hydraulic Fracturing Stress Measurements in Test Hole: ESF-AOD-HDFR\#1, Thermal Test Facility, Exploratory Studies Facility at Yucca Mountain.” DTN: SNF37100195002.001, TDIF 305878. Las Vegas, Nevada: CRWMS M\&O. ACC: MOL.19970717.0005; MOL.19970717.0006; MOL.19970717.0007; MOL.19970717.0008.

100223 CRWMS M\&O 1997. Determination of Available Volume for Repository Siting. BCA000000-01717-0200-00007 REV 00. Las Vegas, Nevada: CRWMS M\&O. ACC: MOL.19971009.0699.

172060 Damjanac, B.; Cundall, P.; and Brandshaug, T. 2004. "Strain Levels Related to Damage in Topopah Spring Tuff - Revised" Technical memorandum from B. Damjanac (Itasca), P. Cundall (Itasca), and T. Brandshaug (Itasca) to J. King (BSC), June 2, 2004, 04-2133-6-19TM. ACC: MOL.20041026.0030.

101557 Day, W.C.; Potter, C.J.; Sweetkind, D.S.; Dickerson, R.P.; and San Juan, C.A. 1998. Bedrock Geologic Map of the Central Block Area, Yucca Mountain, Nye County, Nevada. Miscellaneous Investigations Series Map I-2601. [Washington, D.C.]: U.S. Geological Survey. ACC: MOL.19980611.0339.

170314 DOE (U.S. Department of Energy) 2002. Software Management Report NORM Version 1.01. Software Document Number: 10386-SMR-1.01-00. Las Vegas, Nevada: U.S. Department of Energy, Office of Civilian Radioactive Waste Management. ACC: MOL.20020730.0359.

170315 DOE (U.S. Department of Energy) 2004. Software Management Report for: LOGNORM Version 1.01, Rev. 00 - February 9, 2004. Document ID: 10384-SMR-1.01-00. Las Vegas, Nevada: U.S. Department of Energy, Office of Repository Development. ACC: MOL.20040211.0055.

100033 Flint, L.E. 1998. Characterization of Hydrogeologic Units Using Matrix Properties, Yucca Mountain, Nevada. Water-Resources Investigations Report 97-4243. Denver, Colorado: U.S. Geological Survey. ACC: MOL.19980429.0512. 
159152 Howard, C. 2002. Thermal K Field Program, Thermal Conductivity Field Measurements. Scientific Notebook SN-SNL-SCI-024-V1.

ACC: MOL.20020619.0494.

160331 Itasca Consulting Group. 2002. Itasca Software-Cutting Edge Tools for Computational Mechanics. Minneapolis, Minnesota: Itasca Consulting Group. TIC: 252592.

106219 Jaeger, J.C. and Cook, N.G.W. 1979. Fundamentals of Rock Mechanics. 3rd Edition. New York, New York: Chapman and Hall. TIC: 218325.

116960 Levy, S.S. and O'Neil, J.R. 1989. "Moderate-Temperature Zeolitic Alteration in a Cooling Pyroclastic Deposit." Chemical Geology, 76, (3/4), 321-326. Amsterdam, The Netherlands: Elsevier. TIC: 237819.

157510 McGuire, R.K.; Silva, W.J.; and Costantino, C.J. 2001. Technical Basis for Revision of Regulatory Guidance on Design Ground Motions: Hazard- and Risk-Consistent Ground Motion Spectra Guidelines. NUREG/CR-6728. Washington, D.C.:

U.S. Nuclear Regulatory Commission. TIC: 251294.

149850 Mongano, G.S.; Singleton, W.L.; Moyer, T.C.; Beason, S.C.; Eatman, G.L.W.; Albin, A.L.; and Lung, R.C. 1999. Geology of the ECRB Cross Drift - Exploratory Studies Facility, Yucca Mountain Project, Yucca Mountain, Nevada. [Deliverable SPG42GM3]. Denver, Colorado: U.S. Geological Survey. ACC: MOL.20000324.0614.

106399 Munsell Color Company 1994. Munsell Soil Color Charts. 1994 Revised Edition. New Windsor, New York: GretagMacbeth. TIC: 238646.

163274 NRC (U.S. Nuclear Regulatory Commission) 2003. Yucca Mountain Review Plan, Final Report. NUREG-1804, Rev. 2. Washington, D.C.: U.S. Nuclear Regulatory Commission, Office of Nuclear Material Safety and Safeguards. TIC: 254568.

170727 Otto, S.J., and Buesch, D.C. 2003. "Porosity, bulk density, and rock-particle density of lithostratigraphic components in lithophysal rocks of the Topopah Spring Tuff at Yucca Mountain, Nevada." Geological Society of America Abstracts with Programs, 35, (6), 434-435. Boulder, CO: Geological Society of America. TIC: 254862.

162576 Peterman, Z.E. and Cloke, P.L. 2002. "Geochemistry of Rock Units at the Potential Repository Level, Yucca Mountain, Nevada (includes Erratum).” Applied Geochemistry, 17, ([6,7]), 683-698, 955-958. New York, New York: Pergamon. TIC: $252516 ; 252517$.

172061 Price, R.H. 2002. Supporting Information for Mechanical Properties of Lithophysal Tuff, Batch \#2 (Test Dates: October 22 through 25, 2002). [Albuquerque, New Mexico]: Sandia National Laboratories. ACC: MOL.20030214.0179. 
170894 Price, R.H. 2004. The Mechanical Properties of Lithophysal Tuff: Laboratory Experiments. TDR-EBS-MD-000027 REV 00. Las Vegas, Nevada: Bechtel SAIC Company. ACC: DOC.20040506.0001.

170694 Reiter, L., 2004. "When are ground motion estimates too high?" Seismological Research Letters, 75, (2), 282. El Cerrito, CA: Seismological Society of America. TIC: 256283.

106671 Riehle, J.R.; Miller, T.F.; and Bailey, R.A. 1995. "Cooling, Degassing and Compaction of Rhyolitic Ash Flow Tuffs: A Computational Model." Bulletin of Volcanology, 57, (5), 319-336. Heidelberg, Germany: Springer International. TIC: 236674.

106714 Ross, C.S. and Smith, R.L. 1961. Ash-Flow Tuffs: Their Origin, Geologic Relations, and Identification. Professional Paper 366. Reston, Virginia: U.S. Geological Survey. TIC: 216668.

172401 Sanchez, A. and Howard, C.L. 2004. Thermal K Program: Thermal Conductivity Field Measurements [partial submittal]. Scientific Notebook: SN-SNL-SCI-024-V2. Pages -112 - 160 ACC: MOL.20041011.0044.

100075 Sawyer, D.A.; Fleck, R.J.; Lanphere, M.A.; Warren, R.G.; Broxton, D.E.; and Hudson, M.R. 1994. "Episodic Caldera Volcanism in the Miocene Southwestern Nevada Volcanic Field: Revised Stratigraphic Framework, ${ }^{40} \mathrm{Ar} /{ }^{39} \mathrm{Ar}$ Geochronology, and Implications for Magmatism and Extension." Geological Society of America Bulletin, 106, (10), 1304-1318. Boulder, Colorado: Geological Society of America. TIC: 222523.

106837 Smith, R.L. 1980. Zones and Zonal Variations in Welded Ash Flows. Ash-Flow Tuffs: Their Origin, Geologic Relations and Identification and Zones and Zonal Variations in Welded Ash Flows. Callender, J.F., ed. Special Publication No. 9, 149-159. Socorro, New Mexico: New Mexico Geological Society. TIC: 234928.

170697 Whelan, J.F. 2004. Secondary Mineral Deposits and Evidence of Past Seismicity and Heating of the Proposed Repository Horizon at Yucca Mountain, Nevada. Water-Resources Investigations Report 03-4321. Reston, Virginia: U.S. Geological Survey. ACC: MOL.20040902.0236

170444 Wong, I.G. and Silva, W. 2004. Development of Seismic Design Ground Motion Inputs. SN-M\&O-SCI-037-V3. Pages 1-77 Pages 72-125 ACC: MOL.20031027.0158; MOL.20040918.0004.

125616 Wood, C.A. and Kienle, J., eds. 1990. Volcanoes of North America, United States and Canada. Cambridge, England: Cambridge University Press. p.70-71, Contribution by Wes Hildreth. TIC: 240104. 
172106 YMP (Yucca Mountain Site Characterization Project) 1993. Preliminary Field Composite Borehole Log, Borehole ID: USW NRG-6. Las Vegas, Nevada: YMP (Yucca Mountain Site Characterization Office). ACC: DRC.19960509.0104.

172113 YMP (Yucca Mountain Site Characterization Project) 1995. Composite Borehole Log, Borehole ID: USW UZ-14. Las Vegas, Nevada: Yucca Mountain Site Characterization Office. ACC: DRC.19960702.0263.

172115 YMP (Yucca Mountain Site Characterization Project) 2001. Sample Management and Drilling Department Geologic Log, Borehole Number: ECRB-THERMK-001. [Las Vegas, Nevada: Yucca Mountain Site Characterization Office]. ACC: MOL.20010614.0098; MOL.20010207.0160.

172116 YMP (Yucca Mountain Site Characterization Project) 2001. Sample Management and Drilling Department Geologic Log, Borehole Name: ECRB-THERMK-002. [Las Vegas, Nevada: Yucca Mountain Site Characterization Office]. ACC: MOL.20010614.0135; MOL.20010207.0160.

172117 YMP (Yucca Mountain Site Characterization Project) 2001. Sample Management and Drilling Department Geologic Log, Borehole Name: ECRB-THERMK-003. [Las Vegas, Nevada: Yucca Mountain Site Characterization Office]. ACC: MOL.20010614.0103; MOL.20010207.0160.

172118 YMP (Yucca Mountain Site Characterization Project) 2001. Sample Management and Drilling Department Geologic Log, Borehole Name: ECRB-THERMK-004. [Las Vegas, Nevada: Yucca Mountain Site Characterization Office]. ACC: MOL.20010614.0108; MOL.20010207.0160.

172119 YMP (Yucca Mountain Site Characterization Project) 2001. Sample Management and Drilling Department Geologic Log, Borehole Name: ECRB-THERMK-005. [Las Vegas, Nevada: Yucca Mountain Site Characterization Office]. ACC: MOL.20010614.0113; MOL.20010207.0160.

172121 YMP (Yucca Mountain Site Characterization Project) 2001. Sample Management and Drilling Department Geologic Log, Borehole Name: ECRB-THERMK-006. [Las Vegas, Nevada: Yucca Mountain Site Characterization Office]. ACC: MOL.20010913.0334; MOL.20010207.0160.

172122 YMP (Yucca Mountain Site Characterization Project) 2001. Sample Management and Drilling Department Geologic Log, Borehole Name: ECRB-THERMK-007. [Las Vegas, Nevada: Yucca Mountain Site Characterization Office]. ACC: MOL.20010913.0339; MOL.20010207.0160.

172124 YMP (Yucca Mountain Site Characterization Project) 2001. Sample Management Facility Geologic Log, Borehole Name: ESF-THERMK-008. [Las Vegas, Nevada: Yucca Mountain Site Characterization Office]. ACC: MOL.20010913.0344; MOL.20010207.0160. 
172131 YMP (Yucca Mountain Site Characterization Project) 2001. Sample Management and Drilling Department Geologic Log, Borehole Name: ECRB-THERMK-009. [Las Vegas, Nevada: Yucca Mountain Site Characterization Office]. ACC: MOL.20010913.0349; MOL.20010207.0160.

172132 YMP (Yucca Mountain Site Characterization Project) 2001. Sample Management and Drilling Department Geologic Log, Borehole Name: ECRB-THERMK-010. [Las Vegas, Nevada: Yucca Mountain Site Characterization Office]. ACC: MOL.20010913.0354; MOL.20010207.0160.

172136 YMP (Yucca Mountain Site Characterization Project) 2001. Sample Management and Drilling Department Geologic Log, Borehole Name: ECRB-THERMK-011. [Las Vegas, Nevada: Yucca Mountain Site Characterization Office]. ACC: MOL.20010913.0359.

172138 YMP (Yucca Mountain Site Characterization Project) 2003. Sample Management Facility Geologic Log, Borehole Name: ESF-THERMK-012. [Las Vegas, Nevada: Yucca Mountain Site Characterization Office]. ACC: MOL.20030709.0313; MOL.20011015.0004.

172141 YMP (Yucca Mountain Site Characterization Project) 2003. Sample Management Facility Geologic Log, Borehole Name: ESF-THERMK-013. [Las Vegas, Nevada: Yucca Mountain Site Characterization Office]. ACC: MOL.20030709.0317; MOL.20011015.0004; MOL.20011206.0001.

172143 YMP (Yucca Mountain Site Characterization Project) 2003. Sample Management Facility Geologic Log, Borehole Name: ESF-THERMK-014. [Las Vegas, Nevada: Yucca Mountain Site Characterization Office]. ACC: MOL.20030709.0321; MOL.20011015.0004; MOL.20011206.0001.

172145 YMP (Yucca Mountain Site Characterization Project) 2003. Sample Management Facility Geologic Log, Borehole Name: ESF-THERMK-015. [Las Vegas, Nevada: Yucca Mountain Site Characterization Office]. ACC: MOL.20030709.0325; MOL.20011015.0004; MOL.20011206.0001.

172146 YMP (Yucca Mountain Site Characterization Project) 2003. Sample Management Facility Geologic Log, Borehole Name: ESF-THERMK-016. [Las Vegas, Nevada: Yucca Mountain Site Characterization Office]. ACC: MOL.20030709.0329; MOL.20011015.0004; MOL.20011206.0001.

172149 YMP (Yucca Mountain Site Characterization Project) 2003. Sample Management Facility Geologic Log, Borehole Name: ESF-THERMK-017. [Las Vegas, Nevada: Yucca Mountain Site Characterization Office]. ACC: MOL.20030709.0334; MOL.20011015.0004; MOL.20011206.0001. 
172150 YMP (Yucca Mountain Site Characterization Project) 2003. Sample Management Facility Geologic Log, Borehole Name: ESF-THERMK-018. [Las Vegas, Nevada: Yucca Mountain Site Characterization Office]. ACC: MOL.20030709.0338; MOL.20011015.0004; MOL.20011206.0001.

172151 YMP (Yucca Mountain Site Characterization Project) 2003. Sample Management Facility Geologic Log, Borehole Name: ESF-THERMK-019. [Las Vegas, Nevada: Yucca Mountain Site Characterization Office]. ACC: MOL.20030709.0343; MOL.20011015.0004; MOL.20011206.0001.

172152 YMP (Yucca Mountain Site Characterization Project) 2002. Sample Management and Drilling Department Geologic Log, Borehole Name: ESF-GTEC-CS6500-01. [Las Vegas, Nevada: Yucca Mountain Site Characterization Office]. ACC: MOL.20020703.0126; MOL.20011206.0001.

172154 YMP (Yucca Mountain Site Characterization Project) 2002. Sample Management and Drilling Department Geologic Log, Borehole Name: ESF-GTEC-CS6500-01A. [Las Vegas, Nevada: Yucca Mountain Site Characterization Office]. ACC: MOL.20020703.0130; MOL.20011206.0001.

172155 YMP (Yucca Mountain Site Characterization Project) 2002. Sample Management and Drilling Department Geologic Log, Borehole Name: ESF-GTEC-CS 6500-02. [Las Vegas, Nevada: Yucca Mountain Site Characterization Office]. ACC: MOL.20020703.0134; MOL.20011206.0001.

172156 YMP (Yucca Mountain Site Characterization Project) 2002. Sample Management and Drilling Department Geologic Log, Borehole Name: ESF-GTEC-CS6500-04. [Las Vegas, Nevada: Yucca Mountain Site Characterization Office]. ACC: MOL.20020703.0142; MOL.20011206.0001.

172157 YMP (Yucca Mountain Site Characterization Project) 2002. Sample Management and Drilling Department Geologic Log, Borehole Name: ESF-GTEC-CS6500-04A. [Las Vegas, Nevada: Yucca Mountain Site Characterization Office].

ACC: MOL.20020703.0146; MOL.20011206.0001.

172158 YMP (Yucca Mountain Site Characterization Project) 2002. Sample Management and Drilling Department Geologic Log, Borehole Name: ESF-GTEC-CS6500-05A. [Las Vegas, Nevada: Yucca Mountain Site Characterization Office]. ACC: MOL.20020703.0154; MOL.20011206.0001.

172180 YMP (Yucca Mountain Site Characterization Project) 2002. Sample Management and Drilling Department Geologic Log, Borehole Name: ESF-GTEC-CS6500-05B. [Las Vegas, Nevada: Yucca Mountain Site Characterization Office]. ACC: MOL.20020703.0158; MOL.20011206.0001. 
172181 YMP (Yucca Mountain Site Characterization Project) 2002. Sample Management and Drilling Department Geologic Log, Borehole Name: ESF-GTEC-CS6500-06. [Las Vegas, Nevada: Yucca Mountain Site Characterization Office]. ACC: MOL.20020703.0162; MOL.20011206.0001.

172183 YMP (Yucca Mountain Site Characterization Project) 2002. Sample Management and Drilling Department Geologic Log, Borehole Name: ECRB-GTEC-CS1600-08. [Las Vegas, Nevada: Yucca Mountain Site Characterization Office].

ACC: MOL.20020710.0211; MOL.20011206.0001.

172184 YMP (Yucca Mountain Site Characterization Project) 2002. Sample Management Facility Geologic Log, Borehole Name: ECRB-GTEC-CS1922-01. [Las Vegas, Nevada: Yucca Mountain Site Characterization Office].

ACC: MOL.20021104.0116; MOL.20011206.0001.

172185 YMP (Yucca Mountain Site Characterization Project) 2002. Sample Management Facility Geologic Log, Borehole Name: ECRB-GTEC-CS1928-01. [Las Vegas, Nevada: Yucca Mountain Site Characterization Office].

ACC: MOL.20021104.0132; MOL.20011206.0001.

172186 YMP (Yucca Mountain Site Characterization Project) 2002. Sample Management Facility Geologic Log, Borehole Name: ECRB-GTEC-CS1928-03. [Las Vegas, Nevada: Yucca Mountain Site Characterization Office]. ACC: MOL.20021104.0140; MOL.20011206.0001.

172187 YMP (Yucca Mountain Site Characterization Project) 2002. Sample Management Facility Geologic Log, Borehole Name: ECRB-GTEC-CS1995-01. [Las Vegas, Nevada: Yucca Mountain Site Characterization Office].

ACC: MOL.20021104.0145; MOL.20011206.0001.

\subsection{CODES, STANDARDS, REGULATIONS, AND PROCEDURES}

15660510 CFR 63. Energy: Disposal of High-Level Radioactive Wastes in a Geologic Repository at Yucca Mountain, Nevada. Readily available.

151802 YMP-USGS-GP-32, R2. Underground Geologic Mapping. [Denver, Colorado]: U.S. Geological Survey. ACC: MOL.19980930.0086.

\subsection{SOURCE DATA, LISTED BY DATA TRACKING NUMBER}

108396 GS990408314224.001. Detailed Line Survey Data for Stations 00+00.89 to 14+95.18, ECRB Cross Drift. Submittal date: 09/09/1999.

105625 GS990408314224.002. Detailed Line Survey Data for Stations $15+00.85$ to 26+63.85, ECRB Cross Drift. Submittal date: 09/09/1999.

161910 GS021008314224.002. Lithophysal Data Study from the Tptpll in the ECRB from Stations $14+44$ to $23+26$. Submittal date: $01 / 28 / 2003$. 
169591 GS040108314224.001. Detailed Line Survey Data for Horizontal and Vertical Traverses, ECRB. Submittal date: 02/27/2004.

170312 GS040408314224.003. ESF, ECRB Cross Drift Small Scale Fracture Study: Detailed Line Survey Data for Horizontal and Vertical Traverses 2003. Submittal date: 05/19/2004.

171964 GS040808314224.005. Fractures in Slabs of Core in Crystallized Topopah Spring Tuff. Submittal date: 09/24/2004.

153777 MO0012MWDGFM02.002. Geologic Framework Model (GFM2000). Submittal date: $12 / 18 / 2000$.

162713 MO0210PGVPB107.000. Design Peak Ground Velocity for the Repository Level (Point B) at 10-7 Annual Exceedance Probability. Submittal date: 10/17/2002.

162712 MO0303DPGVB106.002. Design Peak Ground Velocity for the Repository Level (Point B) at 10-6 Annual Exceedance Probability. Submittal date: 03/10/2003.

169099 MO0401SEPPGVRL.022. Peak Ground Velocity for the Repository Level (Point B) at 10-5 Annual Exceedance Frequency. Submittal date: 01/26/2004.

172231 MO0402GSC04031.000. As-built ECRB Locations for the Tptpll Large Lithophysae Inventory, Tptpul-mn Lithophysal Maps and Traverses, and Small Scale Fracture Study. Submittal date: 02/25/2004.

170437 MO0404PGVRL104.000. Peak Ground Velocity for the Repository Level (Point B) at 10-4 Annual Exceedance Frequency. Submittal date: 04/23/2004.

172216 MO0409MWDGMMIO.000. Ground Motion Model Input and Output Files. Submittal date: 09/30/2004.

161871 SN0208L0207502.001. Mechanical Properties of Lithophysal Tuff, Batch \#1 (Test Dates: July 31, 2002 through August 16, 2002). Submittal date: 08/20/2002.

161872 SN0211L0207502.002. Mechanical Properties of Lithophysal Tuff, Batch \#2 (Test Dates: October 22, 2002 through October 25, 2002). Submittal date: 11/13/2002.

163373 SN0305L0207502.005. Material Abundances from Point Counts on Laboratory Mechanical Property Specimens for Batch \#1 and Batch \#2. Submittal date: 05/20/2003.

\subsection{SOFTWARE CODES}

161949 BSC (Bechtel SAIC Company) 2002. Software Code: UDEC. V3.1. PC WINDOWS 2000/NT 4.0. 10173-3.1-00. 
169930 BSC (Bechtel SAIC Company) 2004. Software Code: PFC2D. V 2.0. PC, Windows 2000. 10828-2.0-01.

167994 Dynamic Graphics 2000. Software Code: EARTHVISION. V5.1. SGI/IRIX 6.5. 10174-5.1-00.

163313 Pacific Engineering and Analysis. 2002. Software Code: NORM. V1.01. PC, DOS 6.22. 10386-1.01-00.

170313 Pacific Engineering and Analysis. 2004. Software Code: LOGNORM. V 1.01. PC, DOS 6.22-QEMM 9.0. STN: 10384-1.01-00.

\subsection{OUTPUT DATA, LISTED BY DATA TRACKING NUMBER}

172682 MO0501BPVELEMP.001. Bounded Horizontal Peak Ground Velocity Hazard at the Repository Waste Emplacement Level. Submittal date: 01/11/2005. 


\section{INTENTIONALLY LEFT BLANK}




\section{APPENDIX A \\ GEOLOGIC LIMITS ON THE FORMATION OF FRACTURES IN THE LITHOPHYSAL AND NONLITHOPHYSAL ROCKS OF THE CRYSTAL-POOR MEMBER OF THE TOPOPAH SPRING TUFF}




\section{A1. CONDITION OF TOPOPAH SPRING TUFF WITH RESPECT TO DAMAGE FROM EXTREME SEISMIC GROUND MOTION}

The condition of features such as lithophysae and fractures in the rocks of the Topopah Spring Tuff is a sum of the processes that have affected them since the time of formation, so if the features that result from specific processes can be identified, then the amount to which the features are developed can provide limits as to how active was a particular process. This linkage of understanding the formation of features to the timing and activity of respective processes can be used to develop a petrogenetic history of the rock. This petrogenetic history can, in turn, be used to evaluate and possibly set limits on the amount of damage done to the rock resulting from other specific processes such as seismic activity and specifically peak amounts of ground motion. The relationship of the observed physical condition of the rocks (for example, how fractured they are and when the fracturing occurred) to quantitative estimates of post-depositional strain relies on (1) the descriptive documentation of features in the rocks and (2) comparing these features with those predicted from rock mechanics measurements and modeling of stress and strain in the rocks. This section of Appendix A presents descriptions of the densely welded and crystallized rocks in the Topopah Spring Tuff, with an emphasis on the lithophysal and nonlithophysal rocks of the proposed repository host horizon (RHH) as defined by CRWMS M\&O (1997 [DIRS 100223], Section 7.3). The comparison of these features with the types of damage predicted by rock mechanics models and laboratory test results is presented in section 6.4 and Appendix B of this document.

\section{A1.1 DEVELOPMENT OF LITHOSTRATIGRAPHIC FEATURES}

The Topopah Spring Tuff is a large-volume (greater than 1,000 $\mathrm{km}^{3}$ ) pyroclastic flow deposit (also referred to as an ignimbrite) that was deposited 12.8 million years ago (Sawyer et al. 1994 [DIRS 100075], Table 1), and as a result of depositional, welding, and crystallization processes, the formation is divided into members, zones, subzones, and intervals that form a stratiform deposit (Figure A1-1; Buesch et al. 1996 [DIRS 100106], p. 3). Depositional features include the distributions of lithic and pumice clasts, and the types and abundances of crystal fragments that are consistent with the compositional zonation from high-silica rhyolite in the lower part to the trachyte or quartz latite in the upper part of the ignimbrite (trachyte is used by Sawyer et al. (1994 [DIRS 100075], p. 1313) and quartz latite is used by Peterman and Cloke (2002 [DIRS 162576], p. 685) and the difference is based on the type of classification system used). In Figure A1-1, the depositional features form the crystal-poor and crystal-rich members (crystal in this context refers to the amounts of crystal fragments). The zones of welding are based on (1) vitroclastic textures such as shapes and aspect ratios (where the aspect ratio is the long axis divided by the short axis) of glass shards and pumice clasts and (2) measured properties on core such as rock density and porosity. The Topopah Spring Tuff at Yucca Mountain is mostly (greater than 90 percent of the thickness) densely welded tuff (Buesch et al. 1999 [DIRS 165483], p. A-476) with progressively less welded (moderately to partially welded and nonwelded) rocks near the top and bottom of the formation (Buesch et al. 1996 [DIRS 100106], p. 10). There are two sources of the interstitial vapor (that which is between the particles) at the time of deposition of an ignimbrite (Buesch et al. 1996 [DIRS 100106], p.12). The main source is from the vapor that exsolved from the magma during ascent in the conduit, in the eruption column, or during transportation of and deposition from the pyroclastic flow deposit. The other source is the inclusion of atmospheric air in the eruption column and during transportation of the 
pyroclastic flow. During welding, the redistribution of the vapor phase initially flowed through the compacting matrix, was later focused along fractures, and locally this redistribution resulted in development of lithophysal cavities (Buesch and Spengler 1998 [DIRS 101433], p.21).

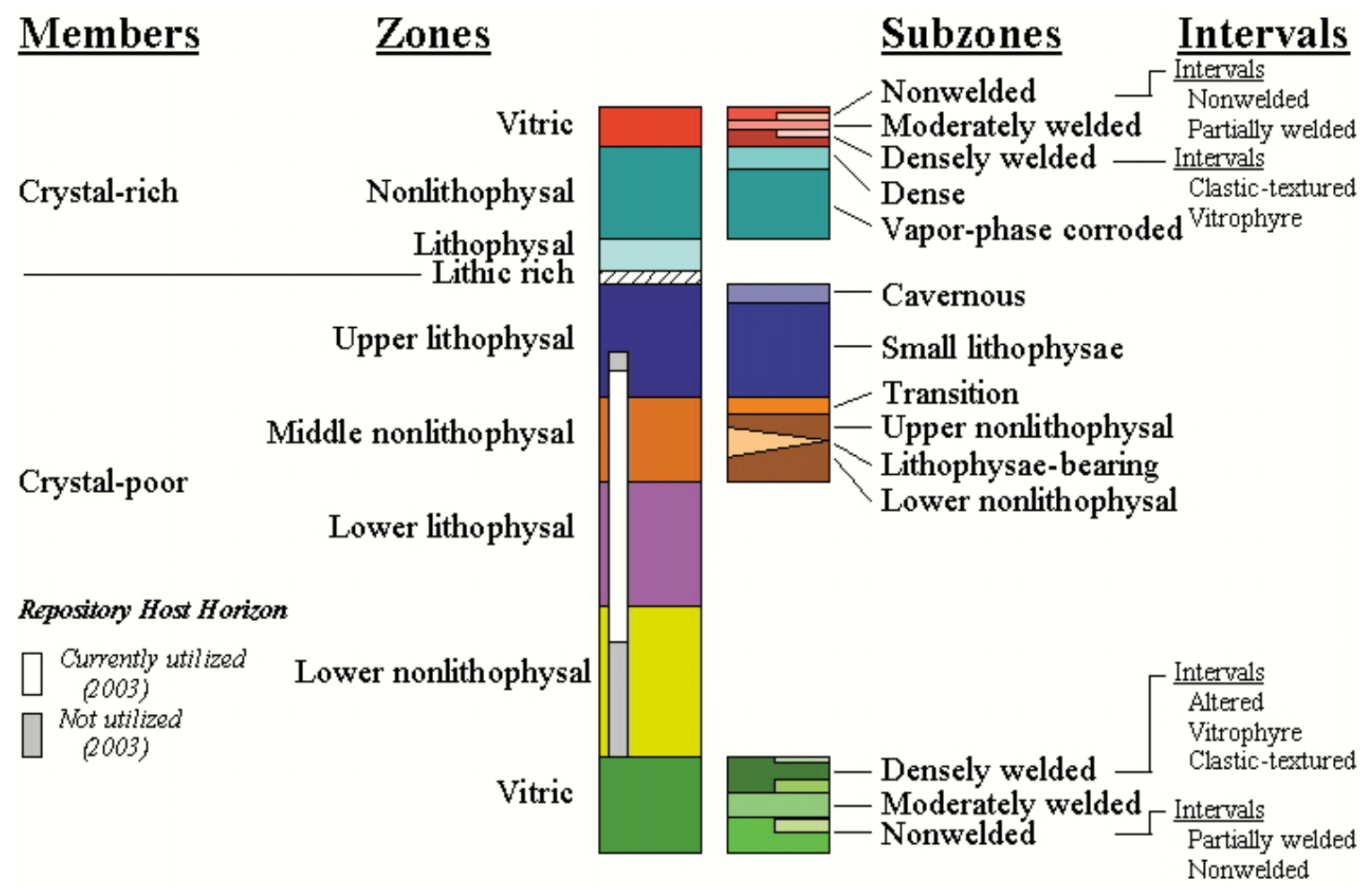

Source: Case and Buesch (2004 [DIRS 172099], p. 6).

Figure A1-1. Lithostratigraphic Units (Members, Zones, Subzones, and Intervals) of the Topopah Spring Tuff at Yucca Mountain, Nevada, Showing the Equivalent Units of the Proposed Repository Host Horizon

Crystallization of the Topopah Spring Tuff resulted from crystallization in the presence of vapor, in the absence of vapor, and from the vapor. During crystallization, the vapor-phase consists of the original interstitial vapor with progressive addition of vapor that exsolved from the glass particles as it crystallized (Smith 1980 [DIRS 106837] [reprint of U.S. Geological Survey Professional Paper 354-F (1960)], p. 153-156; Ross and Smith 1961 [DIRS 106714], p. 40; and Buesch et al. 1996 [DIRS 100106], p.12). This second source is from the magmatic water that did not exsolve from the magma (and glass) during the eruption and is the main source of volatiles described in some ignimbrites by Ross and Smith (1961 [DIRS 106714], p. 38). As the vapor contacted the glass, the two main processes were corrosion of the glass and crystallization of the glass in the presence of vapor. Corrosion can result (at least locally) in the almost complete preservation of the morphologic characteristics of the glass shards and pumice clasts by the secondary pore structure. Crystallization of glass in the presence of (but not from) the vapor phase results in the light gray to pinkish gray rims on lithophysae and fractures (Figure A1-2). In the rims, the grain sizes are typically larger than in the light reddish brown or reddish brown matrix-groundmass that shows no evidence of contact with the vapor phase. Rims typically are composed of elongate, needle-like, radiating, feldspar grains (many of which form spherulitic 
textures) that appear to have nucleated on the cavity walls or on the crystallization front as it advanced away from the wall. Locally the feldspar grains in the spherulites are intergrown with one or more silica polymorphs (quartz, cristobalite, or tridymite). In some rims, tridymite grains appear to have grown around feldspar grains, and this relation is consistent with the in-filling of porous spherulites with vapor-phase mineralization. Crystallization of glass in the presence of vapor was probably facilitated by lowered viscosity of the glass resulting from re-absorption of water vapor (and other volatiles) from the vapor. Additionally, as the rims formed by crystallizing away from the cavity walls, the high porosity $\left(0.30 \pm 0.10 \mathrm{~cm}^{3} / \mathrm{cm}^{3}\right.$, Otto and Buesch 2003 [DIRS 170727], pp. 434-435) of the spherulitic rims enabled deeper penetration of the vapor into the host glass thereby propagating the crystallization of the rims. Some vapor gained access to the areas around the rims, possibly after formation of the rims, and resulted in crystallization of the grayish red purple borders and reddish gray matrix-groundmass (Figure A1-2, see figure for additional colors). In the areas farthest from lithophysae, the matrix-groundmass is typically reddish brown and is interpreted as crystallizing in the absence of vapor. The last stage of crystallization is mineralization from the cooling vapor, although exactly when in the cooling history of the ignimbrite this occurs is a result of the temperature, pressure, and composition of the vapor phase. The textural and inferred timing relations associated with lithophysae, including the sequence of localized concentration of the vapor phase that is surrounded by a rim, a border, reddish gray matrix-groundmass, and reddish brown matrix-groundmass farthest from the main concentration of vapor, and the vapor-phase mineral coatings on cavity walls are important constraints in the formation of lithophysae, but also are associated with many fractures (Figure A1-2).

Fractures in the densely welded and crystallized ignimbrites of the Topopah Spring and Tiva Canyon Tuff are identified on the basis of crystallization and mineralization features as "cooling" fractures, which includes Type 1 and Type 2 fractures (Buesch et al. 1999 [DIRS 165483], p. A-476) and "post-cooling” fractures, herein referred to as Type 3 fractures. Fractures with rims are interpreted as forming very early in the cooling history of the deposit during which the vapor in the fractures interacted with the glass along the walls of the fracture, and these fractures are indicative of Type 1 fractures (Buesch and Spengler 1998 [DIRS 101433], p. 21; Buesch et al. 1999 [DIRS 165483], p. A-476). Tubular structures formed along some Type 1 fractures. Tubular structures consist of "tubes" that are typically 2-to-8-mm across (perpendicular to the plane of the host fracture), with a range of 0.5 to $21 \mathrm{~mm}$, occur across several square meters of the fracture surface (in the plane of the host fracture), locally form intersecting patterns, and they have rims and vapor-phase mineral linings (Figure A1-3; Barton et al. 1993 [DIRS 101425], pp. 35 and 37). Early formation of tubular structures during the time when the deposit was glass also is indicated by the viscous "droop" of a septum between two tubular structures in a block from the Tiva Canyon Tuff (Figure A1-3). This block is not in place, but it has three planar fractures in which two are parallel and the central fracture is at $120^{\circ}$ to the other two, and all three fractures have well-developed tubular structures. On the central fracture, a small part of a septum between two "tubes" has a planar outer surface, which is the same as the main fracture face, but it has "drooped" as much as $1 \mathrm{~cm}$ into what must have been a fracture with at least a 1-cm aperture. This "droop" of the wall indicates the material inside the wall must have been viscous glass. In contrast, fractures that formed late in the cooling history of the deposit do not have rims, formed when the rock was mostly (if not entirely) crystallized, and these fractures are indicative of Type 2 fractures (Buesch and Spengler 1998 [DIRS 101433], p.21; Buesch et al. 1999 [DIRS 165483], p. A-476). 
Vapor-phase mineral coatings typically are on cooling fractures, but they are not necessarily on all cooling fractures because the fracture could have formed after most of the vapor phase had been removed from the area, or the three-dimensional network of fractures simply did not penetrate a region of abundant vapor phase material (Buesch and Spengler 1998 [DIRS 101433], p. 21). Although not previously described, fractures that formed after the rock had cooled to the ambient temperatures of a rock at the paleogeomorphic surface do not have vapor-phase mineral coatings, and these fractures are referred to as Type 3 fractures. So, vapor-phase mineral coatings can form on Type 1 and Type 2 fractures, but they do not form on Type 3 fractures. However, not all Type 2 fractures have vapor-phase mineral coatings, so the distinction of Type 2 and Type 3 fractures can be problematic, and other types of fracture data such as orientation, roughness, offset, trace length, and termination relations might be helpful in distinguishing the Type 2 and Type 3 fractures. One important corollary to this sometime difficult distinction of Type 2 and Type 3 fractures is that some fractures with no distinguishing features (which might be classified as Type 3) can be late-stage Type 2 fractures. In this paper, terms such as "cooling” refer to Type 1 and Type 2 fractures because the lithostratigraphic features such as rims or tubular structures and/or material that lines or fills the fracture are consistent with a fracture being formed during the cooling history of the deposit. The term "indeterminate" is used for fractures that do not have distinguishing features or fracture coating or fill material, so these fractures can be Type 3 or late-stage Type 2 fractures.

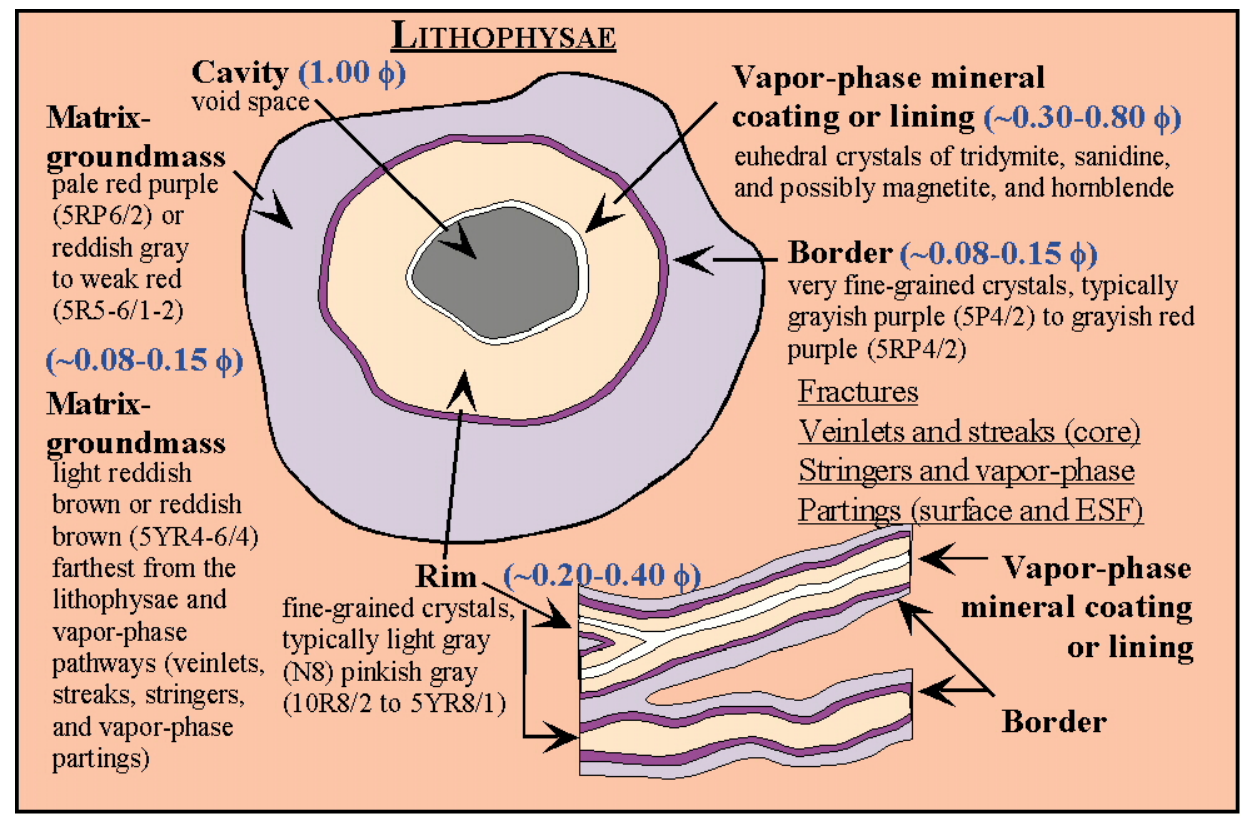

Source: Case and Buesch (2004 [DIRS 172099], p. 5).

NOTE: $\quad$ Porosity values for the matrix-groundmass are by Otto and Buesch (2003 [DIRS 170727], p. 435) approximated from Flint (1998 [DIRS 100033], Table 7) and Buesch (2003 [DIRS 162271], p. 2). The values for rims are from Otto and Buesch (2003 [DIRS 170727], p. 435), and the values for borders and vapor phase mineral coatings are estimates by Buesch (2003 [DIRS 162271], p. 2). Nomenclature and symbols of colors (e.g., pale red purple is 5RP6/2) are based on comparisons with the Munsell Soil Color Chart (Munsell Color Company 1994 [DIRS 106399]).

Figure A1-2. Lithostratigraphic Features and Porosity of Lithophysae and Fractures in Densely Welded and Crystallized Tuff 


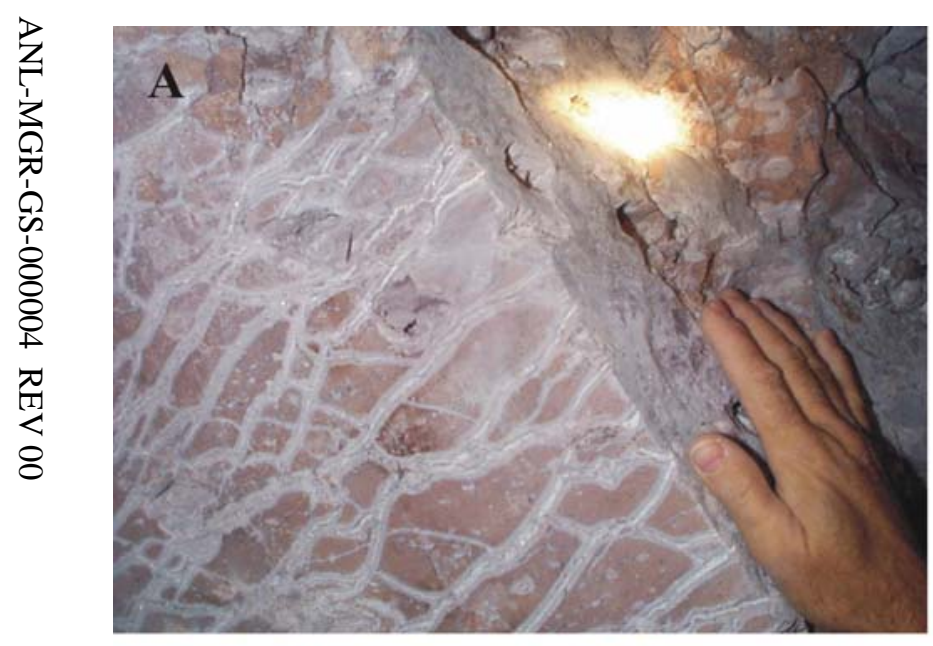

品
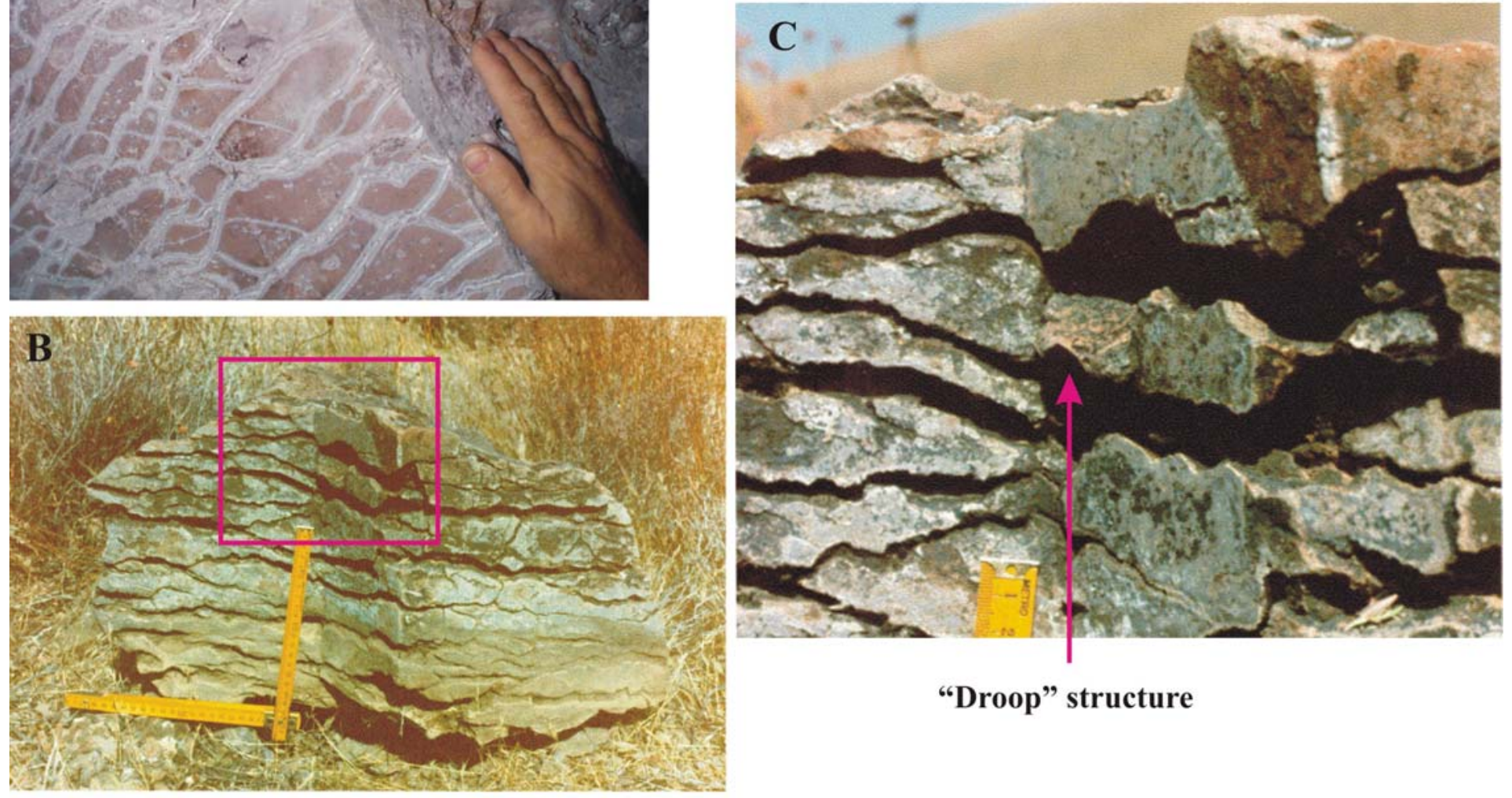

Source: This document.

NOTES: A. Tubular structures on one of two fractures in the upper lithophysal zone (Tptpul) in Alcove 8.

B. Block of Tiva Canyon Tuff with three cooling joints, each at $120^{\circ}$ to the other and each with tubular structures.

Each folding piece of the ruler is $23 \mathrm{~cm}$ long, and the magenta rectangle is the area in photograph $\mathrm{C}$.

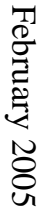

Figure A1-3. Tubular Structures in the Topopah Spring and Tiva Canyon Tuffs 
Lithostratigraphic features also are understood in the context of primary, secondary, and tertiary processes (Buesch and Spengler, 1998 [DIRS 101433], pp. 20-22; [DIRS 104612], pp. 248-249). Primary processes are processes that occur prior to deposition of the material and include the mechanics of eruption and the transportation and deposition of materials (and even processes in the magma chamber prior to eruption). Secondary processes are processes that occur from the moment of deposition to when the deposit attains ambient conditions at the paleogeomorphic surface and include compaction, welding, formation of lithophysae, crystallization, vapor-phase activity including corrosion and mineralization, fumarolic alteration, and development of cooling fractures. Also included as a secondary process is the moderate-temperature alteration of glass described by Levy and O'Neil (1989 [DIRS 116960], p. 325). Tertiary processes are processes that occur after the deposit has attained ambient conditions at the paleogeomorphic surface (even millions of years or more) and include argillic and zeolitic alteration and fracturing resulting from structural deformation (faulting, flexing, and tilting) or tectonic disruption.

In the context of the questions "how did the rocks form and how might have the rocks been affected by post-depositional seismic events?", the important timing is the change from secondary to tertiary processes. There are no historic large-volume eruptions with which to compare the Topopah Spring Tuff, so the amount of time needed for a thick, large-volume ignimbrite to cool is poorly constrained. However, it might take several tens of years to perhaps a few hundred years after deposition, but about 100 years after deposition is probably a reasonable period of time. This estimate is based on (1) petrogenetic relations and processes such as those described in this report, (2) extrapolations of numerical modeling of welding in ignimbrites (Riehle et al. 1995 [DIRS 106671] , pp. 319, 325, and 326), and (3) an analogy with the Valley of Ten Thousand Smokes in Alaska. The 1912 eruption of the Alaskan Novarupta volcano resulted in pyroclastic flow deposits that might be as great as 200-m thick and formed the Valley of Ten Thousand Smokes (Brantley, 1994 [DIRS 170690], p. 7); however, the "ten thousand smokes” in the ignimbrite sheet mostly died out by 1930 (Wood and Kienle, 1990 [DIRS 125616], p. 70).

\section{A1.1.1 Characteristics and Timing of Fracture Development in Crystallized Rocks}

Two studies were conducted that help quantify the (1) timing of when various features formed in the densely welded and crystallized rock of the Topopah Spring Tuff, (2) fracture characteristics of the lithophysal and nonlithophysal zones of the Topopah Spring Tuff, and (3) timing of fracture development. These studies focused on the mineral and textural relations that provide constraints for evaluating the development of fracture, and the geometric relations of fractures such as orientation, planarity, and terminations have not been evaluated as part of this study. The "Fractures in slabs" study is a detailed examination of a wide variety of lithostratigraphic features associated with fractures that have been mapped on slabs of core. The map scale is such that measurements can be made to $0.1 \mathrm{~mm}$ or less. This study evokes the most recent understanding of features associated with crystallization of the tuff. The second study re-examines the Detailed Line Survey (DLS) data on fractures in the Enhanced Characterization of the Repository Block (ECRB) Cross-Drift. The DLS data examined in this study was collected in two stages. The first stage was done as the tunnel was being cut and consists of fractures that intersected the DLS transect and have a minimum trace length of $1 \mathrm{~m}$, and these data are for the total length of the ECRB Cross-Drift. The second stage was the Small-Scale Fracture (SSF) Study in which fractures with no minimum trace length were documented along 
6-m long transects and each location also had three 2-m long vertical transects. For both the total ECRB Cross-Drift and SSF data, the minimum recorded measurements for separation across shears and faults is $1 \mathrm{~cm}$, and the minimum recorded measurements of fracture aperture and widths of mineral coatings on the fracture wall or material filling a fracture is $0.5 \mathrm{~mm}$, although terms such as "trace," "spotty," and "patchy" also are used. The main emphasis of the total ECRB Cross-Drift and SSF DLS studies were to document the geometric relations of fractures such as location, orientation (strike and dip), planarity and roughness, and truncation relations. Identification and measurement of mineral coatings and fracture material fill was routinely done; however, this was of secondary importance during data collection and this gives rise to some small, but not quantifiable, amount of uncertainty to the fracture fill data. However in this study, the values reported by the geologists are assumed to be correct.

Data from the DLS re-examination study that support this document are provided in two Microsoft ${ }^{\circledR}$ Excel workbooks (Appendix D). These workbooks are PGV ECRB DLS Frac-Fill.xls and PGV SSF DLS Frac-Fill.xls. These workbooks contain additional data and various graphical displays that are not presented in this document.

\section{A1.1.1.1 Fractures in Slabs of Core}

Samples for mapping of fractures on slabs of core were collected from two surface-based boreholes (including USW NRG-6 and USW UZ-14) and 32 tunnel-based boreholes (included Thermal-K and Geotechnical boreholes) located in the Exploratory Studies Facility (ESF) Main-Drift and the ECRB Cross-Drift (Figure A1-4; Table A1-1). These boreholes were used to collect samples that represent different lithostratigraphic zones, spatial variations within the zones, samples from different sizes of core, and samples that can be compared to those collected near the tunnel walls (i.e., to evaluate any induced fractures from the tunnel borehole machine). Samples are from ten lithostratigraphic zones and subzones in the Topopah Spring Tuff (Table A1-2). Rocks from the upper lithophysal and lower lithophysal zones tend to have more samples than other zones because (1) these zones (or at least parts of them) comprise the Repository Host Horizons, and (2) the lithophysal zones have some of the larger textural and structural variations compared to nonlithophysal zones. 
Table A1-1. Boreholes from which Core Samples were Collected

\begin{tabular}{|c|c|c|c|c|c|}
\hline Borehole & $\begin{array}{c}\text { Borehole-Sample } \\
\text { Short Identifier }\end{array}$ & $\begin{array}{l}\text { Station or } \\
\text { Northing }^{1}\end{array}$ & Easting & $\begin{array}{l}\text { Diameter of } \\
\text { Core }^{2}(\mathrm{~mm})\end{array}$ & $\begin{array}{c}\text { Number } \\
\text { of } \\
\text { Samples }^{3}\end{array}$ \\
\hline USW NRG-6 & NRG6 & 766726.500 & 564187.000 & $61 \mathrm{~mm}$ & 5 \\
\hline USW UZ-14 & UZ14 & 771309.812 & 560141.562 & $61 \mathrm{~mm}$ & 39 \\
\hline ECRB ThermK-001 & ThermK & 1562.2 & - & $45 \mathrm{~mm}$ & 4 \\
\hline ECRB ThermK-002 & ThermK & 1569.9 & - & $45 \mathrm{~mm}$ & 4 \\
\hline ECRB ThermK-003 & ThermK & 1527.98 & - & $45 \mathrm{~mm}$ & 2 \\
\hline ECRB ThermK-004 & ThermK & 1528.70 & - & $45 \mathrm{~mm}$ & 2 \\
\hline ECRB ThermK-005 & ThermK & 1529.46 & - & $45 \mathrm{~mm}$ & 4 \\
\hline ECRB ThermK-006 & ThermK & 1539.84 & - & $45 \mathrm{~mm}$ & 2 \\
\hline ECRB ThermK-007 & ThermK & 1541.24 & - & $45 \mathrm{~mm}$ & 2 \\
\hline ECRB ThermK-008 & ThermK & 1542.56 & - & $45 \mathrm{~mm}$ & 2 \\
\hline ECRB ThermK-009 & ThermK & 1737.7 & - & $45 \mathrm{~mm}$ & 2 \\
\hline ECRB ThermK-010 & ThermK & 1745.4 & - & $45 \mathrm{~mm}$ & 2 \\
\hline ECRB ThermK-011 & ThermK & 1745.5 & - & $45 \mathrm{~mm}$ & 2 \\
\hline ESF ThermK-012 & ThermK & 5789.9 & - & $45 \mathrm{~mm}$ & 2 \\
\hline ESF ThermK-013 & ThermK & 5782.1 & - & $45 \mathrm{~mm}$ & 2 \\
\hline ESF ThermK-014 & ThermK & 5781.9 & - & $45 \mathrm{~mm}$ & 2 \\
\hline ESF ThermK-015 & ThermK & 5782.8 & - & $45 \mathrm{~mm}$ & 2 \\
\hline ESF ThermK-016 & ThermK & 6336.9 & - & $45 \mathrm{~mm}$ & 2 \\
\hline ESF ThermK-017 & ThermK & 6329.2 & - & $45 \mathrm{~mm}$ & 2 \\
\hline ESF ThermK-018 & ThermK & 6330.1 & - & $45 \mathrm{~mm}$ & 2 \\
\hline ESF ThermK-019 & ThermK & 6330.5 & - & $45 \mathrm{~mm}$ & 2 \\
\hline ESF-GTEC-CS6500-01 & GTEC & 6360.0 & - & $289 \mathrm{~mm}$ & 1 \\
\hline ESF-GTEC-CS6500-01A & GTEC & 6360.0 & - & $289 \mathrm{~mm}$ & 3 \\
\hline ESF-GTEC-CS6500-02 & GTEC & 6368.8 & - & $289 \mathrm{~mm}$ & 2 \\
\hline ESF-GTEC-CS6500-04 & GTEC & 6391.4 & - & $289 \mathrm{~mm}$ & 1 \\
\hline ESF-GTEC-CS6500-04A & GTEC & 6396.0 & - & $289 \mathrm{~mm}$ & 4 \\
\hline ESF-GTEC-CS6500-05A & GTEC & 6386.0 & - & $289 \mathrm{~mm}$ & 1 \\
\hline ESF-GTEC-CS6500-05B & GTEC & 6384.0 & - & $289 \mathrm{~mm}$ & 1 \\
\hline ESF-GTEC-CS6500-06 & GTEC & 6369.0 & - & $289 \mathrm{~mm}$ & 2 \\
\hline ECRB-GTEC-CS1600-08 & GTEC & 1634.0 & - & $289 \mathrm{~mm}$ & 4 \\
\hline ECRB-GTEC-CS1922-01 & GTEC & 1922.2 & - & $289 \mathrm{~mm}$ & 2 \\
\hline ECRB-GTEC-CS1928-01 & GTEC & 1928.47 & - & $289 \mathrm{~mm}$ & 9 \\
\hline ECRB-GTEC-CS1928-03 & GTEC & 1928.7 & - & $289 \mathrm{~mm}$ & 1 \\
\hline ECRB-GTEC-CS1995-01 & GTEC & 1995.9 & - & $289 \mathrm{~mm}$ & 1 \\
\hline
\end{tabular}

${ }^{1}$ Coordinates (in feet) for USW-NRG-6 and USW UZ-14 are from the TDMS GI database, station locations (in meters) of the ThermK boreholes are from SN-SNL-SCI-024-V1 Howard (2002 [DIRS 159152], pp. 136, 145), and SN-SNL-SCI-024-V2 (Sanchez and Howard 2004 [DIRS 172401], p. 121), and station locations (in meters) of the GTEC boreholes are from the Sample Management and Drilling Department "Geologic Logs" (See Section A2 for specific citations). Note that USW NRG-6 and USW UZ-14 are Surface-Based Boreholes, and "ThermK" and "GETC" are Tunnel-Based Boreholes.

2 The diameters for cores and the stations in the tunnels (in meters) for the "ThermK" and "GETC" boreholes are from the Sample

Management and Drilling Department "Geologic Logs" (See Section A2 for specific citations).

3 Detailed sample listings in DTN: GS040808314224.005 [DIRS 171964]. 


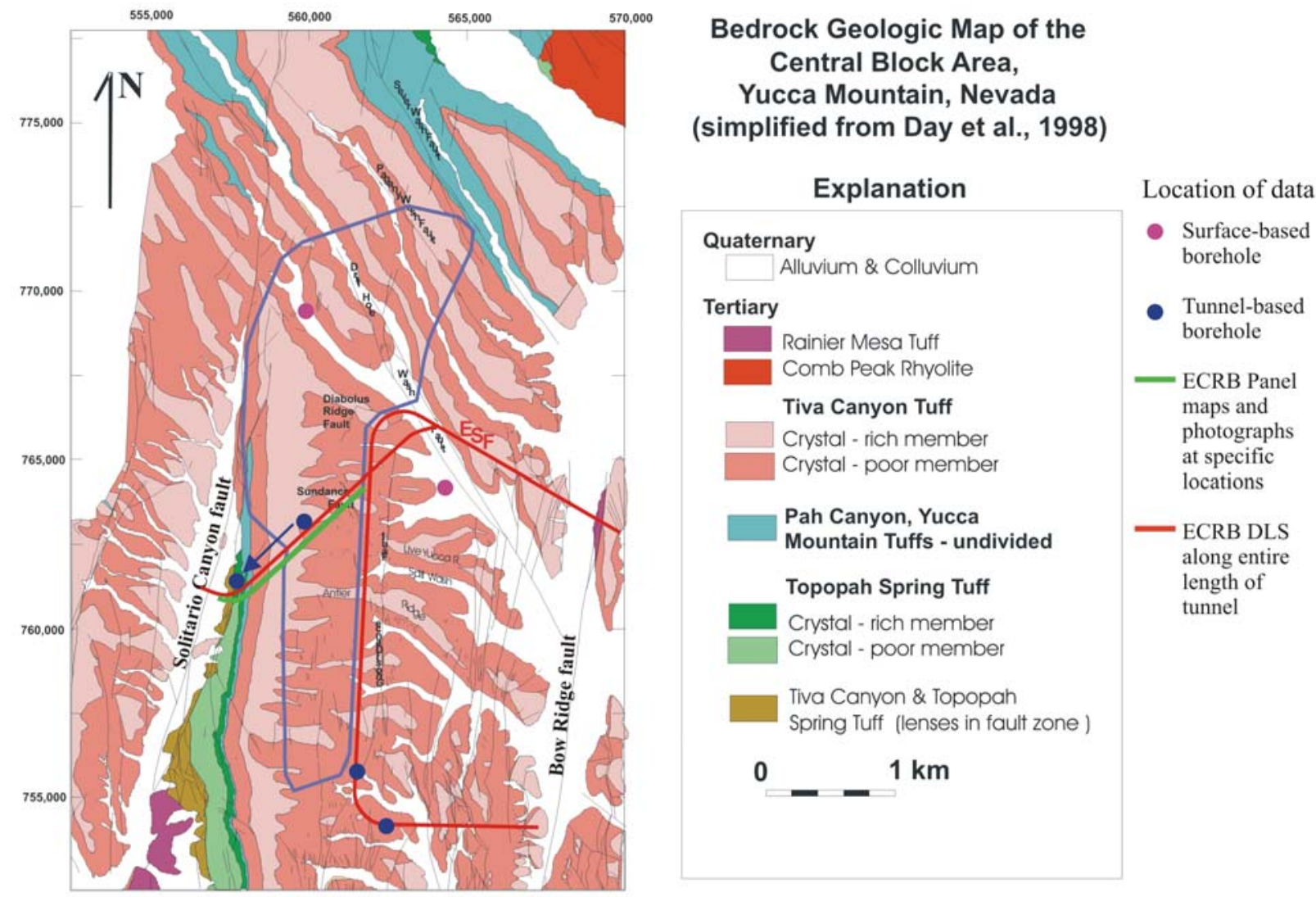

Source: Simplified from Day et al. 1998 [DIRS 101557].

NOTE: $\quad$ Borehole coordinates and station positions in the tunnels are in Table A1-1, station locations for ECRB Panel Maps and Photographs are in Sections A3 and A4, and ECRB DLS in Table 4-1 of this report. Northing and Easting coordinates are in feet and are referenced to the Nevada State Plane, Central Zone [Horizontal Datum is NAD 27]. The area of waste emplacement (BSC 2004 [DIRS 172334], Figure 1-3) is outlined by the blue line.

Figure A1-4. Locations of Surface-Based Boreholes, and Tunnel-Based Boreholes, Detailed Line Survey Data, and Panel Maps and Photographs in the Enhanced Characterization of the Repository Block Cross-Drift 
Table A1-2. Number of Core Samples in Lithostratigraphic Zones and Subzones of the Topopah Spring Tuff

\begin{tabular}{|c|c|c|c|c|}
\hline Lithostratigraphic unit & Symbol $^{1}$ & Short symbol & Unit number ${ }^{2}$ & $\begin{array}{l}\text { Number of } \\
\text { samples }\end{array}$ \\
\hline Crystal-rich member & Tptr & & & \\
\hline Vitric zone & Tptrv & & & \\
\hline Densely welded subzone & Tptrv1 & rv1 & 8.2 & 2 \\
\hline Nonlithophysal zone & Tptrn & $\mathrm{rn}$ & 7.0 & 6 \\
\hline Lithophysal zone & Tptrl & & & \\
\hline Crystal-rich subzone & Tptrl2 & $\mathrm{rl} 2$ & 6.4 & 1 \\
\hline Transition subzone & Tptrl1 & $\mathrm{rl} 1$ & 6.2 & 1 \\
\hline Crystal-poor member & Tptp & & & \\
\hline $\begin{array}{l}\text { Upper lithophysal zone } \\
\text { (ThermK) }\end{array}$ & Tptpul`TK & pul*TK & 5.2 & 8 \\
\hline Upper lithophysal zone & Tptpul & pul & 5.0 & 32 \\
\hline Middle nonlithophysal zone & Tptpmn & & & \\
\hline Transition subzone & Tptpmn4 & pmn4 & 4.4 & 4 \\
\hline Upper nonlithophysal subzone & Tptpmn3 & pmn3 & 4.3 & 1 \\
\hline $\begin{array}{l}\text { Lower lithophysal zone } \\
\text { (ThermK) }\end{array}$ & Tptpll*TK & $\mathrm{pll}{ }^{\star} \mathrm{TK}$ & 3.2 & 36 \\
\hline Lower lithophysal zone & Tptpll & pll & 3.0 & 19 \\
\hline Lower nonlithophysal zone & Tptpln & pln & 2.0 & 7 \\
\hline Vitric zone & Tptpv & & & \\
\hline Densely welded subzone & Tptpv3 & pv3 & 1.6 & 3 \\
\hline
\end{tabular}

Source: DTN: GS040808314224.005 [DIRS 171964]

Fractures are categorized on the basis of features related to cooling history (rims and vapor-phase mineral coating, etc.) and those that are indeterminate where there are no features to constrain the timing of formation (Table A1-3). Cooling-related fractures are divided into 4 categories based on how well rims and vapor-phase mineral coating on the fractures are developed. Three other cooling-related features include annealed fractures that formed as a discontinuity but crystallized back together, veinlets and streaks (where veinlets can also be categorized as one of the rim and vapor-phase mineral coated categories), and fractures with dusky red or reddish purple borders. Fractures with no "cooling” features are categorized as being indeterminate, although as discussed in Section A-1.1, some of these indeterminate fractures can be late-stage cooling fractures. Fractures with very fined-grained black minerals (possibly manganese or iron oxides) are categorized as being indeterminate because these minerals might be deposited from water that moved along the fractures, and it is difficult to know when this deposition occurred. 
Table A1-3. Categories of Fractures Based on Development of Features Related to Cooling of the Deposit or Indeterminate Timing of Formation

\begin{tabular}{|l|l|l|}
\hline \multicolumn{1}{|c|}{ Symbol } & \multicolumn{1}{c|}{ Color } \\
\hline Cooling related fractures (0 to 100 years after deposition)
\end{tabular}

Source: DTN: GS040808314224.005 [DIRS 171964]

Maps of slabs depict the 10 fracture categories and geometric relations of the fractures (Figure A1-5). Four typical relations are demonstrated in the maps in Figure A1-5.

1. Many fractures are of a single category; however, some fractures have different crystallization characteristics along their trace. Typically, variations occur along fractures in the development of the rims or vapor-phase mineral coatings.

2. Some fractures have trace lengths that transect the core; however, many fractures have trace lengths and terminations completely within the core. For fractures that are longer than the core, the "true" trace length is not known and the recorded length is a truncated value.

3. Some fractures intersect or terminate at other fractures, whereas many fractures terminate in the rock. Fracture intersections and terminations occur at angles ranging from acute, to $90^{\circ}$, to obtuse. Some fractures have several splays that either bifurcate or reconnect to form an anastomosing pattern.

4. Although the maps are at a scale where features less than $1 \mathrm{~mm}$ can be identified, fractures rarely have evidence of separation across them. Fractures do not have evidence of mechanical degradation such as brecciation or rounding of corners formed at the intersection of fractures.

Fractures related to cooling of the deposit typically are more numerous than indeterminate fractures, although individual slabs can have more indeterminate fractures than cooling fractures (Figure A1-6). Of the 2022 fractures mapped in the densely welded and crystallized rocks of the Topopah Spring Tuff, 69.7 percent (1410 fractures) are cooling related fractures and 30.3 percent (612 fractures) are indeterminate, although these indeterminate fractures might also have formed 
during the late stage of cooling. These relations also are represented by the "cooling to indeterminate ratio" (C/I ratio) for each sample where the total number of cooling fractures are divided by the total number of indeterminate fractures (Figure A1-7). A C/I ratio of 1 indicates there are equal numbers of cooling and indeterminate fractures in a sample; a ratio larger than 1 indicates there are proportionately more cooling fractures than indeterminate fractures; and a ratio smaller than 1 indicates there are proportionately less cooling fractures than indeterminate fractures. The C/I ratio is plotted by sample (Figure A1-7a) or as a distribution function for each lithostratigraphic unit (Figure A1-7b). For lithostratigraphic units with greater than 5 samples, there is an asymmetric distribution of the $\mathrm{C} / \mathrm{I}$ ratios with cooling fractures being more abundant than indeterminate fractures; thereby, indicating a strong influence by stresses induced during cooling on the formation of fractures. To calculate the C/I ratio and avoid division into or by " 0 ", if there are no cooling or indeterminate fractures in a sample, then a value of 0.1 is assigned to that type of fracture in that sample. 
a)

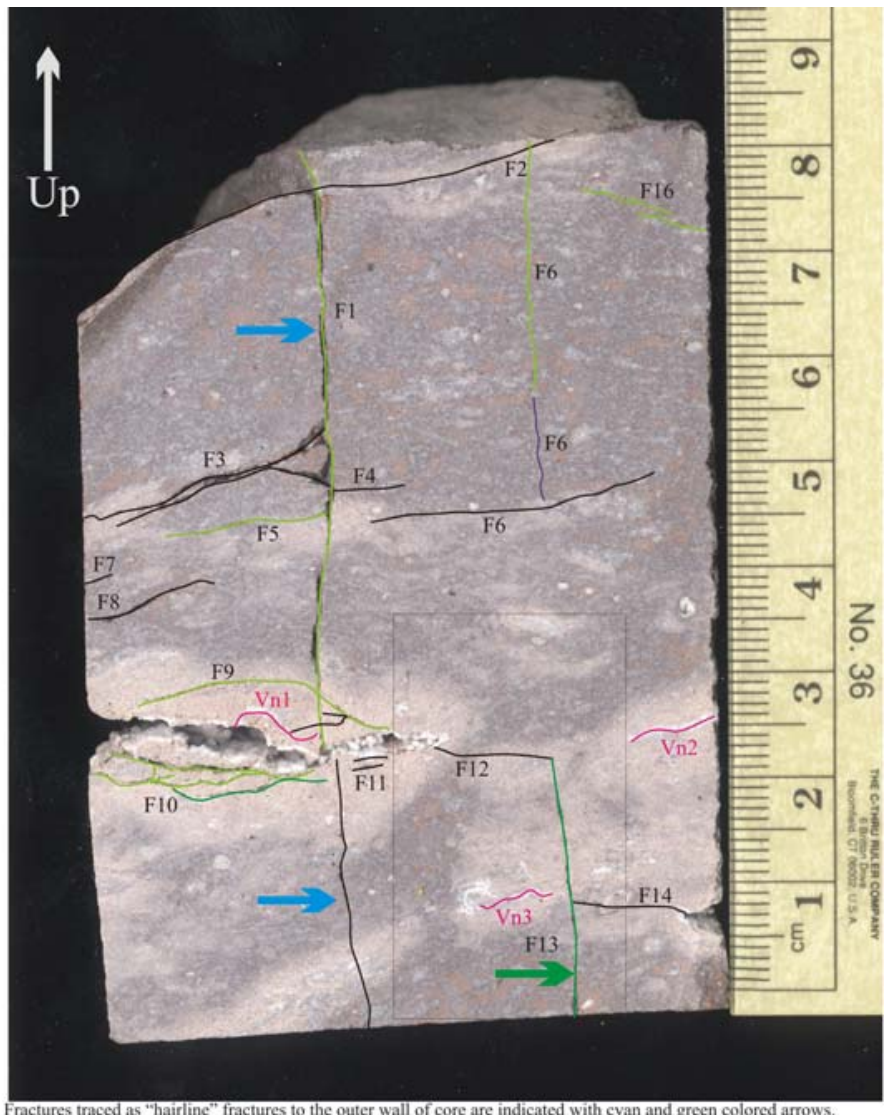

Fractures traced as "hairline" fractures to the outer wall of core are indicated with cyan and green colored arrows.
Fracture cyyan line) also interscects the same lithophysal cavity on core wall with a similar " "jog". The two fractures

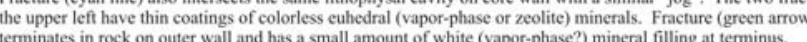

UZ-14 714.1 ft, Tptpul (sample number 0029744) b)

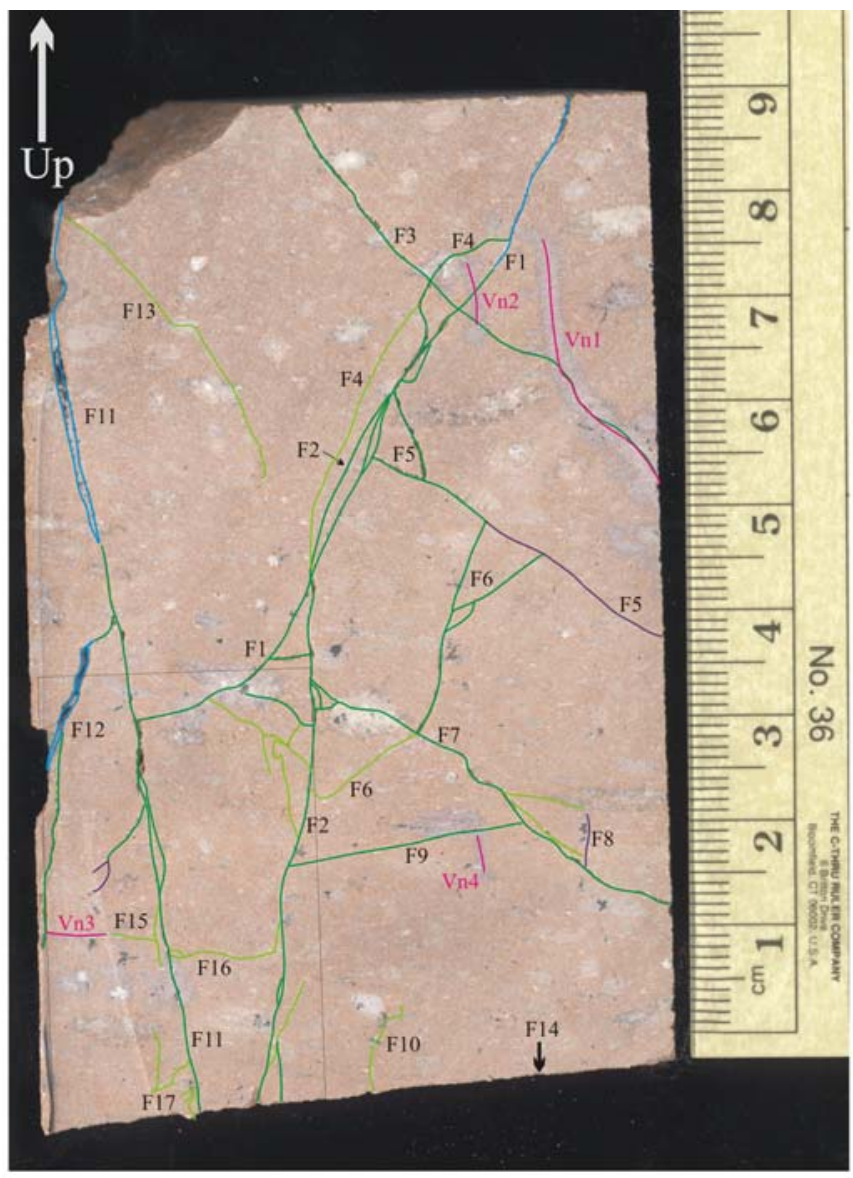

Source: DTN: GS040808314224.005 [DIRS 171964], Readme.doc file, pages 8-9.
a Slab from the upper lithophysal zone at a depth of 7141 ft in USW UZ-14.
b. Slab from the middle nonlithophysal zone (specifically the upper nonlithophysal subzone) at a depth of $732.2 \mathrm{ft}$ in USW UZ-14. Color codes for fractures are listed in Table A1-3 and Figure A1-6.

Figure A1-5. Fracture Maps of Core from Boreholes USW UZ-14 and Therm-K-005 and Therm-K-007 
c)

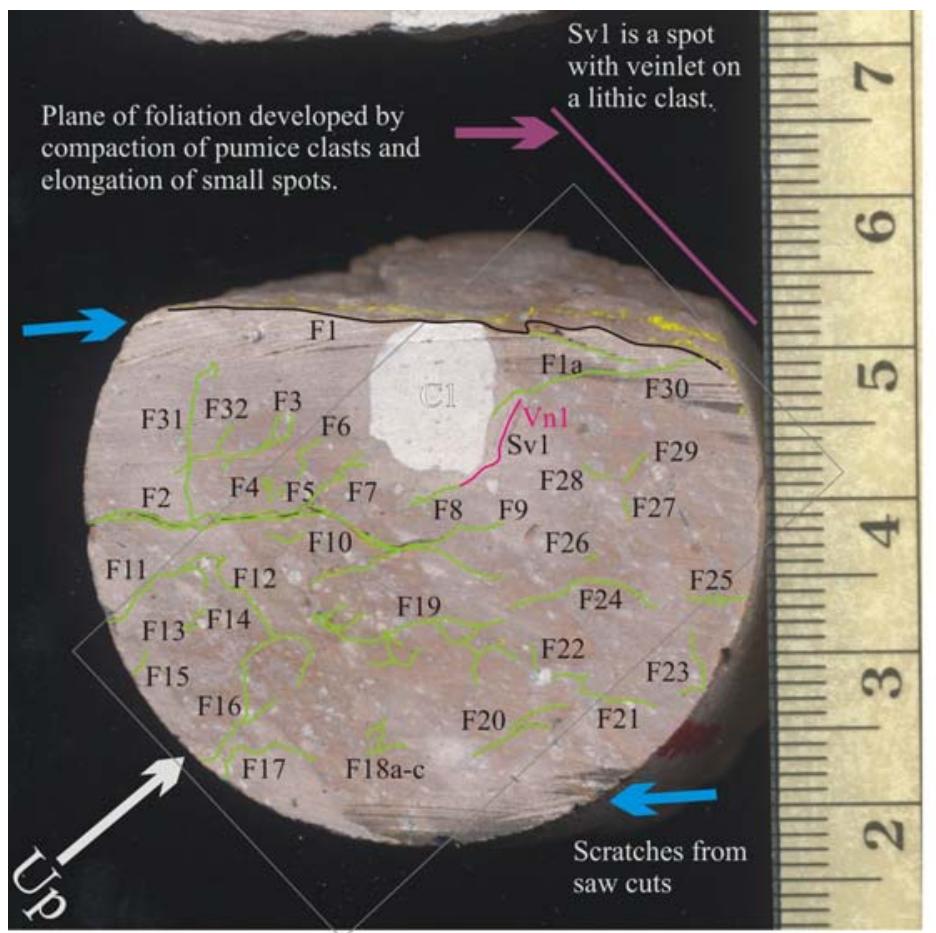

Therm-K-007 $0.4 \mathrm{ft}$, Tptpll (sample number 01013319) d)

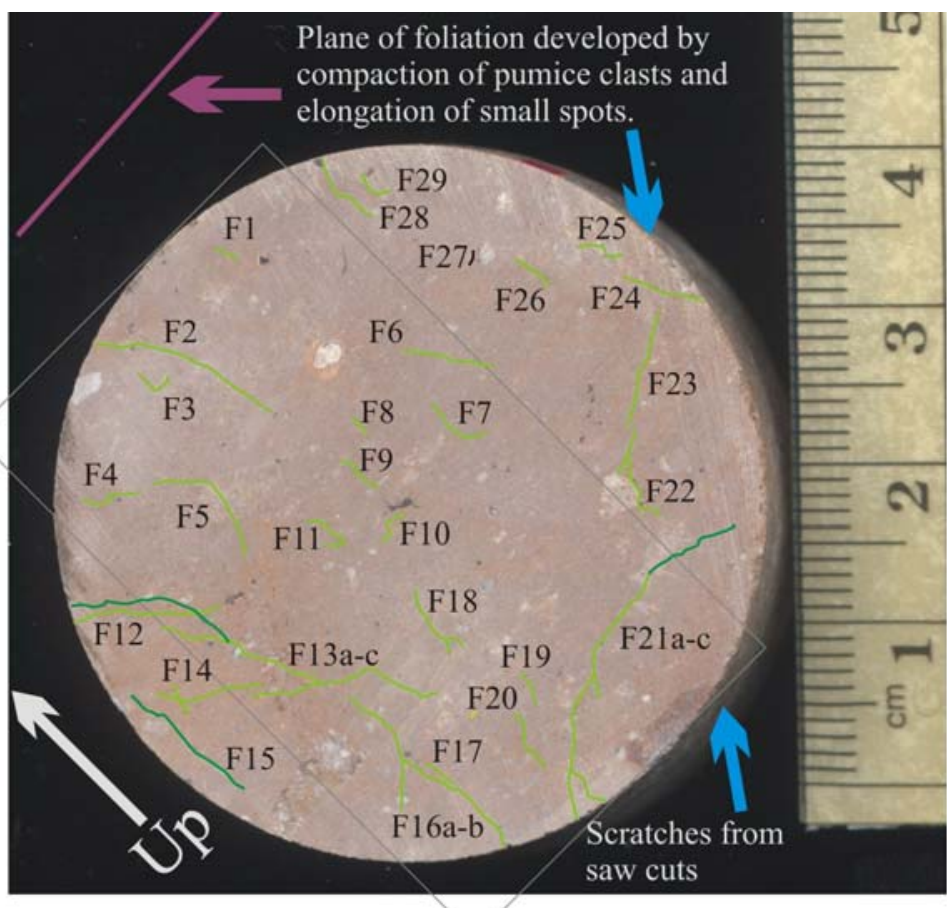

Therm-K-005 $40.1 \mathrm{ft}$, Tptpll (sample number 01013269)

Source: DTN: GS040808314224.005 [DIRS 171964].

NOTES: c. Slab from the lower lithophysal zone at a depth of $0.4 \mathrm{ft}$ in Therm-K-007.

d. Slab from the lower lithophysal zone at a depth of $40.1 \mathrm{ft}$ in Therm-K-005. Color codes for fractures are listed in Table A1-3 and Figure A1-6.

Figure A1-5. Fracture Maps of Core from Boreholes USW UZ-14 and Therm-K-005 and Therm-K-007 (continued) 


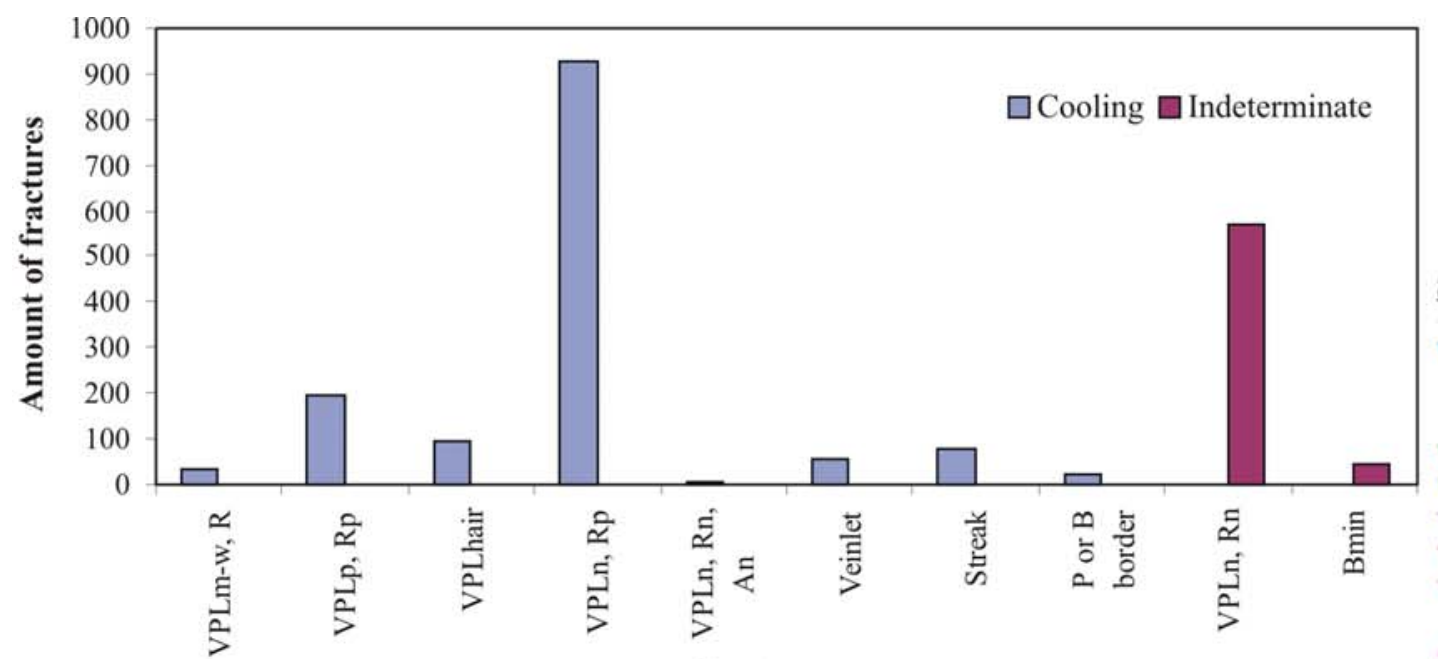

Symbol (Color) Description

Cooling related fractures ( 0 to 100 years after deposition)

VPLm-w, R Vapor-phase lining (VPL) is moderately to well developed, Rims (R) are well developed.

VPLp, Rp VPL and R are poorly developed.

VPL VPL in (fills) hairline fractures.

VPLn, Rp No VPL, Rims are poorly developed.

VPLn, Rn, An No VPL or R, but fracture is annealed.

Veinlet (pathways of vapor-phase

transport) that has VPL.

Fracture types

Streak

Fracture (many are incipient) with rim material, but no VPL.

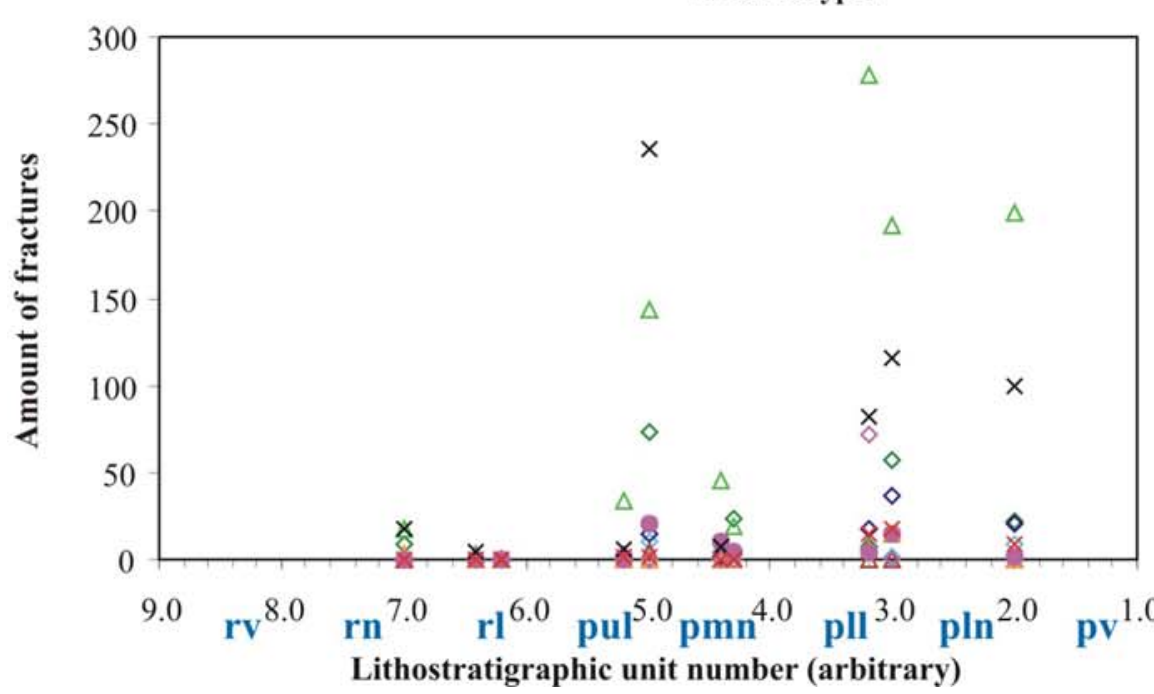

Purple or brown boarders on fractures, but with no VPL.

点

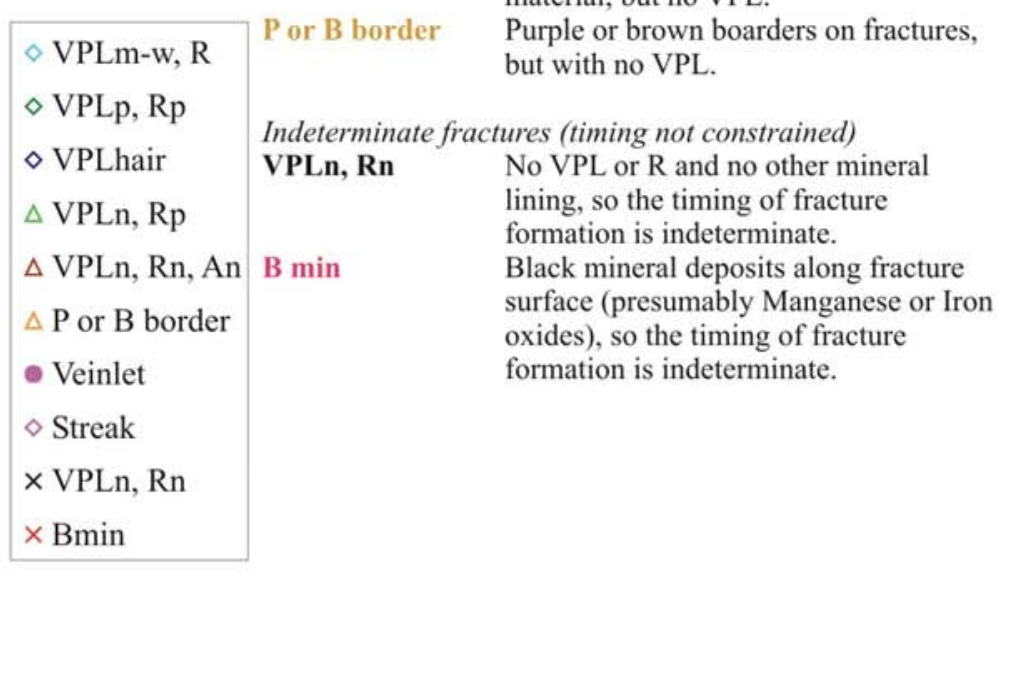

Source: DTN: GS040808314224.005 [DIRS 171964].

NOTE: Symbols of categories and lithostratigraphic units are in Tables A1-2 and A1-3.

Figure A1-6. Number of Fractures Displayed by Category and Lithostratigraphic Zone or Subzone in the Densely Welded and Crystallized Topopah Spring Tuff 

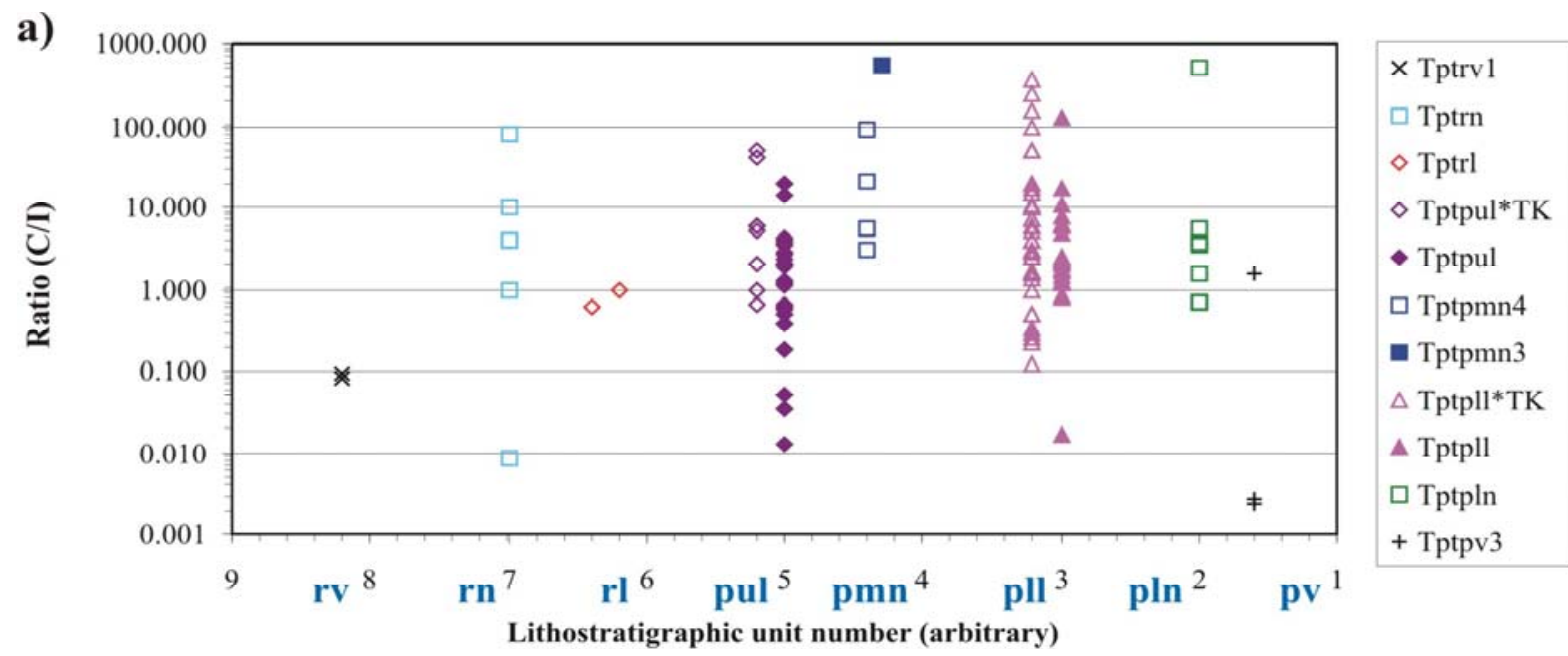

b)

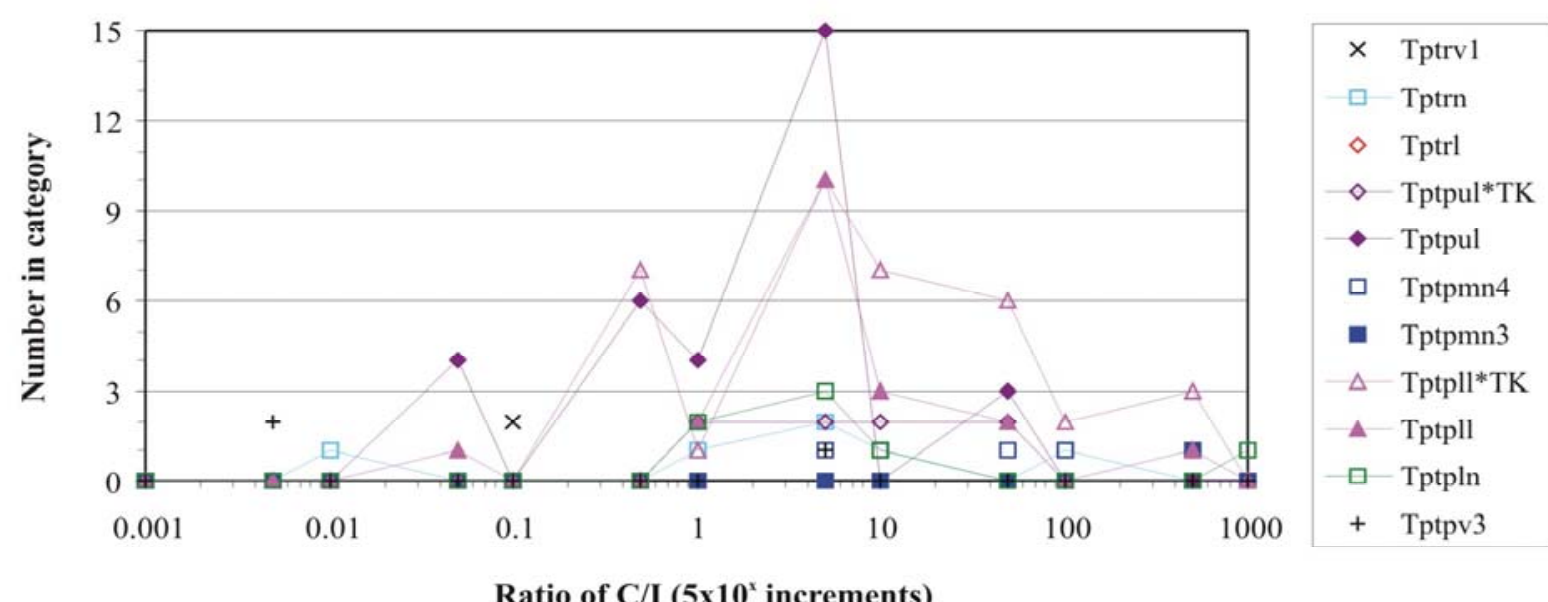

Source: DTN: GS040808314224.005 [DIRS 171964].

NOTES: a. C/I ratios of individual samples plotted by lithostratigraphic zone or subzone. Symbols for lithostratigraphic units are in Table A1-2.

b. The number of $\mathrm{C} / \mathrm{l}$ ratio values in $5 \times 10^{\mathrm{x}}$ increments plotted by lithostratigraphic zone or subzone. Lines are only plotted for units with 5 or more samples.

Figure A1-7. "Cooling to Indeterminate Ratio" (C/l Ratio) of Fractures by Lithostratigraphic Zone or Subzone in the Densely Welded and Crystallized Topopah Spring Tuff

The number of fractures per unit area $\left(\mathrm{cm}^{2}\right)$ of slab varies by lithostratigraphic zone and subzone with the (1) larger values in the deepest part of the section and (2) the lower lithophysal zone having the larger individual values (Figure A1-8a). These trends are similar where the fractures are divided into fractures longer than $1 \mathrm{~cm}$ and especially for those that are shorter than $1 \mathrm{~cm}$ (Figure A1-8b and c). Similar relations of the total area and total fractures per total area compared to the lithostratigraphic zone or subzone also indicate that the lower parts of the section, especially the lower lithophysal zone, have more fractures per unit area than the upper parts of the section (Figure A1-9). Because there are only a few samples from lithostratigraphic units other than the upper and lower lithophysal zones, some bias to the data is possible. These fractures-per-area relations indicate that the various lithostratigraphic units responded differently in the formation of fractures and support the stratiform characterization of fractures. 

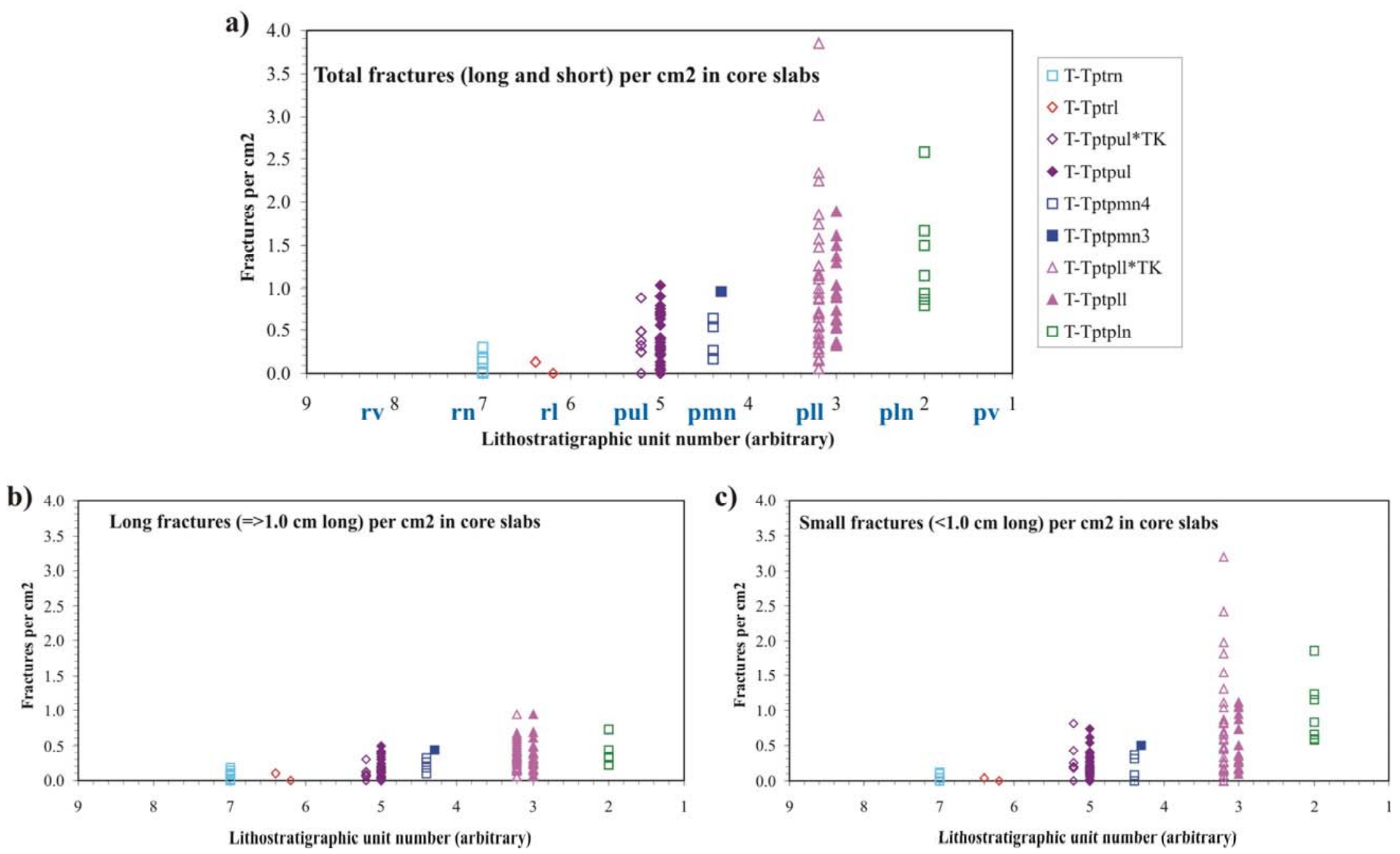

Source: DTN: GS040808314224.005 [DIRS 171964].

NOTES: a. Total number of fractures per $\mathrm{cm}^{2}$ of slab by lithostratigraphic units. Symbols for lithostratigraphic units are in Table A1-2.

b. Number of fractures greater than $1-\mathrm{cm}$ long per $\mathrm{cm}^{2}$ of slab by lithostratigraphic units.

c. Number of fractures less than 1-cm long per $\mathrm{cm}^{2}$ of slab by lithostratigraphic units.

Figure A1-8. Variation in the Numbers of Fractures Per Area $\left(\mathrm{cm}^{2}\right)$ of Slab by Lithostratigraphic Zone and Subzone in the Densely Welded and Crystallized Topopah Spring Tuff 


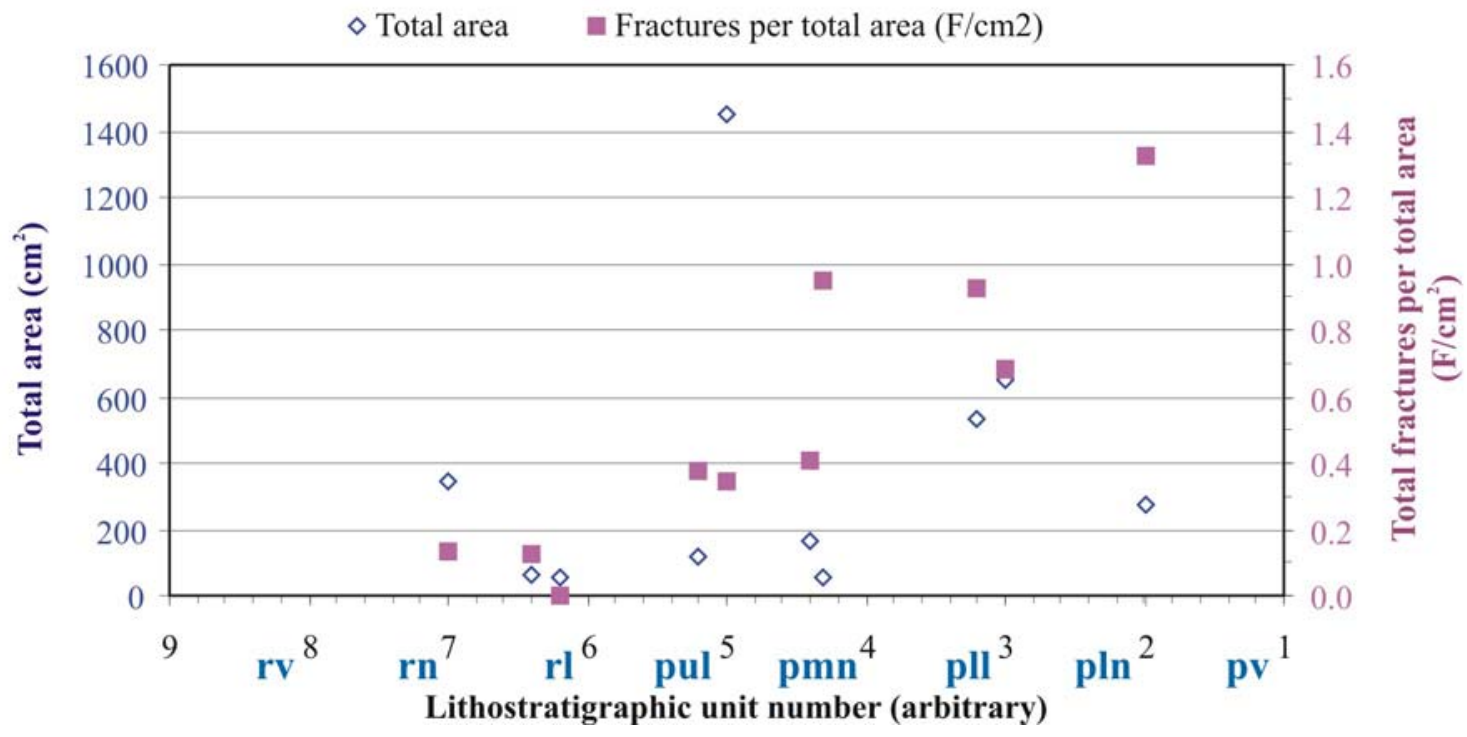

Source: DTN: GS040808314224.005 [DIRS 171964].

NOTE: Symbols for lithostratigraphic units are in Table A1-2.

Figure A1-9. Total Area of Samples and Total Number of Fractures Per Total Area $\left(\mathrm{cm}^{2}\right)$ of Slab by Lithostratigraphic Zone and Subzone in Slabs of Core from the Densely Welded and Crystallized Topopah Spring Tuff

In most tunnel-based ThermK and GTEC boreholes, the relative amounts of cooling fractures and indeterminate fractures are consistent in samples near the tunnel wall with those from near the end of the borehole; however, in some boreholes the amounts differ (Figure A1-10). These relations occur regardless of the rocks being in the upper or lower lithophysal zones. In addition to documenting some of the local variations in fractures, the relative abundance of cooling and indeterminate fractures in tunnel-based boreholes indicates a lack of evidence of fractures induced by the tunnel-boring machine. 


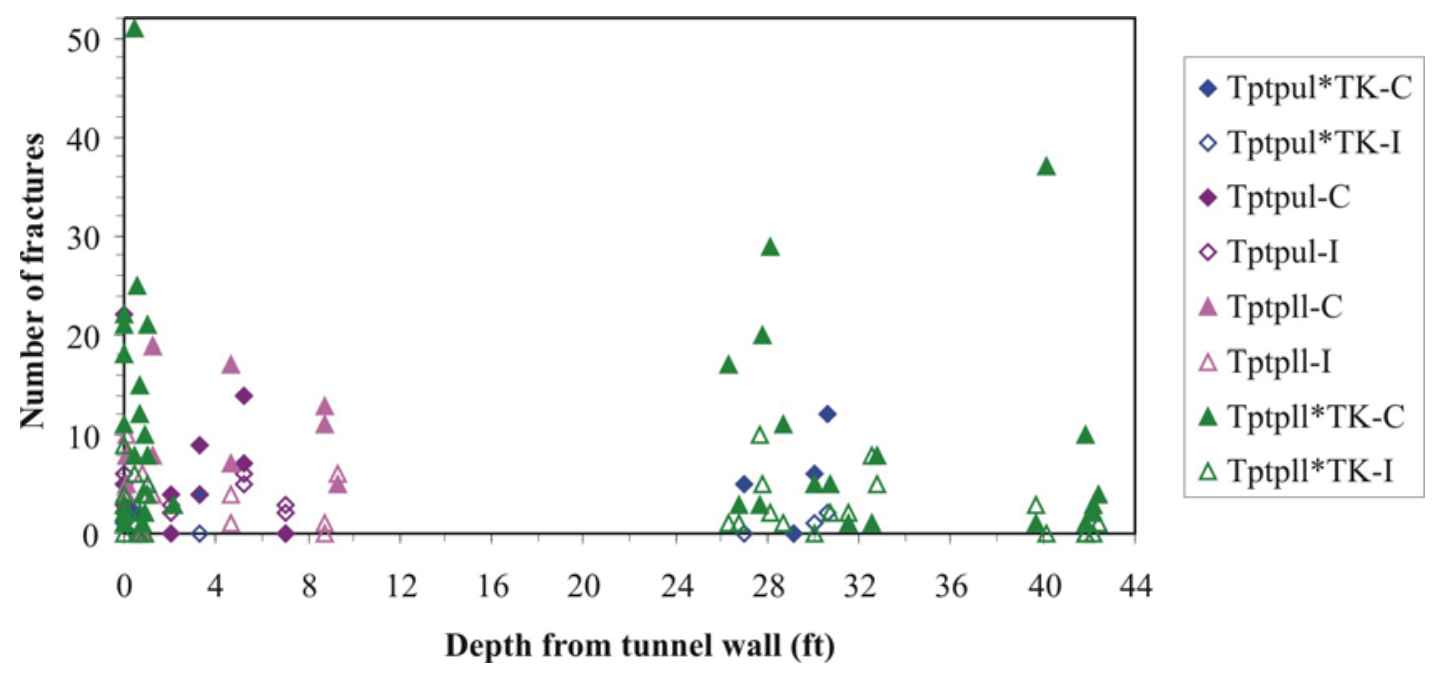

Source: DTN: GS040808314224.005 [DIRS 171964].

NOTE: $\quad$ Symbols for lithostratigraphic units are in Table A1-2.

Figure A1-10. Fractures in Slabs of Core from the Thermk and GTEC Boreholes Plotted by Depth in the Borehole, Number of Cooling (C) and Indeterminate (I) Fractures Per Sample, and Lithostratigraphic Zone in Which Each Borehole Is Located

\section{A1.1.1.2 Detailed Line Surveys in the ECRB Cross-Drift}

DLS data on fractures in the ECRB focused on geometric relations of the fractures; however, other features such as rims developed on fracture walls and material coating or filling the fractures also were documented. In 1998, DLS data in the ECRB were collected for 1810 discontinuities in 2,664 $\mathrm{m}$ of tunnel (DTNs: GS990408314224.001 [DIRS 108396] and GS990408314224.002 [DIRS 105625]; Mongano et al. 1999 [DIRS 149850]), and these data are included in the Microsoft ${ }^{\circledR}$ Excel 97 workbook PGV ECRB DLS Frac-Fill.xls that is part of the supporting data files for this report (Appendix D). Fractures in the DLS are classified as "non-genetic" Fracture (F) (i.e., those not identified as being in any other category), Vapor-phase parting (VPP), Cooling joint (CJ), Shear (SH), Shear zone (SHZ), Fault (FLT), and Fault zone (FZ) with an additional category of "Not applicable" (NA) typically referring to conditions obscuring features on the walls and other comments. For this classification of discontinuities, vapor-phase partings are shallowly dipping with long trace lengths; cooling joints were identified primarily on the geometric relations of long trace length and planarity; shears and shear zones have separation across the feature of less than $0.1 \mathrm{~m}$; and faults and fault zones have separations equal to or greater than $0.1 \mathrm{~m}$. Using this classification of discontinuities, 80.7 percent are non-genetic fractures with only 11.2 percent related to cooling features (vapor-phase partings and cooling joints), 8.0 percent related to shears or faults, and 0.1 percent as "not applicable" (recorded as “rubble zones”) (Figure A1-11a).

Five types of features are used to identify “cooling” fractures including crystallization features such as rims and vapor-phase mineral linings, tubular structures (sometimes shortened to simply "tubes"), and macroscopic features such as vapor-phase partings and "cooling joints" that are identified primarily on the basis of geometric relations (dip angle, trace length, planarity, etc.). Some fractures have more than one of these features; for example, 1010 fractures have only 1 feature, 203 have 2 features, 73 fractures have 3 features, 1 fracture has 4 features, and no 
fractures have 5 features. Of the types of features, vapor-phase mineral linings comprise 76.0 percent of the data, rims are 10.3 percent, tubular structures are 1.3 percent, vapor-phase partings are 4.9 percent, and “cooling joints” are 7.5 percent (Figure A1-12).

Material coatings or fillings of fractures, shears, and faults are products of various processes, so these materials are used to categorize fractures in terms of a petrogenetic history. The coatings or fillings are described with 15 categories and symbols including "No fill" or "Not applicable" (NA), Broken or crushed rock or sand (Br), Breccia (Bx), Calcite (C), Clay (Ar), Fault gouge (Fg), Fault rubble (Fr), Iron oxides (Io), Manganese (M), Opal (O), Silica (amorphous) (S), Quartz (Q), Vapor-phase lining (V), Unknown (U), and Zeolites (Z). Some of these material coatings or fillings are grouped into similar categories such as the "C,O,S,Q" category where calcite and opal, silica, and quartz are grouped because these minerals are typically deposited by water moving along the fractures (although some of the SiO2 polymorphs might have been deposited from cooling of the vapor phase), and the "Misc." category includes manganese oxide (the most abundant mineral), iron oxides, and unknown materials that are probably deposited from aqueous solutions that flowed along the fracture.. Using these categories of material fill, 49.2 percent have vapor-phase linings, 17.4 percent are "Misc." (mostly as manganese oxide), 12.9 percent have no fill, 7.5 percent are "C,O,S,Q", 0.4 percent have clay fill (or partial fill), and 12.6 percent are broken rock (or sand), breccia, fault gouge, or fault rubble (although 11.2 percent of this category is broken rock or sand) (Figure A1-11b).

Shears, shear zones, faults, and fault zones are associated with broken rock (or sand), breccia, fault gouge, or fault rubble (fault gouge and fault rubble are only identified in faults or fault zones). However, the broken rock (or sand) also occurs in numerous fractures that are not shears or faults. This "one way" correlation relation of "shears" and "faults" to broken rock (or sand), breccia, rubble, or gouge is consistent with the fact that there are only 145 "shears" and "faults" (Figure A1-11a) whereas there are 318 occurrences of broken rock (or sand), breccia, rubble, or gouge (Figure A1-11b). Numerous shears and some fractures and shears filled with "broken or crushed rock or sand" have cooling related features such as rims and tubular structures, but in the currently used classification, these features were not included in the categorization. 
a) Fracture types (original)

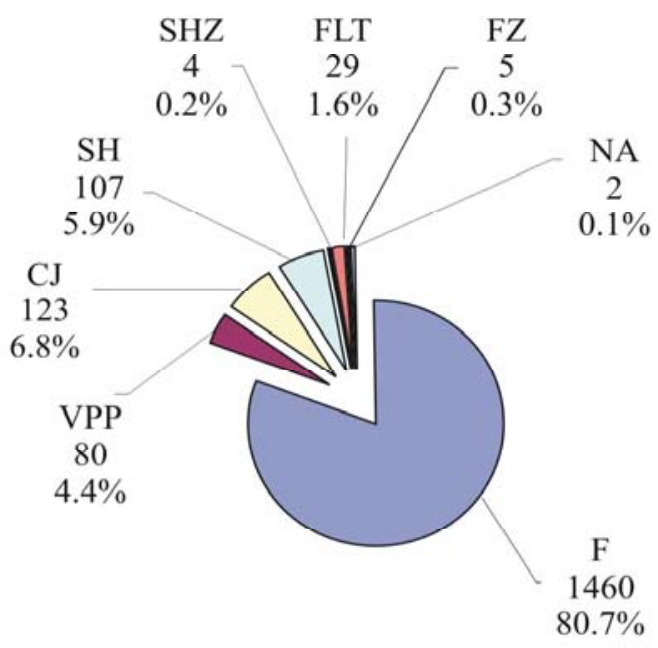

b) Fracture-fill materials

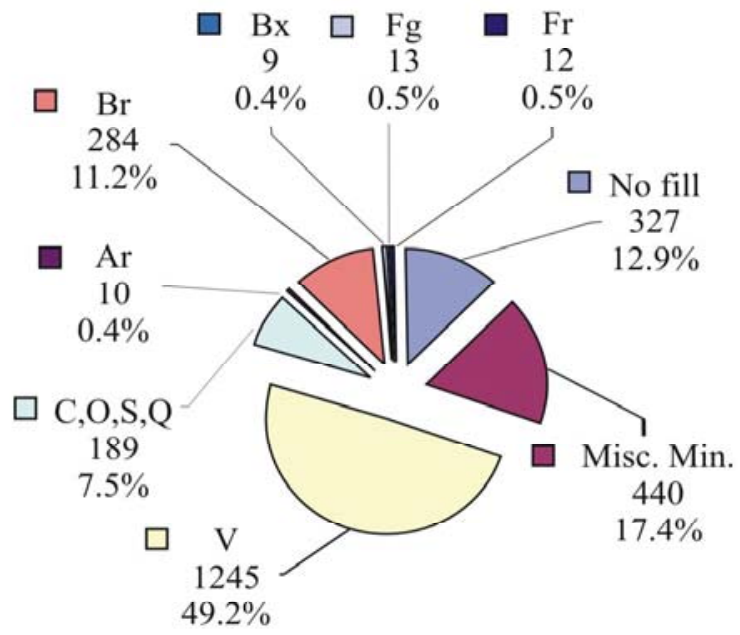

c)

"Re-categorized" Fractures

Fractures only (not including $\mathrm{Br}$ or $\mathrm{Bx}$ ):

71.1\% "Cooling"

$\mathbf{2 8 . 9 \%}$ "Indeterminate"

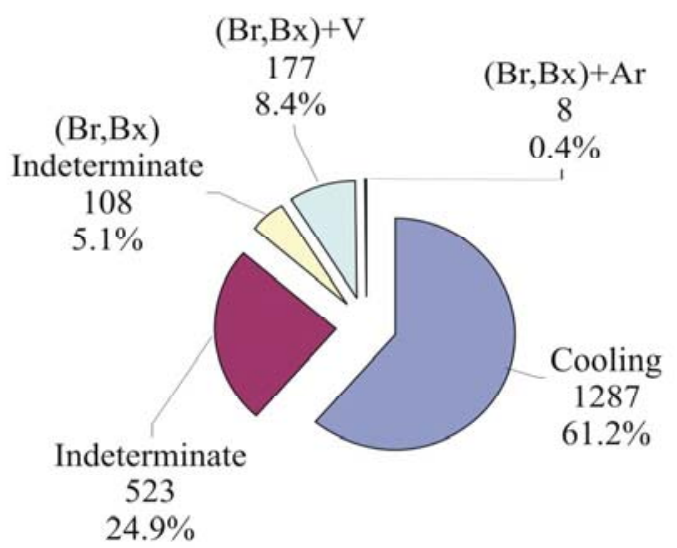

Source: PGV ECRB DLS Frac-Fill.xIs (Appendix D).

NOTES: The numbers of fractures are below the symbol and the percent of the total is at the bottom

a. Fracture types.

b. Fracture lining or filling material.

c. Re-categorized fractures and fill material (figure a) on the basis of cooling and "non-cooling" (indeterminate) fractures.

Figure A1-11. Abundance of Fracture (Discontinuity) Types and Fillings in the ECRB Cross-Drift from Detailed Line Survey Data

Using the cooling and indeterminate fractures and "broken or crushed rock or sand" fracture-fill categorization scheme for fractures, 61.2 percent are cooling related fractures with only 24.9 percent having no diagnostic textural evidence as to when or how it formed (although these might be late-stage cooling fractures), and 13.9 percent having "broken or crushed rock or sand" material filling the fractures (Figure A1-11c). Of the "broken or crushed rock or sand" fill 
material, 8.4 percent is associated with vapor-phase minerals, 0.4 percent is associated with clay, and 5.1 percent is in discontinuities with no or other mineral fillings. One interesting relation resulting from this re-examination of mineral fill is that the clay-filled fractures occur with "broken or crushed or sand" material, and this association reinforces the sedimentary deposition mechanism proposed by Buesch and Lung (2003 [DIRS 170297]).

\section{Cooling Features in ECRB}

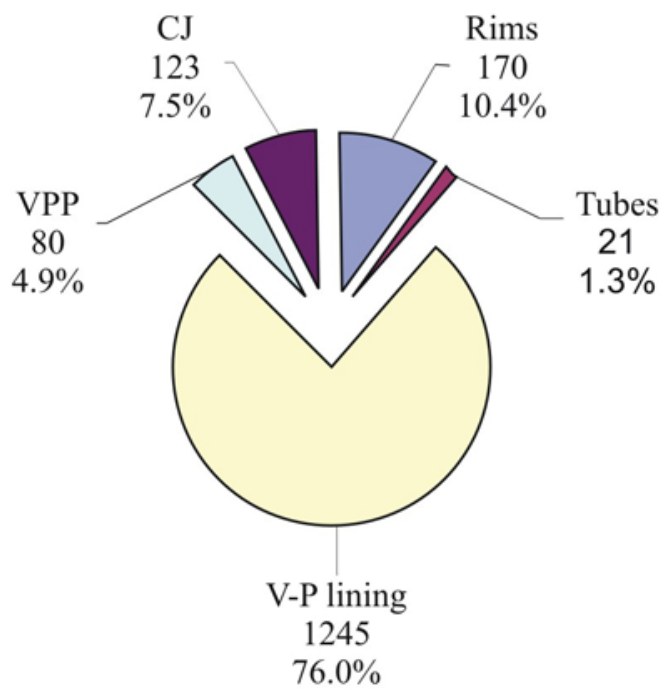

Source: $\quad$ PGV ECRB DLS Frac-Fill.xIs (Appendix D).

NOTE: Some values do not total to 100 percent as a result of rounding. The numbers of fractures are below the symbol and the percent of the total is at the bottom. Each type of feature was counted individually, and some fractures contain more than one of these features, so the total features (1639) is greater than the "cooling" fractures and "broken or crushed rock or sand" filled fractures associated with vapor-phase mineral linings.

Figure A1-12. Abundance and Percent of Discontinuities in the ECRB DLS Data with Cooling Related Features Such as Rims, Tubular Structures (Tubes), or Vapor-Phase Mineral Linings (V-P Lining), or Identified During Logging as Vapor-Phase Partings (VPP) or Cooling Joints (CJ)

Focusing on just the discontinuities filled with "broken or crushed rock or sand”, 68.2 percent are in non-genetic fractures, 29.1 percent are in shears, shear zones, faults, or fault zones, and only 2.8 percent are in cooling joints (Figure A1-13a). This association of "broken or crushed rock or sand” fill material with discontinuities having some amount of separation across them (i.e., shears, shear zones, faults, and fault zones) is not necessarily a surprise. However, it is interesting that most of the "broken or crushed rock or sand" fill material is associated with non-genetic fractures. This second relation with non-genetic fractures indicates that the fractures simply "opened" and dilated to form apertures large enough for the "broken or crushed or sand" material to fill the fracture. With respect to material fill associated with the "broken or crushed rock or sand” filled fractures, 53.8 percent have vapor-phase minerals, 27.8 percent have "Misc." minerals (mostly manganese oxide), 12.2 percent have "C,O,S,Q", 2.5 percent have clay, and 3.7 percent are breccia, fault gouge, or fault rubble (Figure A1-13b). For the vapor-phase minerals to be identified, and not specified as clasts, it is assumed that the vapor-phase minerals are intact coatings or linings on the fracture walls. The integrity of the vapor-phase mineral linings and the 71.0 percent of discontinuities being non-genetic or "cooling joints" (from Figure A1-13a) also indicates most of the fractures simply dilated rather than resulting from 
appreciable shear. These discontinuity-type and material-fill relations for "broken or crushed or sand" filled discontinuities are similar to the general discontinuity population (Figure A1-11a and b), especially the fractures filled with vapor-phase minerals and the "Misc.” and "C,O,S,Q" minerals.

a)

"Breccia" in fracture types

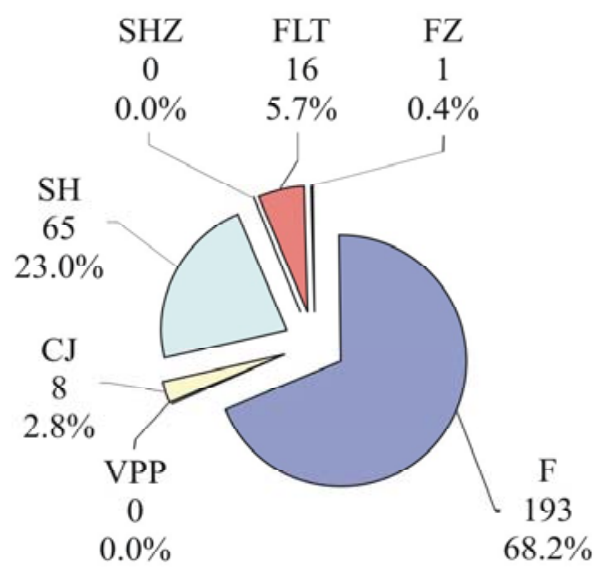

b) "Breccia" with other fillings

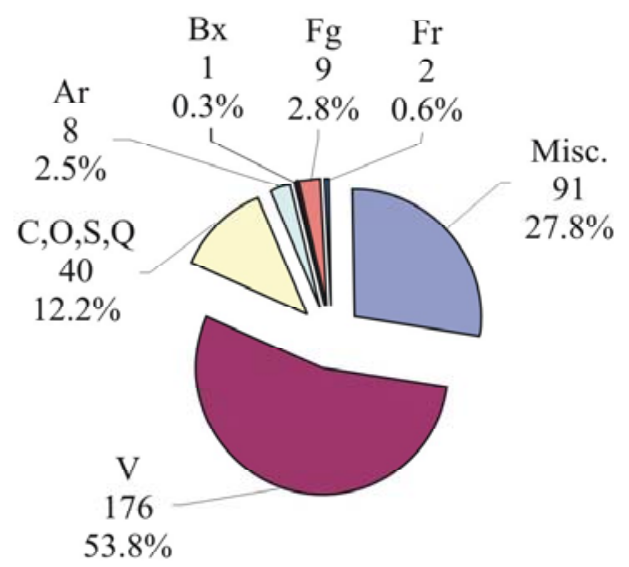

Fractures only:

$61.3 \%$ "Cooling"

$38.7 \%$ "Indeterminate"

Source: PGV ECRB DLS Frac-Fill.xIs (Appendix D).

NOTE: Some values do not total to 100 percent as a result of rounding. The numbers of fractures are below the symbol and the percent of the total is at the bottom.

Figure A1-13. Discontinuities in the ECRB DLS Data that are Filled with "Broken or Crushed Rock or Sand" Compared to (a) Discontinuity Type and (b) Fill Material

The DLS data from the ECRB indicates that of the originally documented discontinuities, only 8.0 percent are related to shears or faults (and 0.1 percent as "not applicable" that is actually two "rubble zones) (Figure A1-11a), so 91.9 percent provide evidence for the petrogenetic development of fractures. The reclassified DLS discontinuity data indicates that 61.2 percent are cooling related fractures, 24.9 percent are indeterminate as to how or when they formed (although these might be late-stage cooling fractures), and 13.9 percent have "broken or crushed rock or sand" material filling the fractures (Figure (A1-11c). However, when the fractures or shears filled with "broken or crushed rock or sand" material are not included, 71.1 percent of the fractures are cooling related and 28.9 percent have no diagnostic features to indicate how or when they formed (i.e., are "indeterminate") (Figure (A1-11c). When the fractures or shears with "broken or crushed rock or sand" material are focused on (and normalized to 100 percent), 61.3 percent are associated with vapor-phase minerals and 38.7 percent are indeterminate in formation and are either not associated with other materials or are associated with clay, calcite and opal, silica, and quartz ("C,O,S,Q ") or manganese oxide, iron oxides, and unknown materials ("Misc."). Although the proportions of "cooling" and "indeterminate" fractures differ by only about 10 percent, comparison of fractures with and without "broken or crushed rock or sand” material indicate that many cooling and indeterminate fractures were simply dilated. A 
few of these fractures with "broken or crushed rock or sand" material might have been used to form some of the shears and faults, although some shears and faults might have formed independently of these "pre-existing" fractures.

In contrast to the total DLS data along the entire ECRB Cross-Drift, where only fractures greater than $1 \mathrm{~m}$ in length were included, the Small-Scale Fracture (SSF) Study used the same techniques as the DLS but the fractures measured have no minimum length. The Small-Scale Fracture Study consists of 14 locations along the ECRB Cross-Drift with 2 locations in the upper lithophysal zone, 2 locations in the middle nonlithophysal zone, 9 locations in the lower lithophysal zone, and 1 location in the lower nonlithophysal zone. The configuration of a SSF location includes a 6-m long horizontal traverse that replicates the position of the original DLS data, and three, vertical, 2-m long traverses positioned (one each at the end of the horizontal traverse and one in the middle). The SSF DLS data from the ECRB Cross-Drift are from the data package DTN: GS040108314224.001 [DIRS 169591] and GS040408314224.003 [DIRS 170312], and these data are included in the Microsoft ${ }^{\circledR}$ Excel 97 workbook PGV SSF DLS Frac-Fill.xls that is part of the supporting data files for this report (Appendix D).

As with the original total ECRB Cross-Drift DLS data, the Small-Scale Fracture DLS data has been analyzed and re-categorized with similar results, although the proportion of specific features differ with the result that there are approximately equal amounts of cooling and indeterminate fractures (48.9 percent and 51.1 percent, respectively) (PGV SSF DLS Frac-Fill.xls in Appendix D). Using the original classification of discontinuities and comparing the SSF to the total DLS, approximately the same percent of non-genetic fractures were identified; however, there were more cooling features (vapor-phase partings and cooling joints) and fewer shears (and no faults) (Figure A1-14a). Using the categories of material fill, in the SSF data there are slightly fewer vapor-phase mineral linings, about three times as many "no fill" fractures, and about the same amount of fractures filled with "broken rock or sand" (Figure A1-14b). For fractures identified as "cooling" fractures, in the SSF data there are about the same percentage of rims and tubular structures, slightly fewer vapor-phase mineral coated, many more vapor-phase partings, and slightly fewer cooling joints (Figure A1-15). Using the cooling and indeterminate fractures and "broken or crushed rock or sand" fracture-fill categorization scheme for fractures, in the SSF data there are fewer cooling fractures, more "no fill" or not diagnostic (indeterminate) fractures, and only slightly fewer "broken or crushed rock or sand" material filling the fractures (Figure A1-14c) than observed from the DSL data (Figure A1-11c).

Focusing on just the discontinuities filled with "broken or crushed rock or sand", almost all are non-genetic fractures with cooling joints as the next abundant (but very small) category (Figure A1-16a). With respect to material fill associated with the "broken or crushed rock or sand" filled fractures, the vast majority have vapor-phase minerals (Figure A1-16b), so the vapor-phase mineral lined fractures appear to be preferentially "popped open".

The one obvious difference in the SSF and total DLS data is the SSF data has fewer cooling and more indeterminate fractures (48.9 percent and 51.1 percent, respectively in the SSF data versus 71.1 percent and 28.9 percent, respectively in the total ECRB data) (Figures A1-14c and A1-11c). The differences in the cooling versus indeterminate ratio, which is 1.0 for the SSF data and 2.5 for the total ECRB data, might result from the large difference in the lengths of traverses sampled (only $168 \mathrm{~m}$ in the SSF compared to 2,664 $\mathrm{m}$ in the total ECRB). Another contributing 
factor in the differences in the cooling versus indeterminate ratios in the SSF and total DLS data might be the relative amounts of data in each lithostratigraphic unit. For example, in the SSF data there are 14.3 percent in the upper lithophysal zone (Tptpul), 14.3 percent are in the middle nonlithophysal zone (Tptpmn), 64.3 percent are in the upper lithophysal zone (Tptpll), and 7.1 percent are in the lower lithophysal zone (Tptpln) whereas in the total ECRB data there are 41.2 percent are in the Tptpul, 16.1 percent are in the Tptpmn, 33.1 percent are in the Tptpll, and 9.6 percent are in the Tptpln.

a)

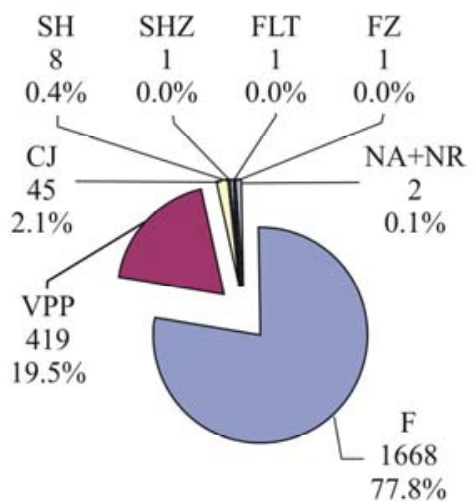

b)

Fracture-fill types

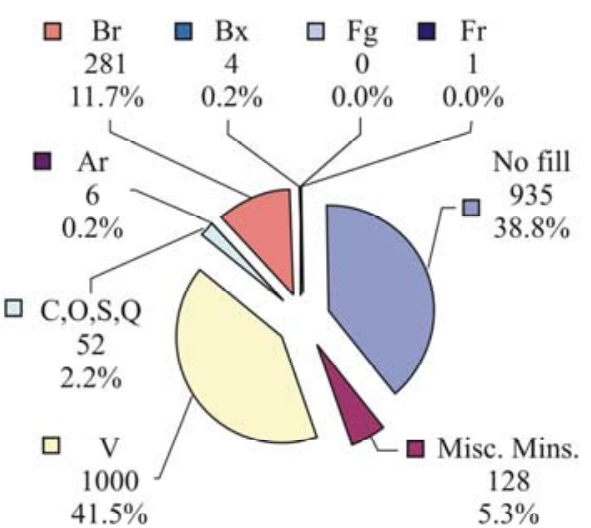

c) "Re-categorized" Fractures

Fractures only (not including $\mathrm{Br}$ or $\mathbf{B x}$ ): 48.9\% "Cooling"

$\mathbf{5 1 . 1 \%}$ "Indeterminate"

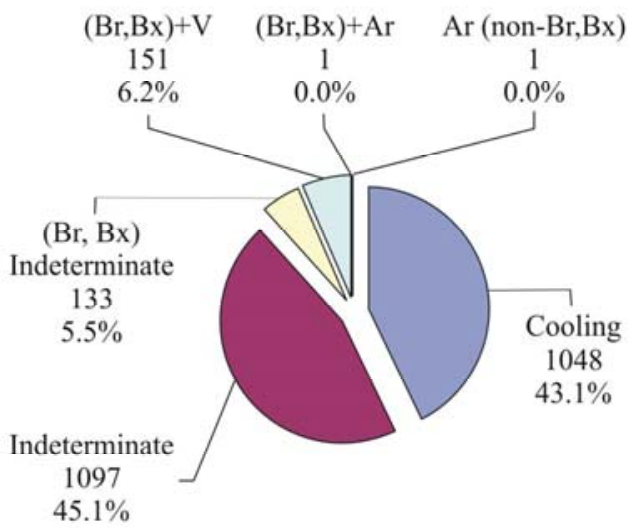

Source: PGV SSF DLS Frac-Fill.xIs (Appendix D).

NOTES: The numbers of fractures are below the symbol and the percent of the total is at the bottom.

a. Fracture types.

b. Fracture lining or filling material.

c. Re-categorized fractures and fill material (figure a) on the basis of cooling and "non-cooling" (indeterminate) fractures.

Figure A1-14. Abundance of Fracture Types and Fillings in the ECRB from Small-Scale Fracture DLS Data 


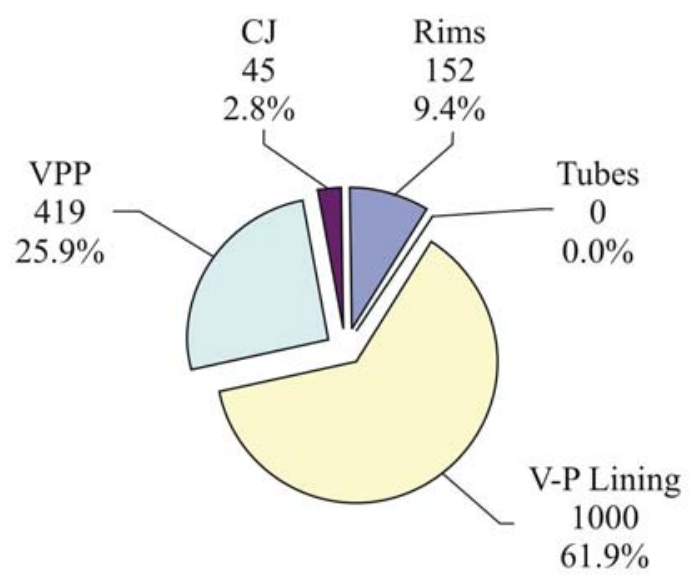

Source: PGV SSF DLS Frac-Fill.xls (Appendix D).

NOTE: The numbers of fractures are below the symbol and the percent of the total is at the bottom. Each type of feature was counted individually, and some fractures contain more than one of these features, so the total features (1616) is greater than the "cooling" fractures and "broken or crushed rock or sand" filled fractures associated with vapor-phase mineral linings.

Figure A1-15. Abundance and Percent of Discontinuities in the ECRB Small-Scale Fracture DLS Data with Cooling Related Features Such as Rims, Tubular Structures (i.e., "Tubes"), or Vapor-Phase Mineral Linings (V-P Lining), or Identified During Logging as Vapor-Phase Partings (VPP) or Cooling Joints (CJ) 
a) Breccia and fracture types

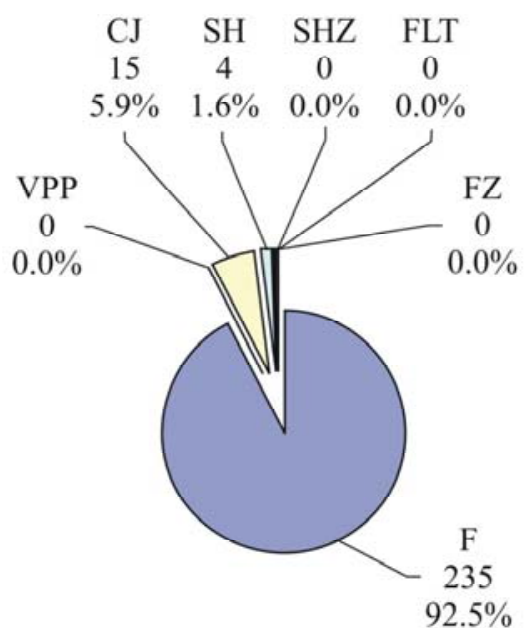

b) Breccia with fracture fill

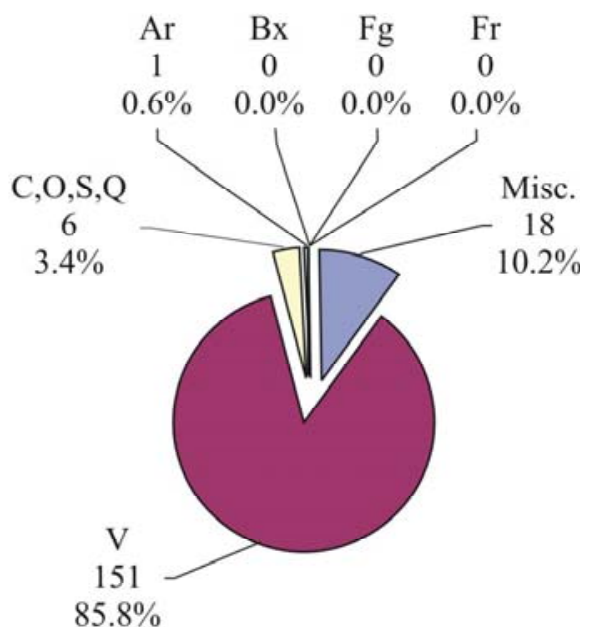

Fractures with breccia only:

$55.1 \%$ "Cooling"

44.9\% "Indeterminate"

Source: PGV SSF DLS Frac-Fill.xIs (Appendix D).

NOTE: The numbers of fractures are below the symbol and the percent of the total is at the bottom.

Figure A1-16. Discontinuities in the ECRB Small-Scale Fracture DLS Data that are Filled with "Broken or Crushed Rock or Sand" Compared to (a) Discontinuity Type and (b) Fill Material

The four types of discontinuities (including shears, shear zones, faults, and fault zones) identified in the DLS data in the ECRB Cross-Drift (Mongano et al. 1999 [DIRS 149850] p. 48) provide constraints on how the rock mass has deformed. Shears and shear zones have less than $0.1 \mathrm{~m}$ of separation and faults and fault zones have $0.1 \mathrm{~m}$ or greater separation. Where features such as pumice or lithic clasts or lithophysae are truncated by a discontinuity, but the matching part of the feature cannot be identified on the opposite side of the discontinuity, the amount of separation is "undeterminable" and the discontinuity is identified as a shear. Of the 1810 discontinuities in the ECRB Cross-Drift, 107 (5.9 percent) are shears, 4 (0.2 percent) are shear zones, 29 (1.6 percent) are faults, and 5 (0.3 percent) are fault zones (Figure A1-11a). The shear and fault data provide insights on the small- and large-scale deformation of the rock mass.

1. On the small scale - The technical procedure for data collection (YMP-USGS-GP-32, R2, [DIRS 151802] Section 5.2.13) uses examples of separations measured to the nearest decimeter and indicates smaller separations can be recorded in centimeters, but a minimum separation is not described. Of the shears and shear zones, 50 are designated as "Unknown" separation and 57 have separations from 1 to $9 \mathrm{~cm}$, so empirically, the minimum resolution for separation recorded in the ECRB DLS data is $1 \mathrm{~cm}$ (PGV ECRB DLS Frac-Fill.xls in Appendix D).

2. On the large scale - Of the 1810 discontinuities in the ECRB, only 8.0 percent have measured separation of greater than $1 \mathrm{~cm}$, and this is consistent with deformation of the mountain-scale rock mass by concentration of shear along relatively few discontinuities (PGV ECRB DLS Frac-Fill.xls in Appendix D). 


\section{A1.1.1.3 Summary of Characteristics and Timing of Fracture Development in Crystallized Rocks}

Data from the fractures in slabs of core and DLS were collected for different reasons and represent different scales of sample size and resolution; however, they form a consistent set of relations (1) in the general petrogenetic formation of the cooling features of fractures, (2) where about 70 percent of fractures are related to cooling and 30 percent are indeterminate (but might be late-stage cooling related), and (3) where the vast majority of fractures have no evidence of shear or mechanical degradation. On the basis of how well features such as rims, borders, and vapor-phase mineral coatings are developed, features related to cooling are identified as "early" or "Type 1" and "late-stage" or "Type 2". Type 1 and 2 fractures were originally defined with multiple criteria including trace length, planarity, and the development of rims, borders, and vapor-phase mineral coatings (Buesch et al., 1999 [DIRS 165483]). Type 1 fractures formed during the time that the host rock was glass, and although not well constrained, this was probably within the first 5 to 15 years after deposition of the Topopah Spring Tuff. Type 2 fractures formed during the time that the host rocks had crystallized but had not cooled to the ambient temperature of a rock near the ground surface, and again this is not well constrained, but was probably in the range of 10 to 100 years (Buesch and Spengler, 1998 [DIRS 101433], p. 21).

Detailed small-scaled studies such as those on slabs of core (and observations in thin sections) and the Small-Scale Fracture studies indicate that although trace length and planarity are important properties, the development of rims, borders, and vapor-phase mineral coatings are the defining characteristics. With this shift in defining characteristics, there are a few refinements to the Type 1 and Type 2 definitions. Type 1 is retained for the general category, and for fractures with trace lengths that are measured on length scales of greater than $1 \mathrm{~m}$. "Type $1 \mathrm{~s}$ " is used for fractures with rims, borders, and tubular structures, and for fractures with trace lengths that are measured on length (or partial length) scales of less than $1 \mathrm{~m}$. Vapor-phase mineral coatings can be on Type 1 and 1 s fractures, but they are not necessarily part of the defining characteristics because the amount of vapor needed to form these deposits might not have been locally available during the appropriate temperatures for mineralization. Similarly, Type 2 is retained for the general category, and for fractures with trace lengths that are measured on length scales greater than $1 \mathrm{~m}$. "Type $2 \mathrm{~s}$ " is used for fractures without rims, borders, and tubular structures but with vapor-phase mineral coatings, and for fractures with trace lengths that are measured on length (or partial length) scales of less than $1 \mathrm{~m}$. Vapor-phase mineral coatings are important for identifying Type 2 and 2s fractures because without the rims, borders, and tubular structures, the vapor-phase mineral coatings are one of the only ways to distinguish cooling fractures from Type 3 fractures that formed after cooling of the deposit.

In the DLS data, the ratio of cooling and indeterminate features is not exactly the same in fractures, shears, and "broken or crushed rock or sand" material filled discontinuities. However, the overall proportions of cooling and indeterminate features in these different discontinuities are consistent with the formation of an intricate, "early formed", fracture network. A subset of this "early formed" network of cooling and indeterminate (but possibly cooling related) fractures were "opened" by (1) dilation of the fractures during thermal contraction and cooling of the rock mass or (2) extension during structural tilting or faulting. "Broken or crushed rock or sand" material filled some fractures and shears (and even some faults). The vast majority of these fractures and shears appear to have formed under the simple conditions of tension and without significant evidence of compression or large amounts of dynamic grinding, shaking, or 
"chattering" of the discontinuities. This lack of significant evidence of compression or large amounts of dynamic grinding, shaking, or "chattering" of the fractures is consistent with the fracture relations in the slabs of core.

It is important to note that this fairly simple tensional deformation history does not necessarily apply to all shears or faults in the repository block of Yucca Mountain for three reasons:

1. The review and re-categorization of the ECRB DLS data focused on the fractures and shears in the main rock mass and did not include detailed analyses of the larger faults and fault zones (especially the Solitario Canyon fault);

2. The internal granular texture, fabric, structure, and architecture of shears and faults have not been studied in detail to determine amounts of mechanical abrasion of fragments. Many shears and small faults have relatively simple characteristics; however, some faults with larger amounts of separation (including the Solitario Canyon fault) appear to have grading in grain sizes that increases away from the wall. This grain structure is consistent with either size sorting during flow of granular materials (i.e., sedimentary processes such as grain flow along an “open” fault plane), or segregation and grading resulting from shear and possibly mechanical abrasion and grain-size reduction resulting from shear (i.e., mechanical processes); and

3. The ECRB Cross-Drift transected several faults typical of many faults at Yucca Mountain, including the Solitario Canyon fault, so there is probably a good representation of fault characteristics in the ECRB data; however, not all the faults at Yucca Mountain have been examined.

\section{A1.1.2 Shapes of Lithophysae as Large Strain Indicators}

Discontinuum numerical model results of drift stability for some $10^{-5}$ and all $10^{-6}$ annual frequency of exceedance ground motion simulations indicate the drift walls and surrounding rocks of the lower lithophysal zone in the Topopah Spring Tuff become pervasively shattered resulting in collapse of the drift (BSC, 2004 [DIRS 166107] Section 6.4.2.2). In contrast, modeling runs for $10^{-4}$ and some of the $10^{-5}$ annual frequency of exceedance ground motion simulations did not result in pervasive shattering of the rocks and therefore, no collapse of the drift (BSC, 2004 [DIRS 166107] Section 6.4.2.2). Discontinuum numerical modeling including lithophysal cavities (Section 6.4.2) suggests that lithophysae would be extensively damaged, and possibly collapsed at high shear strains.

To look for field evidence of collapsed lithophysae, locations in the ECRB Cross-Drift have been re-examined where photographs of the walls document the conditions of the rocks in the lower lithophysal, middle nonlithophysal, and upper lithophysal zones (Table A-4). To support lithophysal studies in 2001 and 2002, 18 photographs (each photograph includes an area of about $1.4 \times 4.2 \mathrm{~m}$ of the tunnel wall) were taken and served as the base-maps for the "Panel Maps" (DTN: GS021008314224.002 [DIRS 161910]). The 1x3-m sized panel maps document the size, shape, and abundance of lithophysae and other features such as spots and lithic clasts (with no minimum size), and the features were mapped in the field at a scale of 1:10 with a minimum resolution of about $1 \mathrm{~mm}$. However, use of the digital images for the panel maps provide photographic interpretive scales of features as small as $2 \mathrm{~mm}$. To support fracture and 
lithophysal studies in 2003 and 2004, 20 photographs (each includes about 2.3x7.4 m of the tunnel wall) were taken to document locations of the 2x6-m sized Small-Scale Fracture and Panel Photograph study locations. Of these 20 photographs, 14 were taken on opposite walls of the tunnel to form pairs of photographs at seven stations. The digital images of the $2 \times 6-m$ areas provide photographic interpretive scales of features as small as $2 \mathrm{~mm}$, and lithophysae with diameters larger than $20 \mathrm{~cm}$ were documented. Photographs for the Panel Maps, Small-Scale Fracture, and Panel Photographic study locations were taken with low-angle illumination to accentuate the edges of cavities.

Table A1-4. Locations (Including Station and Wall), Lithostratigraphic Zones, and Sizes of Photographs of Tunnel Walls in the ECRB Cross-Drift, Including the Primary Study for which the Photographs were Taken and List of the Section in which the Photograph is Displayed

\begin{tabular}{|c|c|c|c|c|c|c|c|}
\hline Station & Wall & $\begin{array}{l}\text { Lithostratigraphic } \\
\text { Zone }\end{array}$ & $\begin{array}{l}\text { Photograph } \\
\text { Size (m) }\end{array}$ & $\begin{array}{l}\text { Nominal } \\
\text { Size }(\mathrm{m})\end{array}$ & Primary Study & $\begin{array}{c}\text { Photograph } \\
\text { Name }\end{array}$ & Section \\
\hline $06+60$ & Left & Tptpul & $2.3 \times 7.4$ & $2 \times 6$ & $\begin{array}{l}\text { Small Scale Fracture } \\
\text { study }\end{array}$ & PP0660L & A4 \\
\hline $06+60$ & Right & Tptpul & $2.3 \times 7.4$ & $2 \times 6$ & Panel photograph study & PP0660R & A4 \\
\hline $07+40$ & Left & Tptpul & $2.3 \times 7.4$ & $2 \times 6$ & Panel photograph study & PP0740L & A4 \\
\hline $07+40$ & Right & Tptpul & $2.3 \times 7.4$ & $2 \times 6$ & Panel photograph study & PP0740R & A4 \\
\hline 08+15 & Left & Tptpul & $2.3 \times 7.4$ & $2 \times 6$ & Panel photograph study & PP0815L & A4 \\
\hline $08+16$ & Right & Tptpul & $2.3 \times 7.4$ & $2 \times 6$ & Panel photograph study & PP0816R & A4 \\
\hline $09+10$ & Left & Tptpul & $2.3 \times 7.4$ & $2 \times 6$ & Panel photograph study & PP0910L & A4 \\
\hline $09+10$ & Right & Tptpul & $2.3 \times 7.4$ & $2 \times 6$ & Panel photograph study & PP0910R & A4 \\
\hline $09+35$ & Left & Tptpul & $2.3 \times 7.4$ & $2 \times 6$ & Panel photograph study & PP0935L & A4 \\
\hline $09+35$ & Right & Tptpul & $2.3 \times 7.4$ & $2 \times 6$ & Panel photograph study & PP0935R & A4 \\
\hline $10+35$ & Left & Tptpmn & $2.3 \times 7.4$ & $2 \times 6$ & $\begin{array}{l}\text { Small Scale Fracture } \\
\text { study }\end{array}$ & PP1035L & A4 \\
\hline $10+35$ & Right & Tptpmn & $2.3 \times 7.4$ & $2 \times 6$ & Panel photograph study & PP1035R & A4 \\
\hline $12+20$ & Left & Tptpmn & $2.3 \times 7.4$ & $2 \times 6$ & Panel photograph study & PP1220L & A4 \\
\hline $12+18$ & Right & Tptpmn & $2.3 \times 7.4$ & $2 \times 6$ & Panel photograph study & PP1218R & A4 \\
\hline $14+93$ & Right & Tptpll & $1.4 \times 4.2$ & $1 \times 3$ & Panel map study & PM1493R & A3 \\
\hline $15+51$ & Left & Tptpll & $1.4 \times 4.2$ & $1 \times 3$ & Panel map study & PM1515L & $\mathrm{A} 3$ \\
\hline $16+10$ & Right & Tptpll & $1.4 \times 4.2$ & $1 \times 3$ & Panel map study & PM1610R & A3 \\
\hline $16+24$ & Right & Tptpll & $1.4 \times 4.2$ & $1 \times 3$ & Panel map study & PM1624R & A3 \\
\hline $16+41$ & Left & Tptpll & $1.4 \times 4.2$ & $1 \times 3$ & Panel map study & PM1641L & A3 \\
\hline $16+41$ & Right & Tptpll & $1.4 \times 4.2$ & $1 \times 3$ & Panel map study & PM1641R & A3 \\
\hline $16+56$ & Left & Tptpll & $1.4 \times 4.2$ & $1 \times 3$ & Panel map study & PM1656L & $\mathrm{A} 3$ \\
\hline $17+26$ & Left & Tptpll & $1.4 \times 4.2$ & $1 \times 3$ & Panel map study & PM1726L & A3 \\
\hline $17+68$ & Left & Tptpll & $1.4 \times 4.2$ & $1 \times 3$ & Panel map study & PM1768L & A3 \\
\hline $17+68$ & Right & Tptpll & $1.4 \times 4.2$ & $1 \times 3$ & Panel map study & PM1768R & A3 \\
\hline $18+05$ & Left & Tptpll & $1.4 \times 4.2$ & $1 \times 3$ & Panel map study & PM1805L & A3 \\
\hline $18+05$ & Left & Tptpll & $2.3 \times 7.4$ & $2 \times 6$ & $\begin{array}{l}\text { Small Scale Fracture } \\
\text { study }\end{array}$ & SSF1805L & A4 \\
\hline $18+86$ & Left & Tptpll & $1.4 \times 4.2$ & $1 \times 3$ & Panel map study & PM1886L & A3 \\
\hline $18+86$ & Left & Tptpll & $2.3 \times 7.4$ & $2 \times 6$ & $\begin{array}{l}\text { Small Scale Fracture } \\
\text { study }\end{array}$ & SSF1886L & A4 \\
\hline
\end{tabular}


Table A1-4. Locations (Including Station and Wall), Lithostratigraphic Zones, and Sizes of Photographs of Tunnel Walls in the ECRB Cross-Drift, Including the Primary Study for which the Photographs were Taken and List of the Section in which the Photograph is Displayed (Continued)

\begin{tabular}{|l|l|l|l|l|l|l|l|}
\hline Station & Wall & $\begin{array}{c}\text { Lithostratigraphic } \\
\text { Zone }\end{array}$ & $\begin{array}{c}\text { Photograph } \\
\text { Size }(\mathbf{m})\end{array}$ & $\begin{array}{c}\text { Nominal } \\
\text { Size }(\mathbf{m})\end{array}$ & \multicolumn{1}{|c|}{ Primary Study } & $\begin{array}{c}\text { Photograph } \\
\text { Name }\end{array}$ & \multicolumn{1}{c|}{ Section } \\
\hline $19+19$ & Left & Tptpll & $1.4 \times 4.2$ & $1 \times 3$ & Panel map study & PM1919L & A3 \\
\hline $19+20$ & Left & Tptpll & $2.3 \times 7.4$ & $2 \times 6$ & $\begin{array}{l}\text { Small Scale Fracture } \\
\text { study }\end{array}$ & SSF1920L & A4 \\
\hline $20+18$ & Left & Tptpll & $1.4 \times 4.2$ & $1 \times 3$ & Panel map study & PM2018L & A3 \\
\hline $20+19$ & Left & Tptpll & $2.3 \times 7.4$ & $2 \times 6$ & $\begin{array}{l}\text { Small Scale Fracture } \\
\text { study }\end{array}$ & SSF2019L & A4 \\
\hline $20+69$ & Left & Tptpll & $1.4 \times 4.2$ & $1 \times 3$ & Panel map study & PM2069L & A3 \\
\hline $20+71$ & Left & Tptpll & $2.3 \times 7.4$ & $2 \times 6$ & $\begin{array}{l}\text { Small Scale Fracture } \\
\text { study }\end{array}$ & SSF2071L & A4 \\
\hline $21+24$ & Left & Tptpll & $1.4 \times 4.2$ & $1 \times 3$ & Panel map study & PM2124L & A3 \\
\hline $21+25$ & Left & Tptpll & $2.3 \times 7.4$ & $2 \times 6$ & $\begin{array}{l}\text { Small Scale Fracture } \\
\text { study }\end{array}$ & SSF2125L & A4 \\
\hline $22+32$ & Left & Tptpll & $1.4 \times 4.2$ & $1 \times 3$ & Panel map study & PM2232L & A3 \\
\hline $22+94$ & Left & Tptpll & $1.4 \times 4.2$ & $1 \times 3$ & Panel map study & PM2294L & A3 \\
\hline
\end{tabular}

Source: DTN: GS021008314224.002 [DIRS 161910], DTN: MO0402GSC04031.000 [DIRS 172231], and Sections A3 and A4 of this report.

Prior to the lithophysal studies conducted from 2001 to 2003, three basic shapes (simple, merged, and cuspate) of lithophysae had been identified and were incorporated into the recent studies, and during the 2001-2002 mapping effort a fourth category (expansion-crack lithophysae) was identified (Figure A1-17). The simple, merged, and expansion-crack lithophysae shapes are entirely consistent with the growth and inflation of cavities during welding and redistribution of the vapor phase. Cuspate lithophysae typically merge with one or more fractures or veinlets along cusps, and this shape is consistent with the partial deflation of the cavity after being breached by a propagating fracture. As the lithophysal studies continued from 2001 to 2003 (and 2004), it became clear that some cuspate lithophysae might be parts of expansion-crack lithophysae, although these lithophysae were not re-examined in detail and possibly re-categorized. For lithophysal cavities to inflate (and some deflate), the host material must have been viscous and ductile; therefore, it was glass. Where the vapor in the cavities interacted with the glass, it formed a rim that is typically composed of elongate feldspar minerals and either quartz or cristobalite. Being composed of minerals, a rim could not deform as a cavity inflated, so the rim typically formed a series of small expansion cracks that broke the wall into several curviplanar plates that moved apart as the cavity inflated. These small expansion cracks typically do not penetrate much beyond the edge of the rim or into matrix-groundmass, although some merge with veinlets or streaks and small fractures. Expansion-crack lithophysae formed in a similar way as other lithophysae, except that a few propagating expansion cracks were the dominant mechanism by which the cavity inflated, and the walls of the cavity between the expansion cracks simply moved away from the center of the lithophysae and from the opposite side of the expansion crack. Some lithophysae, especially expansion-crack lithophysae, appear to have some expansion cracks that merge into a discontinuous network of circum-lithophysal fractures that might represent the final stages of decoupling of the rigid rim and the ductile matrix. 


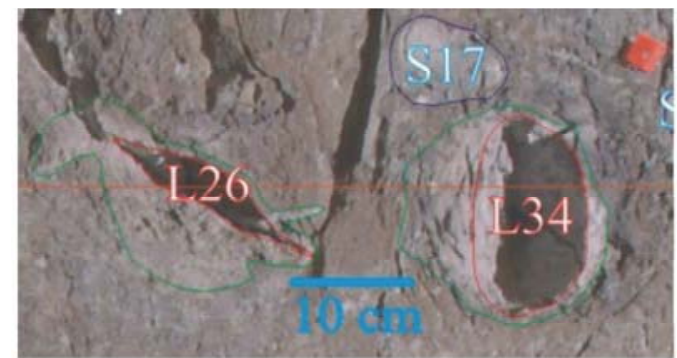

b) "Simple" lithophysae (L45 \& L44)

L44 has small expansion cracks.

(from Panel Map 1493R)

a) "Simple" lithophysae (L34 \& L26). (from Panel Map 1493R)
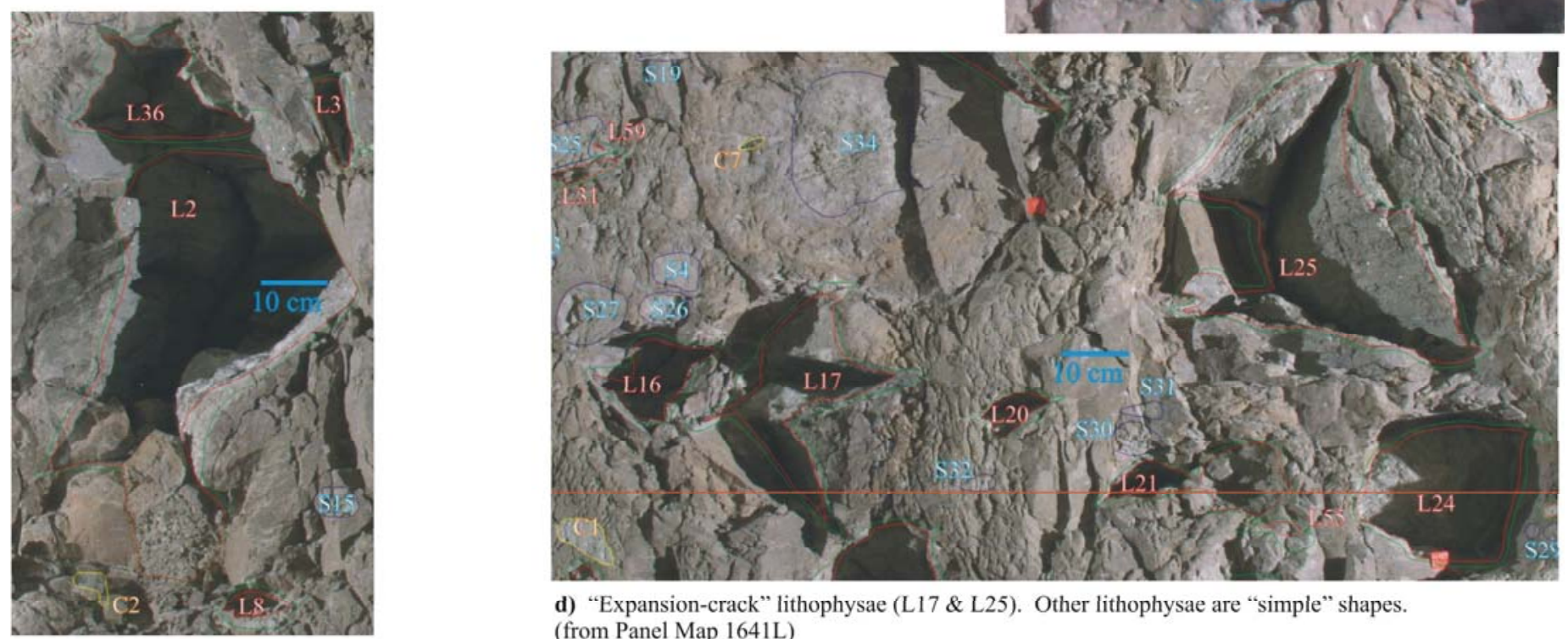

d) "Expansion-crack" lithophysae (L17 \& L25). Other lithophysae are "simple" shapes.

c) Merged lithophysae(L2 \& L36). (from Panel Map 1641L)

L2 itself is merged and has "backfilled" fracture at the base.

Source: Panel maps in DTN: GS021008314224.002 [DIRS 161910] and Section A3 of this report.

NOTES: a. Simple lithophysae.

b. Simple lithophysae with expansion cracks.

17
0
0
0
0
0
0
8
0

Figure A1-17. Shapes of Lithophysae 
Panel Maps include the location and shape of lithophysal cavities, rims on lithophysae, spots, and lithic clasts (Figure A1-18). During the mapping of features on the Panel Maps, individual shapes of features were mapped on the 1:10 scale photographs and several types of measurements (including the shape category) were recorded in Microsoft ${ }^{\circledR}$ Excel workbooks with "Meas" (for "Measurements") in the file title (DTN: GS021008314224.002 [DIRS 161910]). A full set of 18 electronic (JPEG) files of panel maps is included in Section A3. Eleven 2x6-m photographs were used for photographic interpretations of lithophysal shapes where lithophysae greater than $20 \mathrm{~cm}$ in diameter were inventoried (Figure A-19). A full set of 20 electronic (JPEG) files of panel photographs are included in Section A4. Although the walls of the tunnel were initially washed just after they were cut by the tunnel boring machine (TBM) and before they were mapped for the Full Periphery Maps and Detailed Line Surveys by the Bureau of Reclamation, numerous lithophysae were "backfilled" by muck from the TBM. During data collection on the panel maps, "backfilled" lithophysae were dug out by geologists; however, on the 2x6-m panel photographs the "backfilled" lithophysae were simply identified as such, especially if the shape could not be determined. In addition to identifying the four initial (simple, merged, cuspate and expansion-crack) shapes of lithophysae, data such as "backfilled" and "collapsed" lithophysae and those transected by fractures or shears have also been compiled for lithophysae identified in the panel maps and photographs. These data are included in a Microsoft ${ }^{\circledR}$ Excel 97 workbook PGV Lithop Shapes ECRB.xls (Appendix D). 

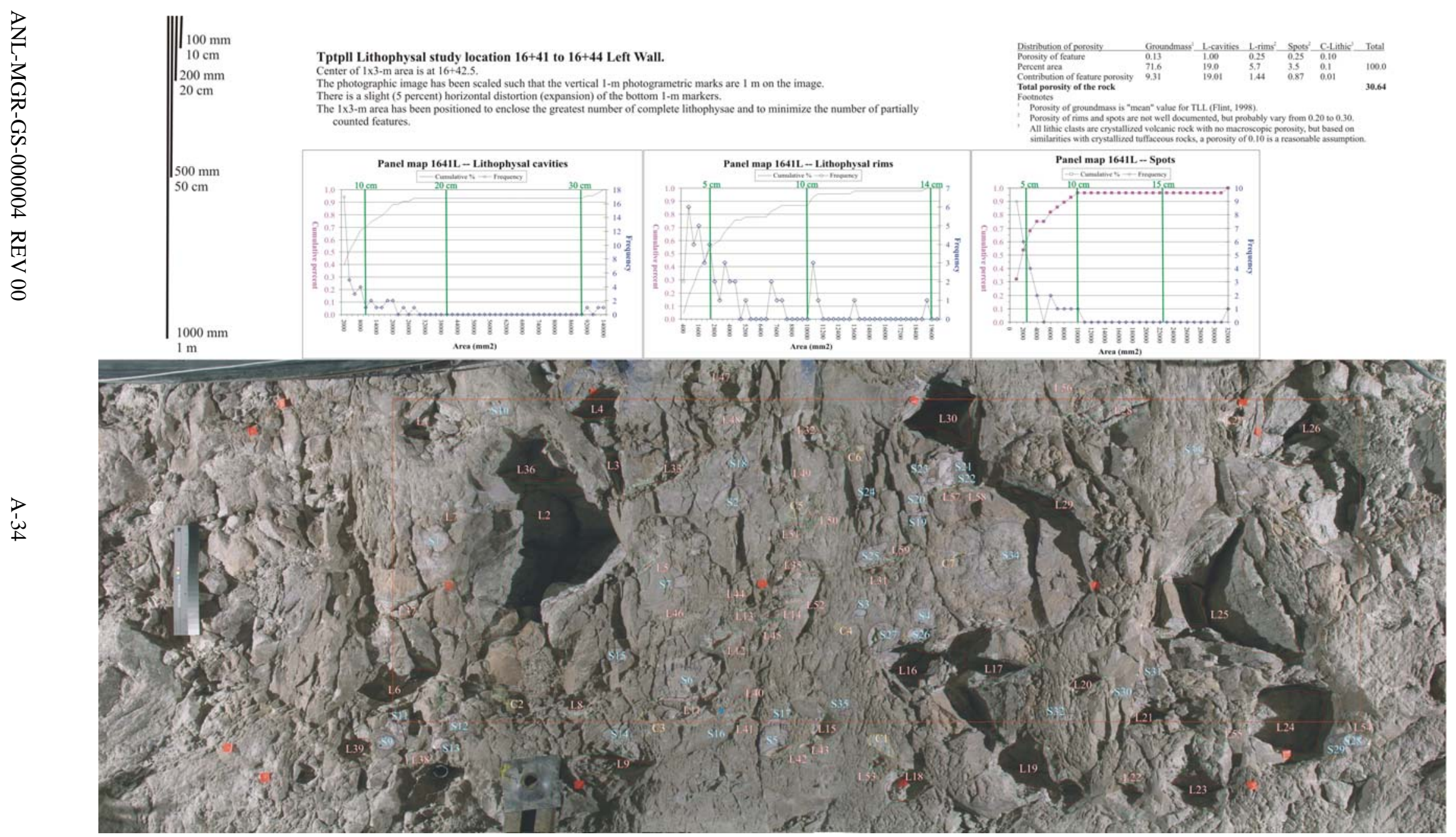

Source: Panel maps in DTN: GS021008314224.002 [DIRS 161910] and Section A3 of this report.

NOTE: Complete panel map at station location $16+41$ on the left rib. Lithophysal cavities are labeled in red with red lines outlining the cavity and green lines outlining the rim. Spots are labeled in cyan with outlines in cyan. Lithic clasts are labeled in orange and outlined in orange. These panel maps were designed to be viewed electronically or printed on 11x17-inch paper.

Figure A1-18a. Example Panel Map of Lithophysal Cavities, Lithophysal Rims, Spots, and Lithic Clasts 

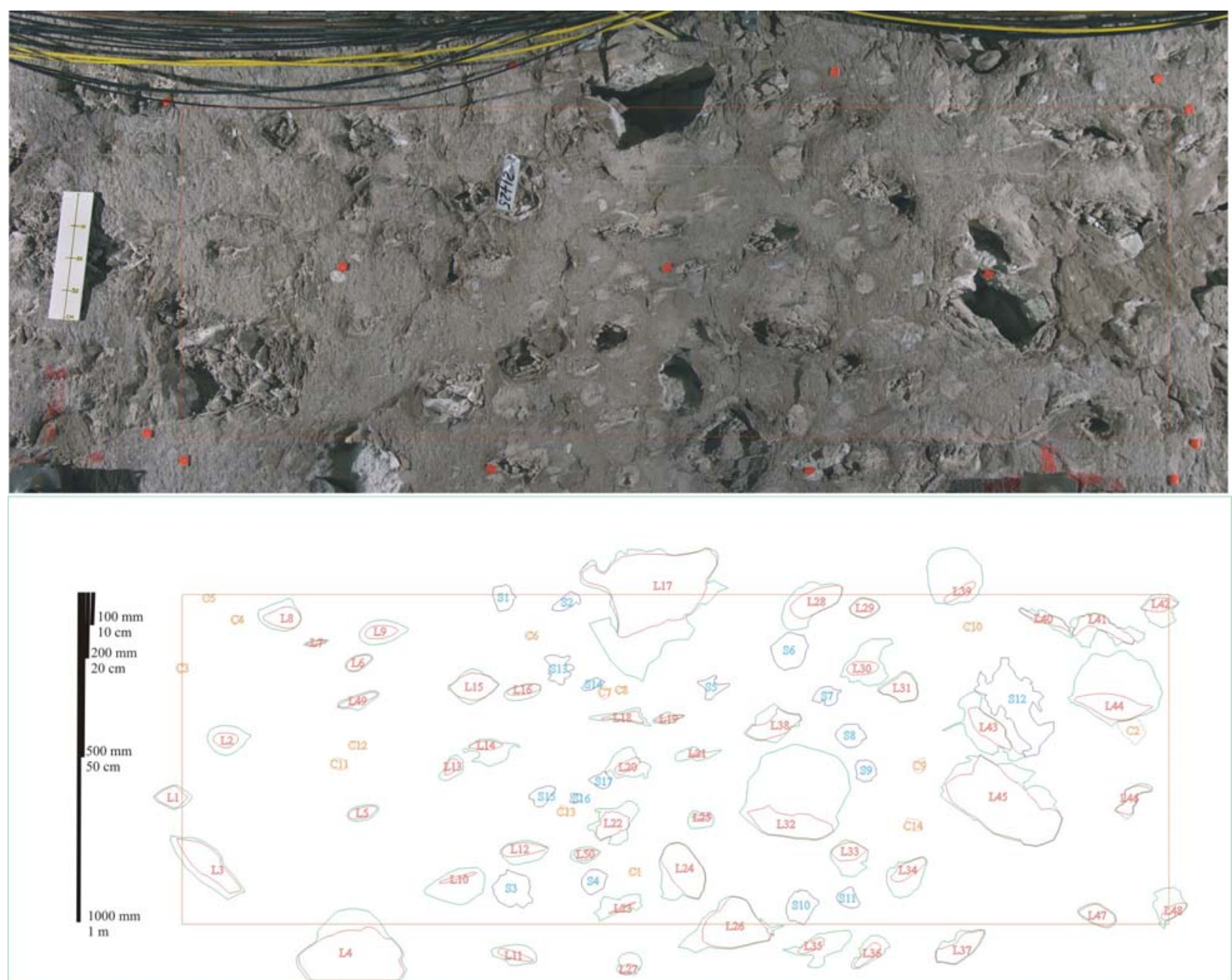

Source: Panel maps in DTN: GS021008314224.002 [DIRS 161910] and Section A3 of this report.

NOTE: Panel map at station location 21+25 on the left rib with photograph and mapped features displayed separately. Lithophysal cavities are labeled in red with red lines outlining the cavity and green lines outlining the rim. Spots are labeled in cyan with outlines in cyan. Lithic clasts are labeled in orange and outlined in orange.

Figure A1-18b. Example Panel Map of Lithophysal Cavities, Lithophysal Rims, Spots, and Lithic Clasts (Continued) 

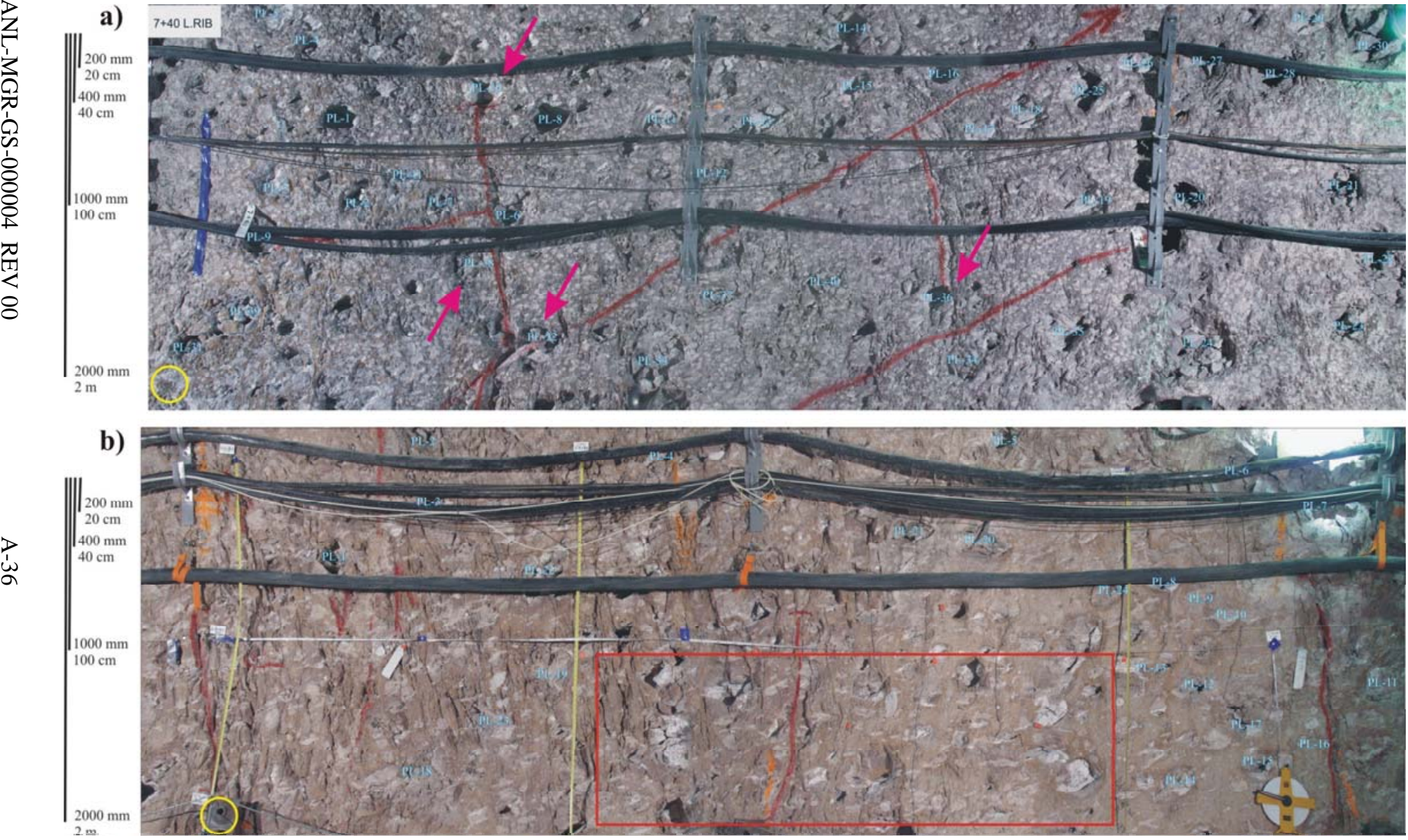

Source: Section A4 of this report.

NOTES: Lithophysal cavities greater than $20 \mathrm{~cm}$ in diameter are labeled in cyan, the yellow circle is $20 \mathrm{~cm}$ in diameter, and red-painted lines are fractures greater than $1 \mathrm{~m}$ in length that were mapped as part of the Detailed Line Survey.

a. Panel photograph at station location $07+40$ on the left rib in the upper lithophysal zone. Four lithophysae (indicated by magenta arrows) are either transected by fractures or the fractures terminate at the lithophysae.

b. Panel photograph at station location $18+86$ on the left rib in the lower lithophysal zone. The red rectangle is the $1 \times 3-m$ sized area of the associated panel map. Lithophysae in the panel map are not included in this photograph, but are displayed in the panel map in Section A3.

Figure A1-19. Panel Photographs with Locations of Lithophysal Cavities Greater Than $20 \mathrm{~cm}$ in Diameter that were Inventoried for Shape and Possible Collapse Features 


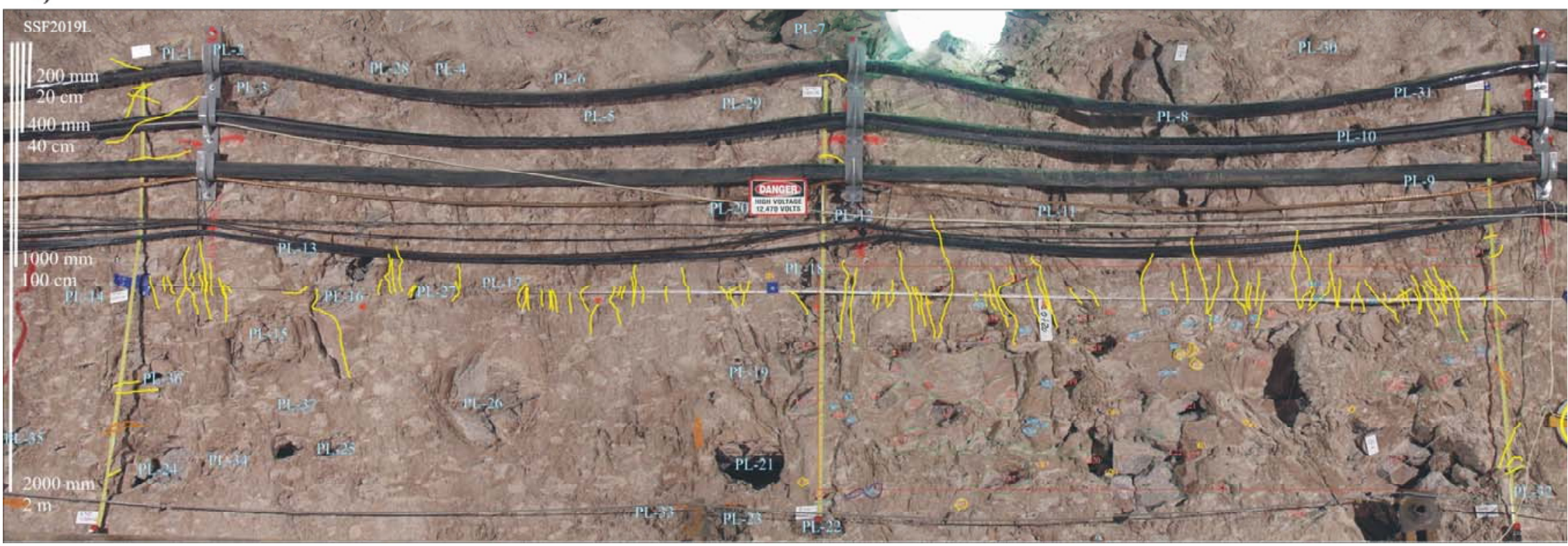

\section{Source: Section A4 of this report.}

NOTE: c. Panel photograph at station location 20+19 on the left rib in the lower lithophysal zone with Small-Scale Fracture data (trace lengths of fractures as yellow lines) and panel map data (lithophysal cavities, rims, spots, and lithic clasts) inside the $1 \times 3-\mathrm{m}$ red rectangle. Figure A-18b displays the detailed panel map at 21+25. Lithophysal cavities greater than $20 \mathrm{~cm}$ in diameter are labeled in cyan, the yellow circle is $20 \mathrm{~cm}$ in diameter, and red-painted lines (far left) are fractures greater than $1 \mathrm{~m}$ in length that were mapped as part of the Detailed Line Survey.

Figure A1-19. Panel Photographs with Locations of Lithophysal Cavities Greater than $20 \mathrm{~cm}$ in Diameter that were Inventoried for Shape and Possible Collapse Features (Continued) 
The 1x3-m panel maps and 2x6-m panel photographs document 1444 lithophysae from the upper lithophysal, middle nonlithophysal, and lower lithophysal zones in the ECRB Cross-Drift (Table A1-5). In the panel photographs, 34 lithophysae are identified only as "backfilled". Of the 1410 lithophysae that have easily identifiable initial shapes, 76.8 percent have simple shapes, 8.0 percent have merged shapes, 2.4 percent have cuspate shapes, and 12.8 percent have expansion-crack shapes (Table A1-5). During data collection, the effects of "damage" to these shapes were implicitly evaluated and determined to be minimal. The apparent "damage" typically was attributed to plucking of pieces on the edges, which were bounded by very small fractures, and were plucked during cutting by the TBM or the (fairly aggressive) washing of the walls. What this means is that the walls of the lithophysae away from the "plucked" segments have intact vapor-phase mineral coatings and features such as small expansion cracks. Of the lithophysae examined, there are none that are categorized as "collapsed”.

Some lithophysae have coatings of calcite along the floor, but the occurrence of rock fragments included in and cemented by the calcite coatings, as described by Whelan (2004 [DIRS 170697]), was not documented in the present study. Some lithophysae have small piles of loose rubble on the floors. However, these deposits were inevitably determined to be residual piles of muck from the TBM that had not been washed out because (1) the apparent grain size distributions were consistent with the tunnel muck, and (2) fairly delicate features such as vapor-phase mineral lining and expansion cracks on the roofs and walls of the lithophysae are intact.

Of the lithophysae inspected, only 7 are transected (or intersected) by fractures, and only 5 are transected by shears. In the panel photograph at station $07+40$ on the left wall (Figure A1-19), two lithophysae are transected by fractures (in the lower left) and two lithophysae are at the terminal ends of fractures (upper left and lower right).

The conclusion of this re-examination of lithophysal cavity shapes in panel maps and panel photographs along the ECRB Cross-Drift is that none of the lithophysae depict damage attributed to shaking or mechanical degradation of the rock. Even the few lithophysae that (1) are transected by fractures, (2) are the terminal end of fractures, or (3) occur along shears, have no appreciable effects of damage to the walls of the lithophysae.

Table A1-5. Initial Shapes of Lithophysae, "Backfilled" Lithophysae, and Lithophysae that are Transected by Fractures or Shears in Panel Maps and Panel Photographs in the ECRB Cross-Drift

\begin{tabular}{|l|l|l|l|l|l|l|l|l|l|}
\hline Type of Data & Simple & Merged & Cuspate & $\begin{array}{c}\text { Expansion- } \\
\text { Crack }\end{array}$ & $\begin{array}{c}\text { Total } \\
\text { Initial } \\
\text { Shapes }\end{array}$ & Backfilled & Collapsed & $\begin{array}{c}\text { Fracture } \\
\text { Transected }\end{array}$ & Sheared \\
\hline Panel map & 940 & 89 & 18 & 61 & 1108 & 0 & 0 & 0 & 3 \\
\hline $\begin{array}{l}\text { Panel } \\
\text { photograph }\end{array}$ & 143 & 24 & 16 & 119 & 302 & 34 & 0 & 7 & 2 \\
\hline Total Number & 1083 & 113 & 34 & 180 & 1410 & 34 & 0 & 7 & 5 \\
\hline
\end{tabular}

Source: PGV Lithop Shapes ECRB.xIs (Appendix D)

\section{A1.1.3 Interaction of Fractures and Lithophysae as Large Strain Indicators}

Failure of lithophysal rocks in laboratory experiments indicates that fractures typically develop through the rock material and many of the fractures connect lithophysae to form 
inter-lithophysae fracture networks. Modeling of rock mechanics with the Particle Flow Code (PFC) computer program enables detailed analyses of the failure mechanisms and the development of inter-lithophysae fractures. The 2-dimensional PFC (PFC2D) rock mechanics model for lithophysal rocks consists of a 1x1-m sized "sample" that has been calibrated to laboratory results (see Section 6.4 and Appendix B). PFC2D model results indicate that the inter-lithophysae fractures develop in "samples" where the lithophysae are depicted as circles, triangles, "stars", or realistic shapes copied from "stencils" derived from the panel maps (BSC 2003 [DIRS 166660], Attachment V-Appendix B). Examples of six stress-strain, PFC model results from stencils derived from panel maps at 16+24 (right wall) and 16+41 (left wall) are depicted in Figure A1-20a and b. In these PFC model results, the blue lines are microfractures formed prior to failure at peak strength and red lines are micro-fractures formed postfailure at peak strength.

The criteria for determining how and when micro-fractures form relative to increasing levels of shear strain are described in detail in Section 6.4 and Appendix B; however, what is critical from the field point of view is if micro-fractures are integrated into systematic fractures that can be identified in the field. The integration of micro-fractures into observable inter-lithophysae fractures and patterns is the key field-based relation of lithophysae and fractures that is used to evaluate whether or not the rocks have ever been exposed to strains large enough to result in failure. This geologically-based observation is comparable to the three damage state definitions discussed in the context of the laboratory tests and rock mechanics modeling: volumetric strain reversal, onset of systematic fracturing, and peak stress (see Section 6.4 and Appendix B). 

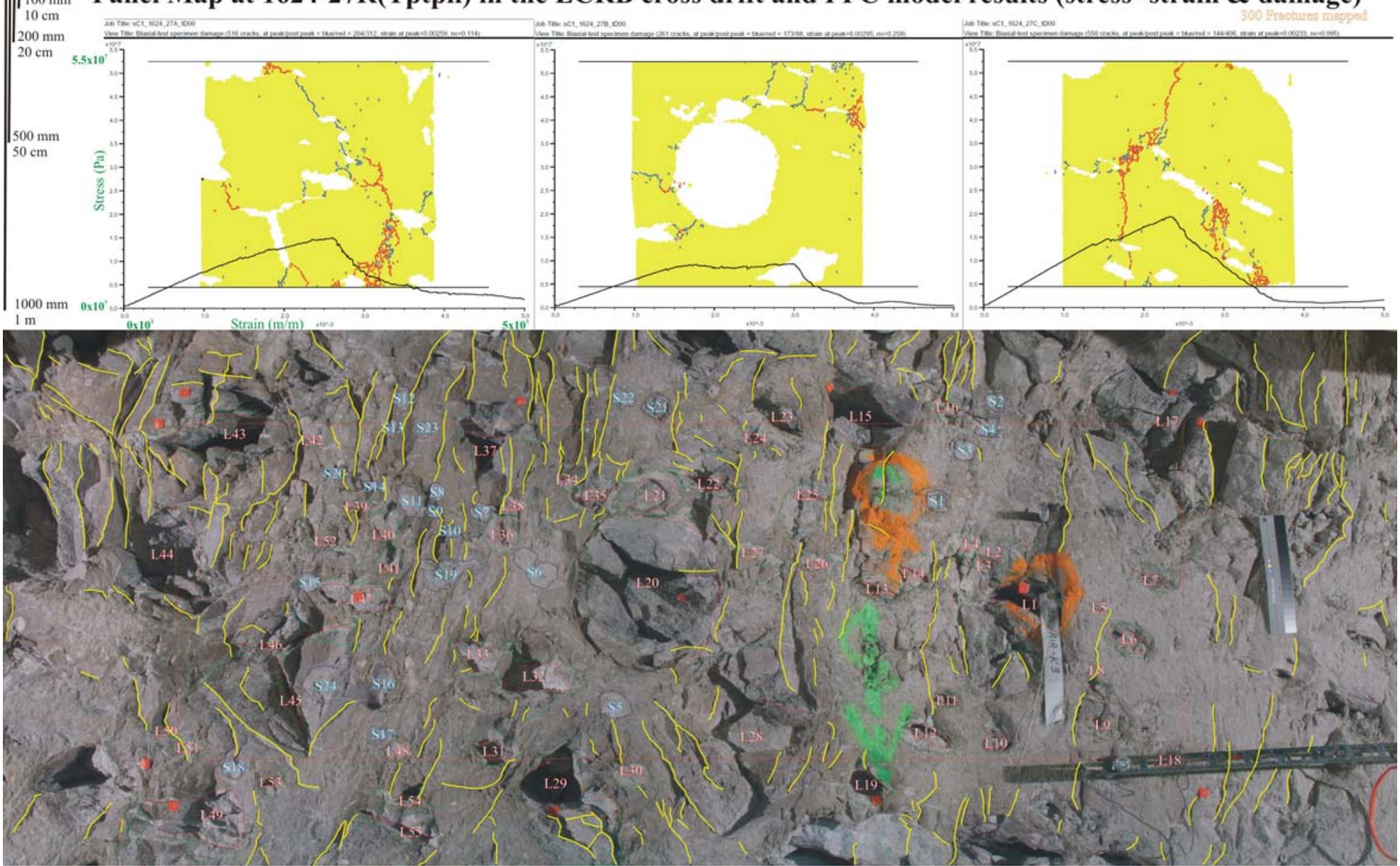

DTN: GS021008314224.002 [DIRS 161910]; BSC (2003 [DIRS 166660], Attachment V- Appendix B, Figure B-4).

Sources:

Upper part of figure shows stress-strain model results (BSC 2004 [DIRS 172334]) using the software code PFC2D. Blue lines are micro-fractures

formed prior to failure at peak strength and red lines are micro-fractures formed post-failure at peak strength. Embedded lithophysae are derived from stencils taken from the panel map below. The lower part of the figure is the panel map at $16+24$ on the right wall with 300 photographically interpreted fractures (yellow lines).

Figure A1-20a. Comparison of Modeled Fracture Development in Lithophysal Rock Samples that are Deformed to Failure to Observed Fractures in the Enhanced Characterization of the Repository Block Cross-Drift 


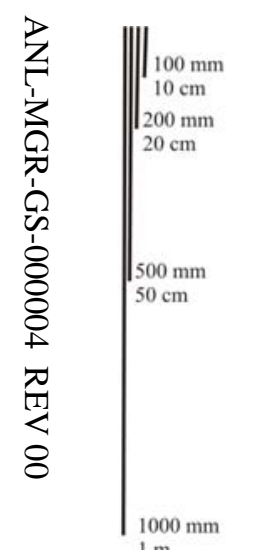

Panel Map at 1641-44L(Tptpll) in the ECRB cross drift and PFC model results (stress -strain \& damage)
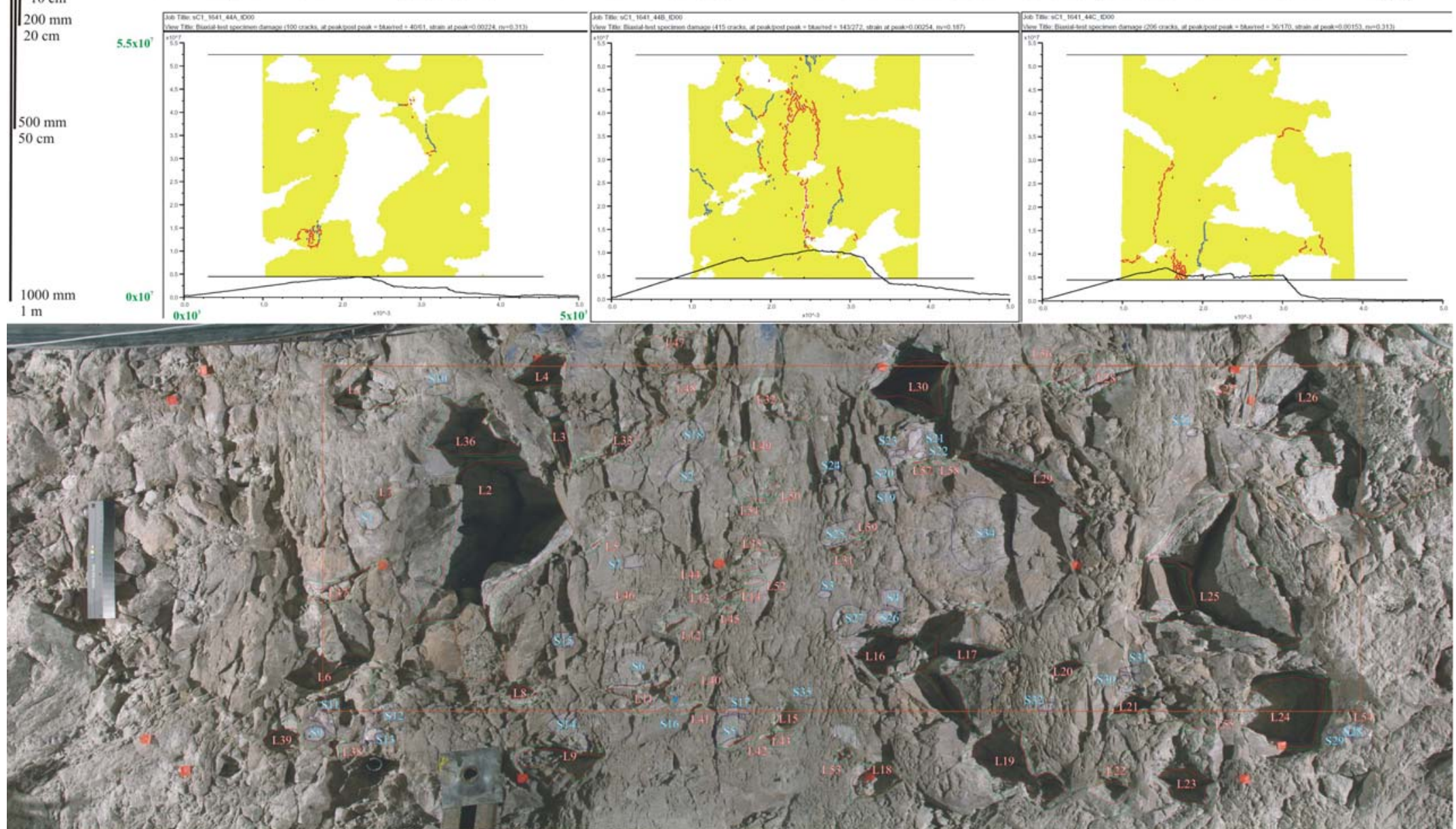

Sources: DTN: GS021008314224.002 [DIRS 161910]; BSC (2003 [DIRS 166660], Attachment V-Appendix B, Figure B-5).

NOTE: Upper part of figure shows stress-strain model results (BSC 2004 [DIRS 172334]) using the software code PFC2D. Blue lines are micro-fractures formed prior to failure at peak strength and red lines are micro-fractures formed post-failure at peak strength. Embedded lithophysae are derived from stencils taken from the panel map below. The lower part of the figure is the panel map at $16+41$ on the left wall.

Figure A1-20b. Comparison of Modeled Fracture Development in Lithophysal Rock Samples that are Deformed to Failure to Observed Fractures in the Enhanced Characterization of the Repository Block Cross-Drift (Continued) 
To better document the relations of fractures and lithophysae in the upper lithophysal, middle nonlithophysal, and lower lithophysal zones, photographs of the tunnel walls in the ECRB Cross-Drift have been examined. In the lower lithophysal zone, photographs of five of the Small-Scale Fracture study locations have the traces of the recorded fractures marked on the wall (in black) (photographs SSF1805L, SSF1886L, SSF1920L, SSF2071L, and SSF2125L), and for one location, the traces have been overlain on the photograph to make them more visible (photograph SSF2019L) (Figure A1-19c, Section A4, GS040408314224.003 [DIRS 170312]). None of the panel maps or panel photographs have explicitly been used to create 2-dimensional fracture maps in the field. One panel map at $16+24$ on the right wall $(16+24 \mathrm{R})$ in the lower lithophysal zone was used to develop a photographically interpreted fracture map (Figure A1-20a). In this map, the edges of lithophysae cavities, rims and spots (red, green, and cyan lines, respectively) were mapped; however, expansion cracks and other fractures inside the lithophysae were not mapped. Some of the lithophysae have moderate-to well-developed circum-lithophysal cavity fractures such as the almost 50-cm diameter expansion-crack lithophysae in the center of the panel map 16+24R (Figure A1-20a).

There are several lithophysae-fracture relations, summarized below, for the 167 fractures depicted in the Small-Scale Fracture data at 20+19L (Figure A1-19c, PGV SSF DLS Frac-Fill.xls in Appendix D) and the 300 fractures depicted on the panel map at 16+24R (Figure A1-20a). Although detailed fractures have not mapped, many of these relations are also in other panel maps and panel photographs (see Section A3 and A4).

1. Most fractures have trace lengths less than $30 \mathrm{~cm}$ long, and only a few are greater than $50 \mathrm{~cm}$ long.

2. Most fractures are steeply dipping; however, some that appear to be more shallowly dipping might in fact be steeply dipping but with an apparent shallow dip in the plane of the tunnel cut.

3. Many fractures have developed in the matrix-groundmass and appear to have formed irrespective of the occurrence of a lithophysae nearby.

4. Some fractures intersect or truncate into lithophysae, but few appear to transect lithophysae.

5. Several fractures are "circum-lithophysal" fractures that formed around or parallel to the margins of lithophysae.

Photographs used for this re-examination of the relations of lithophysae and fractures represent only about 2 percent of the total exposed area of the tunnel walls. However, the locations of the photographs and subsequent studies were identified as being representative of the rocks at various positions along the ECRB Cross-Drift.

The conclusion of this re-evaluation of the photographs is that most of the relations of lithophysae and fractures in the photographs are consistent with (1) localized in situ fracturing of the matrix-groundmass during cooling of the rock mass, or (2) minor amounts of extension of the rock mass, probably during structural tilting of the mountain. Some fractures appear to form the 
type of observable inter-lithophysae fractures and patterns that are predicted from the PFC models, but these are relatively few in number and are not pervasive.

\section{A1.2 SUMMARY OF THE GEOLOGIC CONSTRAINTS ON THE TIMING OF LITHOPHYSAE AND FRACTURE FORMATION}

The features in a rock represent the major processes that have occurred through its geologic history; therefore, the features are used to reconstruct the sequential development of the rock-forming processes. This sequential development of features are placed in a temporal (or petrogenetic) framework that constrains how and when subsequent processes occurred. Furthermore, this petrogenetic framework is used to evaluate whether or not the rocks have ever experienced stresses great enough to result in mechanical failure of the rocks. Beyond the initial cooling-related sources of stress and strain, one of the prime sources of stress and strain to be considered are those associated with paleoseismic events.

The lithostratigraphic units in the Topopah Spring Tuff comprising the repository host horizon consist of densely welded, crystallized, and lithophysal or nonlithophysal rocks. During the welding process, the redistribution of the vapor phase resulted in development of lithophysae and transfer of the vapor phase along fractures. During and shortly after the development of lithophysal cavities and early-formed (Type 1 and Type 1s) fractures, the glass crystallized in the presence of the vapor (but not from the vapor) along the margins of lithophysal cavities and fractures to form light gray to pinkish gray rims. Even some of the matrix-groundmass surrounding the lithophysae and some fractures crystallized to form grayish red purple borders and reddish gray matrix-groundmass, and these features are consistent with crystallization of the matrix-groundmass in the presence of vapor. In the areas farthest from lithophysae and early-formed fractures, the matrix-groundmass is typically reddish brown, and it is interpreted as having crystallized in the absence of vapor. Fractures that formed late in the cooling history of the deposit do not have rims, formed when the rock was mostly (if not entirely) crystallized, and these fractures are indicative of Type 2 and Type 2s fractures. Vapor-phase mineral coatings typically are on cooling fractures, but they are not necessarily on all cooling fractures because the fracture could have formed after most of the vapor phase had been removed from the area, or the three-dimensional network of fractures simply did not penetrate a region of abundant vapor phase material. Lack of distinctive features such as rims or vapor-phase mineral coatings means that some Type 2 fractures might not be identified as being cooling fractures and might be identified as Type 3 fractures (those that formed after the rock had cooled to the ambient temperatures of a rock at the paleogeomorphic surface). To put this another way, some of the "indeterminate" fractures (those that do not have distinctive "cooling" related features such as rims or vapor-phase mineral coatings) can be consistent with being Type 2 cooling fractures. Although not examined in this evaluation, other properties of fractures such as orientation, planarity, roughness, and trace length might be used to help categorize "indeterminate" fractures as being Type 2 cooling fractures or Type 3 fractures.

Data from the fractures in slabs of core and DLS in the ECRB Cross-Drift were collected for different reasons and represent different scales of sample size and resolution; however, they form a consistent set of relations (1) in the petrogenetic formation of the cooling features of fractures, (2) where about 70 percent of fractures are related to cooling and 30 percent are indeterminate (but might be late-stage cooling related), and (3) where the vast majority of fractures have no 
evidence of shear or mechanical degradation. In the DLS data from the ECRB Cross-Drift, the ratio of cooling and indeterminate features is not exactly the same in fractures, shears, and "broken or crushed rock or sand" material filled discontinuities; however, the overall proportions of cooling and indeterminate features in these different discontinuities are consistent with the formation of an intricate, early formed, fracture network.

Lithophysal cavities developed very early in the formation of the rock (probably in the first few years after deposition), and are suspected as being sensitive indicators of applied strains. Of the 1410 lithophysae described in the panel maps and inventoried in the panel photographs, all the lithophysae have shapes that are consistent with the initial formation of the lithophysae during welding of the ignimbrite. None of the lithophysae show "damage" or collapse that could be the result of extreme earthquake ground motions. Of the 1444 lithophysae inspected, only 7 are transected (or intersected) by fractures greater than $1 \mathrm{~m}$ in trace length (the fractures were mapped during collection of DLS data), and only 5 are transected by shears. Although a few lithophysae (1) are transected by fractures, (2) are the terminal end of fractures, or (3) occur along shears, none have appreciable effects of damage to the walls of the lithophysae.

On the basis of PFC2D numerical simulations of rock mechanic properties, one of the most diagnostic relations of lithophysal rocks that have been subjected to significant shear strains is the development of a pervasive network of inter-lithophysal fractures and patterns (Section 6.4 and Appendix B). With increasing shear strain, micro-fractures integrate and form observable inter-lithophysal fractures and patterns. These observable inter-lithophysal fractures and patterns are comparable to the volumetric strain reversal, onset of systematic fracturing, and peak stress damage state definitions discussed in Section 6.4 and Appendix B. The 38 photographs of tunnel walls document textural and structural relations in rocks that contain lithophysae from the upper lithophysal and lower lithophysal zones (including two photographs from the lithophysae-bearing subzone of the middle nonlithophysal zone). Most of the relations of lithophysae and fractures in the photographs are consistent with (1) localized in situ fracturing of the matrix-groundmass during cooling of the rock mass, or (2) minor amounts of extension of the rock mass, probably during structural tilting of the mountain.

The four studies described in this Appendix document lithostratigraphic relations of lithophysae and fractures in densely welded and crystallized rocks in the 12.8-million-year old Topopah Spring Tuff, and by their occurrence (or lack thereof) help establish limits on the maximum strain the rocks have experienced since the time of deposition (for discussions on the strains, see section 6.4 and Appendix B). Because seismically induced stresses and ground motion affect large areas (and volumes) of the rock mass, the evaluation of several different lithostratigraphic units with spatially distributed samples more appropriately addresses probable geologically-observable ground motions than do studies in and adjacent to faults. Although the samples used in these four studies are limited in size and scale relative to the entire rock mass, one of the underlying strengths of these studies is that samples and study locations are spatially and stratigraphically distributed through the rock mass. There are localized examples of fractures that (1) might have resulted from minor amounts of shear and (2) are consistent with geometric relations indicative of the observable inter-lithophysal fractures and patterns. However, the vast majority of the results from these four studies indicate the rocks have not experienced failure and catastrophic damage of the rock mass of the Topopah Spring Tuff. 


\section{A2. SOURCE INFORMATION FOR BOREHOLES}

Table A2.1. Table of Borehole Identifiers and Citations from the Sample Management and Drilling Department "Geologic Logs" Used for Diameters of Core and Station Locations of ThermK and GETC Boreholes

\begin{tabular}{|c|c|c|}
\hline Borehole & Accession Number & Reference [DIRS] \\
\hline USW NRG-6 & DRC.19960509.0104 & YMP (1993 [172106]) \\
\hline USW UZ-14 & DRC.19960702.0263 & YMP (1995 [172113]) \\
\hline ECRB ThermK-001 & MOL.20010614.0098 & YMP (2001 [172115]) \\
\hline ECRB ThermK-002 & .0135 & YMP (2001 [172116]) \\
\hline ECRB ThermK-003 & .0103 & YMP (2001 [172117]) \\
\hline ECRB ThermK-004 & .0108 & YMP (2001 [172118]) \\
\hline ECRB ThermK-005 & .0113 & YMP (2001 [172119\}) \\
\hline ECRB ThermK-006 & MOL.20010913.0334 & YMP (2001 [172121]) \\
\hline ECRB ThermK-007 & .0339 & YMP (2001 [172122]) \\
\hline ECRB ThermK-008 & .0344 & YMP (2001 [172124]) \\
\hline ECRB ThermK-009 & .0349 & YMP (2001 [172131\}) \\
\hline ECRB ThermK-010 & .0354 & YMP (2001 [172132]) \\
\hline ECRB ThermK-011 & .0359 & YMP (2001 [172136]) \\
\hline ESF ThermK-012 & MOL.20030709.0313 & YMP (2003 [172138]) \\
\hline ESF ThermK-013 & .0317 & YMP (2003 [172141]) \\
\hline ESF ThermK-014 & .0321 & YMP (2003 [172143]) \\
\hline ESF ThermK-015 & .0325 & YMP (2003 [172145]) \\
\hline ESF ThermK-016 & .0329 & YMP (2003 [172146]) \\
\hline ESF ThermK-017 & .0334 & YMP (2003 [172149]) \\
\hline ESF ThermK-018 & .0338 & YMP (2003 [172150]) \\
\hline ESF ThermK-019 & .0343 & YMP (2003 [172151]) \\
\hline ESF-GTEC-CS6500-01 & MOL.20020703.0126 & YMP (2002 [172152\}) \\
\hline ESF-GTEC-CS6500-01A & .0130 & YMP (2002 [172154\}) \\
\hline ESF-GTEC-CS6500-02 & .0134 & YMP (2002 [172155]) \\
\hline ESF-GTEC-CS6500-04 & .0142 & YMP (2002 [172156]) \\
\hline ESF-GTEC-CS6500-04A & .0146 & YMP (2002 [172157]) \\
\hline ESF-GTEC-CS6500-05A & .0154 & YMP (2002 [172158]) \\
\hline ESF-GTEC-CS6500-05B & .0158 & YMP (2002 [172180]) \\
\hline ESF-GTEC-CS6500-06 & .0162 & YMP (2002 [172181]) \\
\hline ECRB-GTEC-CS1600-08 & MOL.20020710.0211 & YMP (2002 [172183]) \\
\hline ECRB-GTEC-CS1922-01 & MOL.20021104.0116 & YMP (2002 [172184]) \\
\hline ECRB-GTEC-CS1928-01 & .0132 & YMP (2002 [172185]) \\
\hline ECRB-GTEC-CS1928-03 & .0140 & YMP (2002 [172186]) \\
\hline ECRB-GTEC-CS1995-01 & .0145 & YMP (2002 [172187]) \\
\hline
\end{tabular}




\section{A3. PANEL MAPS IN THE LOWER LITHOPHYSAL ZONE OF THE TOPOPAH SPRING TUFF EXPOSED IN THE ECRB CROSS-DRIFT FROM STATIONS 14+44 TO 23+26. FILES ARE FROM DTN: GS021008314224.002}

The 18 Panel Maps that were completed in 2003 (DTN: GS021008314224.002 [DIRS 161910]) are reproduced in this section (Table A3-1). These maps were designed to be plotted on 11x17-inch paper (or larger) or viewed electronically such that the "zoom" function can be used to see many of the details of the maps and features in the rocks. The "Zoom" function in Microsoft ${ }^{\circledR}$ Word will also enable focusing in on specific features. So, although some of the text might be fairly small in the following paper copy reproductions, most of it can be identified in the electronic copy, otherwise please refer to the original data package.

Table A3-1. Locations of Panel Maps from the Lower Lithophysal Zone (Tptpll) in the ECRB Cross-Drift and the File Names of the Images (DTN: GS021008314224.002 [DIRS 161910])

\begin{tabular}{|c|c|c|c|c|}
\hline Study & Image Name & Station & Wall & Lithostratigraphic Unit \\
\hline Panel map, lithophysal study & PM1493R & $14+93$ & Right & Tptpll \\
\hline Panel map, lithophysal study & PM1551L & $15+51$ & Left & Tptpll \\
\hline Panel map, lithophysal study & PM1610R & $16+10$ & Right & Tptpll \\
\hline Panel map, lithophysal study & PM1624R & $16+24$ & Right & Tptpll \\
\hline Panel map, lithophysal study & PM1641L & $16+41$ & Left & Tptpll \\
\hline Panel map, lithophysal study & PM1641R & $16+41$ & Right & Tptpll \\
\hline Panel map, lithophysal study & PM1656L & $16+56$ & Left & Tptpll \\
\hline Panel map, lithophysal study & PM1726L & $17+26$ & Left & Tptpll \\
\hline Panel map, lithophysal study & PM1768L & $17+68$ & Left & Tptpll \\
\hline Panel map, lithophysal study & PM1768R & $17+68$ & Right & Tptpll \\
\hline Panel map, lithophysal study & PM1805L & $18+05$ & Left & Tptpll \\
\hline Panel map, lithophysal study & PM1886L & $18+86$ & Left & Tptpll \\
\hline Panel map, lithophysal study & PM1919L & $19+19$ & Left & Tptpll \\
\hline Panel map, lithophysal study & PM2018L & $20+18$ & Left & Tptpll \\
\hline Panel map, lithophysal study & PM2069L & $20+69$ & Left & Tptpll \\
\hline Panel map, lithophysal study & PM2124L & $21+24$ & Left & Tptpll \\
\hline Panel map, lithophysal study & PM2232L & $22+32$ & Left & Tptpll \\
\hline Panel map, lithophysal study & PM2294L & $22+94$ & Left & Tptpll \\
\hline
\end{tabular}

Panel maps contain several items.

1 Metric scale is on the left.

2 General information for the panel map.

3 The photograph is a composite of 3 digital images that were taken with low-angle illumination.

4 Red painted lines on the left walls are fractures that were mapped in the total ECRB DLS traverses.

5 Red rectangles are the area of Panel Maps.

6 Lithophysae (including cavities and associated rims) are labeled with red "L", spots are cyan "S", and lithic clasts are dark yellow "C".

7 Lithophysal cavities are outlined with red, rims are green, spots are blue, and lithic clasts are dark yellow. Photographs of some panels were taken prior to the digging out of lithophysae that were "back-filled" by muck from the Tunnel Boring Machine.

8 Abundance and cumulative frequency of the areas $\left(\mathrm{mm}^{2}\right)$ of lithophysal cavities, rims, and spots are plotted with equivalent areas of circles with various diameters.

9 The table in the upper right summarizes the abundance (percent) of each component, the porosity of each component, contribution to the total porosity of the components, and the total porosity of the rock. 


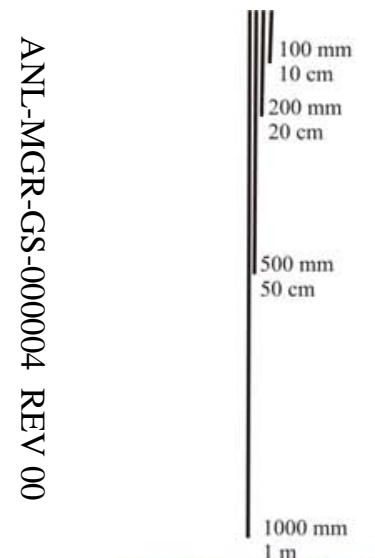

Tptpll Lithophysal study location 14+93 to 14+96 right wall.

The photographic image has been scaled such that the vertical 1-m photogrametric marks are $1 \mathrm{~m}$ on the image There is a slight ( 5 percent) horizontal distortion (expansion) of the bottom 1-m markers.

The Ix3-m area has been positioned to enclose the greatest number of complete lithophysae to minimize the number of partially counted features.
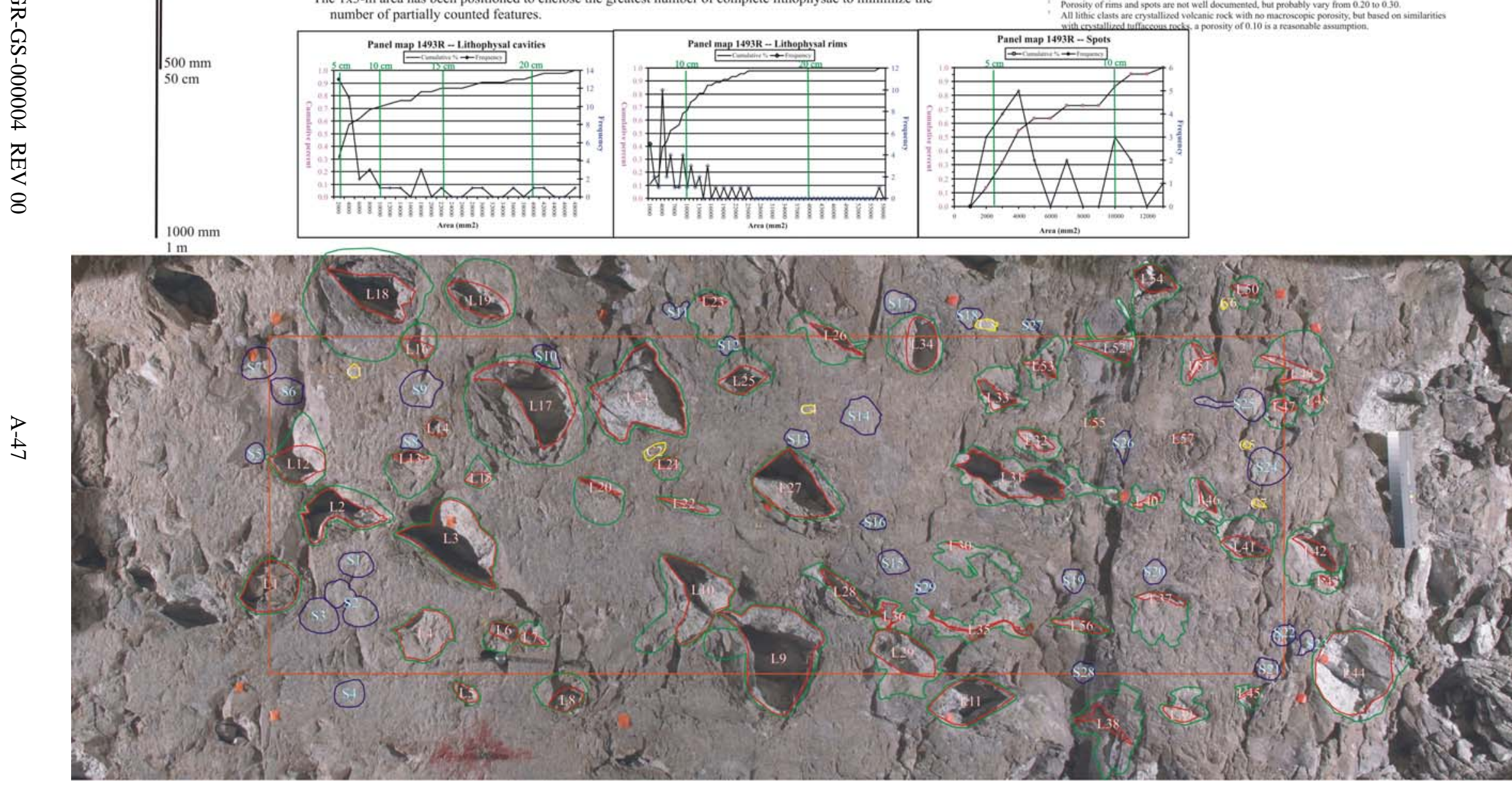

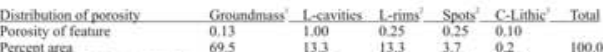

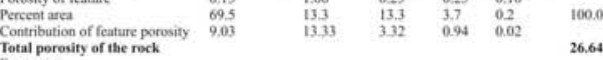
Foomores

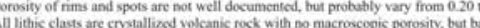

rancitio

Source: DTN: GS021008314224.002 [DIRS 161910].

Figure A3-1. Panel Photograph at Station 14+93 on Right Wall 


3
2
1
3
0
0
0
0
0
0
0
0
1
T⿱
2
8
8

Tptpll Lithophysal study location $15+51$ to $15+54$ left wall.

The photographic image has been scaled such that the vertical 1 -m photogrametric marks are $1 \mathrm{~m}$ on the image There is a slight ( 5 percent) horizontal distortion (expansion) of the bottom 1 -m markers

The Ix3-m area has been positioned to enclose the greatest number of complete lithophysae to minimize the number of partially counted features.
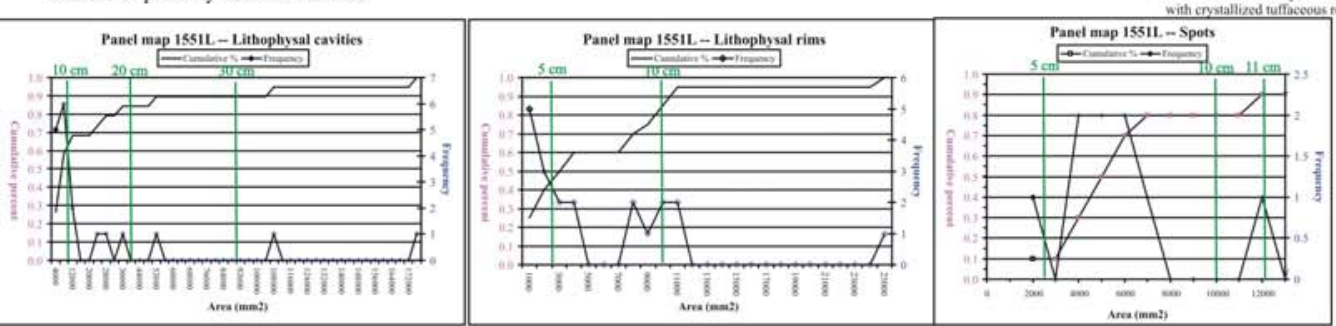

$1000 \mathrm{~mm}$

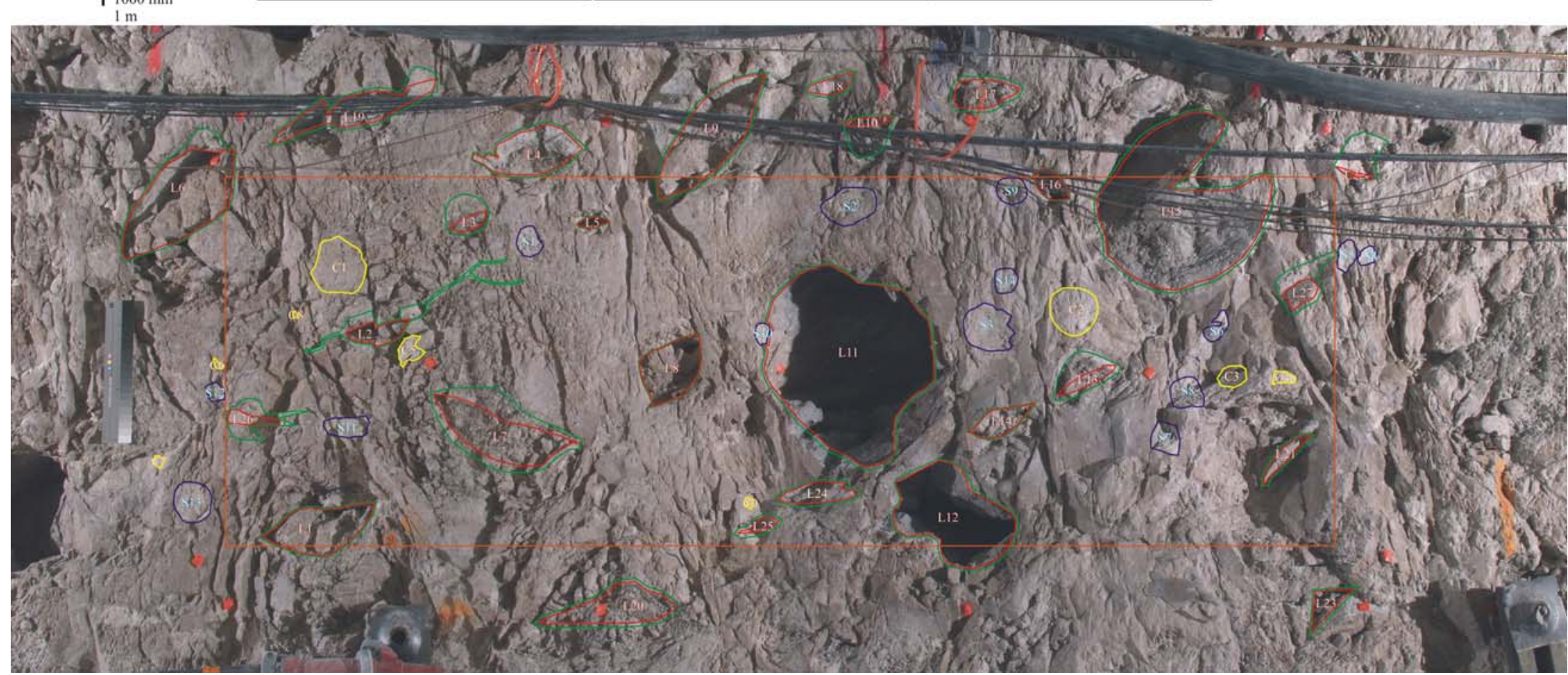

Source: DTN: GS021008314224.002 [DIRS 161910].

Figure A3-2. Panel Photograph at Station 15+51 on Left Wall 
The photographic image has been scaled such that the vertical 1 - $\mathrm{m}$ photogrametric marks are $1 \mathrm{~m}$ on the image There is a slight ( 5 percent) horizontal distortion (expansion) of the bottom $1-\mathrm{m}$ markers. number of partially counted features.
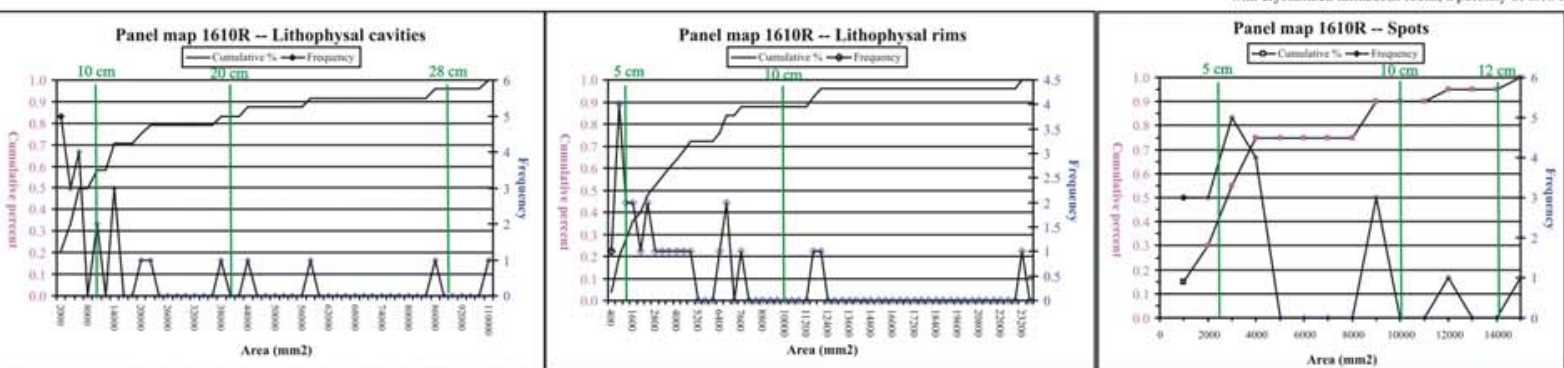

$1000 \mathrm{~mm}$ Area (imm?) Area (mim)

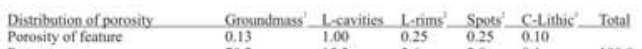

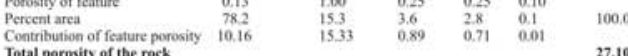

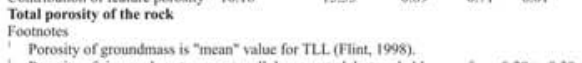

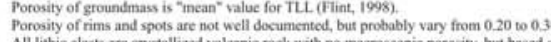

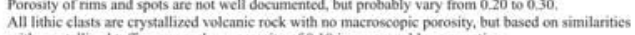

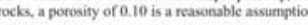

(1)

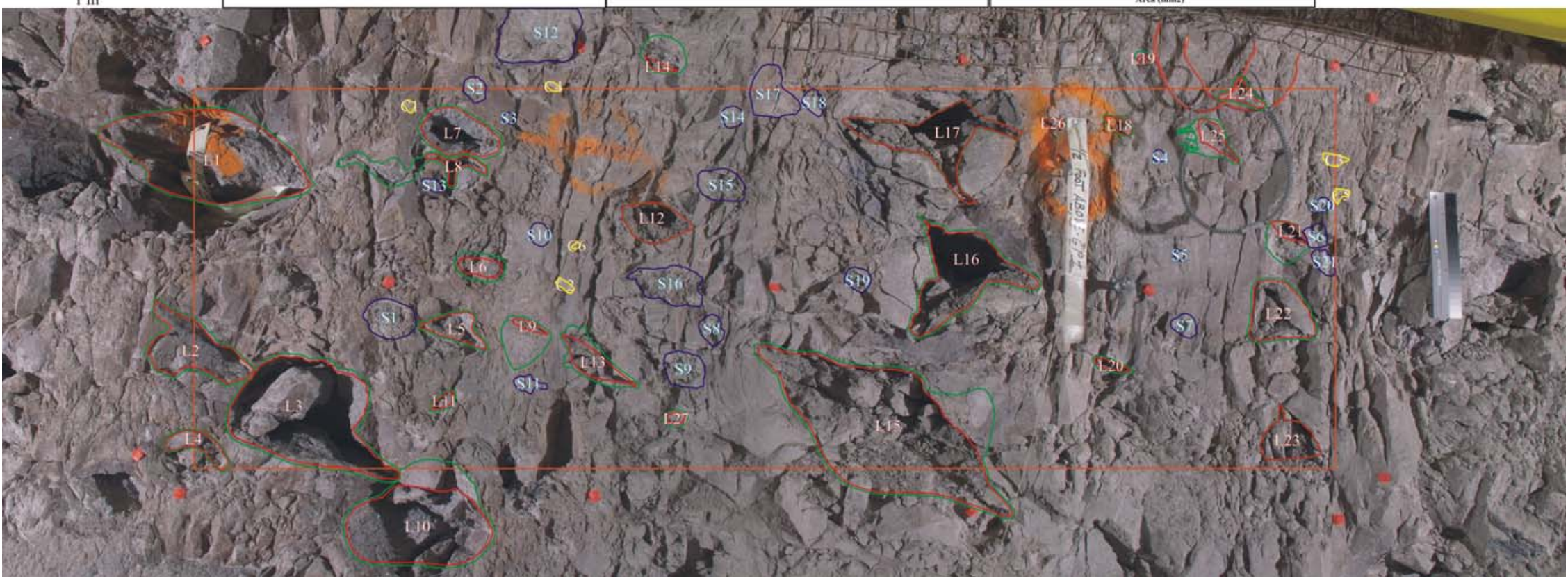

Source: DTN: GS021008314224.002 [DIRS 161910].

Figure A3-3. Panel Photograph at Station $16+10$ on Right Wall 


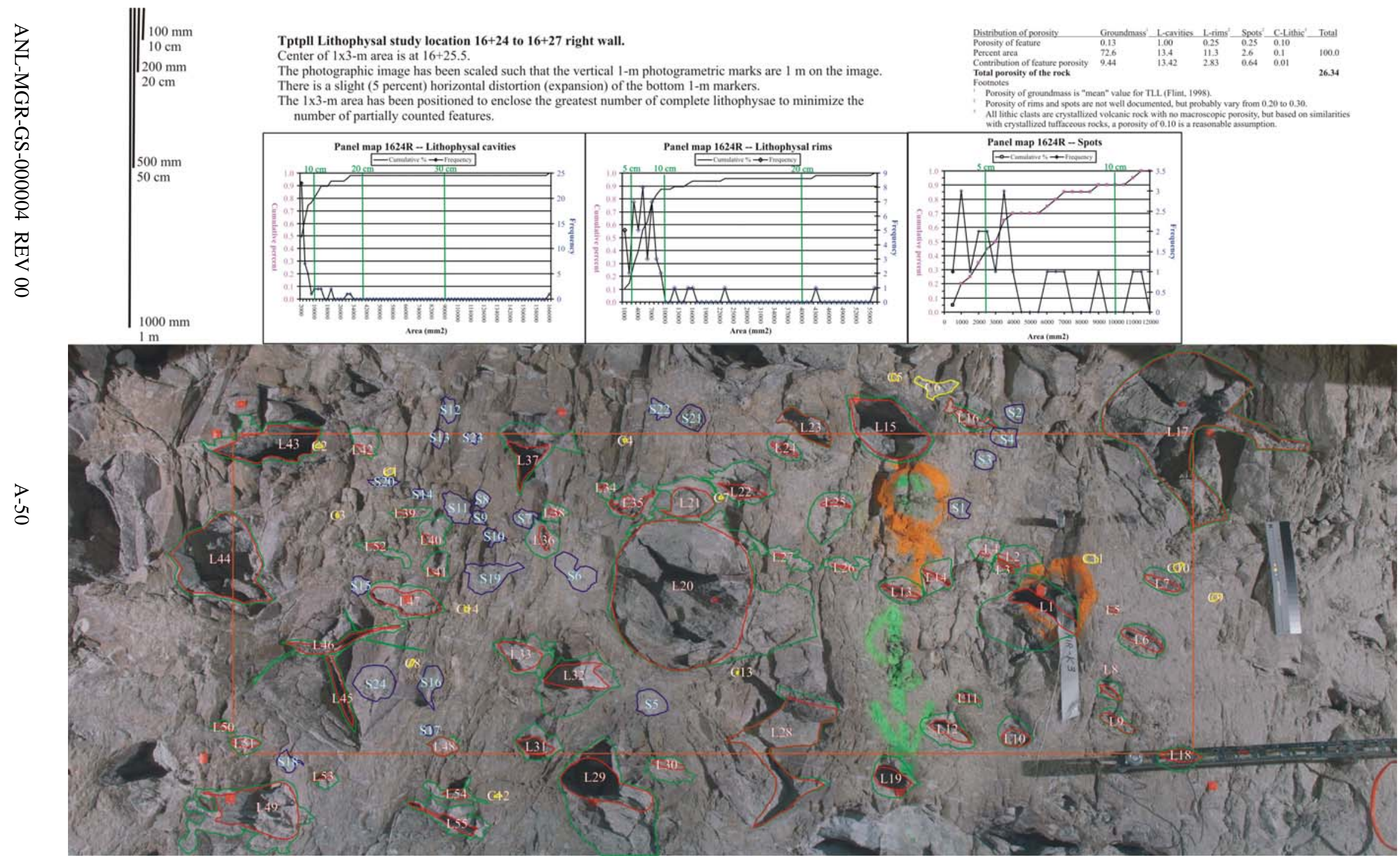




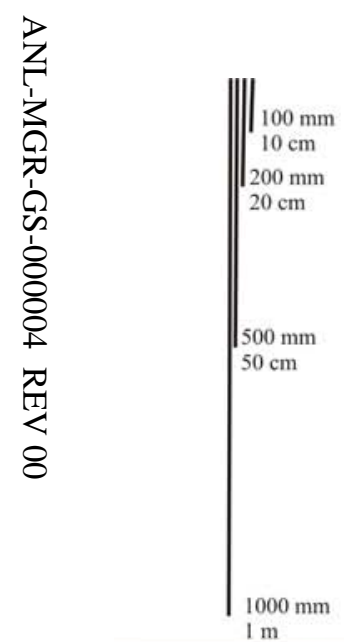

Tptpll Lithophysal study location 16+41 to 16+44 Left Wall.

The photographic image has been scaled such that the vertical 1 -m photogrametric marks are $1 \mathrm{~m}$ on the image

The $1 \times 3-m$ area has been positioned to enclose the greatest number of complete lithophysae and to minimize the number of purtilly

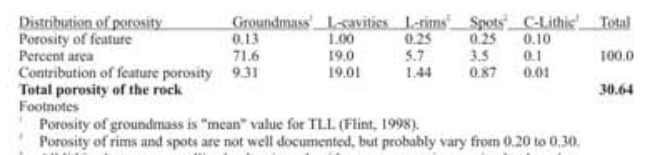

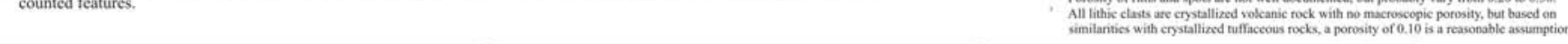
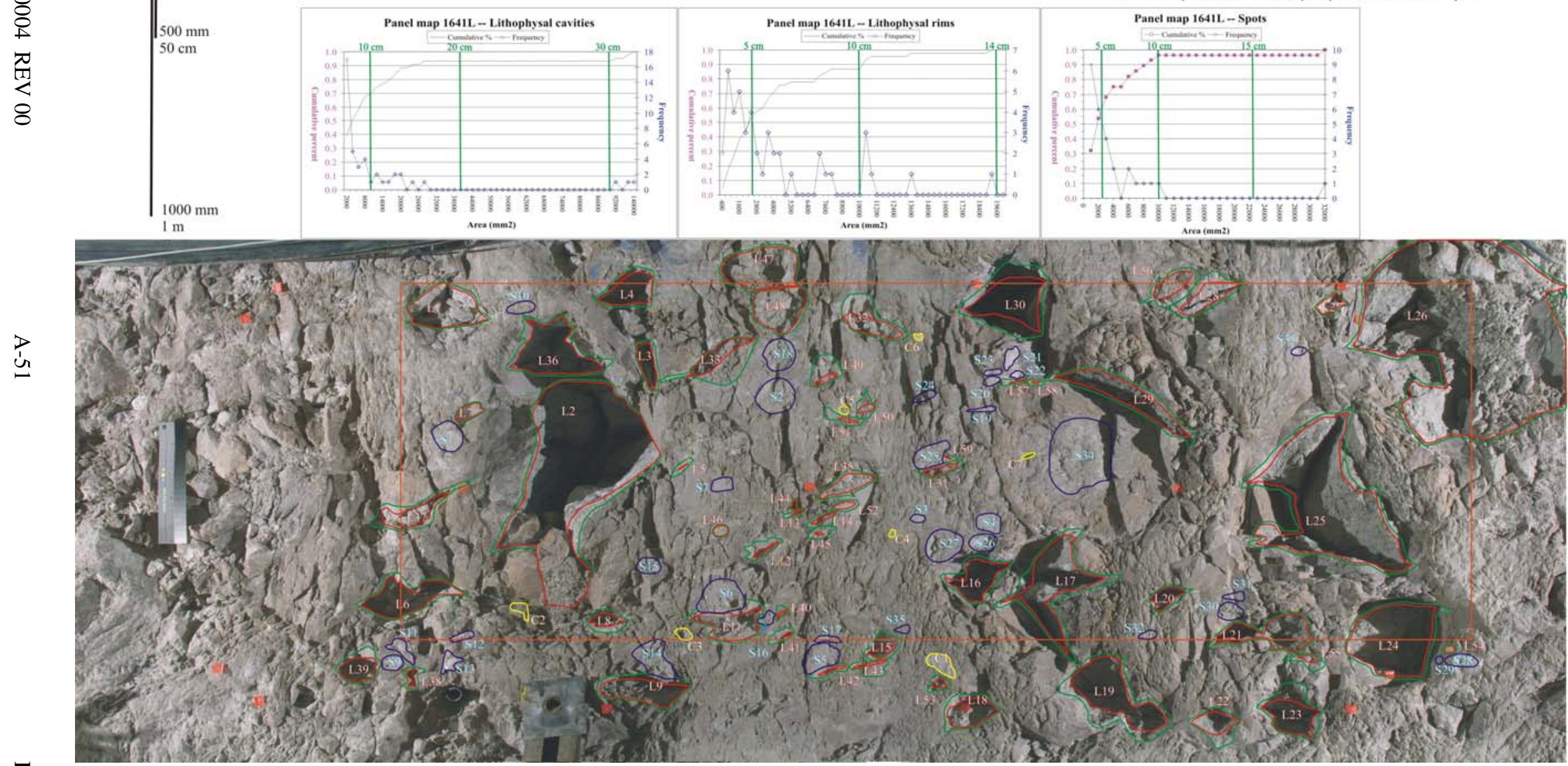

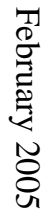

Source: DTN: GS021008314224.002 [DIRS 161910].

Figure A3-5. Panel Photograph at Station $16+41$ on Left Wall 
The photographic image has been scaled such that the vertical 1 -m photogrametric marks are $1 \mathrm{~m}$ on the image. There is a slight ( 5 percent) horizontal distortion (expansion) of the bottom $1-\mathrm{m}$ markers. number of partially counted features.

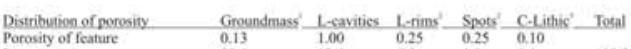

Panel map 164IR - Lithophysal cavities

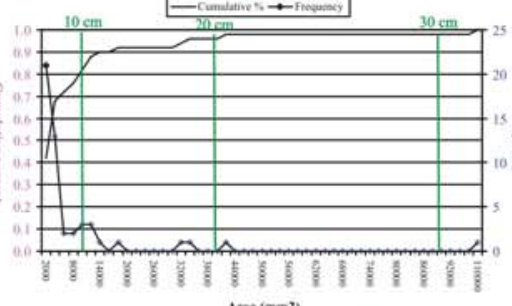
Ares (mm2)
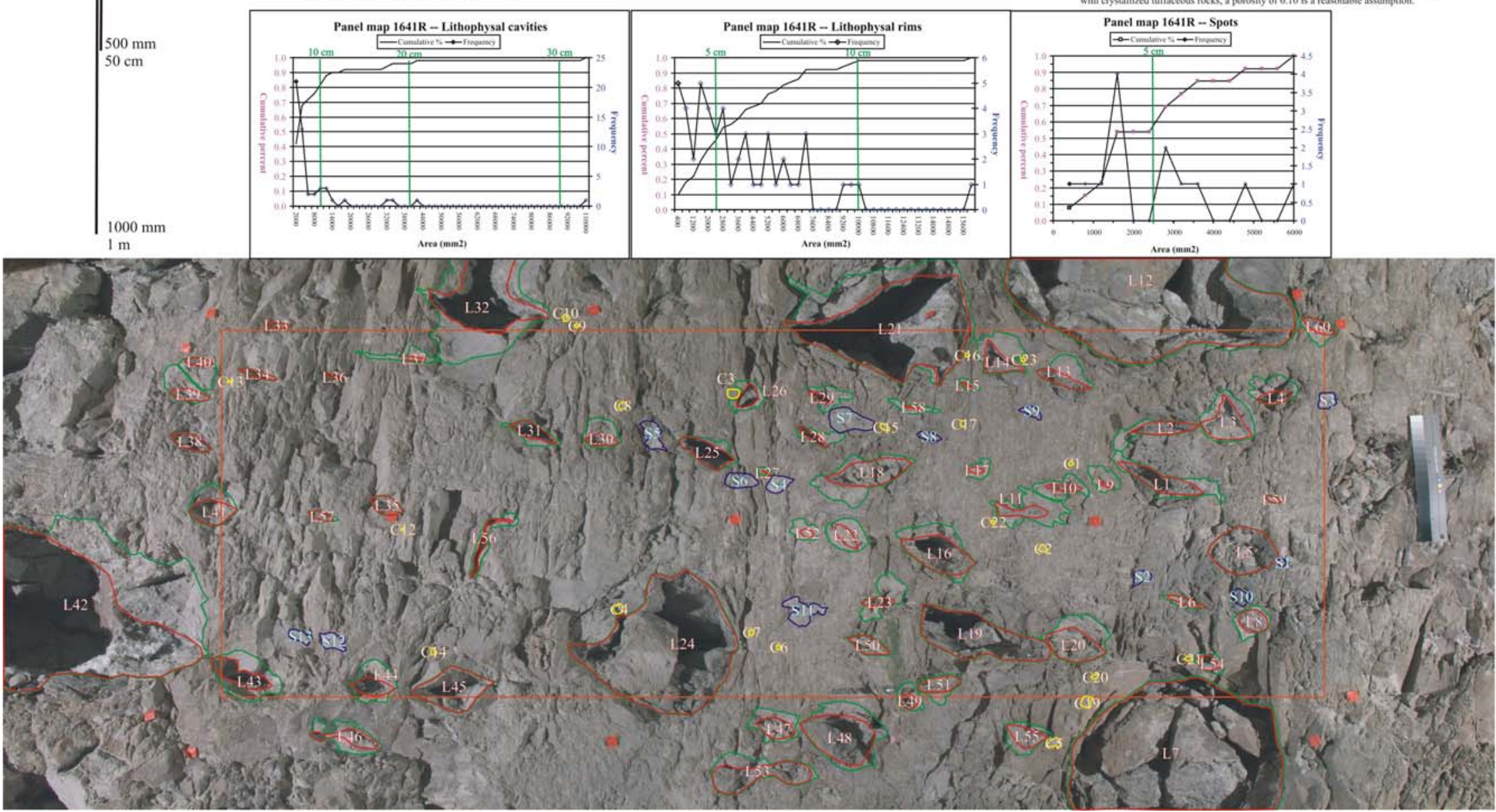

Source: DTN: GS021008314224.002 [DIRS 161910].

Figure A3-6. Panel Photograph at Station $16+41$ on Right Wall 


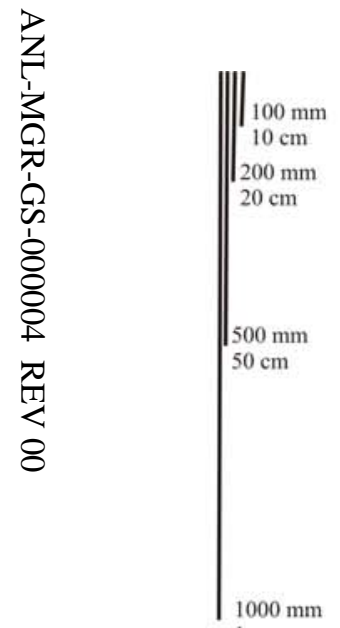

Tptpll Lithophysal study location $16+56$ to $16+59$ left wall.

enter of $1 \times 3-\mathrm{m}$ area is at $16+57.5$.

led such that the vertical 1 -m photogrametric marks are $1 \mathrm{~m}$ on the image There is a slight (5 pereent) horizontal distortion (expansion) of the bottom 1-m marker

Thophsae to minimize the
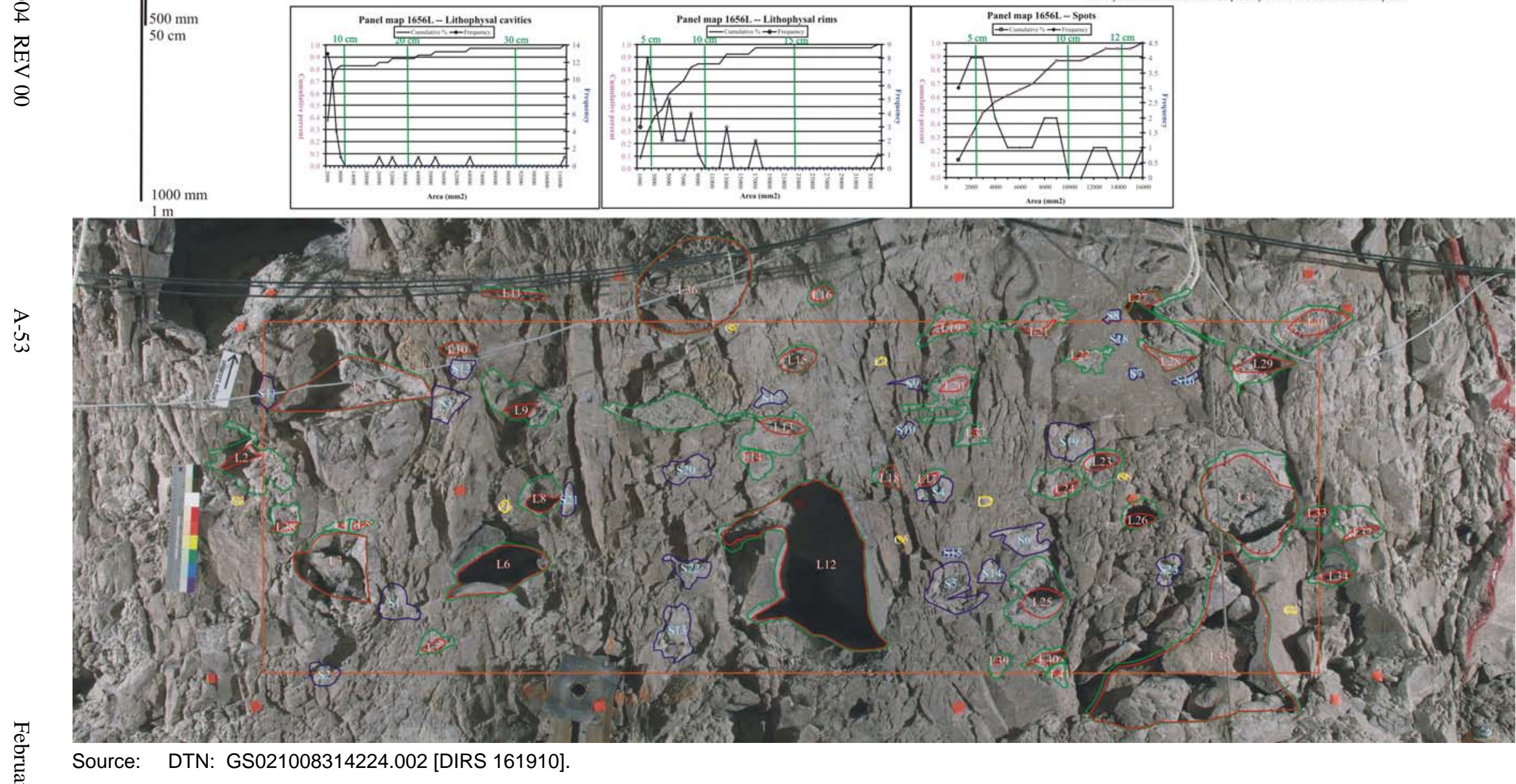

Figure A3-7. Panel Photograph at Station 16+56 on Left Wall 


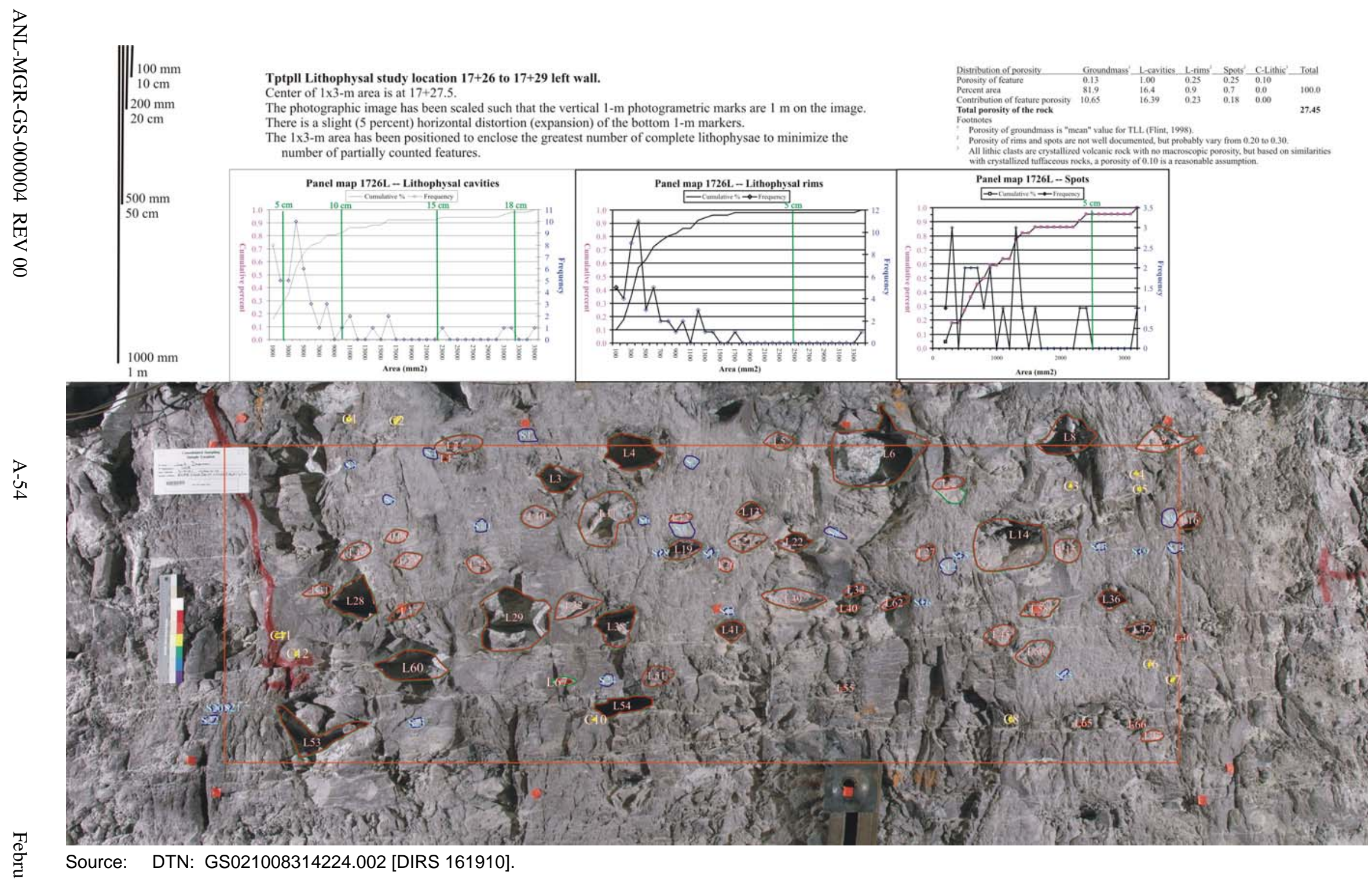

Figure A3-8. Panel Photograph at Station $17+26$ on Left Wall 


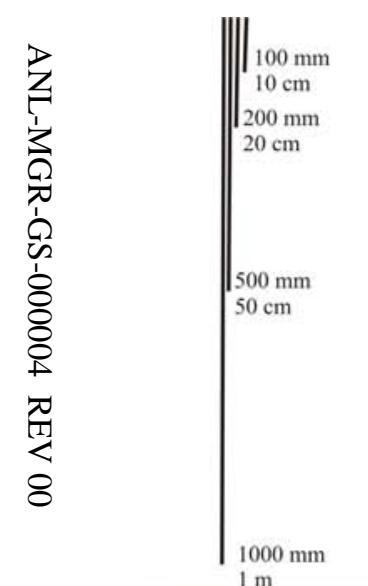

Tptpll Lithophysal study location $17+68$ to $17+71$ left wall.

The photographic image has been scaled such that the vertical $1-\mathrm{m}$ photogrametric marks are $1 \mathrm{~m}$ on the image. There is a slight ( 5 percent) horizontal distortion (expansion) of the bottom 1-m markers.

The ix 3 s area has been positioned to enclose the grest nut number of partially counted features.
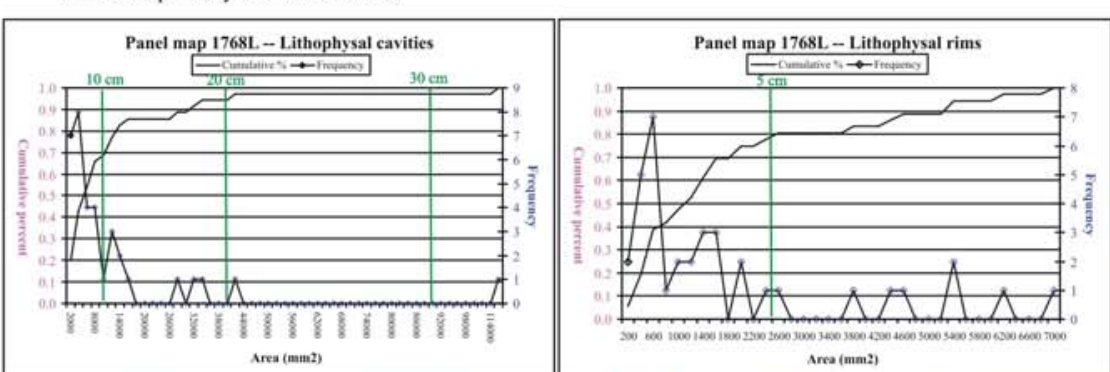

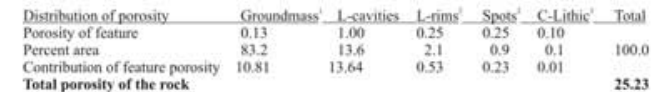

Porosity of groundnass is "mean" value for TLL(Fint, 1998).

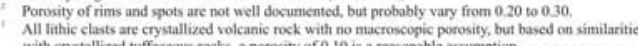
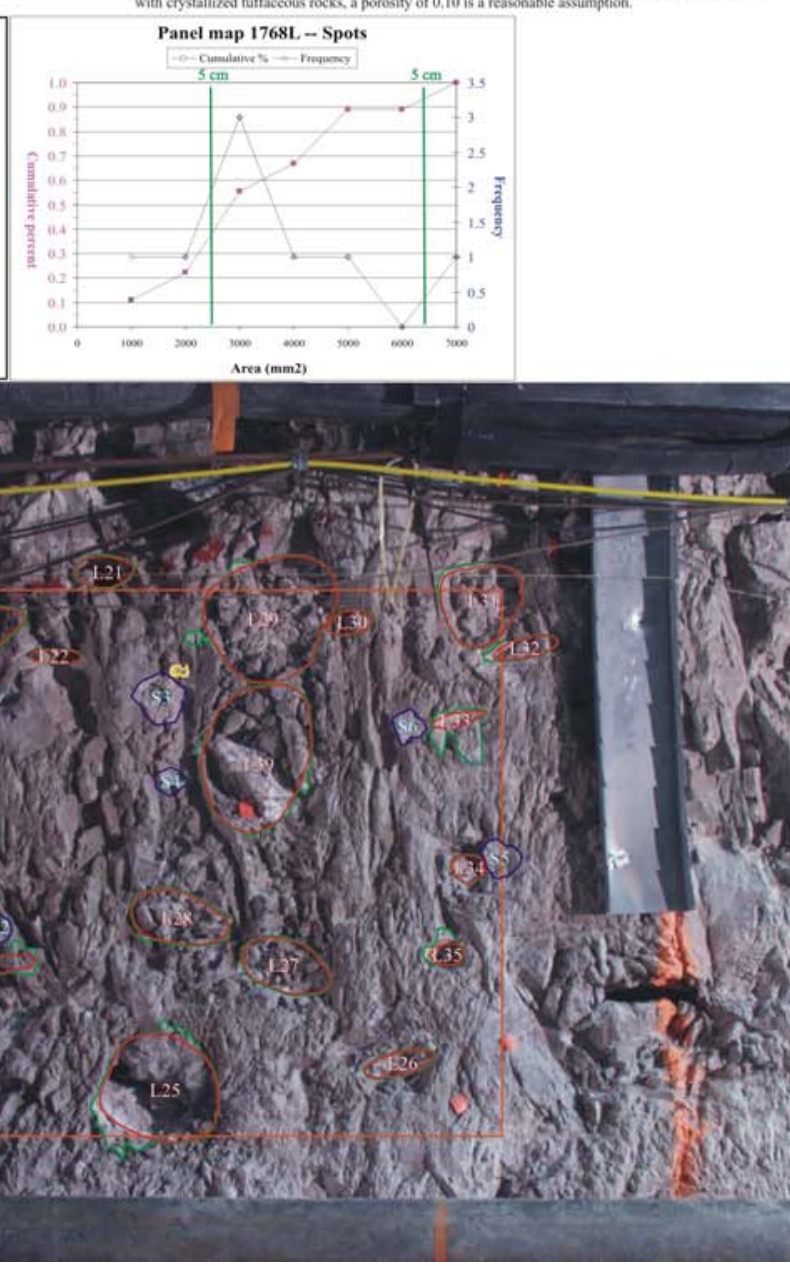
COMPRESSED AIR $\Rightarrow$ 


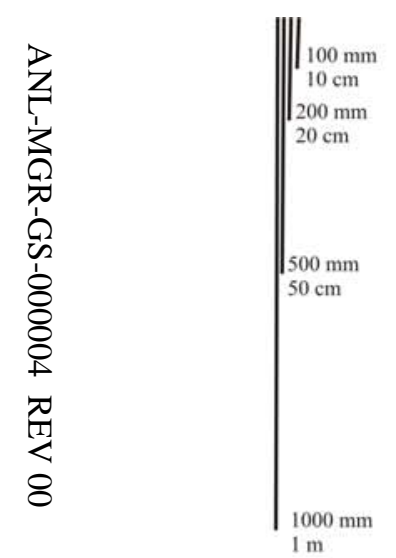

Tptpll Lithophysal study location 17+68 to 17+71 right wall.

The photographic image has been sealed such that the vertical I-m photogrametric marks are $1 \mathrm{~m}$ on the image. There is a slight ( 5 percent) horizontal distortion (expansion) of the bottom 1-m marker

The IX3-m area has been positioned to enclose the greatest number of complete lithophysae to minimize the

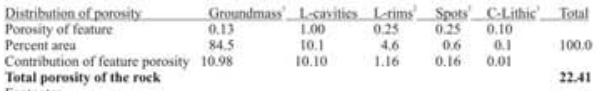
number of partially counted features.
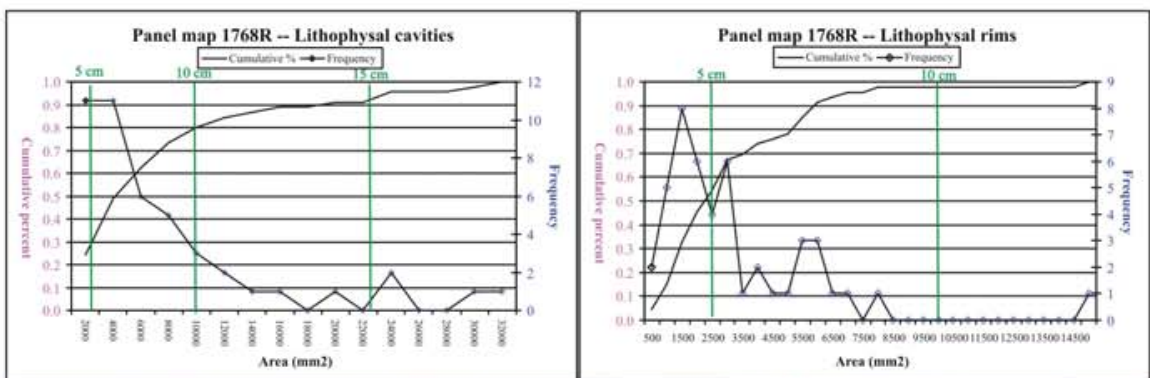

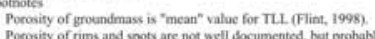
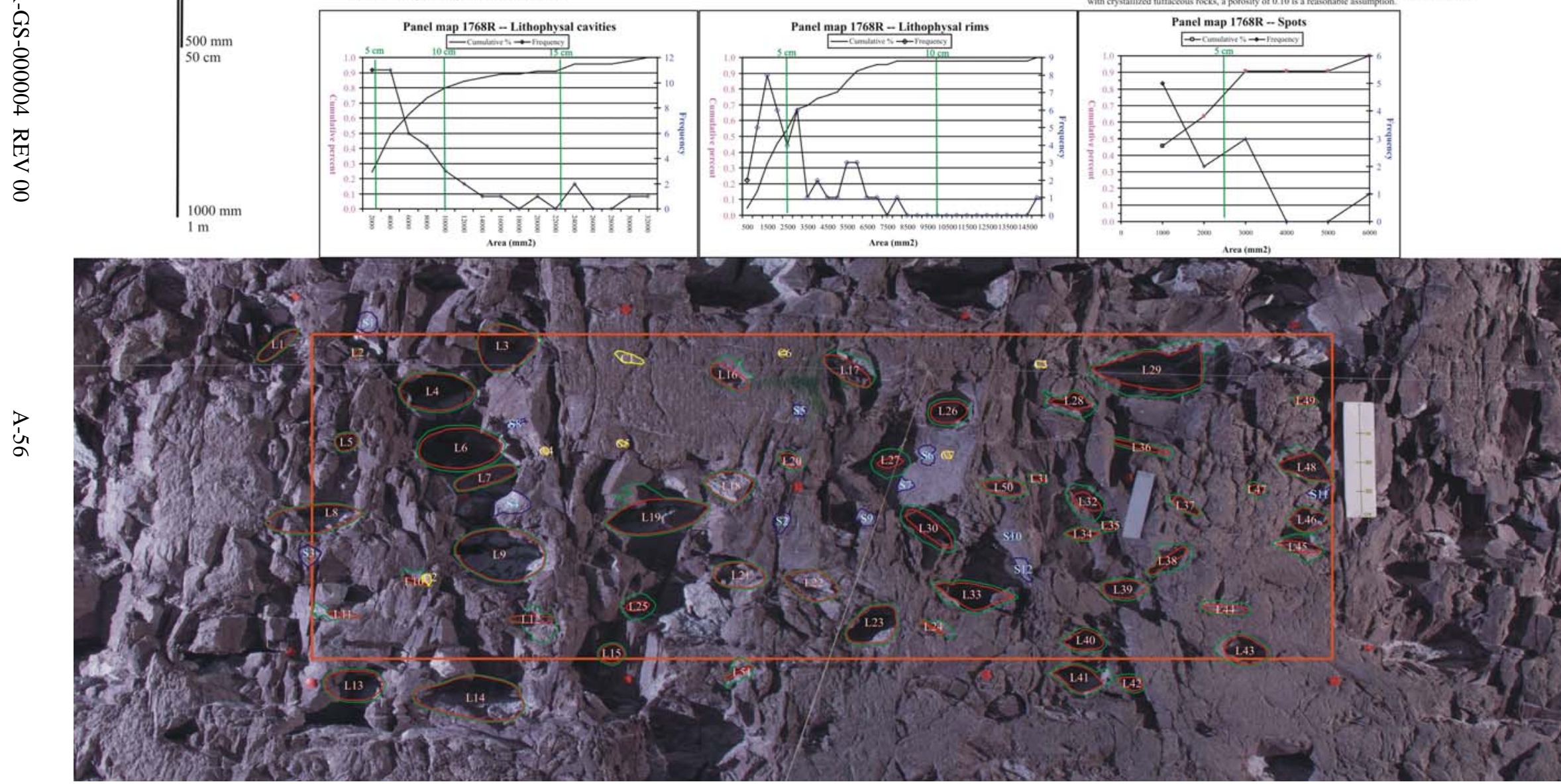

Source: DTN: GS021008314224.002 [DIRS 161910]. 


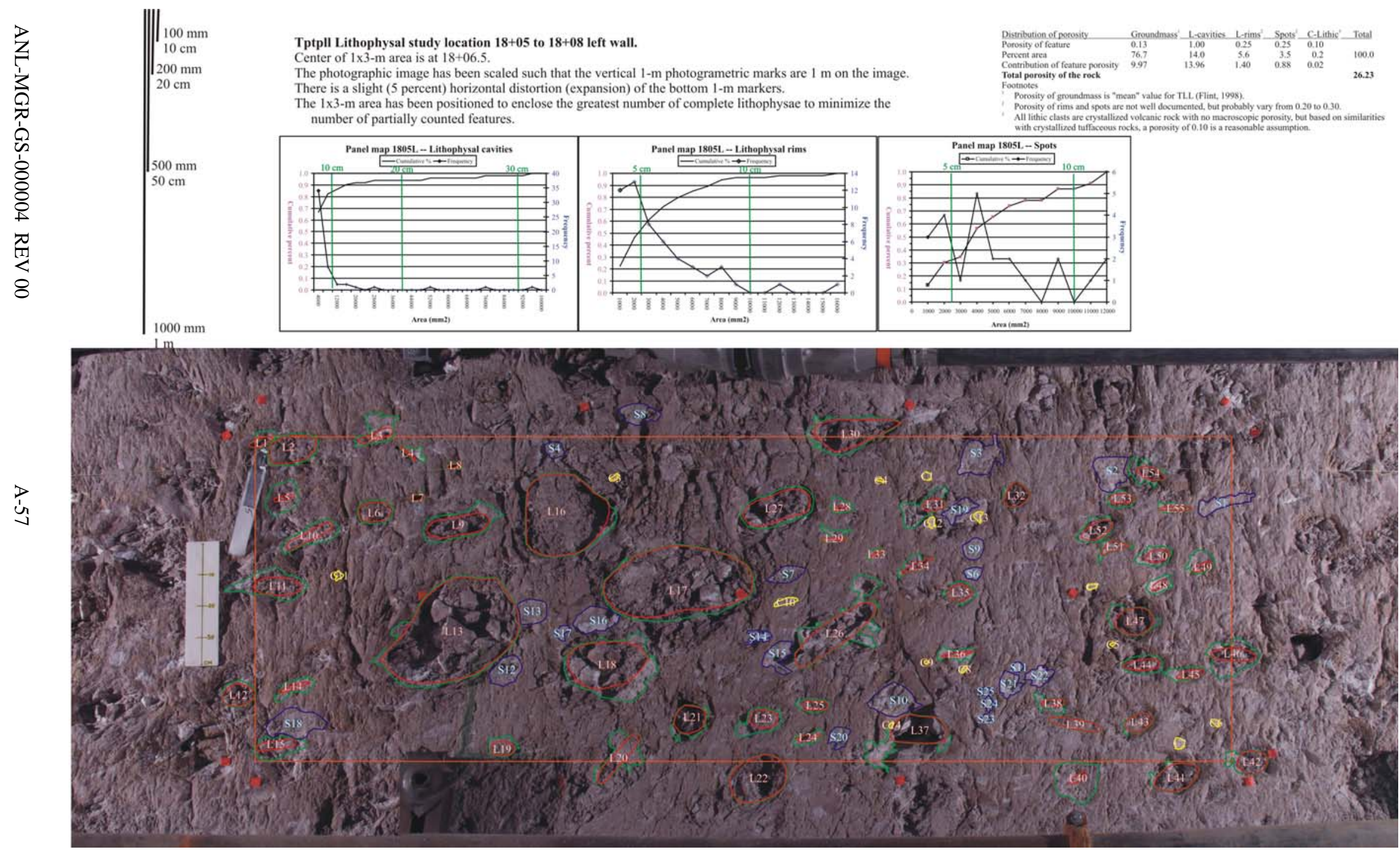




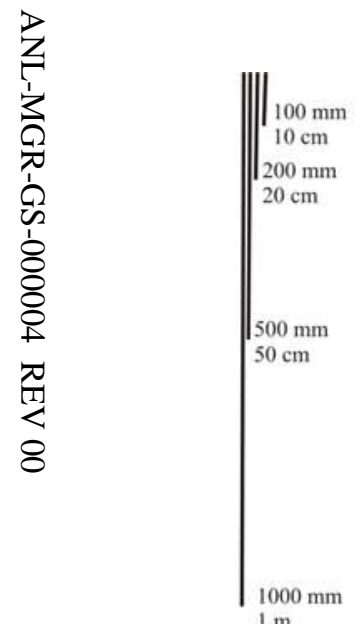

Tptpll Lithophysal study location $18+86$ to $18+89$ left wal.

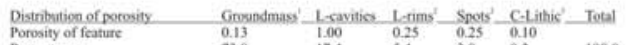

The photographic image has been scaled such that the vertical $1-\mathrm{m}$ photogrametric marks are $1 \mathrm{~m}$ on the image

en $1 \times 3-m$ area has been positioned to enclose the greatest number of complete lithophysae to minimize the number of partially counted features.
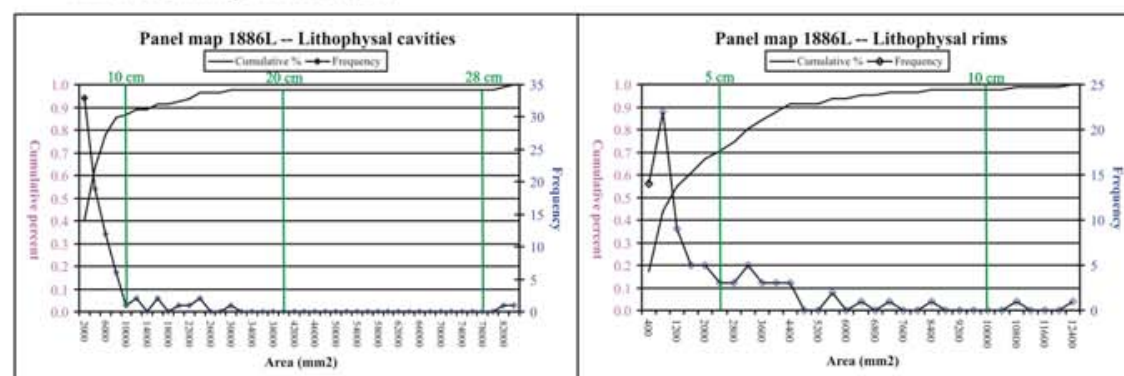

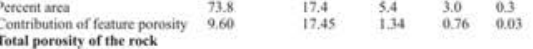

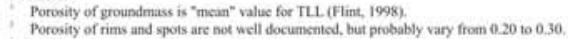

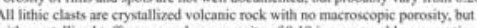

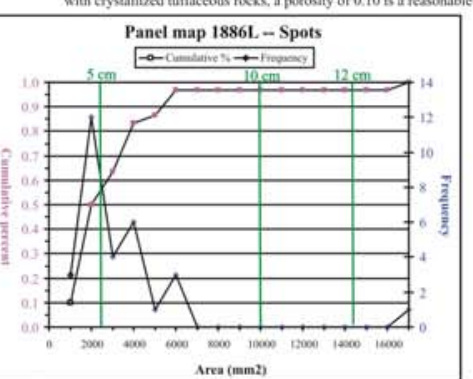

$P_{1}$
$u_{\infty}$

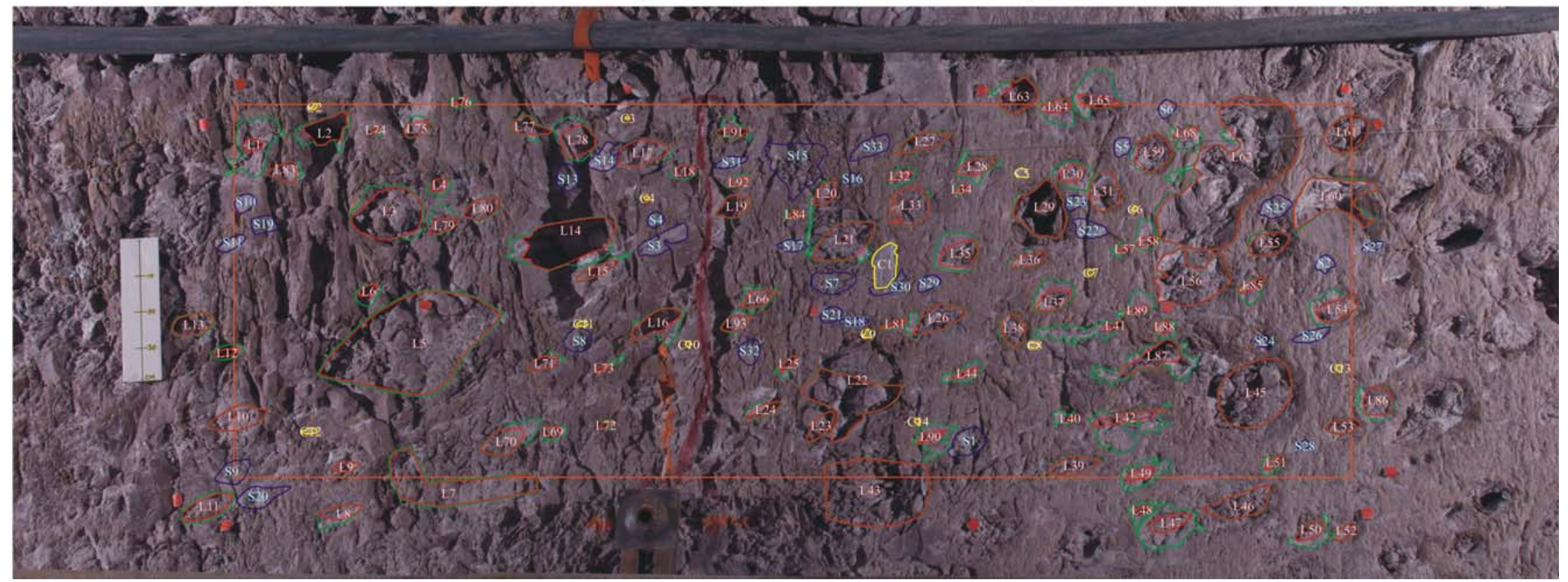

Source: DTN: GS021008314224.002 [DIRS 161910].

Figure A3-12. Panel Photograph at Station 18+86 on Left Wall 


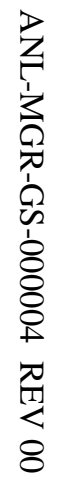

Tptpll Lithophysal study location 19+19 to 19+22 left wall.

The photographic image has been scaled such that the vertical 1 -m photogrametric marks are $1 \mathrm{~m}$ on the image

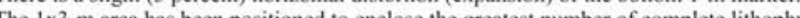
number of partially counted features.

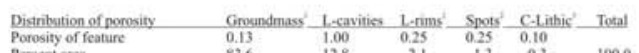

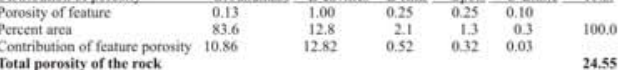

Porosity of groundmass is "mean" value for TLL (Flim, 1998) toscepicic porosity, but bused on similaritios
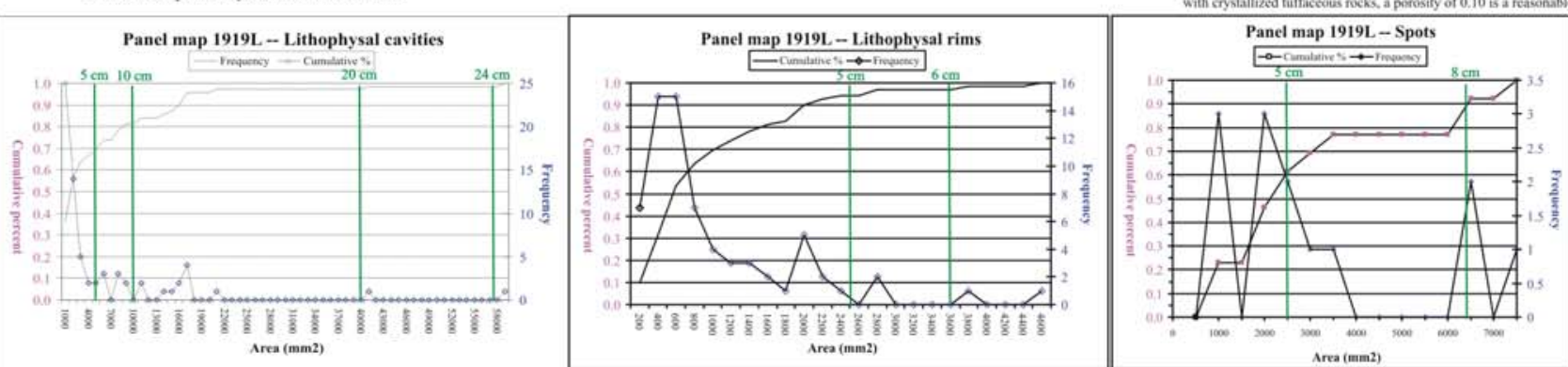

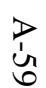

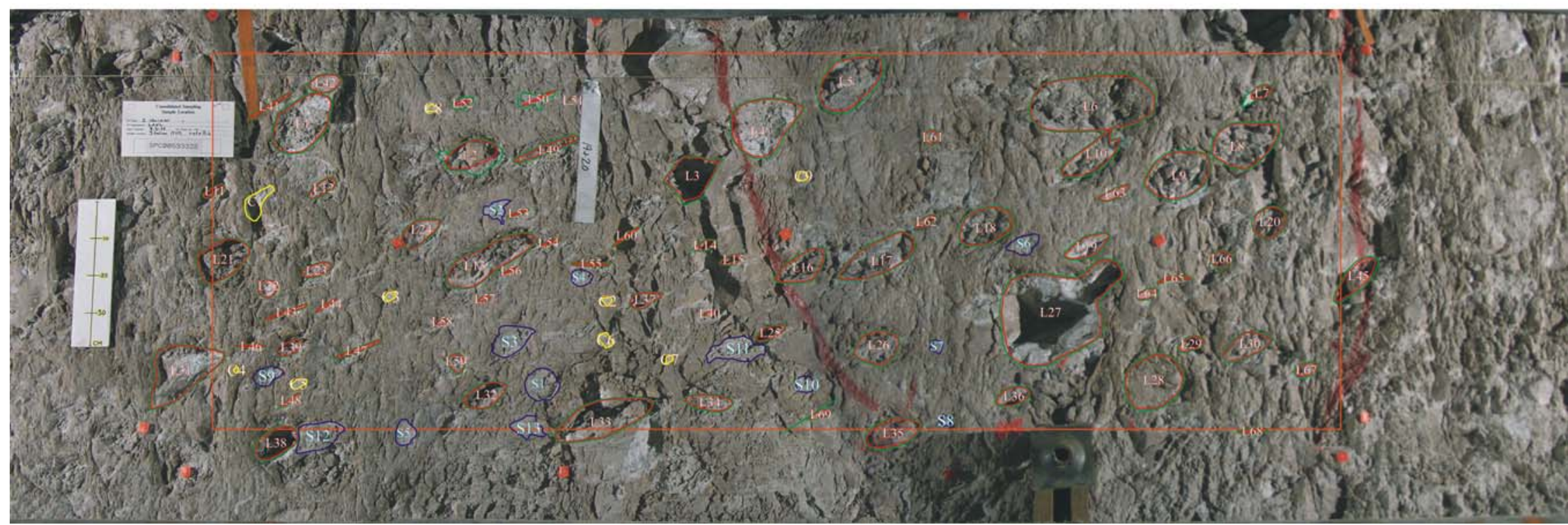

$T$
0
0
0
0
0
8
8

Source: DTN: GS021008314224.002 [DIRS 161910].

Figure A3-13. Panel Photograph at Station 19+19 on Left Wall 


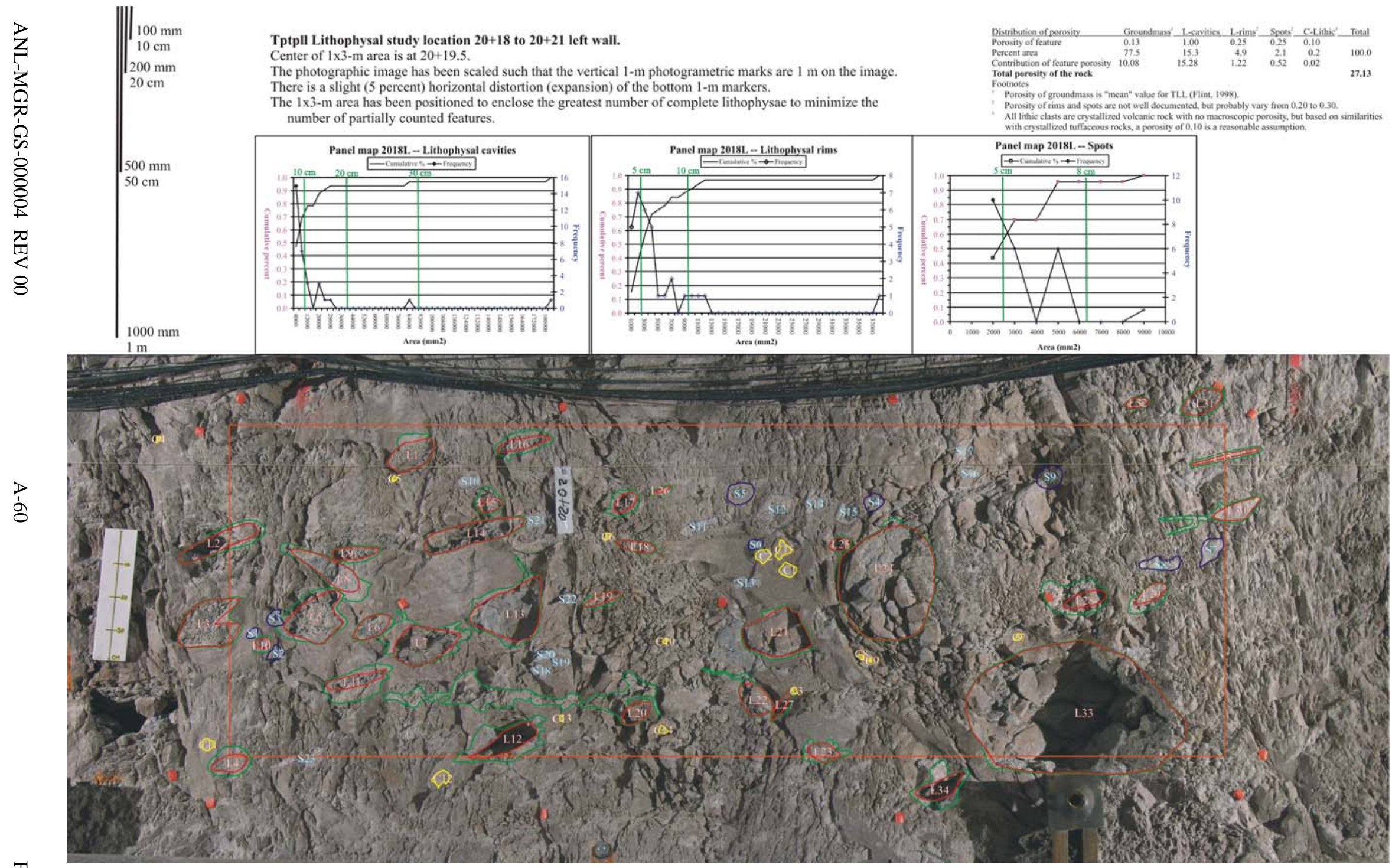




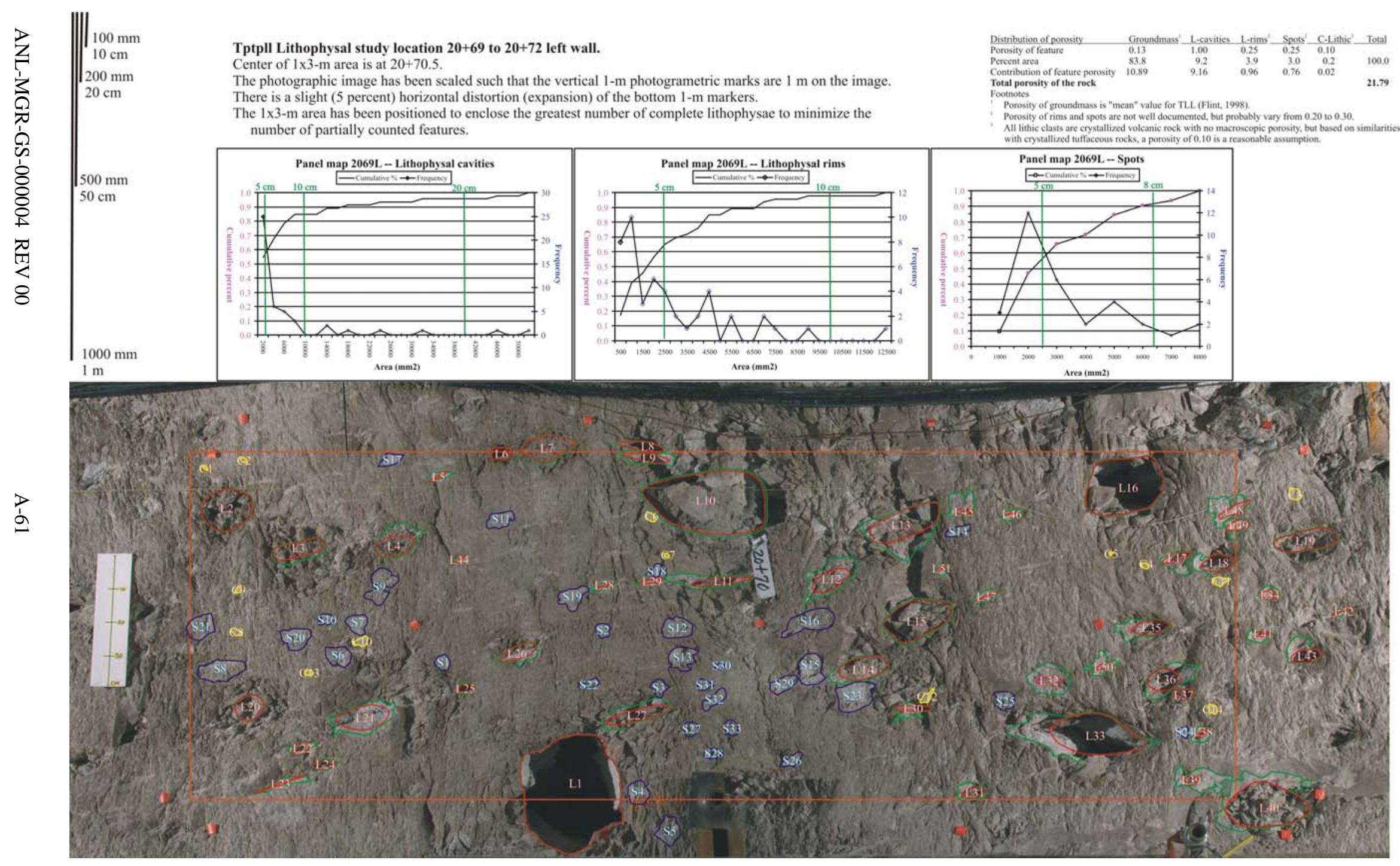

Source: DTN: GS021008314224.002 [DIRS 161910].

Figure A3-15. Panel Photograph at Station 20+69 on Left Wall 


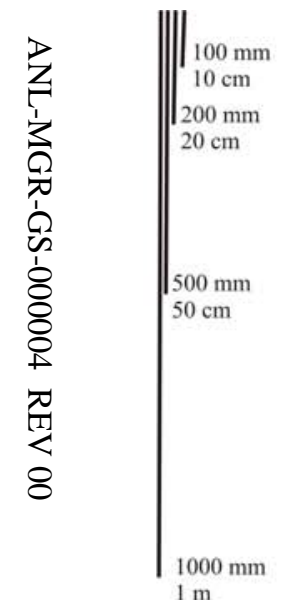

Tptpll Lithophysal study location $21+24$ to $21+27$ left wall.

Distrikntion of promesity
Porosity of feature

The photographic image has been scaled such that the vertical $1-\mathrm{m}$ photogrametric marks are $1 \mathrm{~m}$ on the image. There is a slight ( 5 percent) horizontal distorion (exprnsion) of he bottom $1-\mathrm{m}$ marken.

minimize the tially counted features.
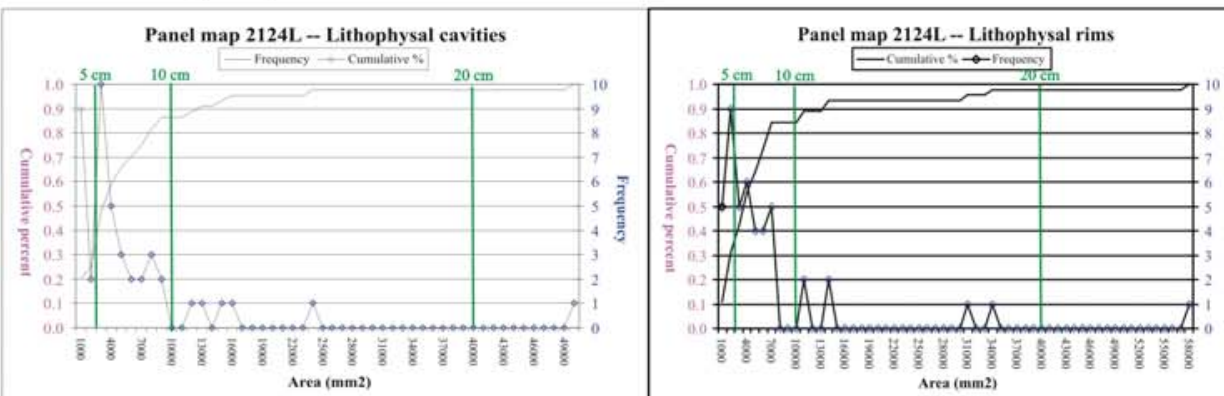
$\begin{array}{lllll}-8.50 & 2.43 & 0.79 & 0.05 & 1000\end{array}$

Porosity of groundmass is "mean" value for TLL (Flint, 1998).

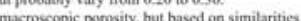
s, a porosity of 0.10 is a reasonable assumption

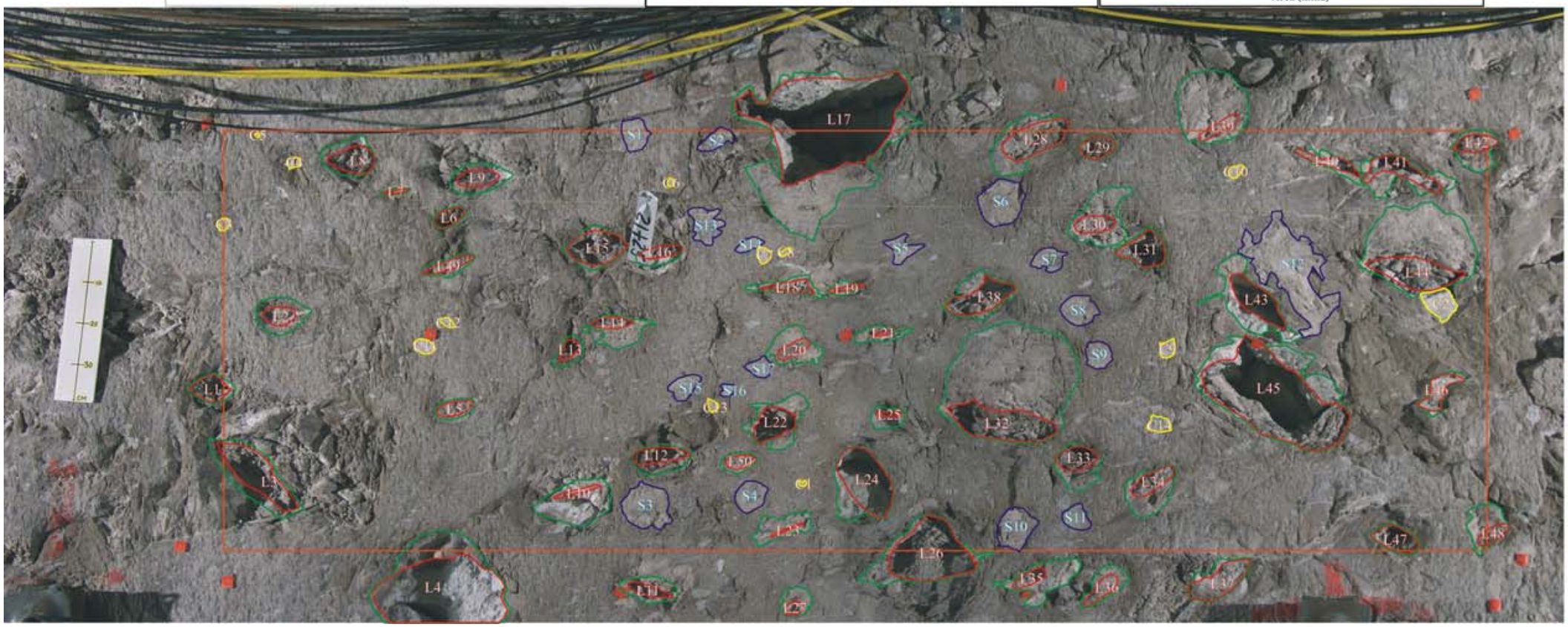

Source: DTN: GS021008314224.002 [DIRS 161910].

Figure A3-16. Panel Photograph at Station 21+24 on Left Wall 


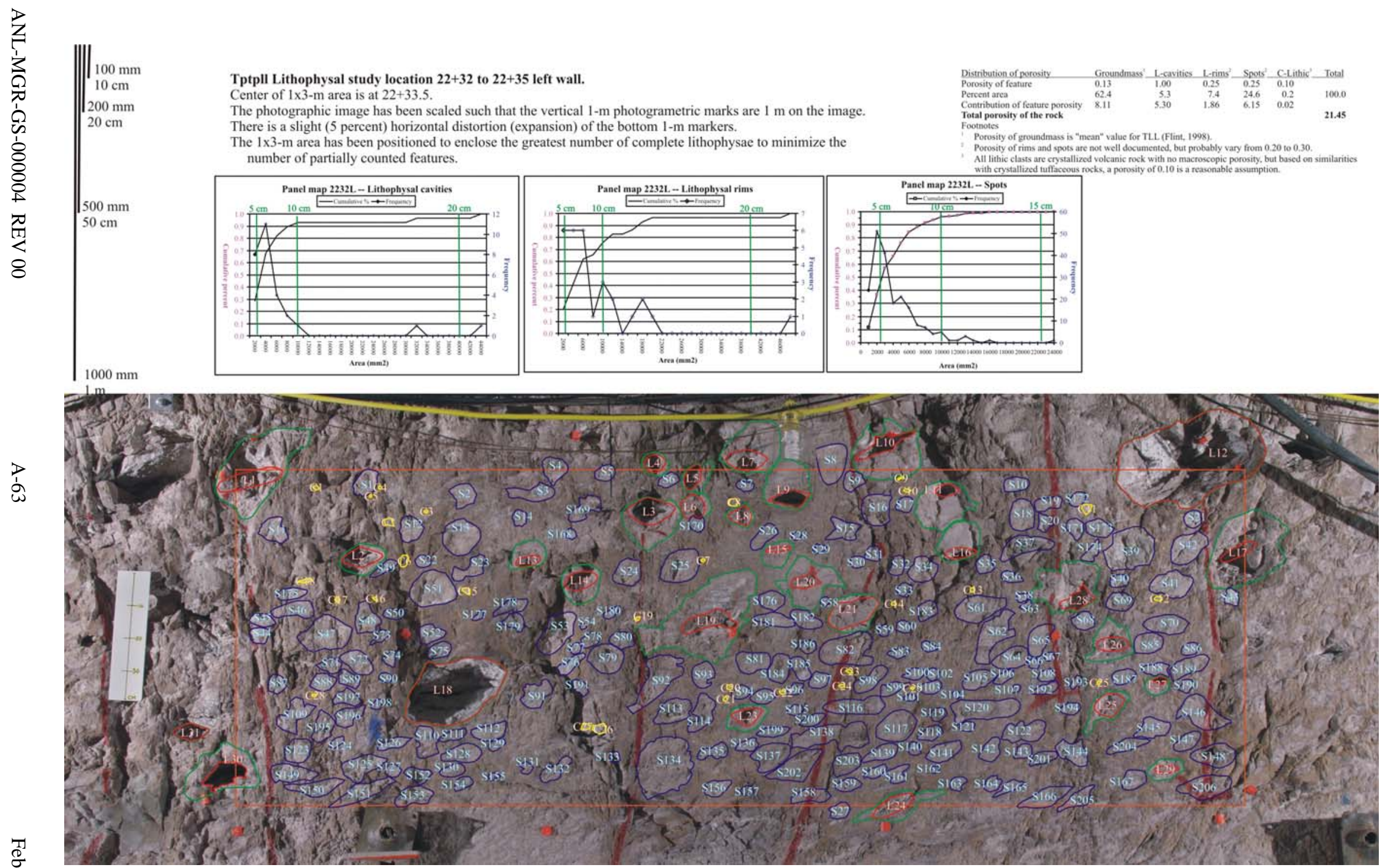

Source: DTN: GS021008314224.002 [DIRS 161910].

Figure A3-17. Panel Photograph at Station 22+32 on Left Wall 


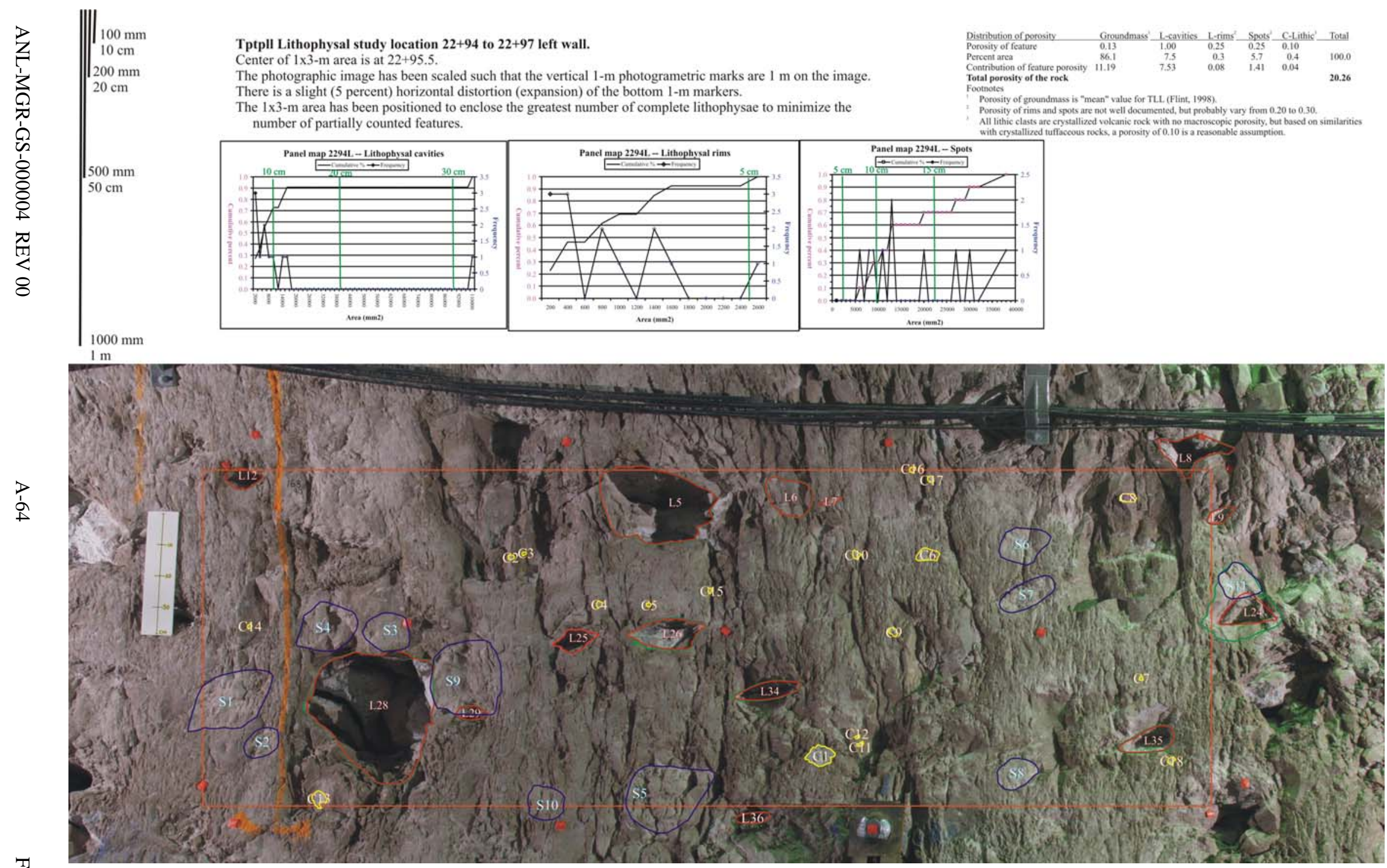




\section{A4. PANEL PHOTOGRAPHS IN THE UPPER LITHOPHYSAL, MIDDLE NONLITHOPHYSAL, AND LOWER LITHOPHYSAL ZONES OF THE TOPOPAH SPRING TUFF EXPOSED IN THE ECRB CROSS-DRIFT FROM STATIONS 06+50 TO 21+25}

The 20 Panel Photographs and photographs of the Small-Scale Fracture locations are reproduced in this section (Table A4-1). These maps were designed to be plotted on 11x17-inch paper (or larger) or viewed electronically such that the "zoom" function can be used to see many of the details of the maps and features in the rocks. The "Zoom" function in Microsoft@ Word will also enable focusing in on specific features. So, although some of the text might be fairly small in the following paper copy reproductions, most of it can be identified in the electronic copy, otherwise please refer to the original data package.

Table A4-1. Locations of Photographs for the Small-Scale Fracture and Panel Photograph Studies in the ECRB Cross-Drift and File Names of the Images (DTN: MO0402GSC04031.000 [DIRS 172231])

\begin{tabular}{|l|l|l|l|l|c|}
\hline \multicolumn{1}{|c|}{ Study } & \multicolumn{1}{c|}{$\begin{array}{c}\text { Additional } \\
\text { Data on Images }\end{array}$} & \multicolumn{1}{c|}{ Image Name } & \multicolumn{1}{c|}{ Station } & \multicolumn{1}{c|}{ Wall } & $\begin{array}{c}\text { Lithostratigraphic } \\
\text { Zone }\end{array}$ \\
\hline Small Scale Fracture study & L-20cm & PP0660L & $06+60$ & Left & Tptpul \\
\hline Panel photograph study & L-20cm & PP0660R & $06+60$ & Right & Tptpul \\
\hline Panel photograph study & L-20cm & PP0745L & $07+45$ & Left & Tptpul \\
\hline Panel photograph study & L-20cm & PP0745R & $07+45$ & Right & Tptpul \\
\hline Panel photograph study & & PP0815L & $08+15$ & Left & Tptpul \\
\hline Panel photograph study & L-20cm & PP0816R & $08+16$ & Right & Tptpul \\
\hline Panel photograph study & & PP0910L & $09+10$ & Left & Tptpul \\
\hline Panel photograph study & L-20cm & PP0910R & $09+10$ & Right & Tptpul \\
\hline Panel photograph study & & PP0935L & $09+35$ & Left & Tptpul \\
\hline Panel photograph study & L-20cm & PP0935R & $09+35$ & Right & Tptpul \\
\hline Small Scale Fracture study & & PP1035L & $10+35$ & Left & Tptpmn \\
\hline Panel photograph study & L-20cm & PP1035R & $10+35$ & Right & Tptpmn \\
\hline Panel photograph study & & PP1220L & $12+20$ & Left & Tptpmn \\
\hline Panel photograph study & L-20cm & PP1218R & $12+18$ & Right & Tptpmn \\
\hline Small Scale Fracture study & L-20cm, SSF & SSF1805L & $18+05$ & Left & Tptpll \\
\hline Small Scale Fracture study & L-20cm, SSF & SSF1886L & $18+86$ & Left & Tptpll \\
\hline Small Scale Fracture study & SSF & SSF1920L & $19+20$ & Left & Tptpll \\
\hline Small Scale Fracture study & SSF & SSF2019L & $20+19$ & Left & Tptpll \\
\hline Small Scale Fracture study & SSF & SSF2071L & $20+71$ & Left & Tptpll \\
\hline Small Scale Fracture study & SSF & SSF2125L & $21+25$ & Left & Tptpll \\
\hline
\end{tabular}

NOTE: Objects that occur on many of the photographs include the following:

1 Metric scale is on the left.

2 Yellow circle is $20 \mathrm{~cm}$ in diameter.

3 Red painted lines on the left walls are fractures that were mapped in the total ECRB DLS traverses.

4 Red rectangles are the area of Panel Maps.

5 Cyan labels such as "PL14" are photographically interpreted lithophysae that are larger than $20 \mathrm{~cm}$ in diameter with the shapes documented in the workbook PGV Lithop Shapes ECRB.xIs.

6 On the SSF photographs, many of the mapped fractures are labeled in black lines and text where they intersect the tape.

7 Station location labels in the upper-left corners of the photographs were inserted by the photographer and are approximate locations determined in the field. Official surveyed station locations on pins or targets are listed in the table. 


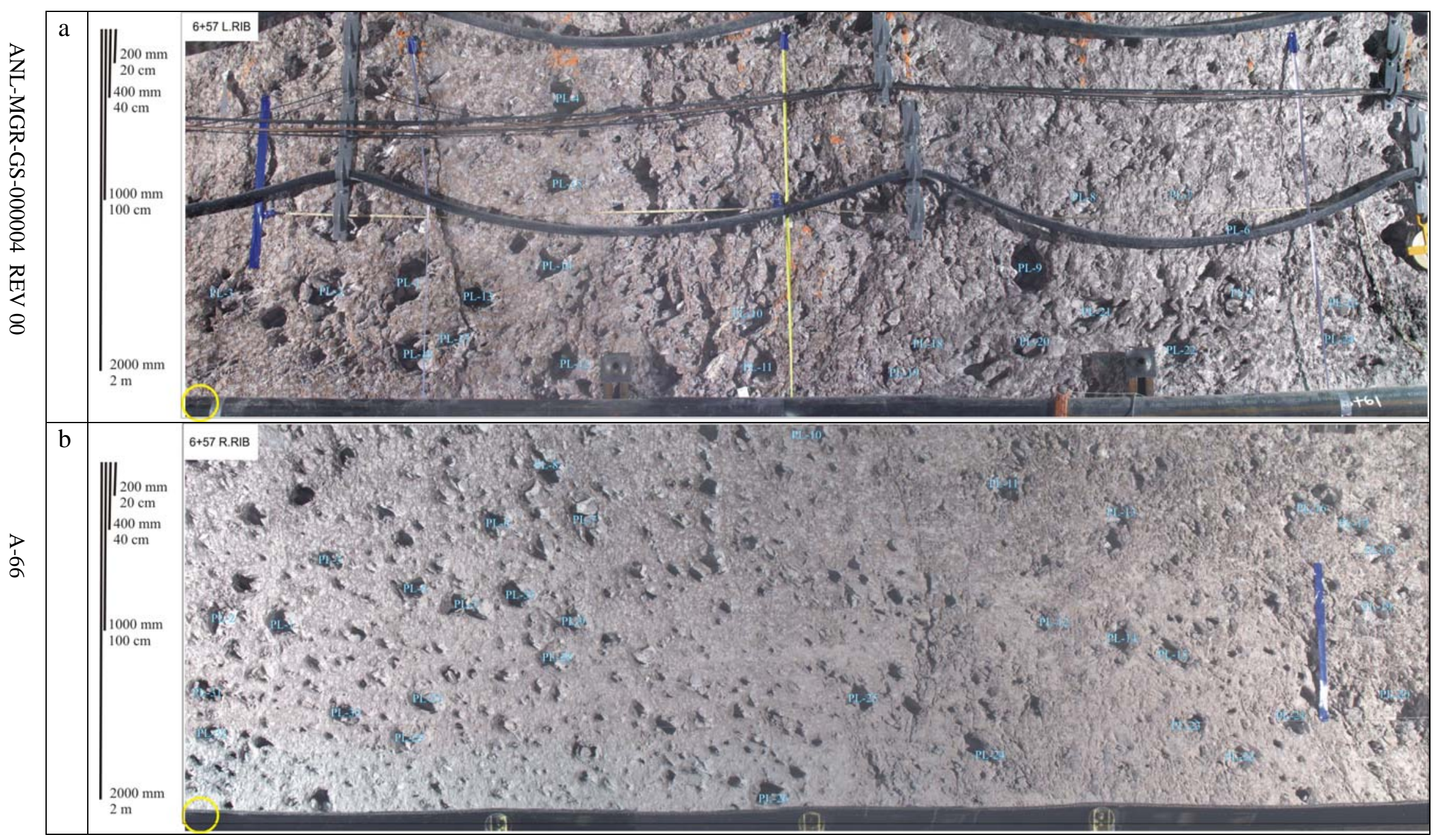

NOTE: Survey station locations from DTN: MO0402GSC04031.000 [DIRS 172231]; labeled lithophysae in PGV Lithop Shapes ECRB.xIs in Appendix D.

Figure A4-1a. Panel Photograph at Station $06+60$ on Left Wall and Small-Scale Fracture Traverse Location H15 with Vertical Traverses V37, V41, and V42 with Lithophysae Larger Than $20 \mathrm{~cm}$ in Diameter Inventoried for Shape

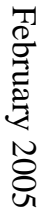

Figure A4-1b. Panel Photograph at Station 06+60 on Right Wall with Lithophysae Larger Than $20 \mathrm{~cm}$ in Diameter Inventoried for Shape 


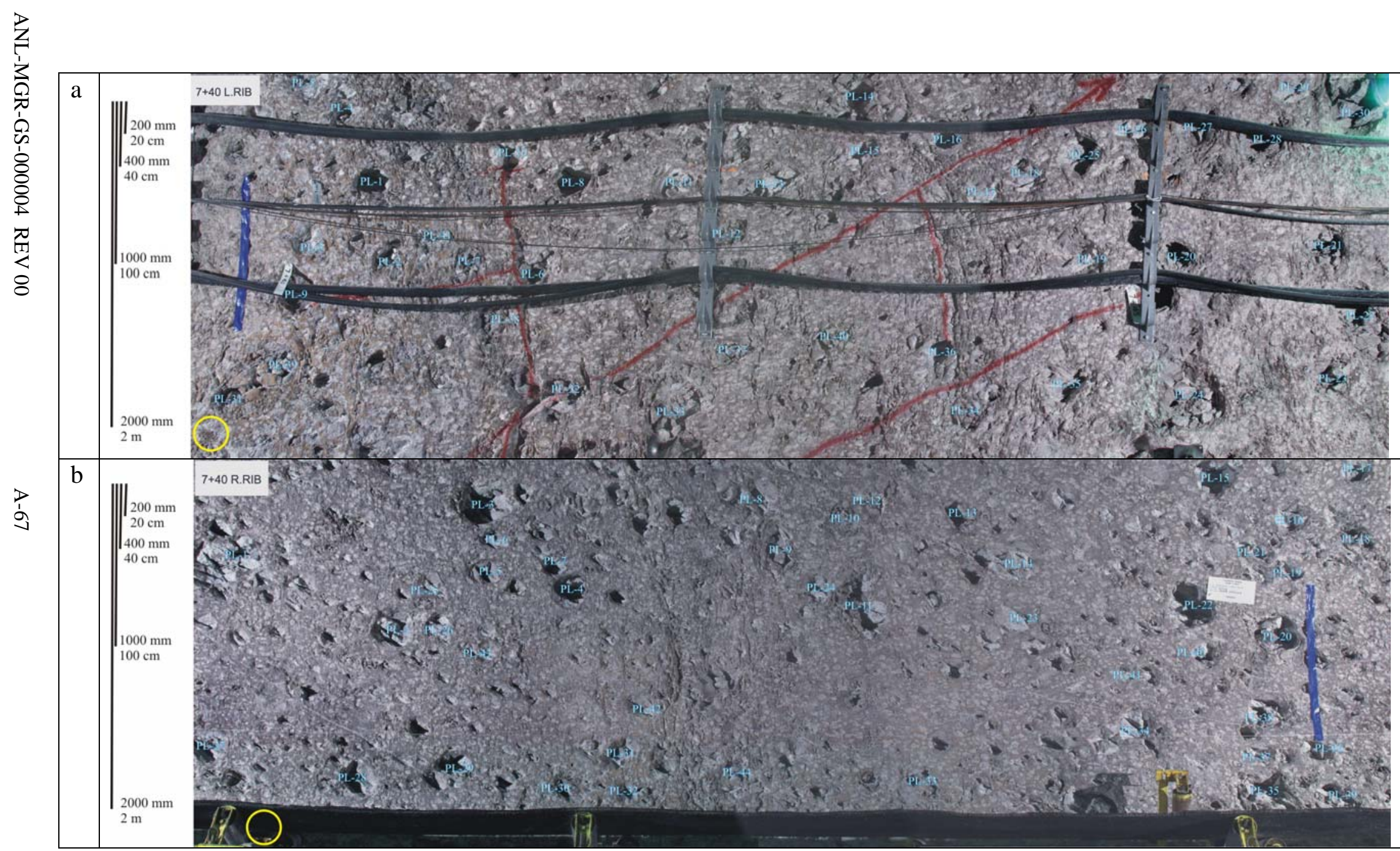

NOTE: Survey station locations from DTN: MO0402GSC04031.000 [DIRS 172231]; labeled lithophysae in PGV Lithop Shapes ECRB.xIs in Appendix D.

Figure A4-2a. Panel Photograph at Station 07+45 on Left Wall and Small-Scale Fracture Traverse Location H15 with Vertical Traverses V37, V41, and V42 with Lithophysae Larger Than $20 \mathrm{~cm}$ in Diameter Inventoried for Shape

Figure A4-2b. Panel Photograph at Station $07+45$ on Right Wall with Lithophysae Larger Than $20 \mathrm{~cm}$ in Diameter Inventoried for Shape 


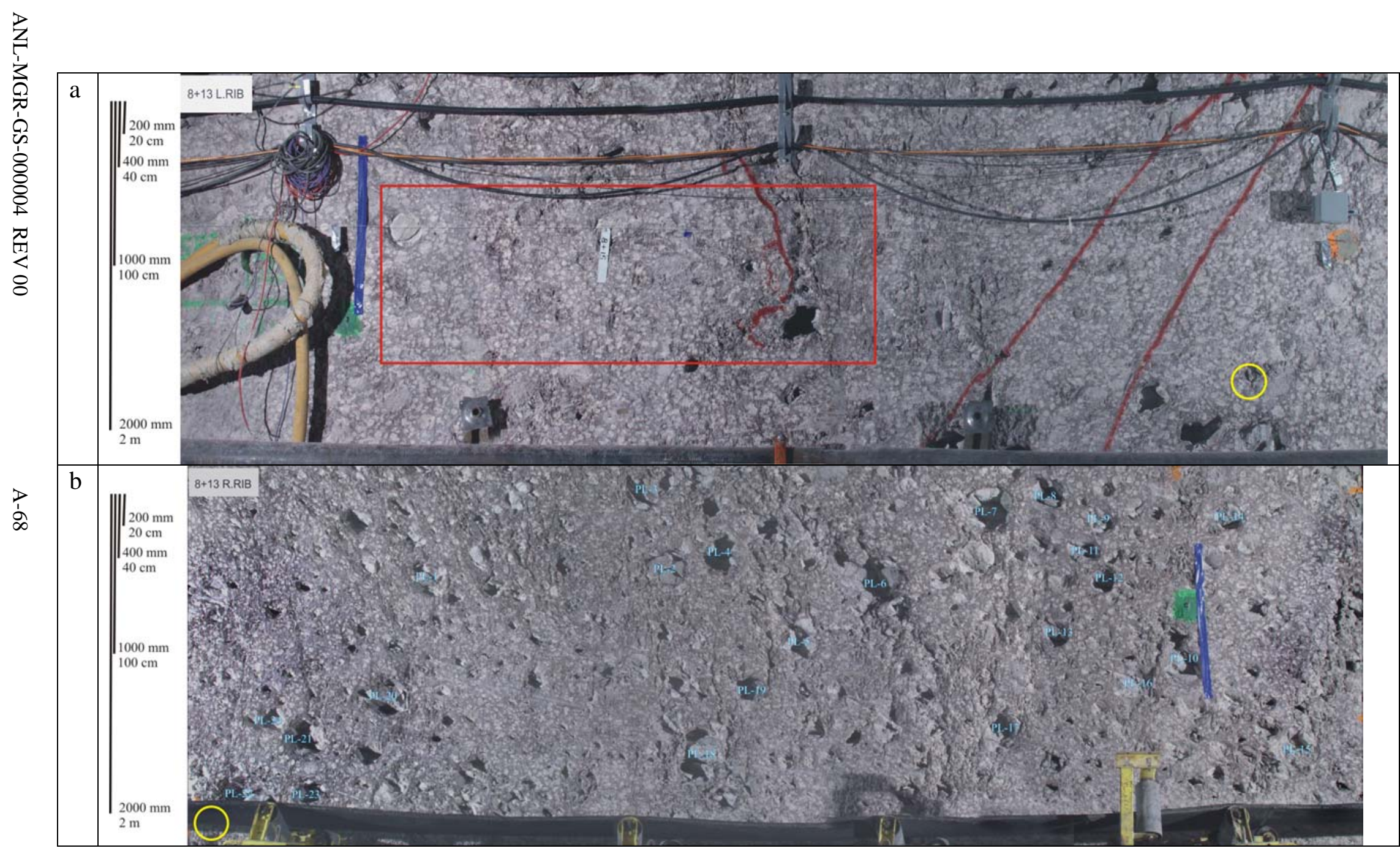

NOTE: Survey station locations from DTN: MO0402GSC04031.000 [DIRS 172231]; labeled lithophysae in PGV Lithop Shapes ECRB.xIs in Appendix D.

Figure A4-3a. Panel Photograph at Station 08+15 on Left Wall with Panel Map 08+15L Location Indicated in Red Box

Figure A4-3b. Panel Photograph at Station 08+16 on Right Wall with Lithophysae Larger Than $20 \mathrm{~cm}$ in Diameter Inventoried for Shape 


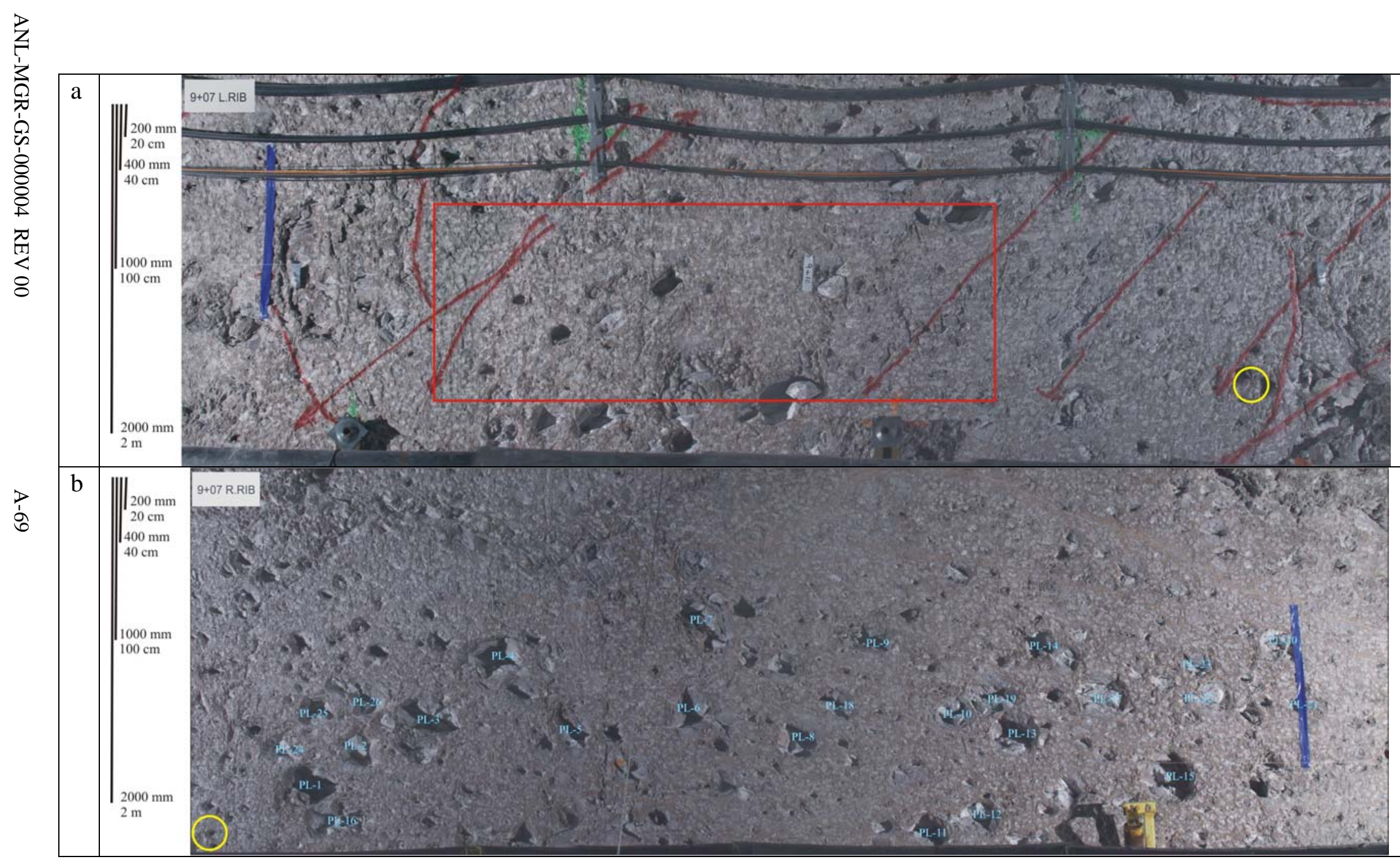

NOTE: Survey station locations from DTN: MO0402GSC04031.000 [DIRS 172231]; labeled lithophysae in PGV Lithop Shapes ECRB.xIs in Appendix D.

Figure A4-4a. Panel Photograph at Station 09+10 on Left Wall with Panel Map 09+10L Location Indicated in Red Box

Figure A4-4b. Panel Photograph at Station 09+10 on Right Wall with Lithophysae Larger Than $20 \mathrm{~cm}$ in Diameter Inventoried for Shape 


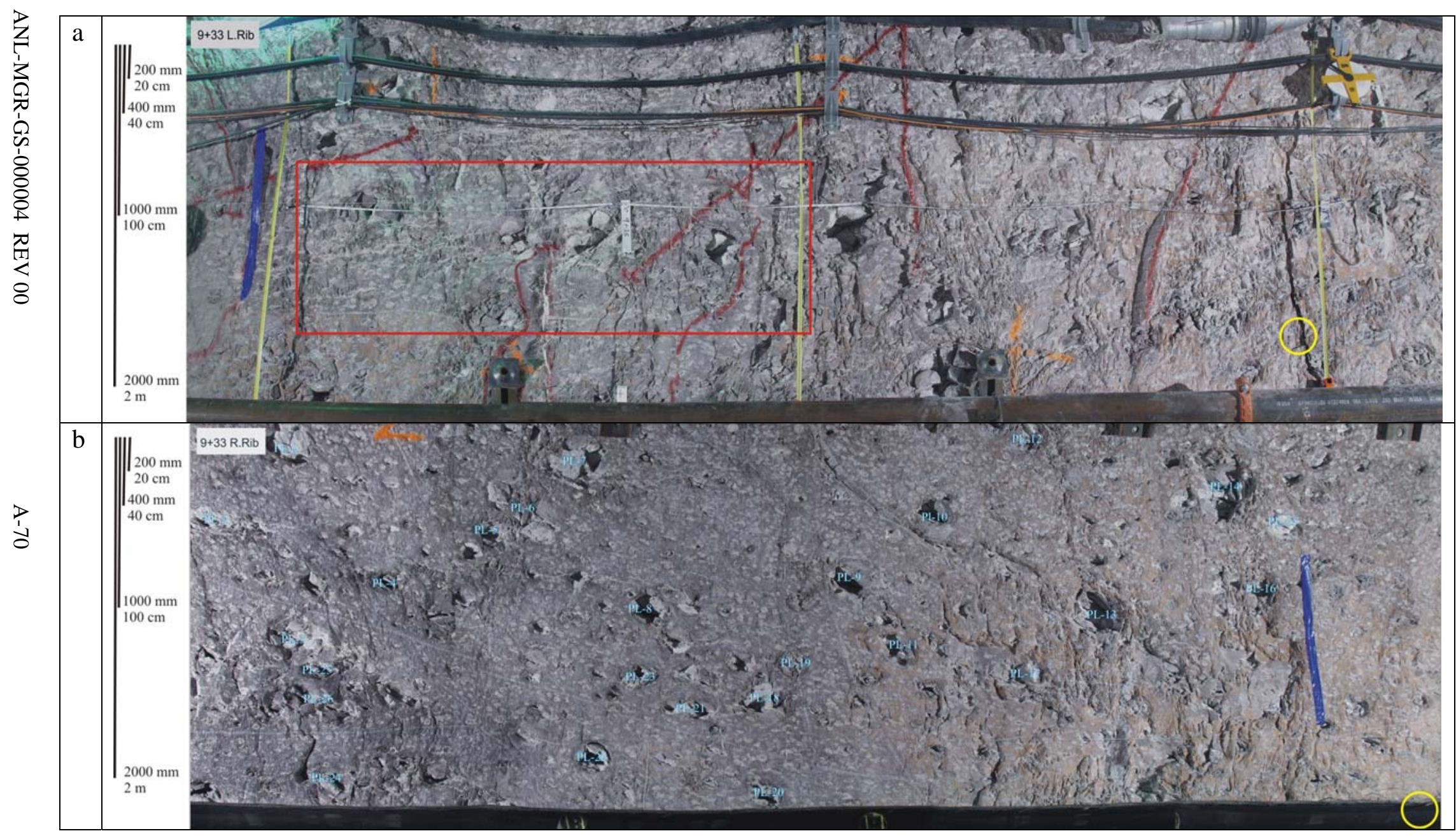

NOTE: Survey station locations from DTN: MO0402GSC04031.000 [DIRS 172231]; labeled lithophysae in PGV Lithop Shapes ECRB.xIs in Appendix D.

Figure A4-5a. Panel Photograph at Station 09+35 on Left Wall and Small-Scale Fracture Traverse Location H16 with Vertical Traverses V38, V39, and V40 with Panel Map 09+35L Location Indicated in Red Box

Figure A4-5b. Panel Photograph at Station 09+35 on Right Wall with Lithophysae Larger Than $20 \mathrm{~cm}$ in Diameter Inventoried for Shape 


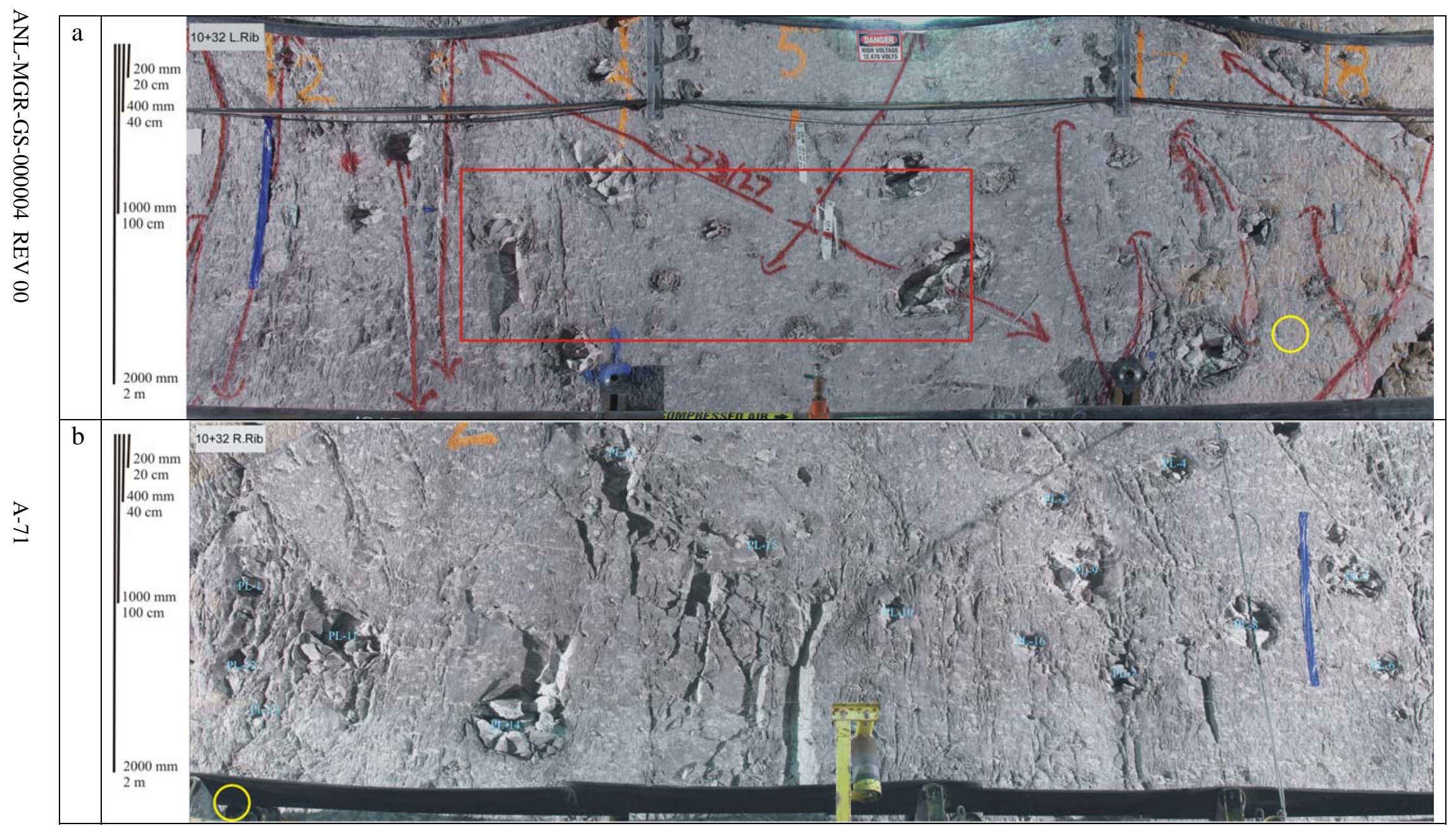

NOTE: Survey station locations from DTN: MO0402GSC04031.000 [DIRS 172231]; labeled lithophysae in PGV Lithop Shapes ECRB.xIs in Appendix D.

Figure A4-6a. Panel Photograph at Station 10+35 on Left Wall with Panel Map 10+35L Location Indicated in Red Box

Figure A4-6b. Panel Photograph at Station 10+35 on Right Wall with Lithophysae Larger Than $20 \mathrm{~cm}$ in Diameter Inventoried for Shape 


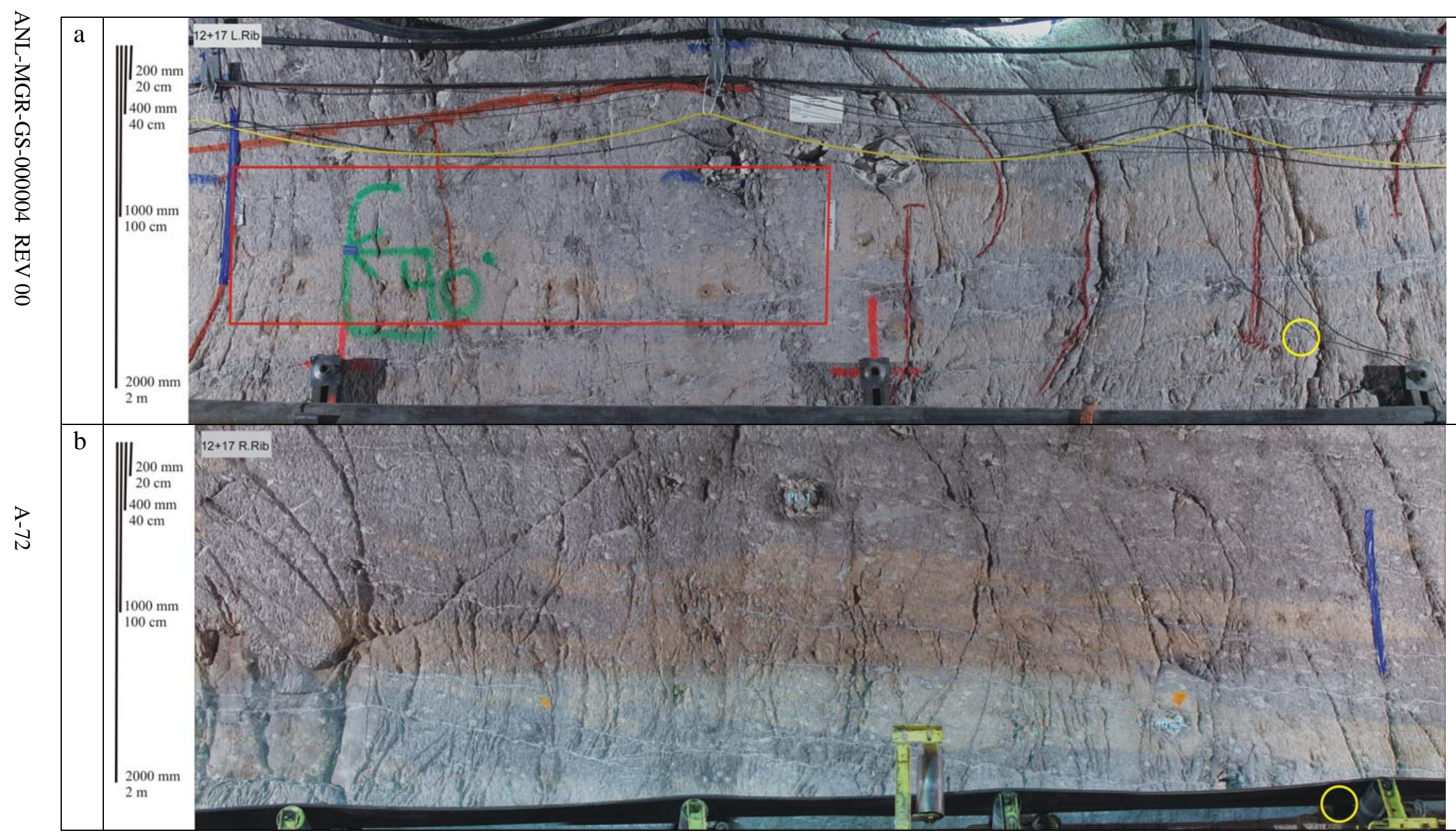

NOTE: Survey station locations from DTN: MO0402GSC04031.000 [DIRS 172231]; labeled lithophysae in PGV Lithop Shapes ECRB.xIs in Appendix D.

Figure A4-7a. Panel Photograph at Station 12+20 on Left Wall with Panel Map 12+20L Location Indicated in Red Box 


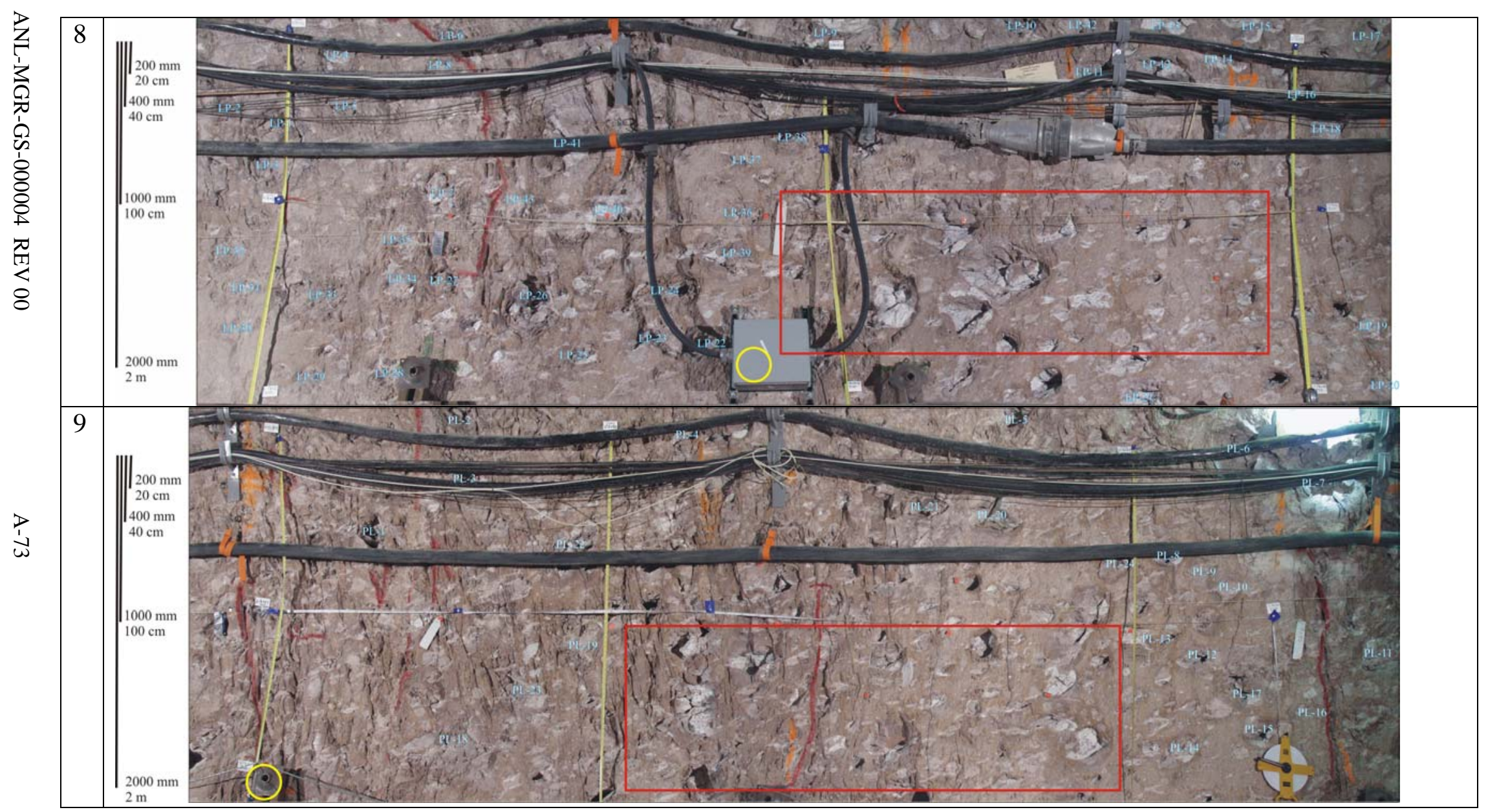

NOTE: Survey station locations from DTN: MO0402GSC04031.000 [DIRS 172231]; labeled lithophysae in PGV Lithop Shapes ECRB.xIs in Appendix D.

Figure A4-8. Panel Photograph at Station 18+05 on Left Wall and Small-Scale Fracture Traverse Location H7 with Vertical Traverses V19, V20, and V21 with Lithophysae Larger Than $20 \mathrm{~cm}$ in Diameter Inventoried for Shape and Panel Map 18+05L Location Indicated in Red Box (See Section A3)

Figure A4-9. Panel Photograph at Station 18+86 on Left Wall and Small-Scale Fracture Traverse Location H8 and H9 with Vertical Traverses V22, V23, and V24 with Lithophysae Larger Than $20 \mathrm{~cm}$ in Diameter Inventoried for Shape and Panel Map 18+86L Location Indicated in Red Box (See Section A3) 


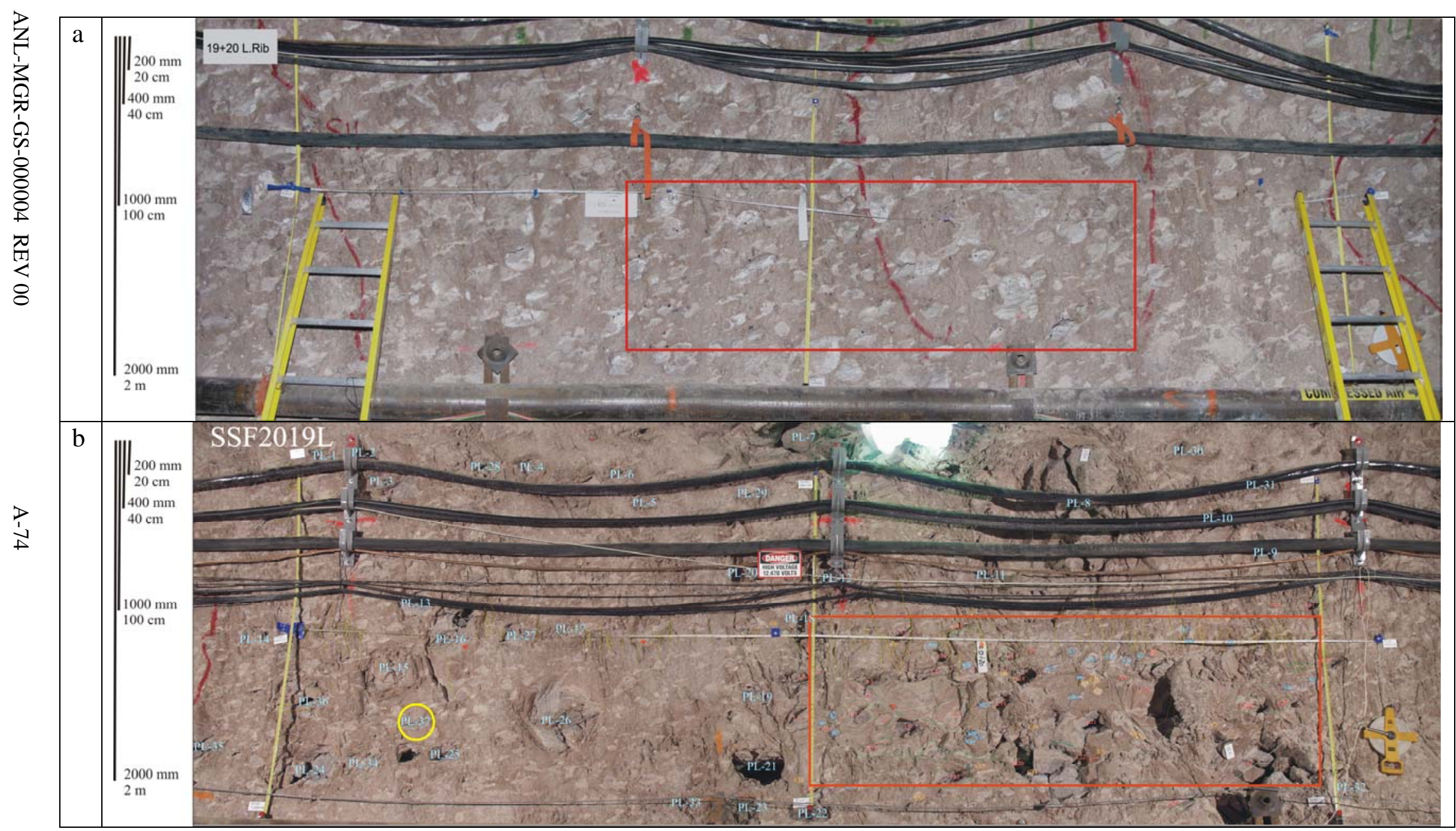

NOTE: Survey station locations from DTN: MO0402GSC04031.000 [DIRS 172231]; labeled lithophysae in PGV Lithop Shapes ECRB.xIs in Appendix D.

Figure A4-10a. Panel Photograph at Station 19+20 on Left Wall and Small-Scale Fracture Traverse Location H14 with Vertical Traverses V34, V35, and V36 with Panel Map 19+19L Location Indicated in Red Box (See Section A3)

Figure A4-10b. Panel Photograph at Station 20+19 on Left Wall and Small-Scale Fracture Traverse Location H10 and H11 with Vertical Traverses V25, V26, and V27 with Lithophysae Larger Than $20 \mathrm{~cm}$ in Diameter Inventoried for Shape and Panel Map 20+18L Location Indicated in Red Box (See Section A3) 


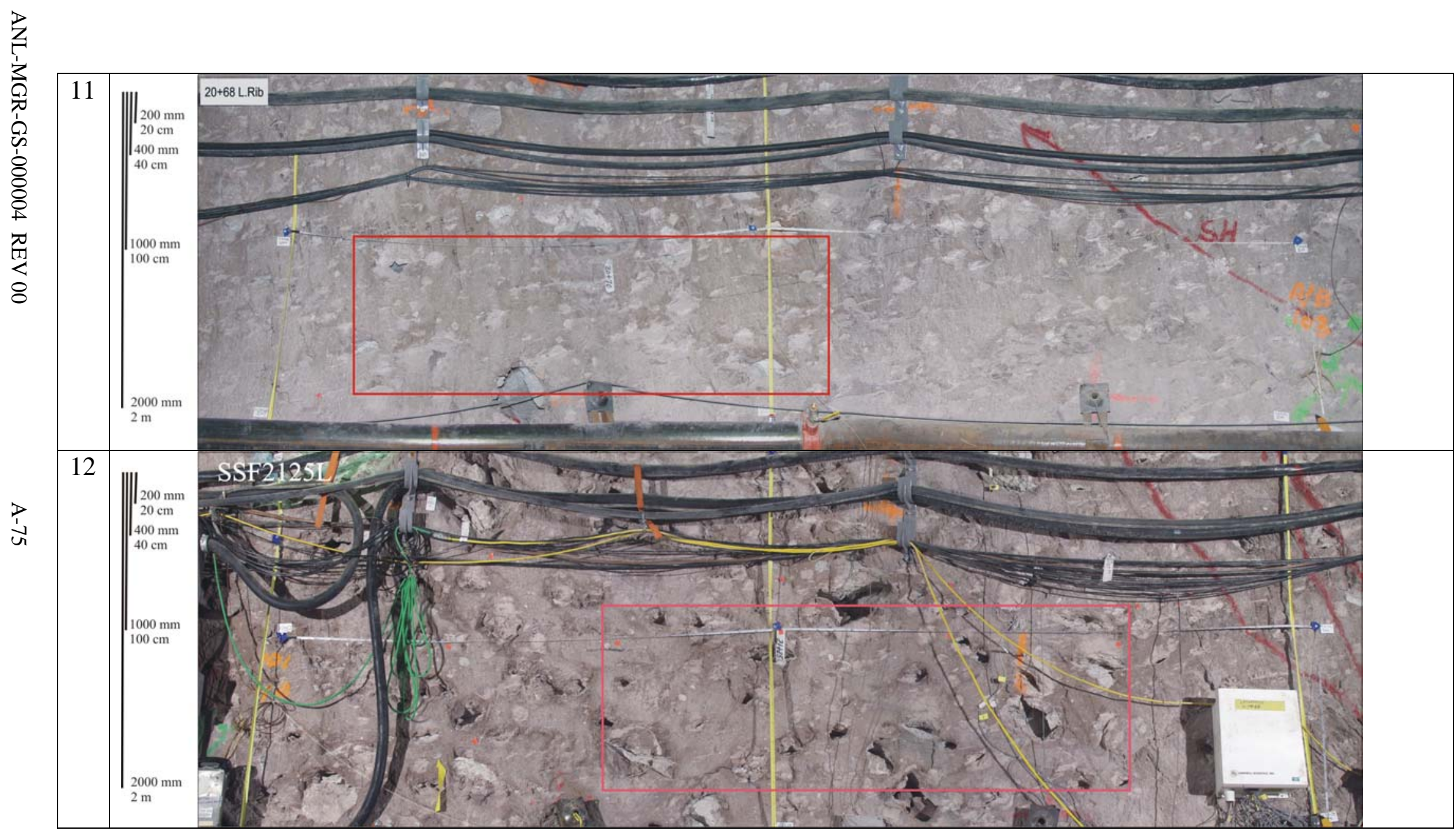

NOTE: Survey station locations from DTN: MO0402GSC04031.000 [DIRS 172231]; labeled lithophysae in PGV Lithop Shapes ECRB.xIs in Appendix D.

Figure A4-11. Panel Photograph at Station 20+71 on Left Wall and Small-Scale Fracture Traverse Location H13 with Vertical Traverses V33, V28, and V29 with Panel Map 20+69L Location Indicated in Red Box (See Section A3)

Figure A4-12. Panel Photograph at Station 21+25 on Left Wall and Small-Scale Fracture Traverse Location H12 with Vertical Traverses V30, V31, and V32 with Panel Map 21+24L Location Indicated in Red Box (See Section A3) 


\section{INTENTIONALLY LEFT BLANK}




\section{APPENDIX B}

STRAIN LEVELS RELATED TO DAMAGE IN TOPOPAH SPRING TUFF 


\section{B1. BACKGROUND}

A credible way to provide limits to the maximum peak ground velocity (PGV) of the synthetic time histories used as input to seismic analyses for the Yucca Mountain Project is to estimate the maximum PGV that could have been experienced at the site in the geological past. To make this estimate, at least two pieces of evidence are necessary:

1. Observations of strain-induced fractures around lithophysae (or lack of such fractures); and

2. Data on the mean strain necessary to initiate fracturing around lithophysae.

Evidence in the first category is available from observations in the Exploratory Study Facility (ESF) and Enhanced Characterization of Repository Block (ECRB) Cross-Drift, which indicate that the majority of the fractures in the lithophysal and nonlithophysal units are induced thermally (see Appendix A).

To supply evidence in the second category, and to evaluate the upper bound to the seismically induced strain experienced by the Topopah Spring Tuff since it has cooled, the shear-strain increments required to cause fracturing of the lithophysal rock mass were calculated based on results of previously performed laboratory compression tests (for units in which the proper test results are available) and results of PFC2D (BSC 2004 [DIRS 169930]) and UDEC (BSC 2002 [DIRS 161949]) numerical micro-mechanical models.

The results of the laboratory uniaxial compression tests were used to estimate the shear-strain increment limit in a lithophysal rock mass. The numerical results of PFC2D and UDEC, based on and calibrated to results of laboratory tests, were used to extrapolate experimental results to wider ranges of lithophysal porosity and different loading conditions that could not be tested in the laboratory (e.g., laboratory tests were conducted for unconfined conditions only). The numerical models also were used to establish the relation between different states of damage evolution and strain. Only the strain at peak stress could be determined from the laboratory results. The results of existing simulations performed in a previous study are re-analyzed. The previous study consisted of modeling mechanical behavior of lithophysal tuff (BSC 2004 [DIRS 172334]). In this study, characteristic fractures were seen to develop around and between lithophysae. The objective of the study was not the correlation of damage with strain per se, but it is possible to re-interpret these results to generate statistical data on the amount of damage (fracturing around lithophysae) related to strain level. Thus, certain features of the simulations (such as levels of confining stress) are not optimal for the present purpose.

The methodology of calculation and shear-strain increments corresponding to different damage states in a lithophysal rock mass is discussed in Section B2.

\section{B2. STRAIN LIMITS IN LITHOPHYSAL TUFF}

\section{B2.1 DAMAGE STATES IN LITHOPHYSAL TUFF}

First, a decision must be made about the damage state (limiting state) at which fracturing would be observable in the field. Clearly, the state at which the first microfractures appear in the intact 
rock matrix would be an underestimate of the threshold shear strain (even though it is recorded in the numerical test), because a few unconnected microfractures would be unnoticed in the field and in the laboratory experiment. It is chosen to record results for three states when possible: (a) the state at which the volumetric strain rate reverses (from compaction to expansion); (b) the onset of systematic fracturing (OSF); and (c) the state at which the peak stress occurs (i.e., the strength of the sample).

Figure B-1 illustrates typical fracturing predicted by the calibrated PFC2D model occurring in a simulated ("synthetic") lithophysal rock sample that has been stressed to failure under uniaxial compression. In this simplest of modeling approaches, the lithophysal voids are represented as circular holes distributed throughout the sample. The rock matrix in this model is composed of several thousand circular particles (too small to be seen at this scale) which are bonded with tensile and shear bonds at their contacts. Fractures, which occur due to breakage of these contact bonds when the sample is stressed, can be seen as red and blue lines within the sample.. At the peak stress point, there usually is considerable damage (e.g., blue fractures in Figure B-1). Analyses of compression of synthetic rock samples show that stress-induced fractures would be expected to interconnect the lithophysae, which act as locations of stress concentration within the mass. This form of predicted fracture development - ubiquitous, long inter-lithophysal fracturing - would allow such fractures to be distinguished - in underground observations - from typical cooling fractures.

The strain state at the peak stress is certainly an upper bound to the threshold strain representing the state for which the fractures connecting lithophysae would be distinguishable in the geologic panel maps of the ESF and the ECRB Cross-Drift. The state at volumetric strain reversal is associated with significant damage, as the sample ceases to behave as an elastic continuum. Structural changes, due to fractures, are the reason for volumetric expansion. The strain at volumetric strain reversal is less than the strain at the peak stress. The strain at the peak stress is determined from the data collected during the laboratory test. The information collected during the laboratory test is insufficient to determine strain at the volumetric strain reversal or other damage states except at the peak stress.

One of the advantages of numerical tests on synthetic models of rock is the ability to monitor evolution of damage much more precisely and at finer detail than is possible in the laboratory. Numerical models allow determination of the OSF by direct monitoring of formation and propagation of macrofractures by coalescence of microfractures. ${ }^{1}$ Consequently, it is not necessary to use macroscopic measures of stress and strain in the sample to interpret the damage state. Instead, the fractures (their number, length and connectivity to the lithophysae) are monitored directly during the test. If OSF is determined directly, it is also possible to assess the level of conservatism in the strain limits determined from the strains at the volumetric strain

\footnotetext{
${ }^{1}$ In PFC2D, microfractures are the result of bond breakage between two particles. In actual rock, this corresponds to a fracture on the scale of the internal structure of the material (i.e., grain size to a bit larger, millimeter to centimeter). Macrofractures develop through the coalescence of microfractures due to stress concentrations and interactions. Macrofractures have a dimension comparable in scale to the characteristic dimension of the problem that is analyzed (e.g., scale of lithophysae). In the determination of the OSF for PFC2D calculations, macrofractures are assessed on the basis of criteria related to the orientation and distance between microfractures.
} 
reversal and at the peak stress. An algorithm for monitoring the evolution of microfractures has been developed and used in PFC2D simulations of uniaxial compressive tests on the lithophysal rock mass.

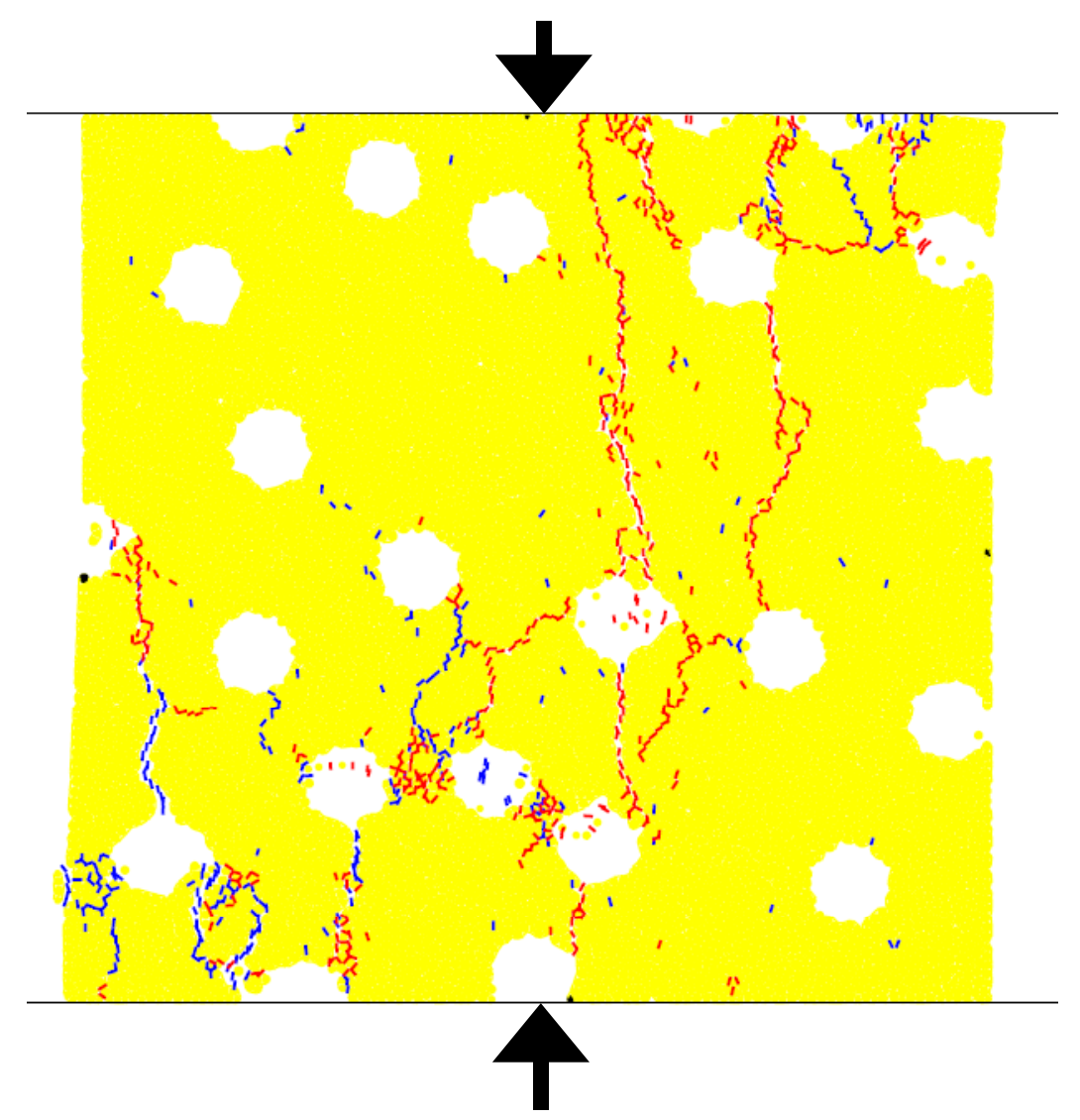

Source: BSC (2003 [DIRS 166660], Attachment VIII, PFC2D Inputs \& Outputs CD \#9, sC1_mKb14_tD@0 bw3.sav); Damjanac et al. (2004 [DIRS 172060], Figure 1).

NOTE: Blue and red lines are stress-induced fractures developed during a simulated uniaxial compression test. The arrows indicate the direction of applied uniaxial stress. Blue lines indicate fractures that developed prior to reaching the peak stress; red lines indicate fractures that developed after the peak stress was reached. "Fractures" located in the middle of a circular void represent particles that have broken off from the edge of the void. The modeling was carried out using the software code PFC2D (BSC 2004 [DIRS 169930]).

Figure B-1. Fractures Developed during Modeled Deformation of a 1-Meter by 1-Meter Synthetic Lithophysal Sample

The microfractures and macrofractures identified during a simulation of a sample with lithophysal geometry generated based on the geologic panel maps (BSC 2003 [DIRS 166660], Section 9.1, Attachment V) are shown in Figure B-2 on the left and right sides, respectively. The algorithm keeps track of "fracture score," which is a weighted total length of macrofractures. If a macrofracture is not connected to any lithophysae the weight is 0 ; the macrofracture does not contribute to the fracture score. If a macrofracture is connected to a single lithophysae the weight is 1 . However, if a macrofracture connects 2 lithophysae the weight is $2-$ i.e., the length of the fracture is counted in the score twice. Knowing that the edge length of the "sample" is $1 \mathrm{~m}$, it seems reasonable that the OSF would correspond to the fracture score of $0.1 \mathrm{~m}$, because this length of connected macrofracture is observable in the field. 

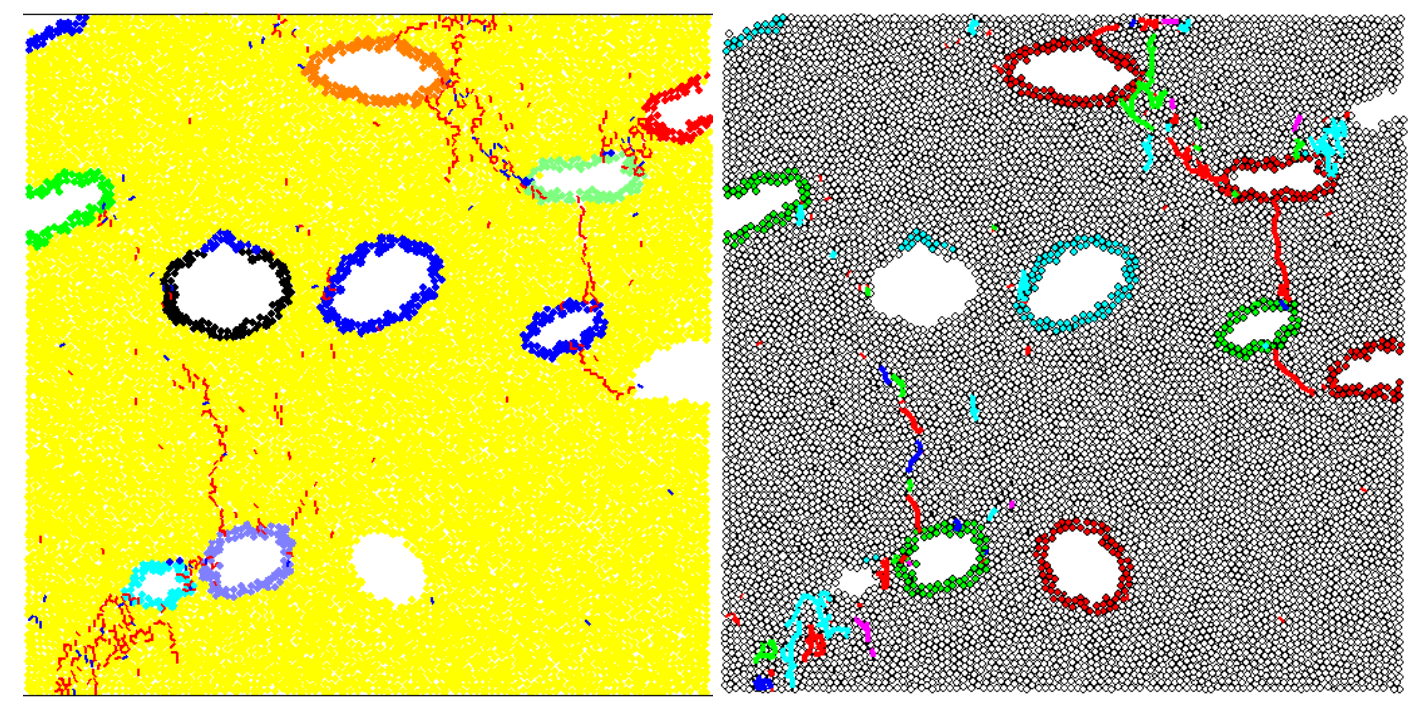

Source: Damjanac et al. (2004 [DIRS 172060], Figure 2).

NOTE: For the lithophysae, the colored particles represent their boundaries. Left side: Microfractures. Blue signifies shear microfractures and red signifies tensile microfractures. Right side: Macrofractures. Different colors are arbitrarily assigned to different macrofractures.

Figure B-2. Microfractures and Macrofractures Identified in a PFC2D Sample

The evolution of 3 variables (axial stress, volumetric strain and fracture score) as functions of axial strain for the sample in Figure B-2 is shown in Figure B-3. The axial strains at peak stress and at the point of volumetric strain reversal are indicated in the figure and correlated to the fracture score. At the point of reversal of volumetric strain (axial strain of $0.225 \%$ ) the fracture score is approximately $0.2 \mathrm{~m}$; at peak stress (axial strain of $0.235 \%$ ) the fracture score is approximately $0.3 \mathrm{~m}$. The first significant fracturing (fracture score of $0.075 \mathrm{~m}$ ) occurs at axial strain of $0.175 \%$. The results of four other cases simulated using the algorithm for detection of OSF exhibit similar relations. In all cases, significant fracturing (i.e., fracture score on the order of $0.1 \mathrm{~m}$ ) is developed at the peak stresses. The differences between strains at peak stress, at the point of volumetric strain reversal and at the OSF (i.e., a state for which fracture score is on the order of $0.1 \mathrm{~m}$ ) are relatively small. These results justify use of the states at peak stress and volumetric strain reversal as conservative estimates of the OSF. 


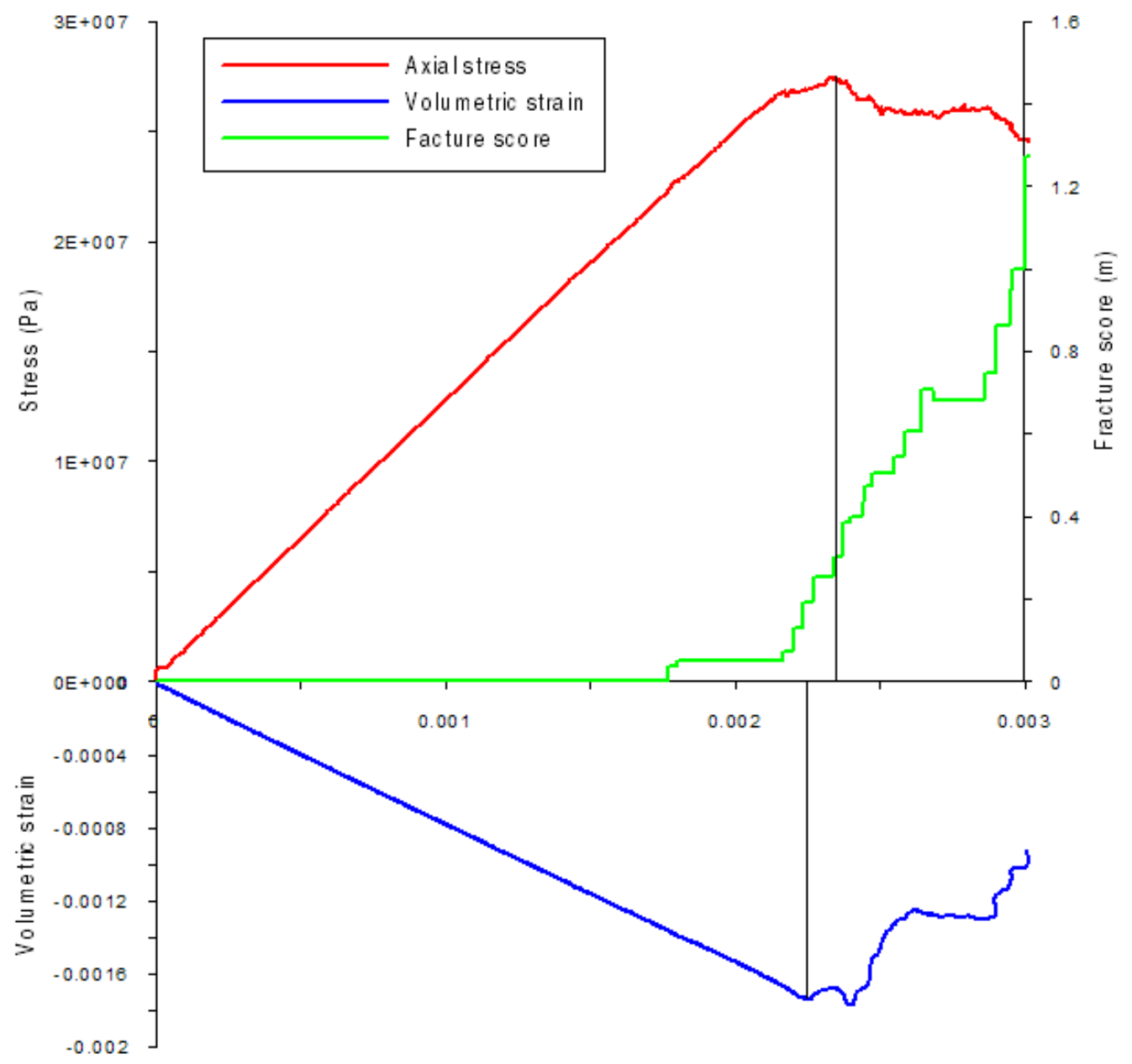

Source: Damjanac et al. 2004 [DIRS 172060], Figure 3.

Figure B-3. Axial Stress, Volumetric Strain and Fracture Score as Functions of Axial Strain for the Sample Shown in Figure B-2

\section{B2.2 METHODOLOGY FOR CALCULATION OF STRAIN INCREMENT}

The cumulative axial strain at a selected damage state (e.g., peak stress or OSF) cannot be used as the strain increment required to cause fracturing of in situ lithophysal rock, because the axial strain measured in the laboratory corresponds to a certain uniaxial stress (and corresponding strain) path from an initial, unstressed state to the damage state. The rock mass exposed in the Yucca Mountain ESF and ECRB Cross-Drift is under an in situ state of stress (strain) with a significant deviatoric component. The horizontal principal stresses are between $30 \%$ and $60 \%$ of the vertical principal stress. For dynamic shear strains associated with seismic ground motion to cause failure of in situ lithophysal rock, the shear strains would have to exceed the shear-strain increment needed to take the rock from the in situ state to the damage state. This is less than the shear-strain increment required to take an unstressed sample in the laboratory (or in a numerical simulation) to the damage state. Mechanical properties determined from laboratory tests and numerical simulations, however, can be used to determine the shear-strain increment required to damage a sample initially at the in situ state. 
In this section, a methodology is discussed for calculating the shear-strain increment that causes stress change from an arbitrary initial stress state (e.g., an in situ state) to a state on a surface (or line) in stress space that defines a limiting stress state (corresponding to a selected damage state). The limiting state is defined by a Mohr-Coulomb condition, a friction angle, $\phi$, and a cohesion, $c$. The "friction angle" in this context characterizes how the limiting state changes as a function of confining stress. It is assumed that the friction angle for the limiting state is the same as the friction angle related to the yield criterion (or peak stress). In the elastic state, the material is characterized by a Young's Modulus, $E$, and a Poisson's ratio, $v$. It is assumed that the lithophysal rock mass behaves as a linear elastic material until the limiting state is reached. The stress path from the initial stress state to the limiting damage state during a strong seismic ground motion can be arbitrary. In this analysis, the shear-strain increment is calculated for the stress path in which the mean stress does not change. Cyclic shear strain under constant vertical stress, which is typically a dominant mode of deformation during a seismic ground motion, results in the stress path along which the mean stress is invariant.

The material initially is in an elastic state with principal stresses $\sigma_{3}^{E}$ and $\sigma_{1}^{E}$, respectively (see point $\mathrm{E}$ in Figure B-4). The mean stress, $\sigma_{m}$, for this state is defined as

$$
\sigma_{m}=\frac{\sigma_{1}+\sigma_{3}}{2}
$$

The material passes from the elastic state (point E in Figure B-4) to the plastic state (point F in Figure B-4) while maintaining the same mean stress, $\sigma_{m}$. In the plastic state (point F), the principal stresses are $\sigma_{3}^{F}$ and $\sigma_{1}^{F}$.

Note that in terms of principal stresses, $\sigma_{3}$ and $\sigma_{1}$, the Mohr-Coulomb failure criterion can be written as (Itasca 2002 [DIRS 160331], FLAC Theory and Background Volume, adapted from Section 2.4.2.2)

$$
\sigma_{1}=K_{\phi} \sigma_{3}+\sigma_{c i}
$$

where

$$
K_{\phi}=\frac{1+\sin \phi}{1-\sin \phi}
$$

and

$$
\sigma_{c i}=2 c \sqrt{K_{\phi}}
$$

$\sigma_{c i}$ is the uniaxial compressive strength, which is denoted as $q u$ in workbooks Limiting strains-Lab Tests.xls and Limiting strains-Numerical Sims.xls (Appendix D). 


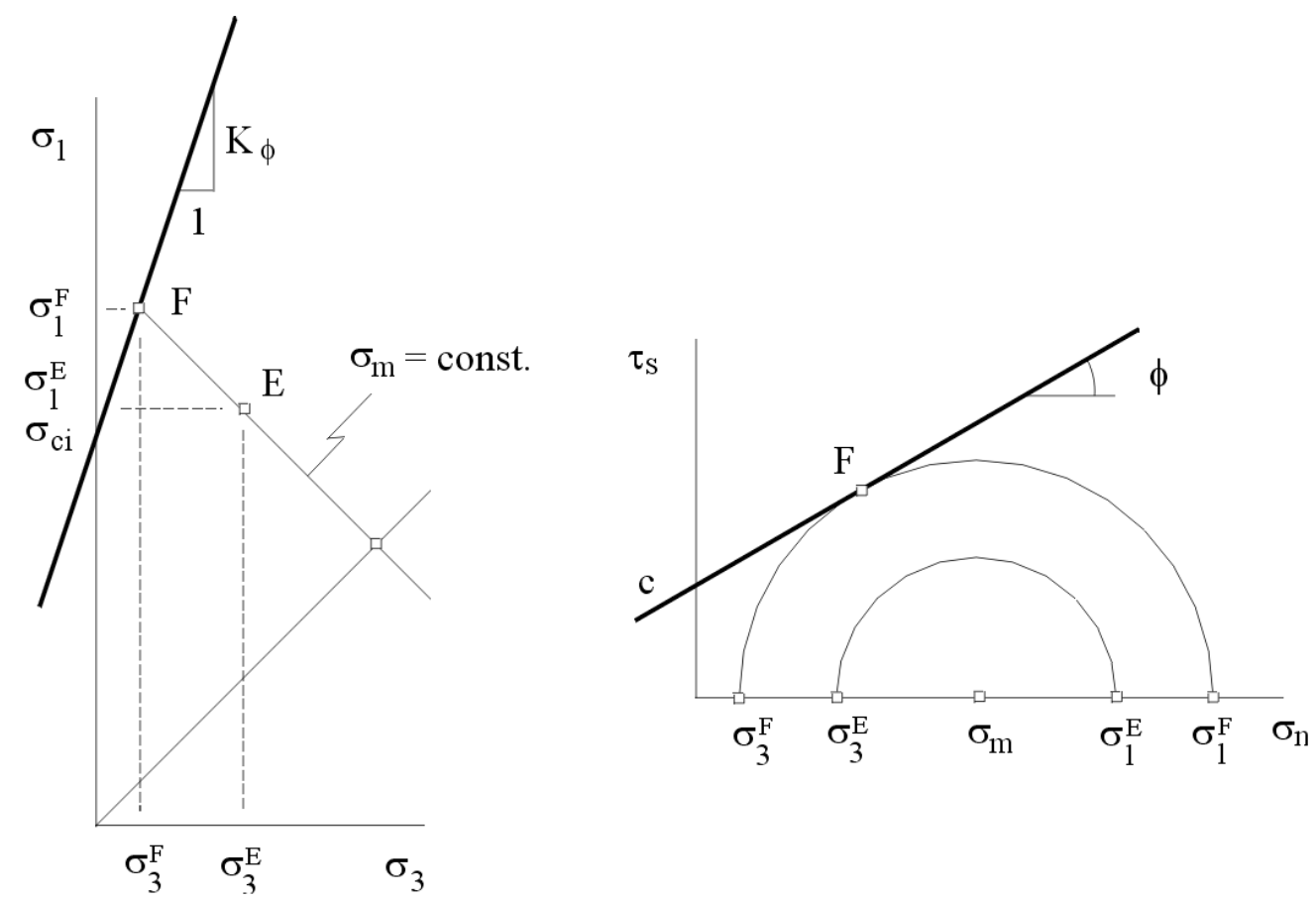

Source: Damjanac et al. 2004 [DIRS 172060], Figure 4.

NOTE: On the right side, $\tau_{\mathrm{s}}$ is shear stress, $\sigma_{\mathrm{n}}$ is normal stress, and $c$ is cohesion. On the left side, symbols are defined in the text.

Figure B-4. Stress Path Corresponding to Constant Mean Stress Displayed on the Mohr-Coulomb Failure Criterion in Terms of Principal Stresses and Normal and Shear Stresses on the Failure Plane

From a simple geometrical construction, the horizontal coordinate of the intersection point $\mathrm{F}$ in the left side of the figure is found to be

$$
\sigma_{3}^{F}=\frac{2 \sigma_{m}-\sigma_{c i}}{K_{\phi}+1}
$$

and the vertical coordinate to be

$$
\sigma_{1}^{F}=K_{\phi} \sigma_{3}^{F}+\sigma_{c i}
$$

The increments of major and minor principal stresses when passing from points $\mathrm{E}$ to $\mathrm{F}$ are written as

$$
\begin{aligned}
& \Delta \sigma_{1}=\sigma_{1}^{F}-\sigma_{1}^{E} \\
& \Delta \sigma_{3}=\sigma_{3}^{F}-\sigma_{3}^{E}
\end{aligned}
$$


The relation between the (increment of) strain, $\Delta \varepsilon_{1}$ and $\Delta \varepsilon_{3}$, and the corresponding (increment of) principal stress, $\Delta \sigma_{1}$ and $\Delta \sigma_{3}$, is computed from Hooke's law, which, for plane strain conditions, is (Jaeger and Cook 1979 [DIRS 106219], Section 5.3)

$$
\begin{aligned}
& \Delta \varepsilon_{1}=\frac{1-v^{2}}{E} \Delta \sigma_{1}-\frac{v(1+v)}{E} \Delta \sigma_{3} \\
& \Delta \varepsilon_{3}=\frac{1-v^{2}}{E} \Delta \sigma_{3}-\frac{v(1+v)}{E} \Delta \sigma_{1}
\end{aligned}
$$

Finally, the increment of shear strain (an engineering strain) when the material passes from point $\mathrm{E}$ to point $\mathrm{F}$ in the figure, is written as,

$$
\Delta \gamma=\Delta \varepsilon_{1}-\Delta \varepsilon_{3}
$$

In the following sections the above methodology is used to calculate the shear-strain increment associated with moving from an in situ state at the repository waste emplacement level to a damage state. Values of Young's modulus, Poisson's ratio, friction angle, yield stress, and peak stress are taken from laboratory tests, numerical simulations, or assumed, as appropriate. The calculated shear-strain increments are used to establish a probability distribution for the shearstrain increment threshold required to damage lithophysal rocks at the waste emplacement level (Section 6.4.3). The shear-strain threshold is compared to dynamic shear strains that would be produced by extreme ground motion (Section 6.5) to place a bound on the level of ground motion that has occurred at Yucca Mountain (Section 6.6).

\section{B2.3 INTERPRETATION OF LABORATORY RESULTS}

Uniaxial compression tests were conducted on the samples from Topopah Spring Tuff, both lithophysal and nonlithophysal. Testing of lithophysal tuff is particularly challenging due to the lithophysae. Large diameter samples are required for determination of representative rock mass properties. As expected, the mechanical properties of the lithophysal tuff exhibit a strong dependence on porosity, which, in turn, can be viewed as a form of sample size dependency. Therefore, the results obtained from the tests on the largest samples, the 288-mm diameter cores (diameter several times larger than the included lithophysae) taken from the ESF and ECRB Cross-Drift, are considered to be the best representation of the mechanical behavior of the lithophysal tuff. The uniaxial compression tests provide stress-strain behavior of the lithophysal tuff, which includes the axial stress and strain levels associated with peak strength.

The test results are summarized in Table B-1. The lithophysal porosity, among other information, is listed for each sample. (The lithophysal porosity, listed in Table B-1 and used in this technical memorandum, is less than the total porosity, which, in addition to lithophysal porosity, also includes matrix porosity and the porosities of rims and spots). The primary factor controlling the mechanical properties of the lithophysal rocks is lithophysal porosity. Distribution of lithophysal porosity as mapped in the ECRB Cross-Drift is shown in Figure B-5. 


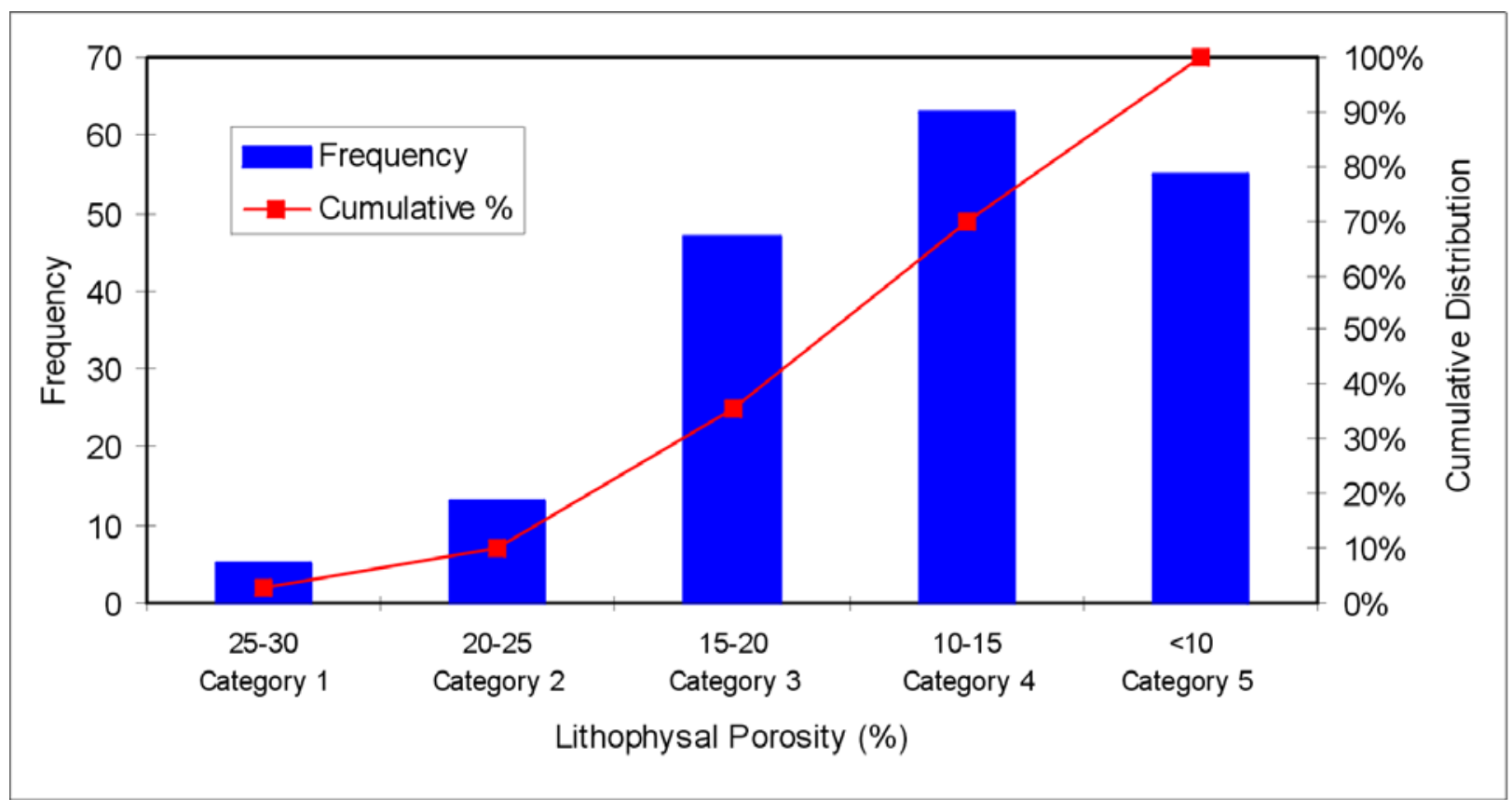

Source: BSC 2004 [DIRS 166107], Figure E-10.

NOTE: Lithophysal porosity data are from ECRB Cross-Drift station $14+44$ to $23+26$.

Figure B-5. Distribution of Lithophysal Porosity in the ECRB Cross-Drift 
Table B-1. Mechanical Properties of Lithophysal Tuff from 288-mm-Diameter Samples

\begin{tabular}{|c|c|c|c|c|c|c|c|c|c|}
\hline 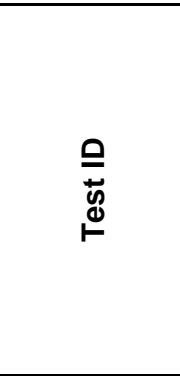 & 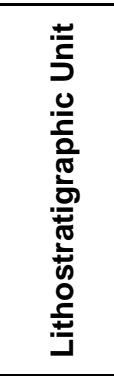 & 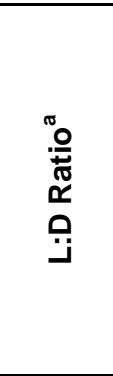 & 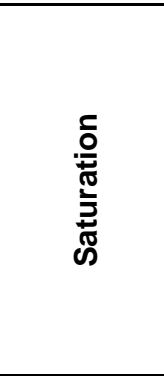 & 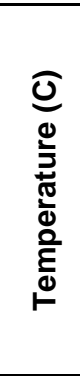 & 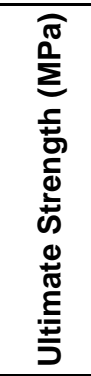 & 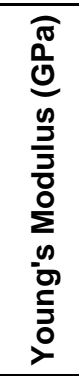 & 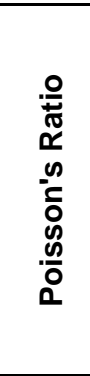 & 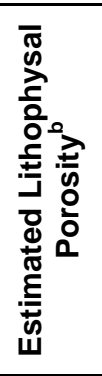 & 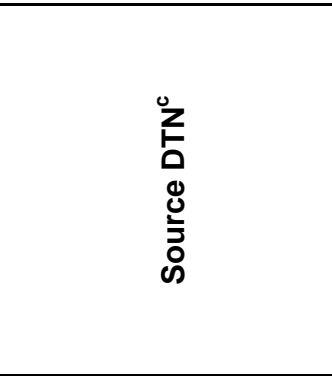 \\
\hline YMPLL49A & Tptpll & $1.1: 1$ & Dry & 195 & 32.2 & 7.1 & 一 & 11.7 & SN0211L0207502.002 \\
\hline YMPLL43A & Tptpll & $1.1: 1$ & Dry & 200 & 31.1 & 6.5 & - & 20.3 & SN0211L0207502.002 \\
\hline YMPLL23A & Tptpll & $1.8: 1$ & Room Dry & 24 & 28.7 & 9.2 & - & 19.2 & SN0211L0207502.002 \\
\hline YMPLL24A & Tptpll & $1.8: 1$ & Room Dry & 24 & 13.3 & 5.0 & - & 22.2 & SN0211L0207502.002 \\
\hline YMPLL46A & Tptpll & $1.8: 1$ & Room Dry & 24 & 21.7 & 8.5 & 一 & 28.4 & SN0211L0207502.002 \\
\hline YMPLL87A & Tptpll & $1.9: 1$ & Saturated & 24 & 15.7 & 5.3 & - & 14.5 & SN0211L0207502.002 \\
\hline YMPUL59B & Tptpul & $1.2: 1$ & Dry & 190 & 19.6 & 7.3 & - & 39.4 & SN0208L0207502.001 \\
\hline YMPUL67A & Tptpul & $1.3: 1$ & Dry & 190 & 34.8 & 9.9 & - & 6.2 & SN0208L0207502.001 \\
\hline YMPUL62B & Tptpul & $1.0: 1$ & Dry & 200 & 37.0 & 13.7 & - & 19.3 & SN0208L0207502.001 \\
\hline YMPUL50A & Tptpul & $1.5: 1$ & Room Dry & 24 & 22.1 & 14.9 & 0.21 & 28.5 & SN0211L0207502.002 \\
\hline YMPUL59A & Tptpul & $2.0: 1$ & Room Dry & 24 & 13.5 & 5.8 & 0.39 & 30.3 & SN0208L0207502.001 \\
\hline YMPUL61A & Tptpul & $1.9: 1$ & Room Dry & 24 & 17.7 & 8.8 & - & 23.9 & SN0208L0207502.001 \\
\hline YMPUL62A & Tptpul & $1.8: 1$ & Room Dry & 24 & 25.9 & 13.7 & - & 12.7 & SN0208L0207502.001 \\
\hline YMPUL64A & Tptpul & $1.7: 1$ & Room Dry & 24 & 33.5 & 20.5 & - & 12.8 & SN0208L0207502.001 \\
\hline YMPUL65A & Tptpul & $2.0: 1$ & Room Dry & 24 & 26.2 & 19.5 & - & 11.9 & SN0208L0207502.001 \\
\hline YMPUL66A & Tptpul & $1.7: 1$ & Room Dry & 24 & 16.5 & 12.4 & - & 16.7 & SN0208L0207502.001 \\
\hline YMPUL60A & Tptpul & $1.8: 1$ & Saturated & 24 & 12.7 & 6.7 & - & 18.6 & SN0208L0207502.001 \\
\hline YMPUL63A & Tptpul & $1.9: 1$ & Saturated & 24 & 9.4 & 5.0 & 0.24 & 20.0 & SN0208L0207502.001 \\
\hline YMPUL68A & Tptpul & $2.1: 1$ & Saturated & 24 & 11.6 & 5.9 & 0.03 & 25.8 & SN0208L0207502.001 \\
\hline
\end{tabular}

Source: BSC (2004 [DIRS 172334], Table 6.3-1).

An example of the stress-strain curve obtained on a sample taken from the lower lithophysal unit is shown in Figure B-6. For this sample (test ID YMPLL24A from Table B-1), the reported uniaxial unconfined strength is $13.3 \mathrm{MPa}$, Young's modulus is $5 \mathrm{GPa}$, and axial strain at failure is $0.4 \%$ (Price 2002 [172061], pp. 207-215). Most likely, the initial non-linear portion of the curve is not due to non-linear material behavior at low stress levels but, rather, a consequence of imperfect contacts between the sample and loading platens. Even if this conjecture is incorrect, the initial non-linear strain is inconsequential for calculating shear-strain increment because the in situ stress state is larger than the stress level for which non-linear deformation is observed in the laboratory experiment. Nominally, the axial strain at the peak stress is $0.4 \%$-i.e., point $\mathrm{C}$ on the curve in Figure B-6. However, from the stress-strain curve, it is clear that the sample is already in an active state of failure at point $\mathrm{B}$, or $0.36 \%$ of axial strain. In the calculation of the shear-strain increment, the material is assumed to behave as linearly elastic-perfectly plastic (as 
discussed in Section B2.2). The elastic behavior is controlled by the Young's modulus, determined by the slope of the line between points $\mathrm{O}$ and $\mathrm{A}^{\prime}$. The state of failure in the elastic-plastic model is at point A', which is, for strain of $0.34 \%$, smaller than strain at point B. The difference in the strains between points A (or A') and B is relatively small. Also, macro-fractures probably are already visible in the sample at state A. The calculated shear-strain increment, from an in situ stress state corresponding to a 250 -m overburden to the state A' on the failure surface, based on this laboratory experiment, is $0.20 \%$, using the correction for in situ state described in Section B2.2. The in situ principal stresses for $250 \mathrm{~m}$ overburden are vertical, $\sigma_{1}^{E}=4.81 \mathrm{MPa}$, and horizontal, $\sigma_{3}^{E}=2.41 \mathrm{MPa}$. The mean stress is an average of $\sigma_{1}^{E}$ and $\sigma_{3}^{E}$ (Eq. B-1). The Young's modulus, E, (the slope of the linear portion of the loading part of the stress-strain curve in Figure B-6) is 5.0 GPa (Test ID YMPLL24A in Table B-1); and the uniaxial compressive strength, $\sigma_{c i}$, is $13.3 \mathrm{MPa}$ (Test ID YMPLL24A in Table B-1). Assuming the friction angle, $\phi$, to be 30 degrees, stress state (i.e., $\sigma_{1}^{F}$ and $\sigma_{3}^{F}$ ) at the failure are calculated from relations B-5 and B-6. Finally, the shear-strain increment, $\Delta \gamma$, is calculated from the principal strain increments, which are obtained by applying the elastic relation between the stress and strain increments (Eq. B-8).

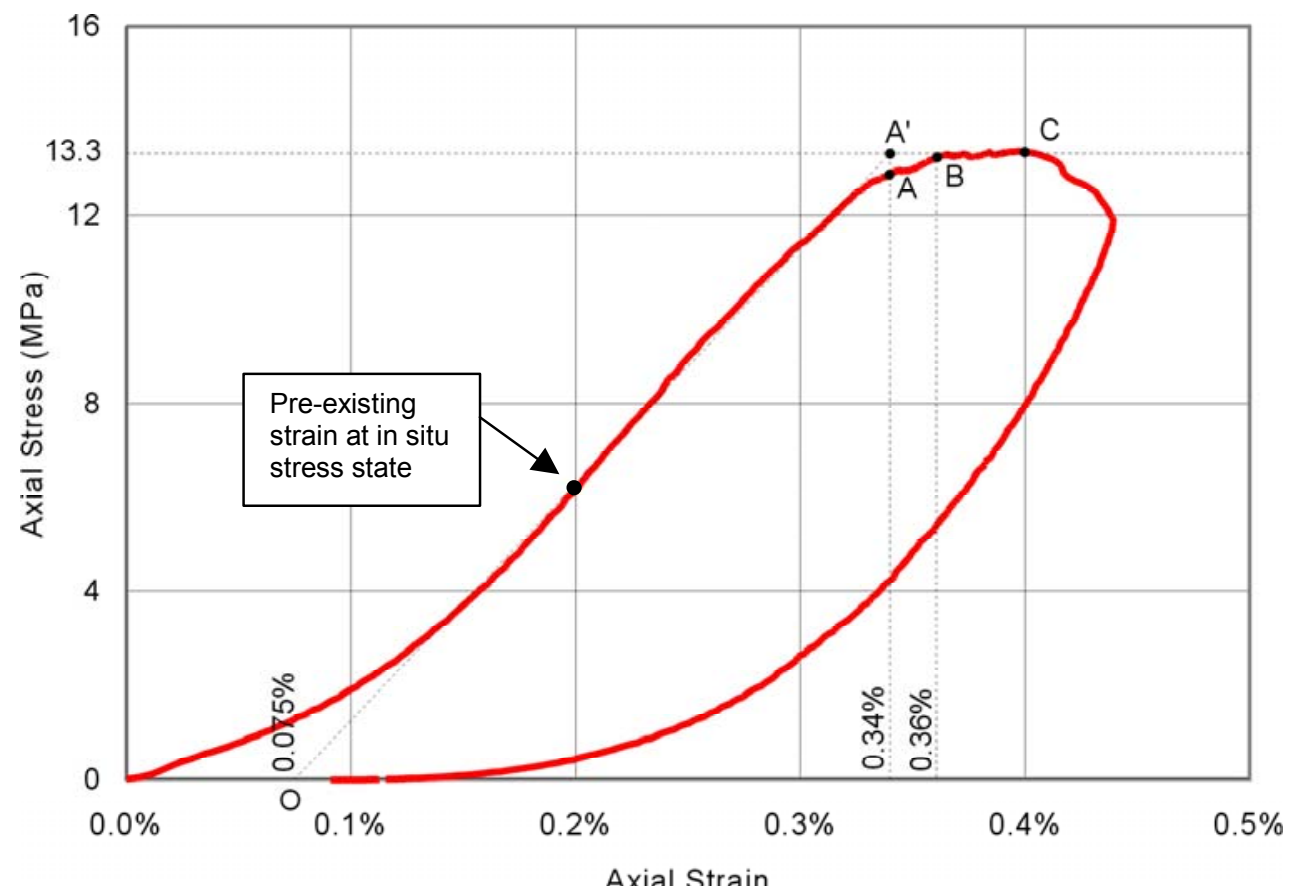

Source: DTN : SN0211L0207502.002 [DIRS161872], Price (2002 [172061], pp. 207-215).

Figure B-6. Stress Strain Curve Obtained on a 288-mm Sample (ID YMPLL24A) from the Lower Lithophysal Unit, Tested Under Room-Dry Conditions at a Temperature of $24^{\circ} \mathrm{C}$

\section{B2.4 SHEAR STRAIN LIMITS ESTIMATED FROM LABORATORY RESULTS}

The shear-strain increments at peak strength were calculated for laboratory results obtained on 288-mm diameter samples taken from the ESF and ECRB Cross-Drift. The experimental results were obtained for unconfined compression conditions only. Calculations were carried out for 
overburden depths of 250 and $400 \mathrm{~m}$ representing the range of overburden for the repository (Appendix D, Limiting Strains - Lab Tests.xls). An internal angle of friction angle of $30^{\circ}$ was assumed in the calculation (Section 5, Assumption 2). This assumption results in conservative (larger) estimates of the shear strain associated with peak strength and thus larger potential peak ground velocities to produce observable yield in situ. The results for the 288-mm diameter samples, using an overburden depth of $250 \mathrm{~m}$ and divided into two categories based on height-to-diameter ratio $(H / D>1.5$ and $H / D \leq 1.5)$, are shown in Figure B-7 as a function of lithophysal porosity. It is preferred to have the height-to-width, or height-to-diameter, ratio for the laboratory test sample equal to or larger than 2 to minimize the effect of confinement resulting from friction between the loading platen and the sample. The sample to platen friction exerts a small radial confining stress to short-length samples, thus resulting in artificially higher compressive strengths. Note that the results show no relationship between shear strain at failure and lithophysal porosity (Figure B-7). Statistics of the results are presented in Table B-2.

Table B-2. Summary of Statistics of Calculated Shear-Strain Increments Based on Laboratory Testing

\begin{tabular}{|c|c|c|c|c|}
\hline & $\begin{array}{c}\text { Number of } \\
\text { Samples }\end{array}$ & $\begin{array}{c}\text { Overburden Depth Used in Calculation } \\
\text { of Shear-Strain Increment (m) }\end{array}$ & $\begin{array}{c}\text { Mean } \\
\text { Deviation }\end{array}$ \\
\hline & & & $\%$ & $\%$ \\
\hline $\begin{array}{c}\text { 288-mm diameter, } \\
\text { H/D > 1.5 }\end{array}$ & 13 & 250 & 0.16 & 0.04 \\
\hline \multirow{2}{2}{$\begin{array}{c}\text { 288-mm diameter, } \\
\text { all }\end{array}$} & 19 & 400 & 0.17 & 0.05 \\
\cline { 2 - 5 } & 250 & 0.18 & 0.07 \\
\hline
\end{tabular}

Source: Appendix D, Limiting Strain - Lab Tests.xls. 


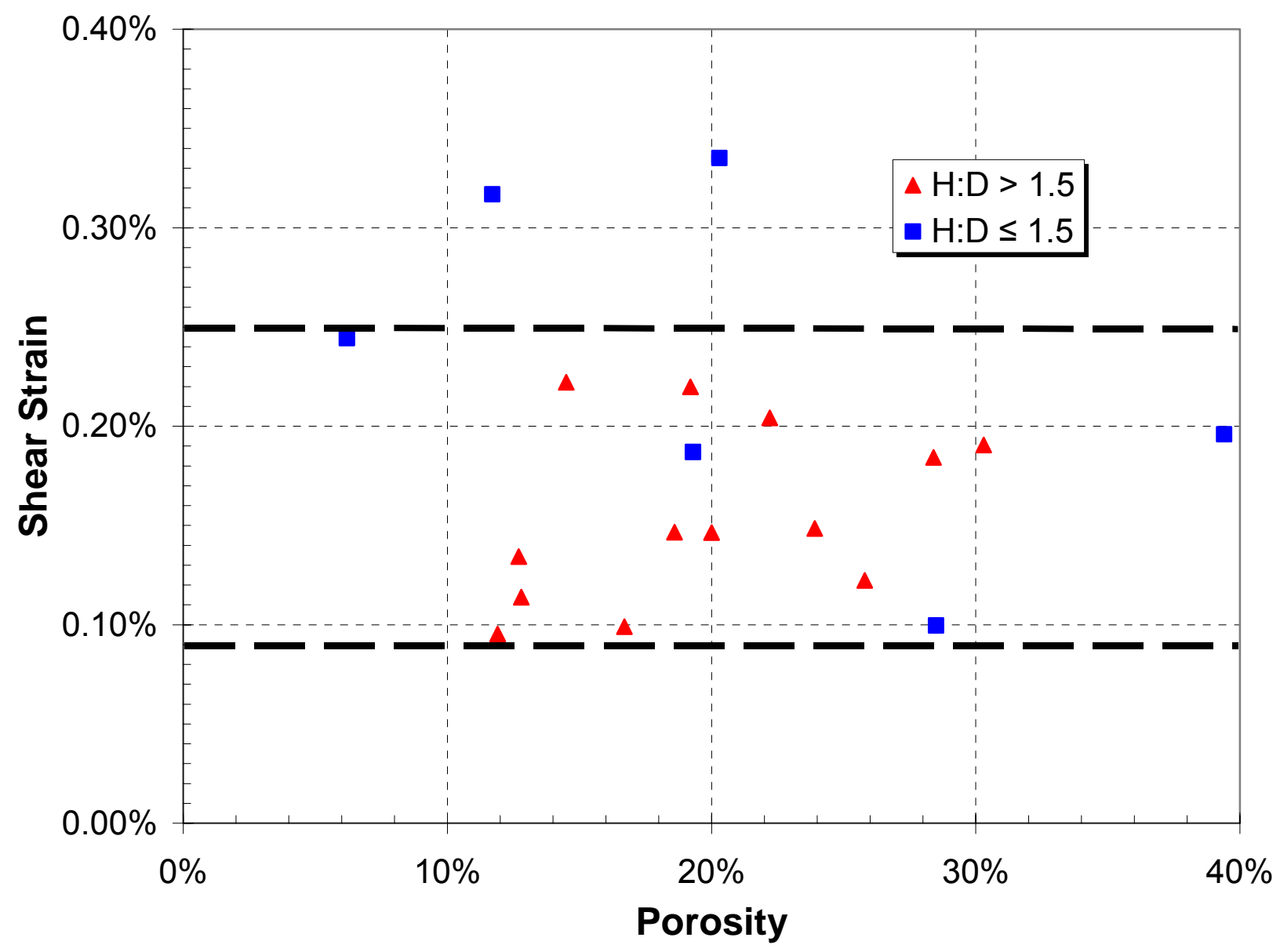

Source: $\quad$ Appendix D, Limiting Strain - Lab Tests.xls.

NOTE: Shear-strain increments shown are calculated for an overburden depth of $250 \mathrm{~m}$. For this case, the mean shear-strain increment for all $288-\mathrm{mm}$ diameter samples is $0.18 \%$ strain. For the samples having a ratio $H / D>1.5$, which are considered the best representation of the mechanical behavior of lithophysal rock, the mean shear-strain increment is $0.16 \%$ (Table B-2). The bold horizontal dashed lines indicate the lower and upper bound of the shear strain threshold probability distribution developed in Section 6.4.3.

Figure B-7. Calculated Shear Strain Increment for 288-mm Diameter Samples

\section{B2.5 SHEAR STRAIN LIMITS ESTIMATED FROM NUMERICAL RESULTS}

Numerical micro-mechanical models are used to better understand the mechanics of deformation and failure of lithophysal tuff and to extrapolate laboratory results to loading conditions, lithophysal content, and scales that could not be tested. In addition, numerical simulation allows full control and monitoring of the testing process (e.g., evolution of damage in the sample from microfractures to observable macrofractures and sample failure). The results of the existing numerical tests of the effect of lithophysal porosity on the mechanical properties of tuff are re-analyzed here to determine the strain at certain damage states. The simulations were carried out using PFC2D (BSC 2004 [DIRS 169930]) and UDEC (BSC 2002 [DIRS 161949]). PFC2D represents the rock as a bonded assembly of disks whereas UDEC represents the rock as a bonded assembly of polygons. The results of the numerical simulation are reported by BSC 
(2004 [DIRS 172334], Section 6.5) and incorporated into BSC (2003 [DIRS 166660], Sections 9.1 and 9.2) and BSC (2004 [DIRS 166107], Sections 7.5 and 7.6). The original reports provide details of the various numerical models and testing procedures.

The numerical models of the lithophysal rock mass first were calibrated to reproduce the mechanical behavior observed in the laboratory compression tests on samples with a particular lithophysal porosity. Subsequently, the effects of changing lithophysal porosity and shape of lithophysae, among other factors, were investigated. Thus, it is assumed in the numerical analysis that lithophysal porosity and lithophysae shape are the only parameters affecting mechanical behavior of the lithophysal rock mass. The distribution of the lithophysae within a laboratory sample can also impact the strength, resulting in additional variability in test results. This is probably the main reason the numerical results show less scatter than what is observed in the laboratory tests. The numerical models, however, clearly show the controlling impact of lithophysal voids on strength and elastic modulus, and demonstrate the same trends in strength and modulus with porosity as observed in the laboratory.

The shear-strain increments are calculated for the state of volumetric strain reversal and the strain state at peak stress. The PFC2D samples were tested for unconfined compression conditions only. An internal angle of friction of $30^{\circ}$ was used in calculating the shear-strain increment based on PFC2D results. The UDEC samples were tested for both unconfined and confined conditions. The friction angle determined from the UDEC results was used in the calculating the shear-strain increment based on UDEC results. The results for three types of 2D simulation are superimposed on each graph shown in Figures B-8 through B-11: (a) circular voids, modeled by PFC2D; (b) irregular (stenciled) voids, modeled by PFC2D; and (c) circular voids, modeled by UDEC. Four figures are presented, corresponding to two different levels of confining stress $(250 \mathrm{~m}$ and $400 \mathrm{~m}$ of overburden based on Wong and Silva (2004 [DIRS 170444], p. 70) and two different assumptions about the damage state at which fracturing would be distinguishable in the field.

In Figures B-8 through B-11, the engineering shear strain (axial strain minus lateral strain) increment for a particular state (reversal of volumetric strain rate, or peak stress) is plotted against lithophysal porosity. On each figure, the different symbols correspond to the three types of model (PFC2D circular voids-triangle symbol, PFC2D irregular voids-diamond symbol, and UDEC circular voids-square symbol). For the case of the state at peak stress for an overburden of $250 \mathrm{~m}$, the shear-strain increments and standard deviations are listed in Table B-3. Although the UDEC and PFC2D models were calibrated to the same laboratory results, the shear-strain increment calculated from the UDEC results is systematically smaller than the shear-strain increment calculated from the PFC2D results. One reason for this is that UDEC synthetic sample is calibrated in such a way that its strength was slightly less than the strength of the PFC2D sample; at the same time, stiffness of the UDEC sample was larger than the stiffness of the PFC2D sample, resulting in the smaller strain increment calculated based on UDEC results. The other reason is that shear-strain increment based on the PFC2D results is calculated assuming a friction angle of $30^{\circ}$. The shear-strain increment based on the UDEC results is calculated using friction angles determined from the UDEC results, which generally are larger than $30^{\circ}$. In this case, smaller friction angles result in larger shear-strain increments. 
Table B-3. Mean and Standard Deviations of Shear Strain for a Peak-Stress Criterion for Different Porosity Ranges; Overburden $=250 \mathrm{~m}$

\begin{tabular}{|c|c|c|c|c|}
\hline & Porosity Range & $\begin{array}{l}\text { PFC2D 90mm } \\
\text { Circles }\end{array}$ & $\begin{array}{c}\text { PFC2D Panel Map } \\
\text { Stencils }\end{array}$ & $\begin{array}{l}\text { UDEC } 90 \mathrm{~mm} \\
\text { Circles }\end{array}$ \\
\hline mean & \multirow{2}{*}{$0-5 \%$} & $0.18 \%$ & & $0.15 \%$ \\
\hline standard deviation & & $0.02 \%$ & & $0.01 \%$ \\
\hline mean & \multirow[b]{2}{*}{$5 \%-10 \%$} & $0.16 \%$ & $0.14 \%$ & \\
\hline standard deviation & & $0.02 \%$ & $0.02 \%$ & \\
\hline mean & \multirow[b]{2}{*}{$10 \%-15 \%$} & $0.14 \%$ & $0.13 \%$ & $0.10 \%$ \\
\hline standard deviation & & $0.01 \%$ & $0.02 \%$ & $0.01 \%$ \\
\hline mean & \multirow[b]{2}{*}{$15 \%-20 \%$} & $0.15 \%$ & $0.13 \%$ & $0.09 \%$ \\
\hline standard deviation & & $0.01 \%$ & $0.03 \%$ & $0.01 \%$ \\
\hline mean & \multirow[b]{2}{*}{$20 \%-25 \%$} & $0.14 \%$ & $0.14 \%$ & $0.10 \%$ \\
\hline standard deviation & & $0.01 \%$ & $0.03 \%$ & $0.01 \%$ \\
\hline mean & \multirow[b]{2}{*}{$25 \%-30 \%$} & $0.15 \%$ & $0.15 \%$ & $0.10 \%$ \\
\hline standard deviation & & $0.02 \%$ & $0.03 \%$ & $0.00 \%$ \\
\hline mean & \multirow[b]{2}{*}{$30 \%-35 \%$} & & $0.16 \%$ & \\
\hline standard deviation & & & $0.06 \%$ & \\
\hline
\end{tabular}

Source: Appendix D, Limiting Strains-Numerical Sims.xIs. 


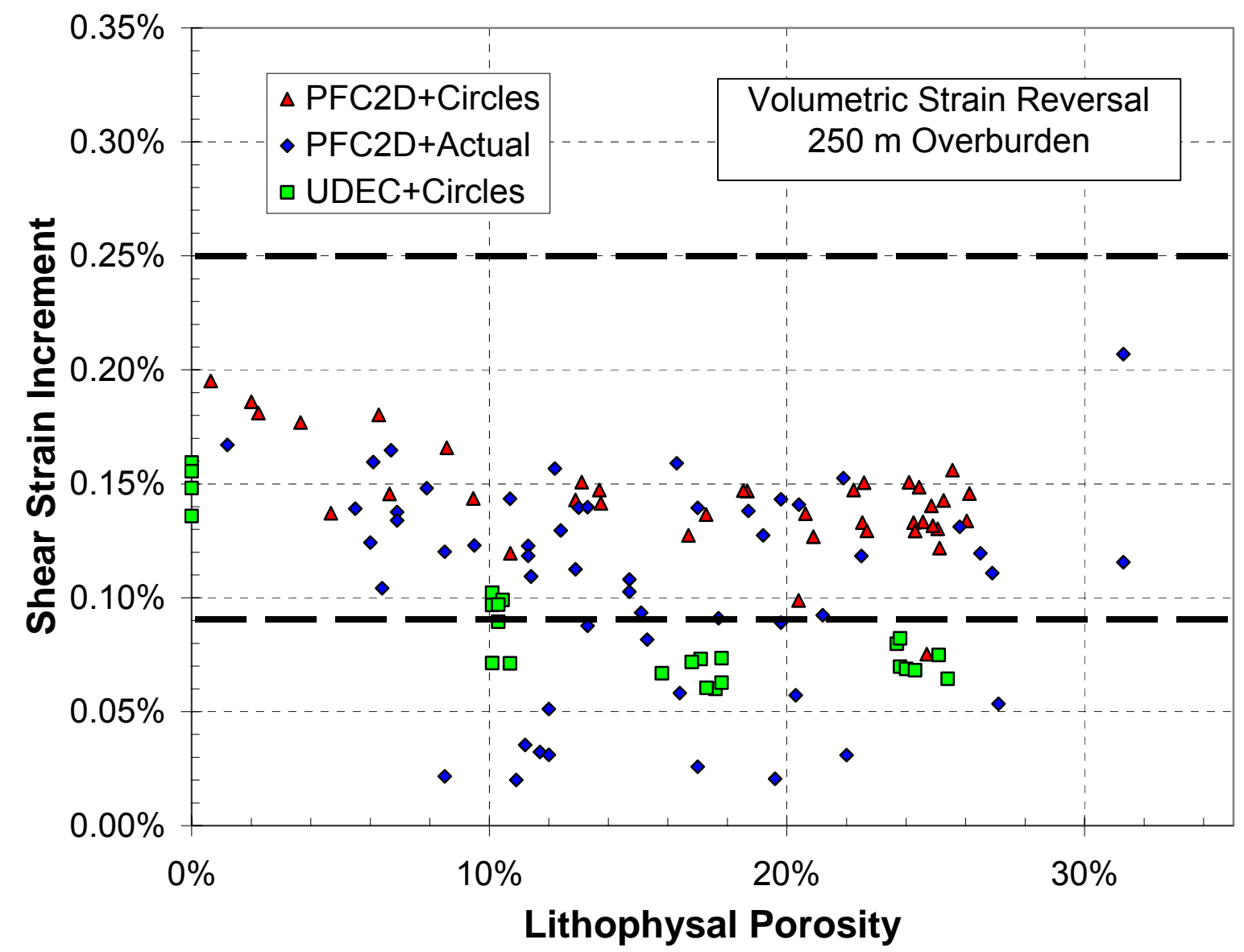

Source: Appendix D, Limiting Strains-Numerical Sims.xls.

NOTE: Shear strain increment determined for an overburden depth of $250 \mathrm{~m}$. Numerical simulations carried out using software codes PFC2D and UDEC. The bold horizontal dashed lines indicate the lower and upper bound of the shear strain threshold probability distribution developed in Section 6.4.3.

Figure B-8. Shear Strain Increment Determined Using the Volumetric-Strain Reversal Criterion; Overburden $=250 \mathrm{~m}$ 


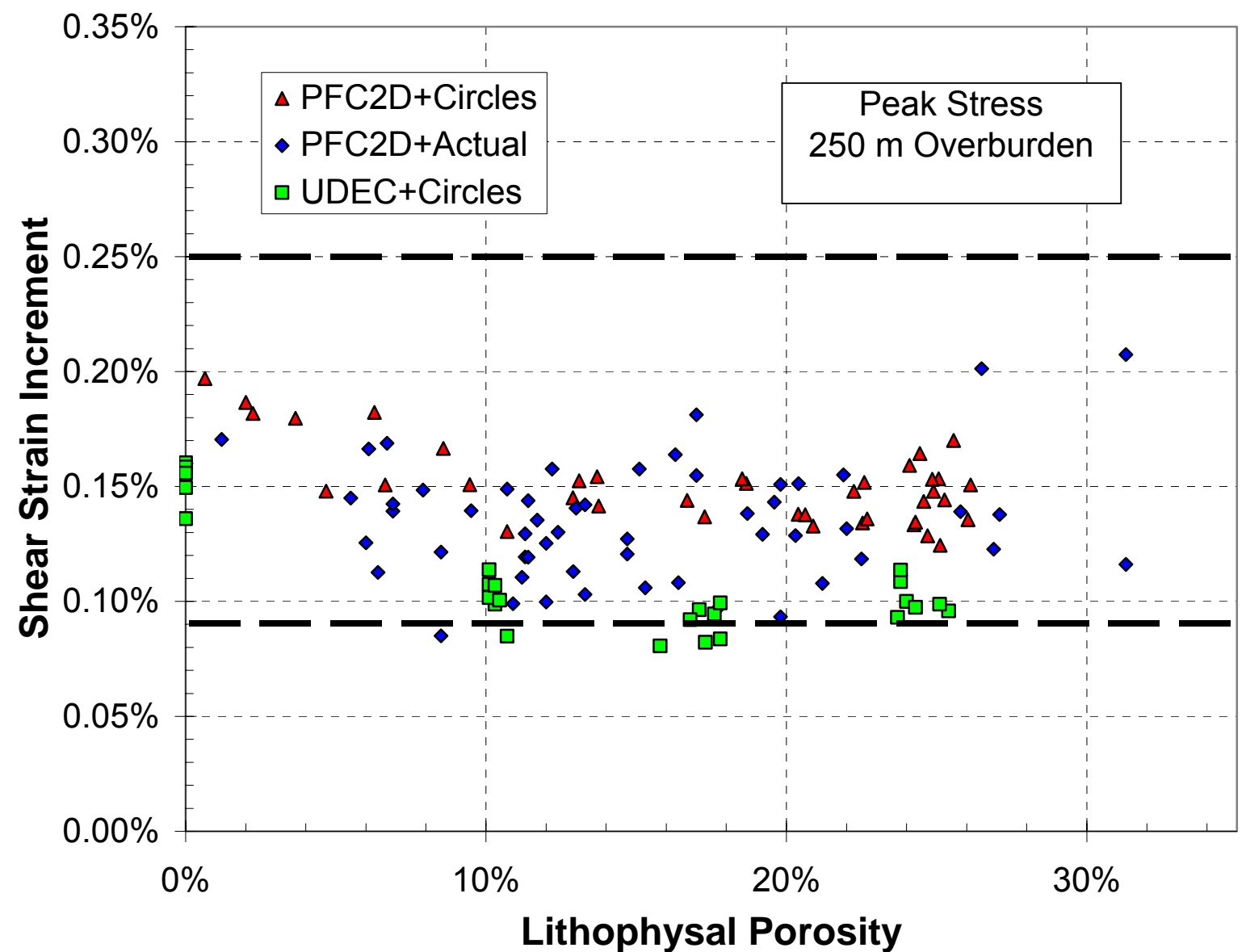

Source: Appendix D, Limiting Strains-Numerical Sims.xIs.

NOTE: $\quad$ Shear strain increment determined for an overburden depth of $250 \mathrm{~m}$. Numerical simulations carried out using software codes PFC2D and UDEC. The bold horizontal dashed lines indicate the lower and upper bound of the shear strain threshold probability distribution developed in Section 6.4.3.

Figure B-9. Shear Strain Increment Determined Using the Peak-Stress Criterion; Overburden $=250 \mathrm{~m}$ 


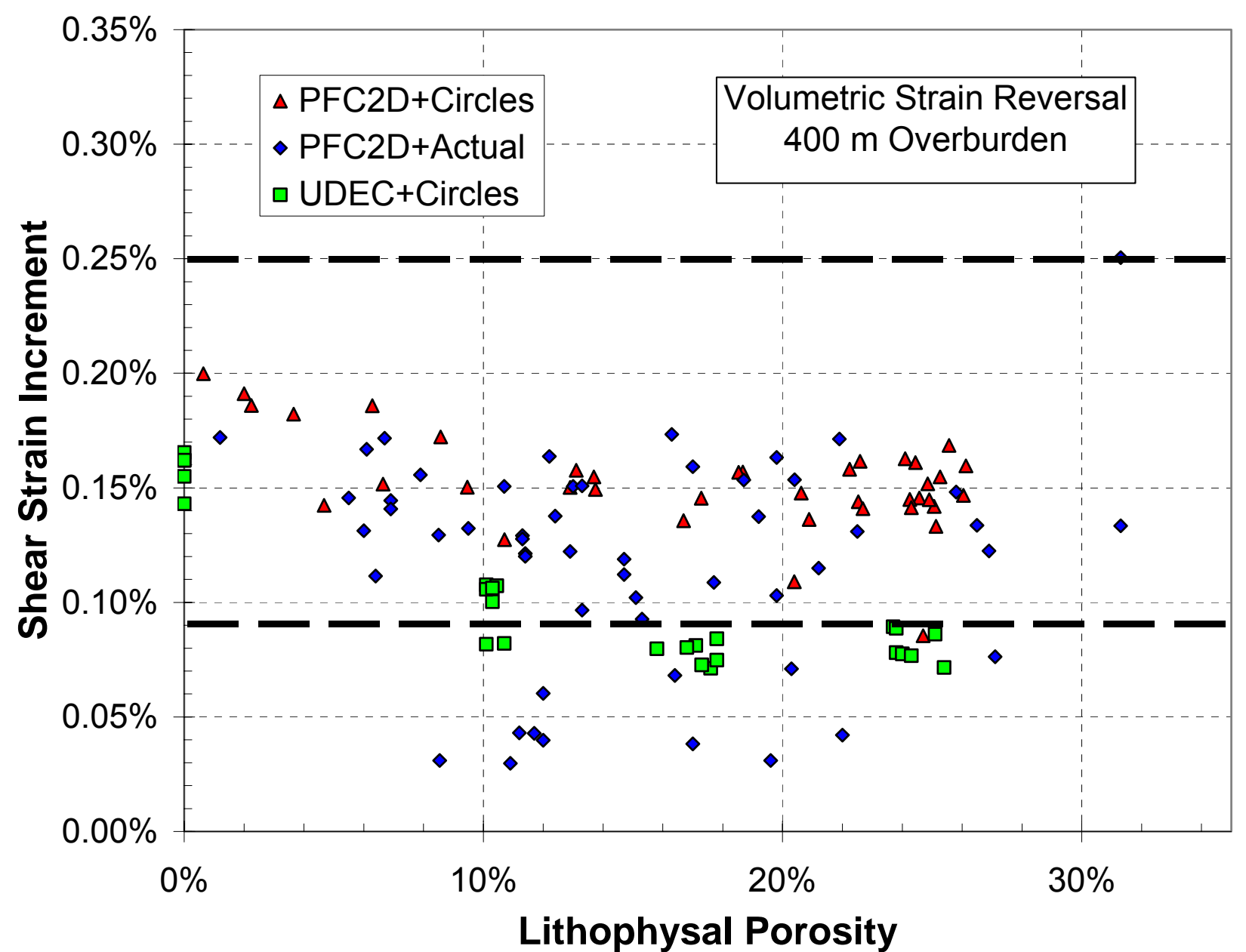

Source: Appendix D, Limiting Strains-Numerical Sims.xls.

NOTE: Shear strain increment determined for an overburden depth of $400 \mathrm{~m}$. Numerical simulations carried out using software codes PFC2D and UDEC. The bold horizontal dashed lines indicate the lower and upper bound of the shear strain threshold probability distribution developed in Section 6.4.3.

Figure B-10. Shear Strain Increment Determined Using the Volumetric-Strain Reversal Criterion;

Overburden $=400 \mathrm{~m}$ 


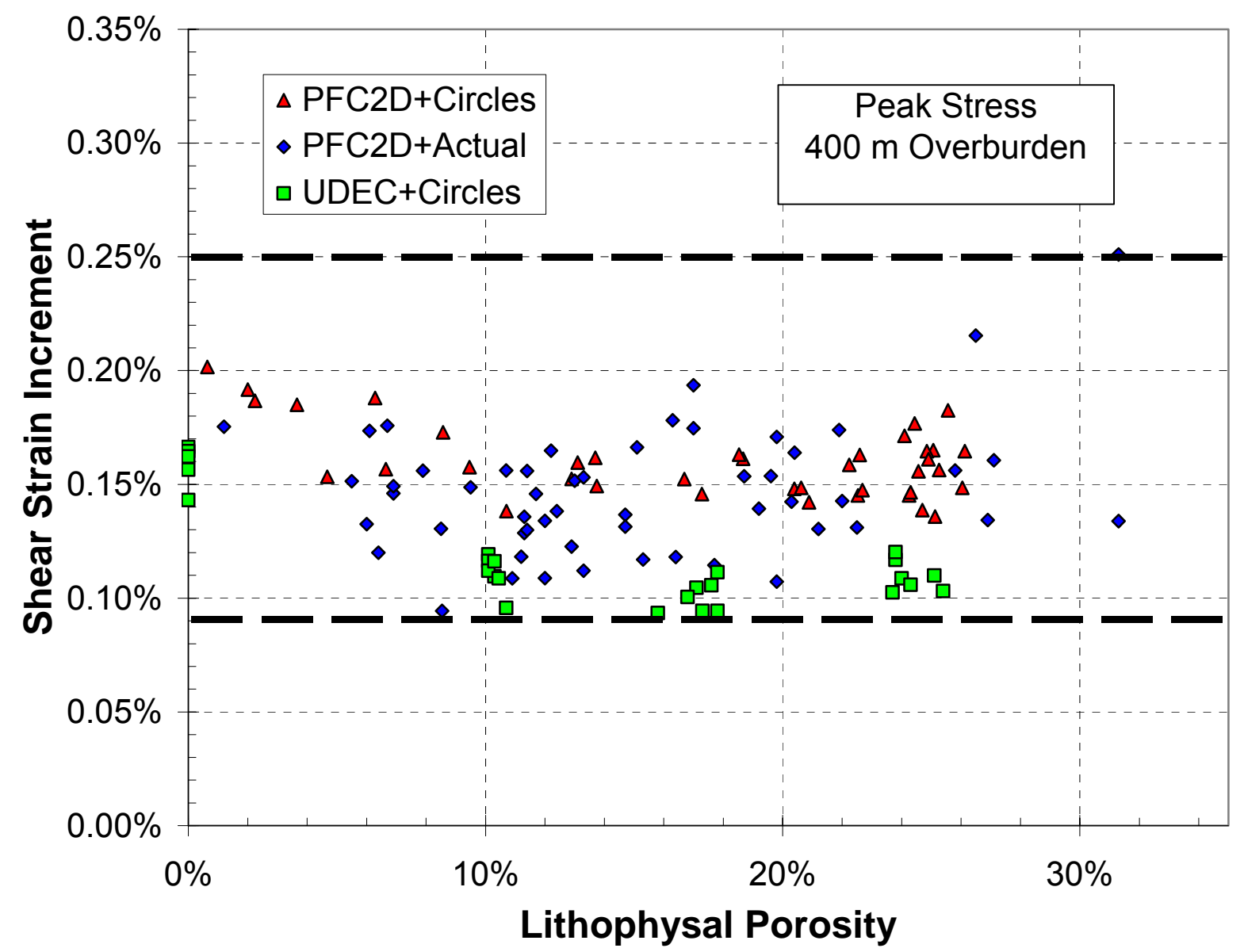

Source: Appendix D, Limiting Strains-Numerical Sims.xls.

NOTE: Shear strain increment determined for an overburden depth of $400 \mathrm{~m}$. Numerical simulations carried out using software codes PFC2D and UDEC. The bold horizontal dashed lines indicate the lower and upper bound of the shear strain threshold probability distribution developed in Section 6.4.3.

Figure B-11. Shear Strain Increment Determined Using the Peak-Stress Criterion; Overburden $=400 \mathrm{~m}$ 


\section{B3. CONCLUSIONS}

The re-analysis of the laboratory results and the two sets of simulations has provided a correlation between mean shear-strain increment experienced by a rock mass and the damage to internal structures (lithophysae). This appendix provides only an analysis of the raw data extracted from the laboratory and numerical results. However, because it appears that no damage (i.e., systematic fractures around and between lithophysae) is observed at the site (Section 6.3 and Appendix A), the maximum shear-strain increment over the past 12.8 million years is likely to have been between $0.1 \%$ and $0.2 \%$. For the $288-\mathrm{mm}$ diameter samples (shown in Figure B-7), which are considered the best representation of the mechanical behavior of lithophysal rock, the majority of the results are in the range between $0.1 \%$ and $0.2 \%$ of strain. 


\section{APPENDIX C}

\section{CALCULATION OF PEAK GROUND VELOCITIES FOR EXTREME GROUND MOTIONS}




\section{C1. INTRODUCTION}

This analysis uses results of previous site-response modeling (BSC 2004 [DIRS 170027]) to determine the relation between mean horizontal peak ground velocity (PGV) at the waste emplacement level and the corresponding mean dynamic shear strain. This relation is used to transpose a shear strain threshold, which geologic and rock mechanics evidence indicates has not been exceeded at the waste emplacement level at Yucca Mountain (see Sections 6.3 and 6.4, Appendix A and B), to a value of horizontal PGV that has not been exceeded.

Development of the relation between dynamic shear strain and horizontal PGV is subject to the limitations of the site-response model (BSC 2004 [DIRS 170027], Section 6.1.14). These limitations are

- Two- and three-dimensional effects are not treated explicitly

- Nonlinear behavior is treated in an approximate (equivalent-linear) fashion.

Validation studies indicate that the model is adequate for its intended use (BSC 2004 [DIRS 170027], Section 7).

In addition to model limitations, some inputs to the model also have limitations. In particular, control motion inputs are derived from the probabilistic seismic hazard analysis (PSHA). Characterization of epistemic uncertainty and aleatory variability for ground motion at Yucca Mountain results in seismic hazard curves that increase without bound as lower and lower frequencies of exceedance are considered. At low frequencies of exceedance (e.g., $10^{-6}, 10^{-7}$ ), the control motion inputs to the site-response model reach levels that are not credible (Corradini 2003 [DIRS 171191]). For this analysis the motions are used without modification, as the purpose is to determine the correspondence between extreme ground motions and the shear strains they would generate within the site materials.

Following this introduction, Section C2 describes the analysis to determine the relation between dynamic shear strain and horizontal PGV at the waste emplacement level. Section C3 summarizes the conclusions of the analysis.

\section{C2. HORIZONTAL PEAK GROUND VELOCITIES AND DYNAMIC SHEAR STRAINS FOR THE WASTE EMPLACEMENT LEVEL}

In this section, previous results of ground-motion site-response modeling (BSC 2004 [DIRS 170027]) are used to determine the relation between horizontal PGV and the associated dynamic shear strains. Site-response modeling for ground motions with annual frequencies of exceedance of $10^{-4}, 10^{-5}, 10^{-6}$, and $10^{-7}$ are used to determine the relation over a range of horizontal PGV and shear strain values. To obtain results for the waste emplacement level, the relation is based on horizontal PGV and shear strain for the average depth range of the Topopah Springs Tuff lower lithophysal zone. 


\section{C2.1 SITE RESPONSE MODELING INPUTS}

One output of the ground-motion site-response modeling for the repository block at Yucca Mountain is the variation with depth of horizontal PGV and shear strain (BSC 2004 [DIRS 170027], Section 6.3.4). That model output forms the input to this analysis to determine the relation between horizontal PGV and associated shear strain. In modeling site response, the magnitude range of earthquakes contributing to the seismic hazard for a given annual frequency of exceedance and uncertainties and variability in site material properties are incorporated into the calculations. This approach is taken to obtain site-response ground motions that have a hazard level consistent with the one for the input control motions (McGuire et al. 2001 [DIRS 157510], Section 6.1).

In implementing this approach, site-response modeling incorporates the following steps (BSC 2004 [DIRS 170027], Section 6.3.1):

- Develop control motions consisting of three "deaggregation earthquakes" for each of two response spectrum frequency ranges (1 to $2 \mathrm{~Hz}$ and 5 to $10 \mathrm{~Hz}$ ).

- Develop base-case small-strain velocity profiles and dynamic material property curves representing epistemic uncertainty in the site characterization.

- Using the base-case site properties, randomly develop suites of 60 profiles and curves to represent the aleatory variability in site properties.

- Using the deaggregation earthquakes, determine the angle of incidence for the control motion. Both inclined and vertically propagating ground motions are assessed in the modeling.

- Determine the site response for each combination of deaggregation earthquake, velocity profile, dynamic material property curves, and wave propagation type.

As a result of implementing these steps, for each annual frequency of exceedance, the model outputs nominally include 2880 profiles showing the variation of horizontal PGV and shear strain as a function of depth. If runs fail to converge, the total number of profiles will be less for that case.

Control motions forming input to the site-response model are based on the PSHA for Yucca Mountain (BSC 2004 [DIRS 170027], Section 6.2.2). For a given annual frequency of exceedance, the seismic hazard is deaggregated to identify the earthquake magnitudes and distances controlling ground motion for the response spectral frequency ranges of $1-2 \mathrm{~Hz}$ and 5-10 Hz. To account for magnitude-dependence of the site response, three deaggregation earthquakes (DEAs) were developed for each frequency range to represent the range of magnitudes contributing to the hazard. The DEAs correspond nominally to the mean (MM), 5th (ML), and 95th (MH) percentile of the deaggregated hazard (with respect to magnitude only). In some cases, different percentiles were used to appropriately capture the magnitude distribution resulting from the deaggregation. Response spectra for the DEAs are scaled to match the UHS in the appropriate frequency range $(1-2 \mathrm{~Hz}$ or $5-10 \mathrm{~Hz})$ to maintain the appropriate hazard level. 
The site-response model employs a one-dimensional random-vibration-theory-based equivalent-linear approach (BSC 2004 [DIRS 170027], Section 6.1). The power spectral density of the input control motion (deaggregation earthquake) is propagated through the model. Random vibration theory is used to predict peak time domain values of shear strain based upon the shear-strain power spectrum. These values form the basis for adjusting the material properties of the model layers and the process is iterated until a strain-compatible solution is obtained. For horizontal ground motion, both inclined SV (vertically polarized shear-wave) and inclined and vertically propagating $\mathrm{SH}$ (horizontally polarized shear-wave) waves can be included in the modeling. In this analysis, only the results from inclined and vertically propagating SH waves are used.

Site-response modeling takes into account both the uncertainty and spatial variability in site material properties at Yucca Mountain (BSC 2004 [DIRS 170027], Section 6.2.1). Uncertainty is incorporated through use of multiple base-case (mean) velocity profiles and dynamic material property curves (strain-dependent shear modulus and hysteretic damping). Variability is incorporated by use of 60 randomized representations of each base-case velocity profile and dynamic material property curve. For the repository block, two base-case velocity profiles (P1 and P2) and two base case sets of dynamic material property curves (UMT=upper mean tuff and LMT=lower mean tuff) are used (BSC 2004 [DIRS 170027], Sections 6.2.3 and 6.2.4).

For each of the 8 combinations of base-case velocity profile, base-case dynamic property curves, and wave propagator type (inclined or vertically incident), the site response is computed using the 6 DEAs (ML, MM, MH for 1-2 and 5-10 Hz) as the input control motion. For a given combination, each DEA control motion is propagated through the 60 randomized velocity profiles with associated randomized dynamic property curves producing 60 curves of horizontal PGV and shear strain versus depth. This results in a suite of 2880 curves $(8 \times 6 \times 60)$ for each hazard level.

\section{C2.2 ANALYSIS OF HORIZONTAL PEAK GROUND VELOCITY AND ASSOCIATED DYNAMIC SHEAR STRAIN}

Using the results of the previous site-response modeling summarized above (MO0409MWDGMMIO.000 [DIRS 172216], and discussed in more detail in BSC (2004 [DIRS 170027]), the analysis to determine the relation between horizontal PGV and shear strain consists of the following steps for each annual frequency of exceedance:

- For each of the 8 combinations of base-case site material properties and wave propagator type, aggregate the results for the 3 DEAs for each frequency range. Using the aggregate DEA results for each frequency range, compute the median (geometric mean) horizontal PGV and shear strain as a function of depth for each combination.

- For each of the 16 combinations for base case site material properties, wave propagator type, and frequency range, compute the average horizontal PGV and shear strain value over the depth range of the lower lithophysal unit of the Topopah Spring Tuff. 
- For each of the 8 combinations of base case material properties and frequency range, compute the average horizontal PGV and shear strain for the two wave propagator types.

- For each of the 8 combinations of base-case material properties and frequency range, use the horizontal PGV and shear strain results for the various annual frequencies of exceedance to scale horizontal PGV for target shear strain values.

In the first step, for each of the 8 combinations of base case material properties and wave propagation type, the results for the three DEAs associated with each response spectrum frequency range are aggregated. This aggregated data set forms the basis for computing median (geometric mean) values of horizontal PGV and shear strain as a function of depth. The medians are determined using the software code LOGNORM (Software Tracking Number [STN] 10384-1.01-00) (Pacific Engineering and Analysis, 2004 [DIRS 170313]). Although the upper and lower magnitude DEAs are less likely, results for the three DEAs are weighted equally in this analysis.

In the second step, for each of the 16 combinations of base case material properties, wave propagator type, and response spectrum frequency range, an average (arithmetic mean) value of median horizontal PGV and median shear strain is computed for the depth range of the lower lithophysal unit of the Topopah Spring Tuff. These average values of median horizontal PGV and median shear strain over the depth range of the lower lithophysal unit are used to represent the values of these parameters in the subsequent analyses. The depth range for the lower lithophysal unit was determined from the Yucca Mountain Geologic Framework Model (GFM2000, Data Tracking Number [DTN] MO0012MWDGFM02.002 [DIRS 153777]) using software code EarthVision 5.1 (STN 10174-5.1-00) (Dynamic Graphics 2000 [DIRS 167994]). The range was taken as extending from the average depth of the top of the lower lithophysal unit $(951 \mathrm{ft}[290 \mathrm{~m}])$ to the average depth of the bottom of the unit $(1286 \mathrm{ft}[392 \mathrm{~m}])$. Average depths for the unit contacts were computed for that portion of the model lying within the footprint of the waste emplacement area. To compute the means of the median horizontal PGV and median shear strain values within this depth range, the software code NORM (STN 103861.01-00) (Pacific Engineering and Analysis 2002 [DIRS 163313]) was used.

In the third step, the results for the two wave propagator types were averaged for each of the 8 combinations of base-case material properties and response spectrum frequency range. For each combination, the mean of the values for inclined and vertically propagating waves was determined using the commercial-off-the-shelf software code, Microsoft ${ }^{\circledR}$ Excel. This step is documented in the workbook PGV\&Strain-Average of Vertical \& Inclined Results.xls (Appendix D) and summarized in Table C-1.

The analysis of site-response modeling results to determine average horizontal PGV and shear strain values for the 8 combinations is carried out for 4 annual frequencies of exceedance $\left(10^{-4}\right.$, $10^{-5}, 10^{-6}$, and $10^{-7}$ ) based on results of the PSHA. To determine values of average horizontal PGV for other values of dynamic shear strain (i.e., 0.05, 0.1, 0.2, 0.3, 0.4, 0.5\%) the fourth step consists of a linear interpolation/extrapolation process. This interpolation/extrapolation is carried out for each of the 8 combinations of dynamic material properties and response spectrum frequency range and documented in the workbook $P G V \vee$ Shear Strain.xls (Appendix D) and summarized in Table C-2. 
These results are used in Section 6.6 to develop probability distributions for horizontal peak ground velocity based on an assessed triangular bounding shear strain threshold. A probability distribution is determined for each combination of material properties and response spectrum frequency range.

\section{C3. CONCLUSIONS}

The results of the model calculations provide a link between the shear-strain threshold determined in Section 6.4 of the main report and the level of horizontal PGV that would be needed to reach that threshold. An assessment documented in Section 6.6 of the main report provides distributions for the value of horizontal PGV that evidence indicates has not occurred at the waste emplacement level (Figure 6-8). The distributions ("triangular") consist of 8 cases representing the epistemic uncertainty in site response. These distributions fall into 2 classes according to the dynamic material property curves used. If the lower mean tuff set of curves is used, the triangular distributions group together with a range from about 100 to $250 \mathrm{~cm} / \mathrm{sec}$ and a mode of about $175 \mathrm{~cm} / \mathrm{sec}$. If the upper mean tuff set of curves is used, the four distributions range from about 200 to $500 \mathrm{~cm} / \mathrm{sec}$ with a mode of about $335 \mathrm{~cm} / \mathrm{sec}$. In Section 6.8 these triangular distributions are used to develop a composite horizontal PGV hazard curve for the waste emplacement level.

Table C-1. Modeled Horizontal Peak Ground Velocity and Shear Strain at the Waste Emplacement Level (Point B)

APE 10-7 HSHH

(Point A PGV $=655 \mathrm{~cm} / \mathrm{sec}$ )

\begin{tabular}{|c|c|c|c|c|c|c|c|c|}
\hline \multirow{2}{*}{$\mathbf{1 - 2 ~ H z}$} & \multicolumn{2}{|c|}{ P1 UMT } & \multicolumn{2}{c|}{ P1 LMT } & \multicolumn{2}{c|}{ P2 UMT } & \multicolumn{2}{c|}{ P2 LMT } \\
\cline { 2 - 10 } & $\begin{array}{c}\text { PGV } \\
\text { (cm/s) }\end{array}$ & $\begin{array}{c}\text { Strain Syz } \\
\mathbf{( \% )}\end{array}$ & PGV (cm/s) & $\begin{array}{c}\text { Strain Syz } \\
\mathbf{( \% )}\end{array}$ & PGV (cm/s) & $\begin{array}{c}\text { Strain Syz } \\
\text { (\%) }\end{array}$ & PGV (cm/s) & $\begin{array}{c}\text { Strain Syz } \\
\text { (\%) }\end{array}$ \\
\hline Inclined & 512.027 & 0.259 & 496.056 & 0.847 & 521.078 & 0.255 & 492.612 & 1.004 \\
\hline 0 degree & 511.996 & 0.280 & 502.484 & 0.890 & 518.140 & 0.289 & 497.186 & 1.078 \\
\hline Average & 512.012 & 0.270 & 499.270 & 0.869 & 519.609 & 0.272 & 494.899 & 1.041 \\
\hline
\end{tabular}

\begin{tabular}{|l|c|c|c|c|c|c|c|c|}
\hline \multirow{2}{*}{$\mathbf{5 - 1 0 ~ H z ~}$} & \multicolumn{2}{|c|}{ P1 UMT } & \multicolumn{2}{c|}{ P1 LMT } & \multicolumn{2}{c|}{ P2 UMT } & \multicolumn{2}{c|}{ P2 LMT } \\
\cline { 2 - 9 } & $\begin{array}{c}\text { PGV } \\
\text { (cm/s) }\end{array}$ & $\begin{array}{c}\text { Strain Syz } \\
\text { (\%) }\end{array}$ & PGV (cm/s) & $\begin{array}{c}\text { Strain Syz } \\
\text { (\%) }\end{array}$ & PGV (cm/s) & $\begin{array}{c}\text { Strain Syz } \\
\text { (\%) }\end{array}$ & PGV (cm/s) & $\begin{array}{c}\text { Strain Syz } \\
\text { (\%) }\end{array}$ \\
\hline Inclined & 521.739 & 0.280 & 520.090 & 0.894 & 540.837 & 0.288 & 516.638 & 1.071 \\
\hline 0 degree & 519.178 & 0.291 & 524.730 & 0.916 & 539.875 & 0.306 & 519.818 & 1.107 \\
\hline Average & 520.459 & 0.286 & 522.410 & 0.905 & 540.356 & 0.297 & 518.228 & 1.089 \\
\hline
\end{tabular}

APE 10-6 HSHH (Point A PGV = $301 \mathrm{~cm} / \mathrm{sec}$ )

\begin{tabular}{|l|c|c|c|c|c|c|c|c|}
\hline & \multicolumn{2}{|c|}{ P1 UMT } & \multicolumn{2}{c|}{ P1 LMT } & \multicolumn{2}{c|}{ P2 UMT } & \multicolumn{2}{c|}{ P2 LMT } \\
\cline { 2 - 10 } 1-2 Hz & $\begin{array}{c}\text { PGV } \\
\mathbf{( c m / s )}\end{array}$ & $\begin{array}{c}\text { Strain Syz } \\
\mathbf{( \% )}\end{array}$ & PGV (cm/s) & $\begin{array}{c}\text { Strain Syz } \\
\mathbf{( \% )}\end{array}$ & PGV (cm/s) & $\begin{array}{c}\text { Strain Syz } \\
\text { (\%) }\end{array}$ & $\begin{array}{c}\text { PGV (cm/s) } \\
\text { PGtrain Syz } \\
\text { (\%) }\end{array}$ \\
\hline Inclined & 242.516 & 0.113 & 230.584 & 0.254 & 245.274 & 0.109 & 230.751 & 0.313 \\
\hline 0 degree & 242.790 & 0.122 & 233.375 & 0.272 & 243.339 & 0.122 & 232.068 & 0.348 \\
\hline Average & 242.653 & 0.118 & 231.980 & 0.263 & 244.307 & 0.116 & 231.410 & 0.331 \\
\hline
\end{tabular}


Table C-1. Modeled Horizontal Peak Ground Velocity and Shear Strain at the Waste Emplacement Level (Point B) (Continued)

\begin{tabular}{|l|c|c|c|c|c|c|c|c|}
\hline & \multicolumn{2}{|c|}{ P1 UMT } & \multicolumn{2}{c|}{ P1 LMT } & \multicolumn{2}{c|}{ P2 UMT } & \multicolumn{2}{c|}{ P2 LMT } \\
\cline { 2 - 9 } & $\begin{array}{c}\text { PGV } \\
\mathbf{5 - 1 0 ~ H z}\end{array}$ & $\begin{array}{c}\text { Strain Syz } \\
\mathbf{( \% )}\end{array}$ & PGV (cm/s) & $\begin{array}{c}\text { Strain Syz } \\
\text { (\%) }\end{array}$ & PGV (cm/s) & $\begin{array}{c}\text { Strain Syz } \\
\text { (\%) }\end{array}$ & PGV (cm/s) & $\begin{array}{c}\text { Strain Syz } \\
\text { (\%) }\end{array}$ \\
\hline Inclined & 246.020 & 0.121 & 236.407 & 0.269 & 250.268 & 0.121 & 234.866 & 0.339 \\
\hline 0 degree & 246.387 & 0.127 & 238.988 & 0.283 & 248.750 & 0.132 & 236.496 & 0.363 \\
\hline Average & 246.204 & 0.124 & 237.698 & 0.276 & 249.506 & 0.127 & 235.681 & 0.351 \\
\hline
\end{tabular}

\begin{tabular}{|c|c|c|c|c|c|c|c|c|}
\hline \multicolumn{3}{|c|}{ APE 10-5 HSHH } & \multicolumn{6}{|c|}{ (Point A PGV = $127 \mathrm{~cm} / \mathrm{sec}$ ) } \\
\hline \multirow[b]{2}{*}{$1-2 \mathrm{~Hz}$} & \multicolumn{2}{|c|}{ P1 UMT } & \multicolumn{2}{|c|}{ P1 LMT } & \multicolumn{2}{|c|}{ P2 UMT } & \multicolumn{2}{|c|}{ P2 LMT } \\
\hline & $\begin{array}{l}\text { PGV } \\
(\mathrm{cm} / \mathrm{s})\end{array}$ & $\begin{array}{c}\text { Strain Syz } \\
\text { (\%) }\end{array}$ & PGV $(\mathrm{cm} / \mathrm{s})$ & $\begin{array}{c}\text { Strain Syz } \\
(\%)\end{array}$ & PGV $(\mathrm{cm} / \mathrm{s})$ & $\begin{array}{c}\text { Strain Syz } \\
\text { (\%) }\end{array}$ & PGV (cm/s) & $\begin{array}{c}\text { Strain Syz } \\
\text { (\%) }\end{array}$ \\
\hline Inclined & 110.660 & 0.047 & 103.713 & 0.072 & 112.270 & 0.044 & 105.751 & 0.081 \\
\hline 0 degree & 110.680 & 0.053 & 105.249 & 0.081 & 110.536 & 0.052 & 105.893 & 0.098 \\
\hline Average & 110.670 & 0.050 & 104.481 & 0.076 & 111.403 & 0.048 & 105.822 & 0.089 \\
\hline
\end{tabular}

\begin{tabular}{|l|c|c|c|c|c|c|c|c|}
\hline & \multicolumn{2}{|c|}{ P1 UMT } & \multicolumn{2}{c|}{ P1 LMT } & \multicolumn{2}{c|}{ P2 UMT } & \multicolumn{2}{c|}{ P2 LMT } \\
\cline { 2 - 8 } 5-10 Hz & $\begin{array}{c}\text { PGV } \\
\mathbf{( c m / s )}\end{array}$ & $\begin{array}{c}\text { Strain Syz } \\
\mathbf{( \% )}\end{array}$ & PGV (cm/s) & $\begin{array}{c}\text { Strain Syz } \\
\text { (\%) }\end{array}$ & PGV (cm/s) & $\begin{array}{c}\text { Strain Syz } \\
(\mathbf{\%})\end{array}$ & PGV (cm/s) & $\begin{array}{c}\text { Strain Syz } \\
\text { (\%) }\end{array}$ \\
\hline Inclined & 99.268 & 0.049 & 92.650 & 0.069 & 100.268 & 0.047 & 93.678 & 0.081 \\
\hline 0 degree & 99.308 & 0.053 & 93.821 & 0.075 & 99.132 & 0.052 & 94.035 & 0.090 \\
\hline Average & 99.288 & 0.051 & 93.236 & 0.072 & 99.700 & 0.049 & 93.857 & 0.085 \\
\hline
\end{tabular}

APE 10-4 HSHH
\begin{tabular}{|c|c|c|c|c|c|c|c|c|}
\hline & \multicolumn{2}{|c|}{ P1 UMT } & \multicolumn{2}{|c|}{ P1 LMT } & \multicolumn{2}{c|}{ P2 UMT } & \multicolumn{2}{c|}{ P2 LMT } \\
\cline { 2 - 9 } & $\begin{array}{c}\text { PGV } \\
\mathbf{1 - 2} \mathbf{~ H z} \\
\mathbf{( c m / s )}\end{array}$ & $\begin{array}{c}\text { Strain Syz } \\
\mathbf{( \% )}\end{array}$ & PGV (cm/s) & $\begin{array}{c}\text { Strain Syz } \\
\mathbf{( \% )}\end{array}$ & PGV (cm/s) & $\begin{array}{c}\text { Strain Syz } \\
(\%)\end{array}$ & PGV (cm/s) & $\begin{array}{c}\text { Strain Syz } \\
(\%)\end{array}$ \\
\hline Inclined & 45.234 & 0.018 & 42.754 & 0.022 & 45.605 & 0.017 & 43.819 & 0.021 \\
\hline 0 degree & 45.279 & 0.021 & 51.777 & 0.025 & 44.729 & 0.020 & 43.523 & 0.027 \\
\hline Average & 45.256 & 0.020 & 47.266 & 0.023 & 45.167 & 0.018 & 43.671 & 0.024 \\
\hline
\end{tabular}

\begin{tabular}{|l|c|c|c|c|c|c|c|c|}
\hline & \multicolumn{2}{|c|}{ P1 UMT } & \multicolumn{2}{c|}{ P1 LMT } & \multicolumn{2}{c|}{ P2 UMT } & \multicolumn{2}{c|}{ P2 LMT } \\
\cline { 2 - 8 } $\mathbf{5 - 1 0 ~ H z ~}$ & $\begin{array}{c}\text { PGV } \\
\mathbf{( c m / s )}\end{array}$ & $\begin{array}{c}\text { Strain Syz } \\
\mathbf{( \% )}\end{array}$ & PGV (cm/s) & $\begin{array}{c}\text { Strain Syz } \\
\mathbf{( \% )}\end{array}$ & PGV (cm/s) & $\begin{array}{c}\text { Strain Syz } \\
\mathbf{( \% )}\end{array}$ & PGV (cm/s) & $\begin{array}{c}\text { Strain Syz } \\
\text { (\%) }\end{array}$ \\
\hline Inclined & 31.592 & 0.015 & 29.489 & 0.017 & 31.587 & 0.015 & 30.075 & 0.017 \\
\hline 0 degree & 31.660 & 0.017 & 29.810 & 0.019 & 31.079 & 0.017 & 29.923 & 0.024 \\
\hline Average & 31.626 & 0.016 & 29.650 & 0.018 & 31.333 & 0.016 & 29.999 & 0.021 \\
\hline
\end{tabular}

Source: Appendix D, PGV\&Strain-Average of Vertical \& Inclined Results.xIs.

NOTE: $\mathrm{P} 1=$ Base-case velocity profile 1; $\mathrm{P} 2=$ =Base-case velocity profile 2; UMT=Base-case dynamic material property curve set 1; LMT=Base-case dynamic material property curve set 2; PGV=Horizontal peak ground velocity. 
Table C-2. Modeled and Interpolated/Extrapolated Horizontal Peak Ground Velocity for Shear Strain Values

\begin{tabular}{|c|c|c|c|c|c|c|c|c|}
\hline \multirow[t]{2}{*}{$\begin{array}{l}\text { Annual } \\
\text { Frequency of } \\
\text { Exceedance } \\
(1 / y r) \\
\end{array}$} & \multicolumn{2}{|c|}{$\begin{array}{l}\text { Velocity Profile P1 + Upper } \\
\text { Mean Tuff Dynamic Material } \\
\text { Property Curves + } 1 \text { to } 2 \mathrm{~Hz}\end{array}$} & \multicolumn{2}{|c|}{$\begin{array}{l}\text { Velocity Profile P1 + Lower } \\
\text { Mean Tuff Dynamic Material } \\
\text { Property Curves + } 1 \text { to } 2 \mathrm{~Hz}\end{array}$} & \multicolumn{2}{|c|}{$\begin{array}{l}\text { Velocity Profile P2 + Upper } \\
\text { Mean Tuff Dynamic Material } \\
\text { Property Curves + } 1 \text { to } 2 \mathrm{~Hz}\end{array}$} & \multicolumn{2}{|c|}{$\begin{array}{l}\text { Velocity Profile P2 + Lower } \\
\text { Mean Tuff Dynamic Material } \\
\text { Property Curves }+1 \text { to } 2 \mathrm{~Hz}\end{array}$} \\
\hline & $\begin{array}{c}\text { Modeled } \\
\text { Horizontal } \\
\text { Peak Ground } \\
\text { Velocity } \\
(\mathrm{cm} / \mathrm{sec}) \\
\end{array}$ & $\begin{array}{l}\text { Modeled Shear } \\
\text { Strain (Syz, \%) }\end{array}$ & $\begin{array}{c}\text { Modeled } \\
\text { Horizontal } \\
\text { Peak Ground } \\
\text { Velocity } \\
(\mathrm{cm} / \mathrm{sec}) \\
\end{array}$ & $\begin{array}{c}\text { Modeled } \\
\text { Shear Strain } \\
(\text { Syz, \%) }\end{array}$ & $\begin{array}{c}\text { Modeled } \\
\text { Horizontal } \\
\text { Peak Ground } \\
\text { Velocity } \\
(\mathrm{cm} / \mathrm{sec}) \\
\end{array}$ & $\begin{array}{c}\text { Modeled } \\
\text { Shear Strain } \\
(\text { Syz, \%) } \\
\end{array}$ & $\begin{array}{c}\text { Modeled } \\
\text { Horizontal } \\
\text { Peak Ground } \\
\text { Velocity } \\
(\mathrm{cm} / \mathrm{sec}) \\
\end{array}$ & $\begin{array}{c}\text { Modeled } \\
\text { Shear Strain } \\
(\text { Syz, \%) }\end{array}$ \\
\hline $1 \times 10^{-4}$ & 45.26 & 0.020 & 47.27 & 0.023 & 45.17 & 0.018 & 43.67 & 0.024 \\
\hline $1 \times 10^{-5}$ & 110.67 & 0.050 & 104.48 & 0.076 & 111.40 & 0.048 & 105.82 & 0.089 \\
\hline $1 \times 10^{-5}$ & 242.65 & 0.118 & 231.98 & 0.263 & 244.31 & 0.116 & 231.41 & 0.331 \\
\hline $1 \times 10^{-7}$ & 512.01 & 0.270 & 499.27 & 0.869 & 519.61 & 0.272 & 494.90 & 1.041 \\
\hline
\end{tabular}

\begin{tabular}{|c|c|c|c|c|c|c|c|c|}
\hline & \multicolumn{2}{|c|}{$\begin{array}{l}\text { Velocity Profile P1 + Upper } \\
\text { Mean Tuff Dynamic Material } \\
\text { Property Curves + } 5 \text { to } 10 \mathrm{~Hz}\end{array}$} & \multicolumn{2}{|c|}{$\begin{array}{l}\text { Velocity Profile P1 + Lower } \\
\text { Mean Tuff Dynamic Material } \\
\text { Property Curves }+5 \text { to } 10 \mathrm{~Hz}\end{array}$} & \multicolumn{2}{|c|}{$\begin{array}{l}\text { Velocity Profile P2 + Upper } \\
\text { Mean Tuff Dynamic Material } \\
\text { Property Curves + } 5 \text { to } 10 \mathrm{~Hz}\end{array}$} & \multicolumn{2}{|c|}{$\begin{array}{l}\text { Velocity Profile P2 + Lower } \\
\text { Mean Tuff Dynamic Material } \\
\text { Property Curves + } 5 \text { to } 10 \mathrm{~Hz}\end{array}$} \\
\hline & $\begin{array}{c}\text { Modeled } \\
\text { Horizontal } \\
\text { Peak Ground } \\
\text { Velocity } \\
(\mathrm{cm} / \mathrm{sec}) \\
\end{array}$ & $\begin{array}{c}\text { Modeled Shear } \\
\text { Strain (Syz, \%) }\end{array}$ & $\begin{array}{c}\text { Modeled } \\
\text { Horizontal } \\
\text { Peak Ground } \\
\text { Velocity } \\
(\mathrm{cm} / \mathrm{sec})\end{array}$ & $\begin{array}{c}\text { Modeled } \\
\text { Shear Strain } \\
(\text { Syz, \%) }\end{array}$ & $\begin{array}{c}\text { Modeled } \\
\text { Horizontal } \\
\text { Peak Ground } \\
\text { Velocity } \\
(\mathrm{cm} / \mathrm{sec})\end{array}$ & $\begin{array}{c}\text { Modeled } \\
\text { Shear Strain } \\
(\text { Syz, \%) }\end{array}$ & $\begin{array}{c}\text { Modeled } \\
\text { Horizontal } \\
\text { Peak Ground } \\
\text { Velocity } \\
(\mathrm{cm} / \mathrm{sec})\end{array}$ & $\begin{array}{c}\text { Modeled } \\
\text { Shear Strain } \\
\text { (Syz, \%) }\end{array}$ \\
\hline $1 \times 10^{-4}$ & 31.63 & 0.016 & 29.65 & 0.018 & 31.33 & 0.016 & 30.00 & 0.021 \\
\hline $1 \times 10^{-5}$ & 99.29 & 0.051 & 93.24 & 0.072 & 99.70 & 0.049 & 93.86 & 0.085 \\
\hline $1 \times 10^{-5}$ & 246.20 & 0.124 & 237.70 & 0.276 & 249.51 & 0.127 & 235.68 & 0.351 \\
\hline $1 \times 10^{-7}$ & 520.46 & 0.286 & 522.41 & 0.905 & 540.36 & 0.297 & 518.23 & 1.089 \\
\hline
\end{tabular}

Source: Appendix D, PGV v Shear Strain.xls 
Table C-2. Modeled and Interpolated/Extrapolated Horizontal Peak Ground Velocity for Shear Strain Values (Continued)

\begin{tabular}{|c|c|c|c|c|}
\hline & $\begin{array}{l}\text { Velocity Profile P1 + Upper } \\
\text { Mean Tuff Dynamic Material } \\
\text { Property Curves + } 1 \text { to } 2 \mathrm{~Hz}\end{array}$ & $\begin{array}{l}\text { Velocity Profile P1 + Lower } \\
\text { Mean Tuff Dynamic Material } \\
\text { Property Curves }+1 \text { to } 2 \mathrm{~Hz}\end{array}$ & $\begin{array}{l}\text { Velocity Profile P2 + Upper } \\
\text { Mean Tuff Dynamic Material } \\
\text { Property Curves }+1 \text { to } 2 \mathrm{~Hz}\end{array}$ & $\begin{array}{l}\text { Velocity Profile P2 + Lower } \\
\text { Mean Tuff Dynamic Material } \\
\text { Property Curves + } 1 \text { to } 2 \mathrm{~Hz}\end{array}$ \\
\hline $\begin{array}{c}\text { Target Shear } \\
\text { Strain Values } \\
\text { (Syz, \%) }\end{array}$ & $\begin{array}{c}\text { Interpolated/Extrapolated } \\
\text { Horizontal Peak Ground } \\
\text { Velocity (cm/sec) }\end{array}$ & $\begin{array}{c}\text { Interpolated/Extrapolated } \\
\text { Horizontal Peak Ground } \\
\text { Velocity (cm/sec) }\end{array}$ & $\begin{array}{c}\text { Interpolated/Extrapolated } \\
\text { Horizontal Peak Ground } \\
\text { Velocity (cm/sec) }\end{array}$ & $\begin{array}{c}\text { Interpolated/Extrapolated } \\
\text { Horizontal Peak Ground } \\
\text { Velocity }(\mathrm{cm} / \mathrm{sec})\end{array}$ \\
\hline 0.05 & 110.67 & 76.09 & 115.92 & 68.38 \\
\hline 0.10 & 208.44 & 120.67 & 213.93 & 111.34 \\
\hline 0.20 & 388.85 & 188.96 & 392.95 & 163.43 \\
\hline 0.30 & 566.06 & 248.31 & 568.86 & 215.52 \\
\hline 0.40 & 743.27 & 292.46 & 744.78 & 257.18 \\
\hline 0.50 & 920.48 & 336.60 & 920.69 & 294.27 \\
\hline
\end{tabular}

\begin{tabular}{|c|c|c|c|c|}
\hline & $\begin{array}{l}\text { Velocity Profile P1 + Upper } \\
\text { Mean Tuff Dynamic Material } \\
\text { Property Curves + } 5 \text { to } 10 \mathrm{~Hz}\end{array}$ & $\begin{array}{l}\text { Velocity Profile P1 + Lower } \\
\text { Mean Tuff Dynamic Material } \\
\text { Property Curves + } 5 \text { to } 10 \mathrm{~Hz}\end{array}$ & $\begin{array}{l}\text { Velocity Profile P2 + Upper } \\
\text { Mean Tuff Dynamic Material } \\
\text { Property Curves }+5 \text { to } 10 \mathrm{~Hz}\end{array}$ & $\begin{array}{l}\text { Velocity Profile P2 + Lower } \\
\text { Mean Tuff Dynamic Material } \\
\text { Property Curves }+5 \text { to } 10 \mathrm{~Hz}\end{array}$ \\
\hline $\begin{array}{c}\text { Target Shear } \\
\text { Strain Values } \\
\text { (Syz, \%) }\end{array}$ & $\begin{array}{c}\text { Interpolated/Extrapolated } \\
\text { Horizontal Peak Ground } \\
\text { Velocity (cm/sec) }\end{array}$ & $\begin{array}{c}\text { Interpolated/Extrapolated } \\
\text { Horizontal Peak Ground } \\
\text { Velocity (cm/sec) }\end{array}$ & $\begin{array}{c}\text { Interpolated/Extrapolated } \\
\text { Horizontal Peak Ground } \\
\text { Velocity (cm/sec) }\end{array}$ & $\begin{array}{c}\text { Interpolated/Extrapolated } \\
\text { Horizontal Peak Ground } \\
\text { Velocity }(\mathrm{cm} / \mathrm{sec})\end{array}$ \\
\hline 0.05 & 97.74 & 67.48 & 100.73 & 58.98 \\
\hline 0.10 & 198.04 & 113.13 & 197.97 & 101.63 \\
\hline 0.20 & 375.26 & 183.91 & 374.89 & 155.04 \\
\hline 0.30 & 545.08 & 248.56 & 545.47 & 208.44 \\
\hline 0.40 & 714.90 & 293.83 & 716.06 & 254.44 \\
\hline 0.50 & 884.72 & 339.09 & 886.64 & 292.73 \\
\hline
\end{tabular}

Source: Appendix D, PGV v Shear Strain.xls 